\title{
INTERNATIONAL NUCLEAR ENERGY RESEARCH INITIATIVE
}

\section{Fundamentals of Melt-Water Interfacial Transport Phenomena: Improved Understanding for Innovative Safety Technologies in ALWRs}

Principal Investigators (US):M.Anderson, M.Corradini

Principal Investigator (International): K.Y. Bang

Collaborators: R. Bonazza, UW-Madison

D. Cho, Argonne Nat'l Lab

Project Number: 2002-008-K

Project Start Date: January 2002

Project End Date: January 2005

Reporting Period: Final Report - Year 3 of INERI Grant

\section{TABLE of CONTENTS:}

Abstract.................................................................. $\quad 2$

Research Objectives...................................................... 2

Task I: Transient Thermal Mapping of Melt-Water Mixing ....................... 3

Task II: Molten Pool Quench Phenomena with Real-Time Xray Imaging............ 28

Task III: Modeling of Interfacial Phenomena: Separate Effects Tests...............69

Task IV: Integration of Analytical Models................................... 116

Task V: Development of Innovative Core Cooling Concepts....................... 124

References ............................................................. 139

Program Organization, Finances, Deliverables and Schedule .................... 144 


\begin{abstract}
The interaction and mixing of high-temperature melt and water is the important technical issue in the safety assessment of water-cooled reactors to achieve ultimate core coolability. For specific advanced light water reactor (ALWR) designs, deliberate mixing of the core-melt and water is being considered as a mitigative measure, to assure exvessel core coolability. The goal of this work is to provide the fundamental understanding needed for melt-water interfacial transport phenomena, thus enabling the development of innovative safety technologies for advanced LWRs that will assure ex-vessel core coolability. The work considers the ex-vessel coolability phenomena in two stages. The first stage is the melt quenching process and is being addressed by Argonne National Lab and University of Wisconsin in modified test facilities. Given a quenched melt in the form of solidified debris, the second stage is to characterize the long-term debris cooling process and is being addressed by Korean Maritime University via test and analyses. We then address the appropriate scaling and design methodologies for reactor applications.
\end{abstract}

\title{
Research Objectives:
}

Our research objectives for this work are to:

Task I: Measure the cool down behavior of the melt-water mixing zone by thermal mapping of this multiphase, multi-component system (ANL lead).

Task II: Measure the flow regime and interfacial area behavior of the melt-water multiphase, multi-component mixture by the use of innovative real-time X-ray imaging (UW lead).

Task III: Develop and integrate analytical models of interfacial transport phenomena in a model, including separate-effects experimental studies (Korean researchers at the Korea Maritime University lead).

Task IV: Integrate the various models for long-term debris coolability into an overall approach (Korean researchers at the Korea Maritime University lead).

Task V: Develop an approach for applying this fundamental knowledge to the development of a novel safety concept of ex-vessel core debris coolability in a regulatory context (All participants). 
Task I: Transient Thermal Mapping of the Melt-Water mixing Zone (ANL Lead)

\section{I.1 Objective:}

The objective of the ANL experiments is to measure the transient quenching behavior of a high-temperature melt mixed with vaporizing water. The ANL apparatus represents a one-dimensional flow-channel simulation of the bottom injection of water into core melt in the reactor cavity. The melt-water mixing zone is formed by injection of water into a column of melt from bottom.

\section{I.2 Experimental Apparatus and Procedure}

The experimental apparatus is shown schematically in Fig. 1. It consists of a test section and associated components (e.g., water supply tank, condenser, melt vessel, containment vessel, and instrumentation). Details of the melt vessel and test section are shown, Fig. 2.

The test section is a 1.0-m long section of a 0.095-m I.D., 0.0095-m thick Type 410 SS seamless pipe. It is instrumented with 39 thermocouples equi-spaced along its length and protruding through the wall on the inside. In addition, there are 8 thermocouples secured to the outer wall of the test section, two at each of four axial locations (see Fig. 3 for thermocouple locations). There is also a pressure transducer located at the top of the test section. The test section is heated by high-power density band heaters clamped around the outside wall of the test section. The water injection port is inserted into the test section through the base of the test section. The basic design of the injector is a stainless steel tube with a single hole at the exit. The injector hole size is $1 \mathrm{~mm}$ in diameter. The top of the test section is closed except for a $0.0127-\mathrm{m}$ OD tube that carries steam through the top of the containment vessel to a condenser system. 


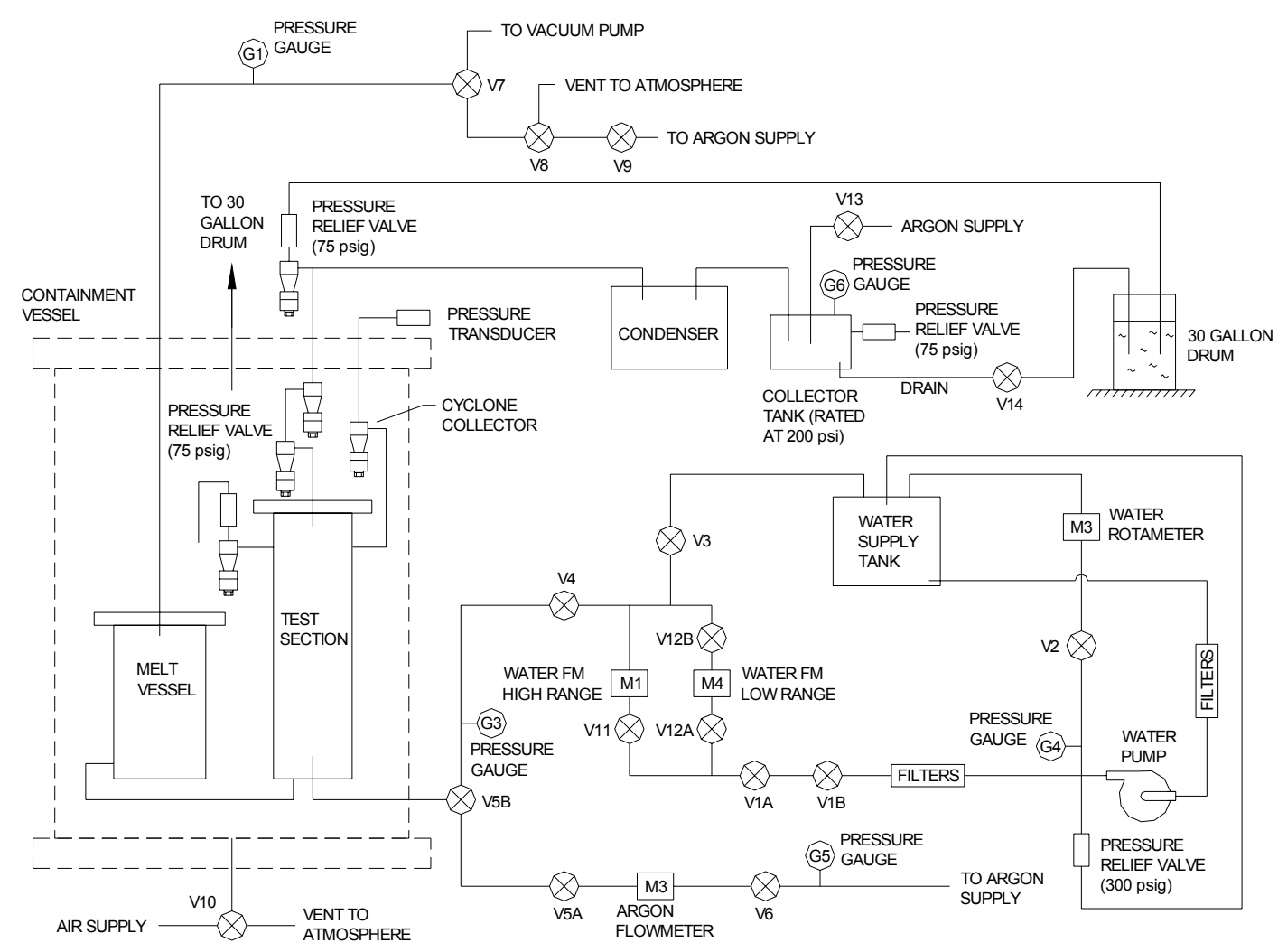

Figure 1. Schematic of the Experimental Facility.

The melt vessel is a $0.5-\mathrm{m}$ long section of a Schedule 40, 4-inch SS pipe heated by band heaters. It is located next to the test section. The test section and melt vessel are joined by a $0.00635-\mathrm{m}$ OD stainless steel tube through which molten metal is transferred.

During runs when water is injected into molten metal, the test section and melt vessel are placed in a containment chamber (see Fig. 2). The body of the containment chamber is a 1.8-m long section of a 0.91-m O.D., 0.025-m thick carbon steel pipe. The containment chamber provides blast protection from potential explosive interactions between molten metal and water and also environmental protection from lead alloy contamination. 


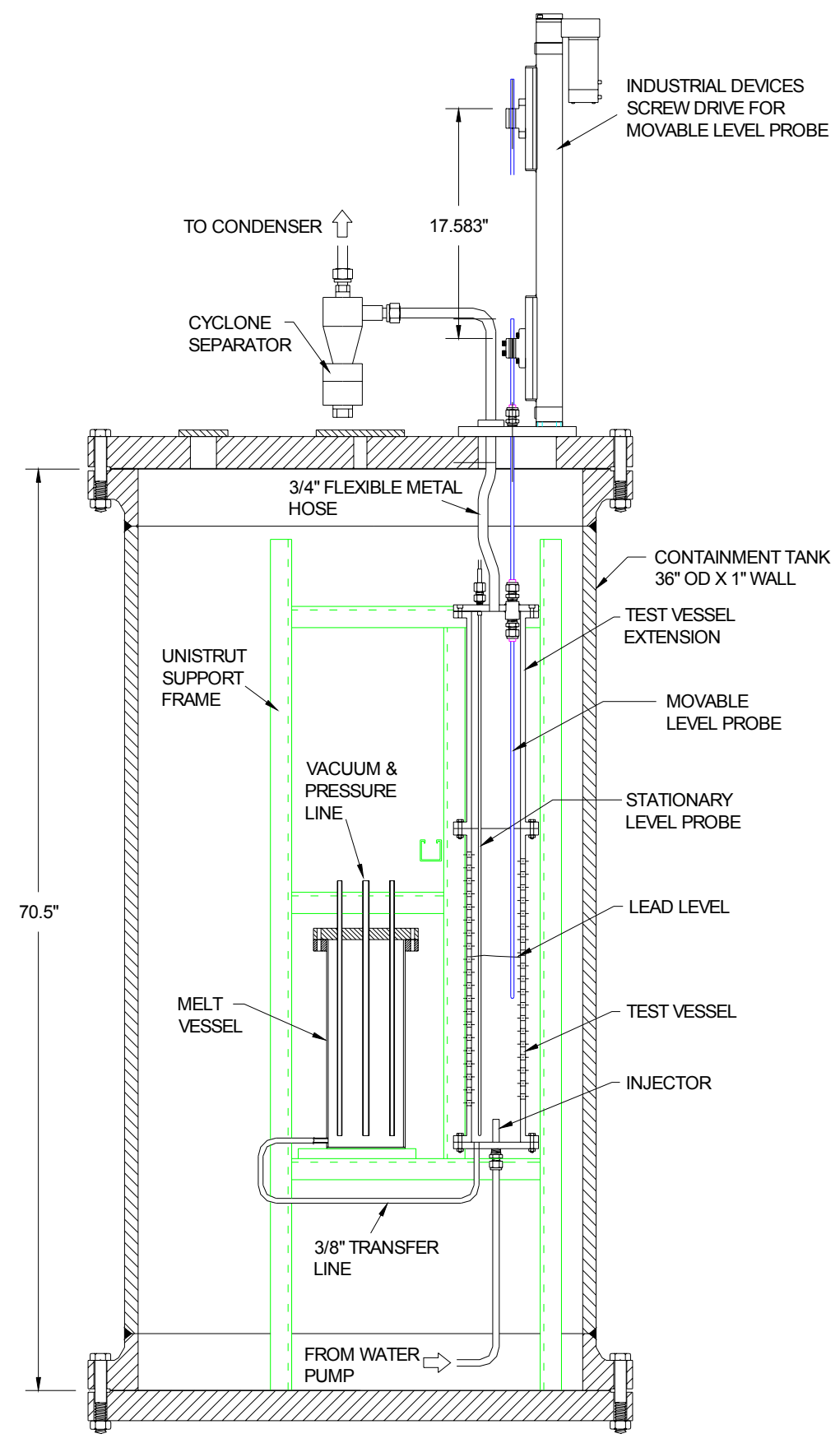

Figure 2. Details of the Test Section.

Water is pumped from a supply tank to the injector through a set of filters. The water flow rate is metered by valves and measured by flow meters with ranges of 14 to 100 $\mathrm{ml} / \mathrm{min}$ and 50 to $500 \mathrm{ml} / \mathrm{min}$. There is also an argon supply to the injector, the purpose being to have flow through the injector while molten metal is being transferred to the test section from the melt vessel. Without this argon flow, metal would flow down into the injector and plug it. 
Lead alloy (lead-bismuth eutectic, m.p. $=125^{\circ} \mathrm{C}$ ) that has previously been loaded into the melt vessel is heated to a temperature sufficiently above the melting point for the lead alloy to flow easily. Once this temperature is reached, lead alloy starts to flow under gravity from the melt vessel into the test section. To complete the transfer, the melt vessel is pressurized with argon. During the transfer, a flow of argon gas through the injector is maintained to prevent backflow of molten metal into the injection port. Once transfer is complete, as indicated by level probes in the test section, the air supply to the containment vessel is turned on and the heater on the transfer tube is turned off. This enables a metal plug to form in the transfer line and prevents molten lead alloy from flowing back into the melt vessel. The molten metal in the test section may now be further heated. When the desired metal temperature is reached, water flow to the injector is turned on at a pre-set rate so that there is a mix of argon and water flowing through the injector. Once water flow is established, the argon flow may be gradually reduced to zero, if so desired. Heat transfer measurements are made using the thermocouples in the molten metal and on the test section wall, and by measuring the power output of the test section heaters.

\section{I.3 Experimental Results and Discussion}

Each of the tests conducted is described below.

INERI-1: No data was available because of an early plugging of the water injector.

INERI-2: In this test the coolant was a mixture of water and argon flows. The water flow rate was $40 \mathrm{ml} / \mathrm{min}$ (see discussion later) and the argon flow rate $8 \mathrm{slpm}$. The initial melt temperature was $250^{\circ} \mathrm{C}$ and the collapsed melt height was about $32 \mathrm{~cm}$. The input heater power was 1000 Watts and remained constant throughout the cooldown transient until the melt started to freeze. It was found that the melt temperature during the transient was remarkably uniform throughout the melt-water mixing zone, as has previously been observed and remained so until it was very close to the freezing point. Axial temperature gradients began to appear as the melt temperature approached the freezing point. 


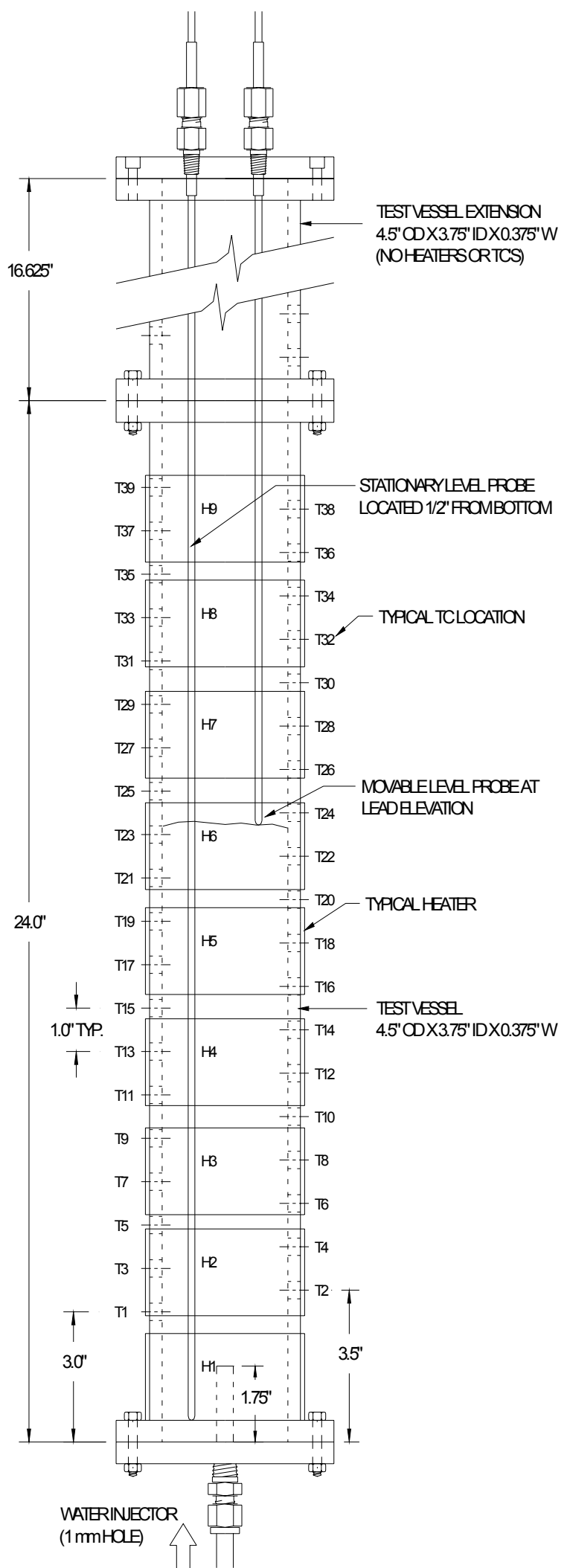

Figure 3. Thermocouple Locations. 
Table I-1: Summary of Experiments

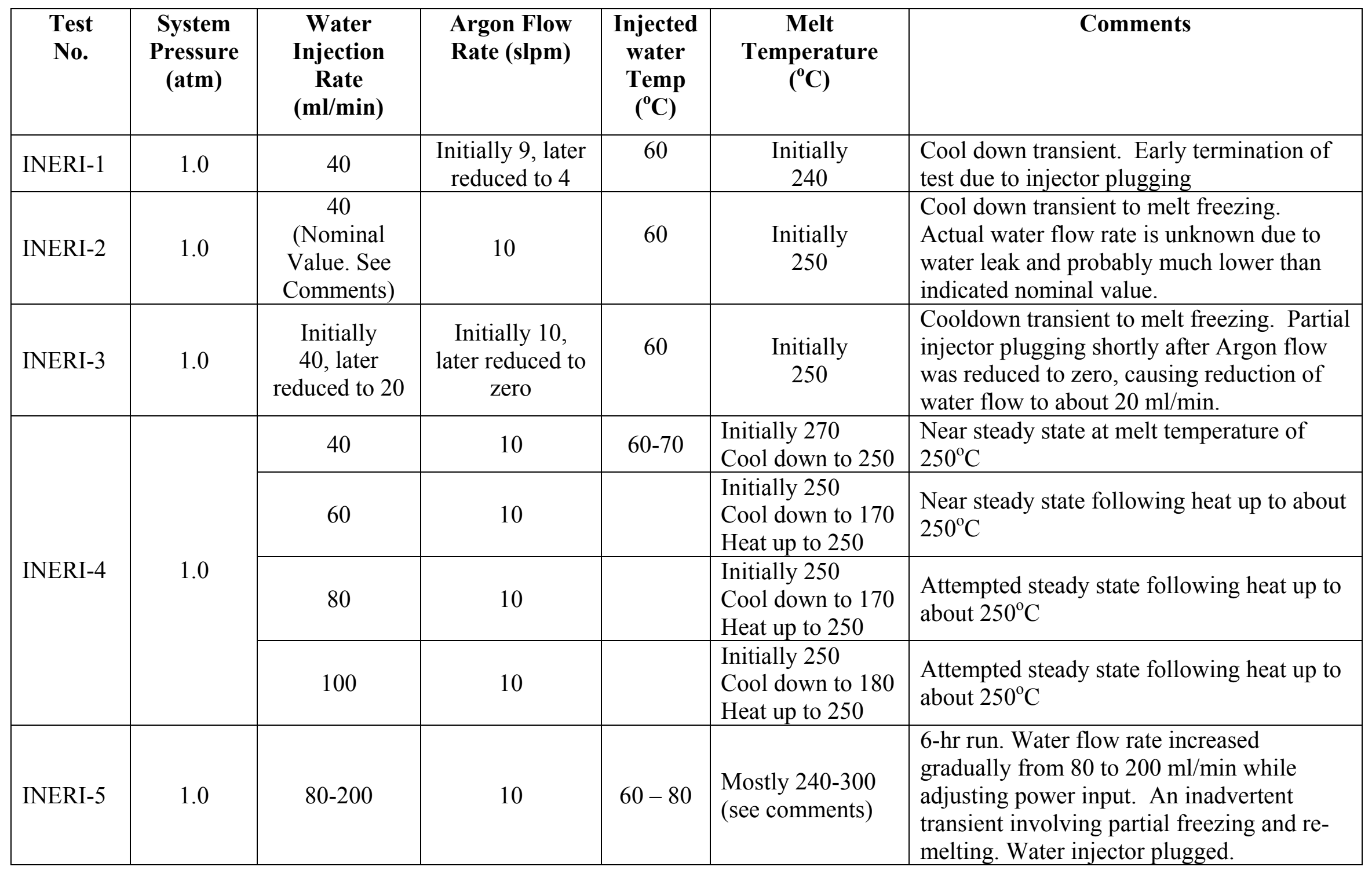


Table I-1. Summary of Experiments

\begin{tabular}{|c|c|c|c|c|c|c|}
\hline $\begin{array}{l}\text { Test } \\
\text { No. }\end{array}$ & $\begin{array}{l}\text { System } \\
\text { Pressure } \\
\text { (atm) }\end{array}$ & $\begin{array}{l}\text { Water } \\
\text { Injection } \\
\text { Rate } \\
(\mathrm{ml} / \mathrm{min})\end{array}$ & $\begin{array}{l}\text { Argon } \\
\text { Flow } \\
\text { Rate } \\
\text { (slpm) }\end{array}$ & $\begin{array}{c}\text { Injected } \\
\text { water } \\
\text { Temp }\left({ }^{\circ} \mathrm{C}\right)\end{array}$ & $\begin{array}{c}\text { Melt } \\
\text { Temperature }\left({ }^{\circ} \mathrm{C}\right)\end{array}$ & Comments \\
\hline INERI-6 & $1.0-3.0$ & $150-320$ & 10 & $50-65$ & $\begin{array}{l}\text { Mostly } \\
150-200\end{array}$ & $\begin{array}{l}\text { 4-hr run. Water flow rate increased from } 150 \\
\text { to } 320 \mathrm{ml} / \mathrm{min} \text { while power input reached the } \\
\max (8.2 \mathrm{KW}) \text {. }\end{array}$ \\
\hline INERI-7 & $1.0-3.0$ & $150-260$ & 10 & $50-70$ & $200-300$ & $\begin{array}{l}\text { 3-hr run. Water flow rate increased from } 150 \\
\text { to } 260 \mathrm{ml} / \mathrm{min} \text { while adjusting power input. }\end{array}$ \\
\hline INERI-8 & $1.0-4.0$ & $100-350$ & 10 & $60-85$ & $\begin{array}{l}\text { Initially } 200 \\
\text { Cool down to } 140 \\
\text { Heat up to } 520\end{array}$ & $\begin{array}{l}\text { 3-hr run. Pressure increased in steps to } 4 \text { atm. } \\
\text { Difficult to control melt temperature. Noise- } \\
\text { producing melt-water interactions caused } \\
\text { flow instabilities, leading to test termination. } \\
\text { Injector plugged. Steam ventline coil plugged }\end{array}$ \\
\hline INERI-9 & 1.0 & $150-400$ & 10 & $50-65$ & $\begin{array}{l}\text { 1-hr long heat up } \\
\text { from } 190 \text { to } 230 \\
\text { Rapid quenching to } \\
\text { freezing } \\
\text { Remelting and heat } \\
\text { up to } 400\end{array}$ & $\begin{array}{l}\text { 3-hr run. } 1 \text { hour long, stable heat up at water } \\
\text { flow of } 150 \mathrm{ml} / \mathrm{min} \text {. Rapid quench to freeze } \\
\text { when water flow increased to } 400 \mathrm{ml} / \mathrm{min} \text {. } \\
\text { Remelting with reduced water flow. Melt } \\
\text { temperature was over } 400^{\circ} \mathrm{C} \text { when booming } \\
\text { noises were heard. Erratic fluctuations in } \\
\text { water and Argon flows terminated test. }\end{array}$ \\
\hline INERI-10 & 1.0 & $200-390$ & 20 & $30-32$ & $150-250$ & $\begin{array}{l}\text { One-hour long heatup followed by } \\
\text { cooling/heatup cycles. The increased Argon } \\
\text { gas flow (i.e. } 20 \text { slpm) appears to have } \\
\text { stabilized the operation. }\end{array}$ \\
\hline
\end{tabular}


At the same time, the level of the melt, as indicated by the conductivity level probe, suddenly decreased, although there was no change in the water/argon flow rate. It appears that the melt freezing started to occur in the upper third of the melt column and propagated downwards. There were temperature indications of the presence of water in the frozen portion of the melt. Also, the conductivity level probe indicated that a little later in the freezing process, water began to accumulate on the top of the frozen melt surface. (This accumulated water could be visually inspected when the apparatus was cool.) The cooldown histories of selected test section thermocouples for INERI-2 are shown in Figure 4.

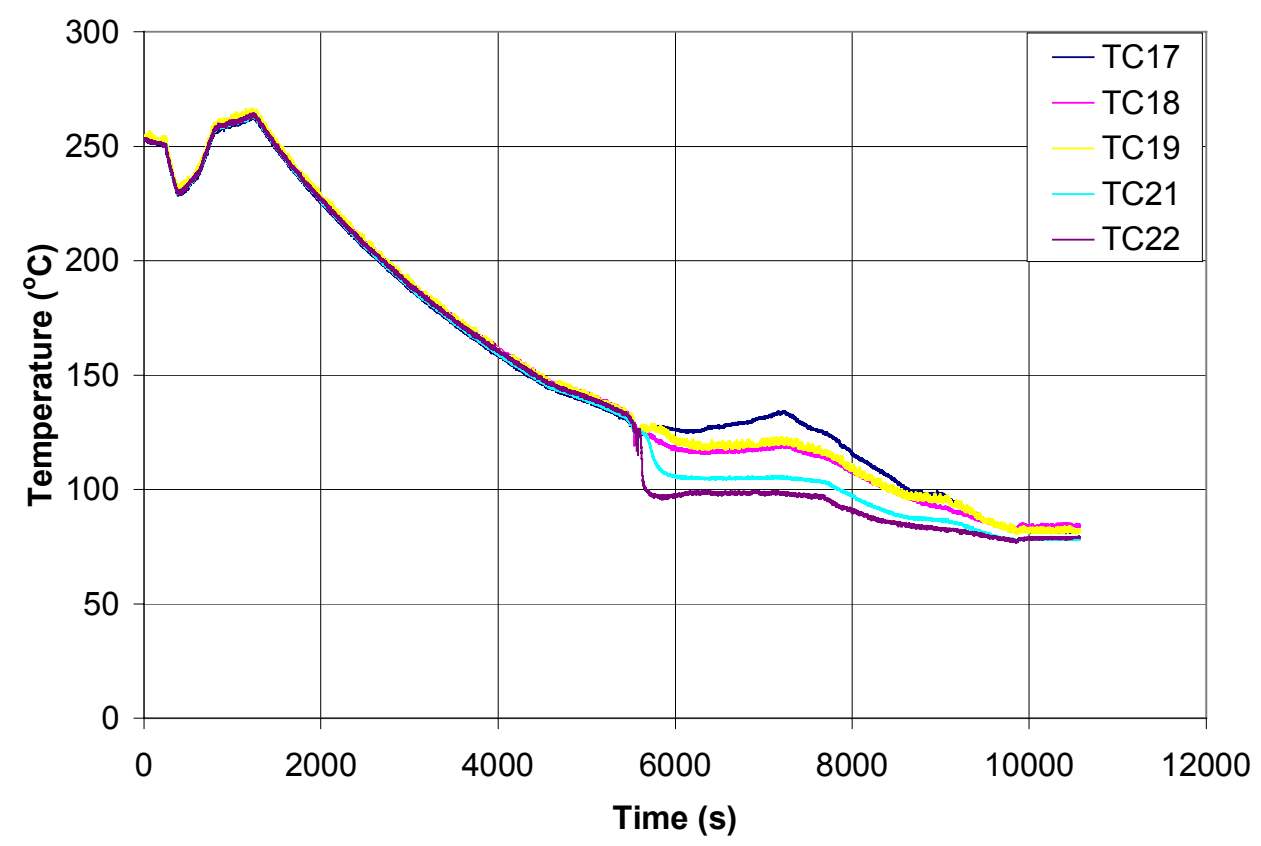

Figure 4. Cooldown History of Selected Test Section Thermocouple for INERI-2.

INERI-3: In this test the intent was to cool the melt with water flow alone at $40 \mathrm{ml} / \mathrm{min}$. However, the injector became partially plugged shortly after the argon flow was shut off. Nevertheless, it was possible to complete the test at a reduced water flow rate in the range of 20-25 $\mathrm{ml} / \mathrm{min}$. As in INERI-2, the initial melt temperature was $250^{\circ} \mathrm{C}$ and the collapsed melt height was about $32 \mathrm{~cm}$. The input heater power during the initial phase of cooldown transient (lasting about $1500 \mathrm{sec}$ ) was 620 Watts and zero for the remainder of the test. The observed cooldown behavior of the melt was very similar to that of 
INERI-2 in that the melt temperature was uniform until close to the freezing point, and the freezing started to occur in the upper part of the melt and was accompanied by appearance of water in the frozen portion. The cooldown histories of selected test section thermocouples for INERI-3 are shown in Figure 5.

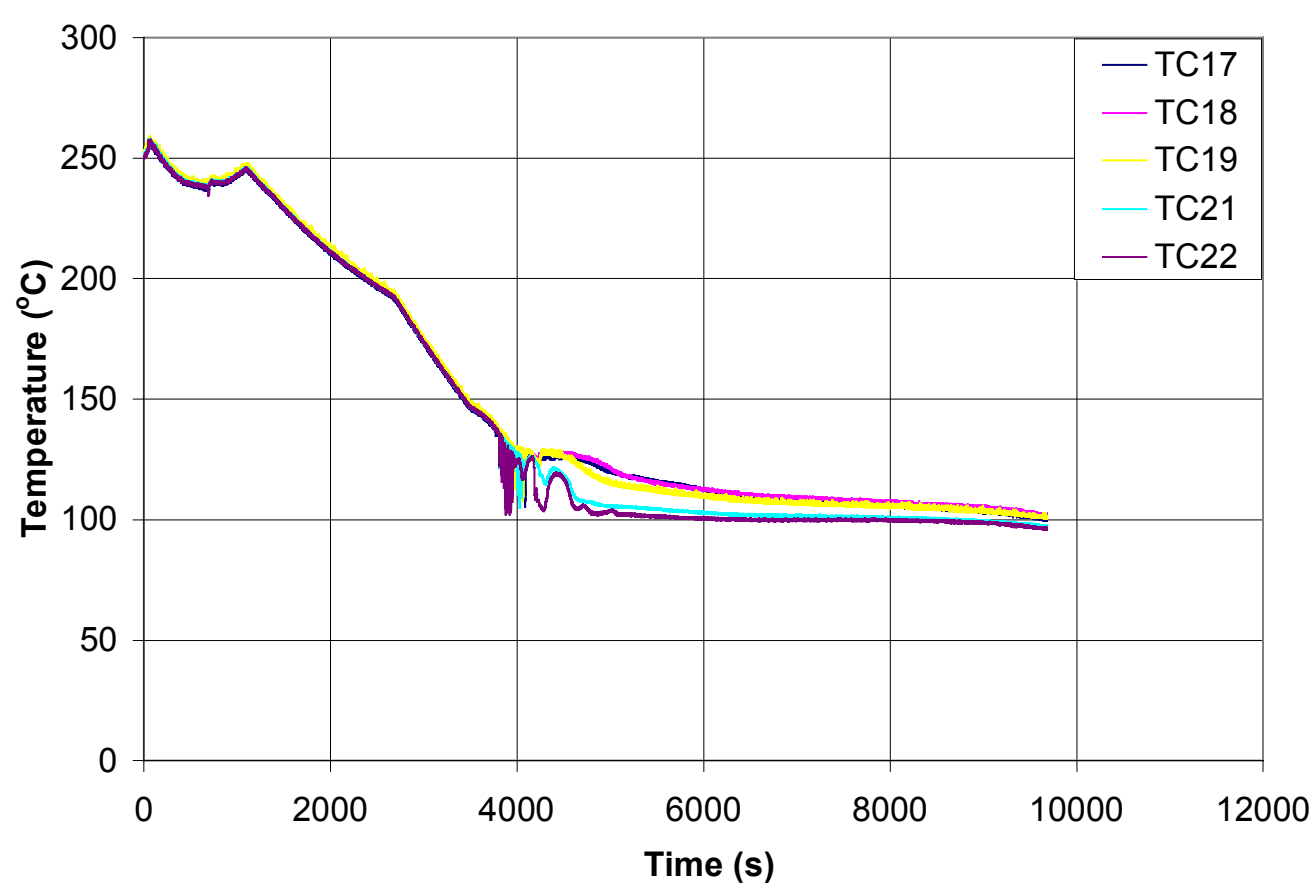

Figure 5. Cooldown Histories for Selected Test Section Thermocouples for INERI-3.

INERI-4: In this test, a series of power increases was made with increasing water flow rate while keeping the Argon gas flow rate constant at $10 \mathrm{slpm}$. Four different water mass flow rates were used, namely 40, 60, 80 and $100 \mathrm{ml} / \mathrm{min}$. At each of the water flow rates, an attempt was made to establish a steady state for about $15 \mathrm{~min}$. The water flow rate was then increased to the next higher level while keeping the power constant, leading to a cooldown transient in the melt. This transient lasted about $30 \mathrm{~min}$. and then the power was adjusted to establish a steady state at the increased water mass flow rate. Attempts were made to establish steady states at a melt temperature of $250^{\circ} \mathrm{C}$. As in INERI-2 and -3, the melt temperature was found to be uniform throughout the test section during the cooldown transient as well as the steady period. The time histories of the power, water and Argon flows, and melt temperature for the four different segments of 
the test (designated as INERI-4.1, -4.2, -4.3 and -4.4) are shown respectively, in Figs. 6 to 9 .

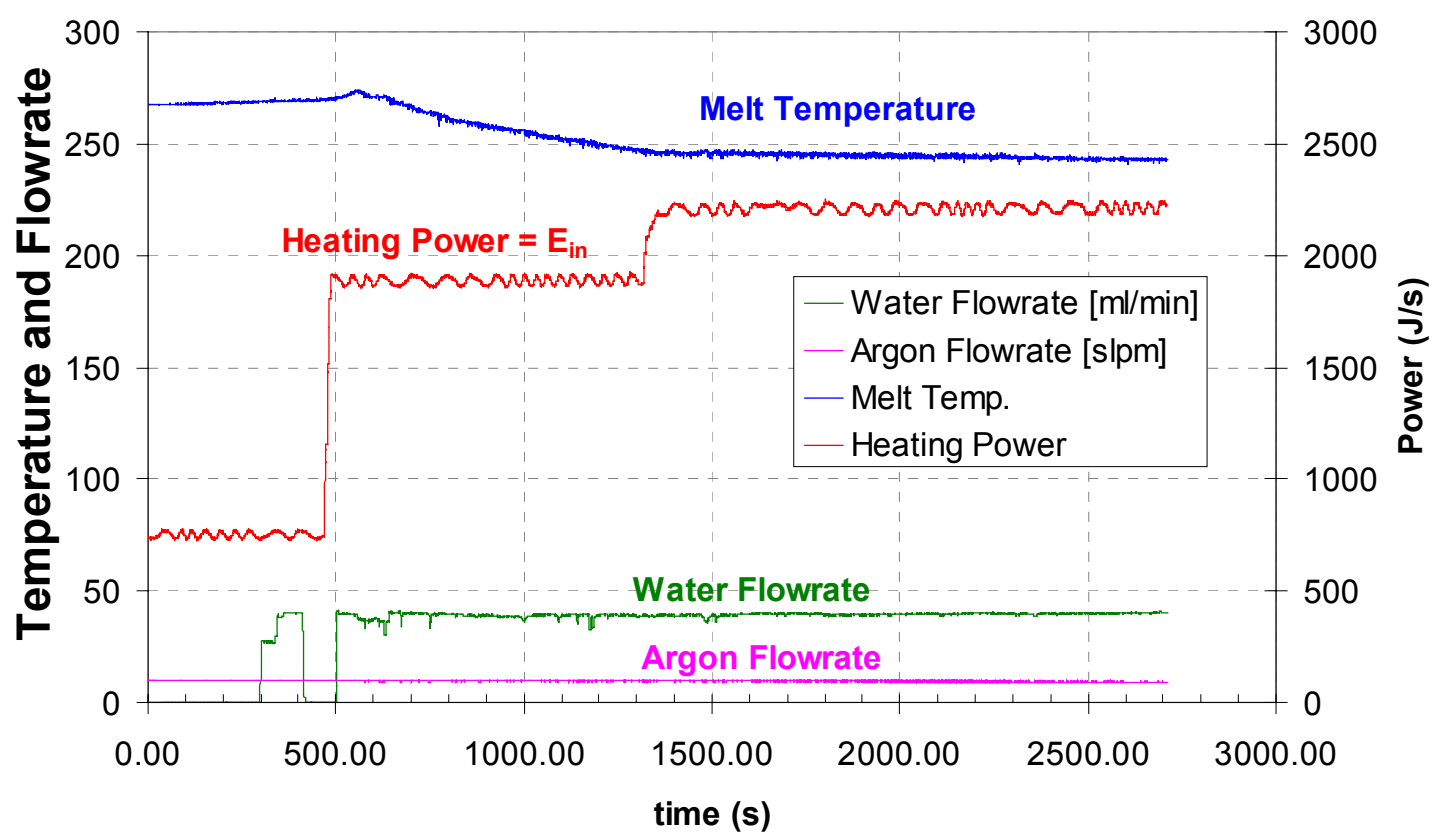

Figure 6. Time Histories for INERI-4.1. 


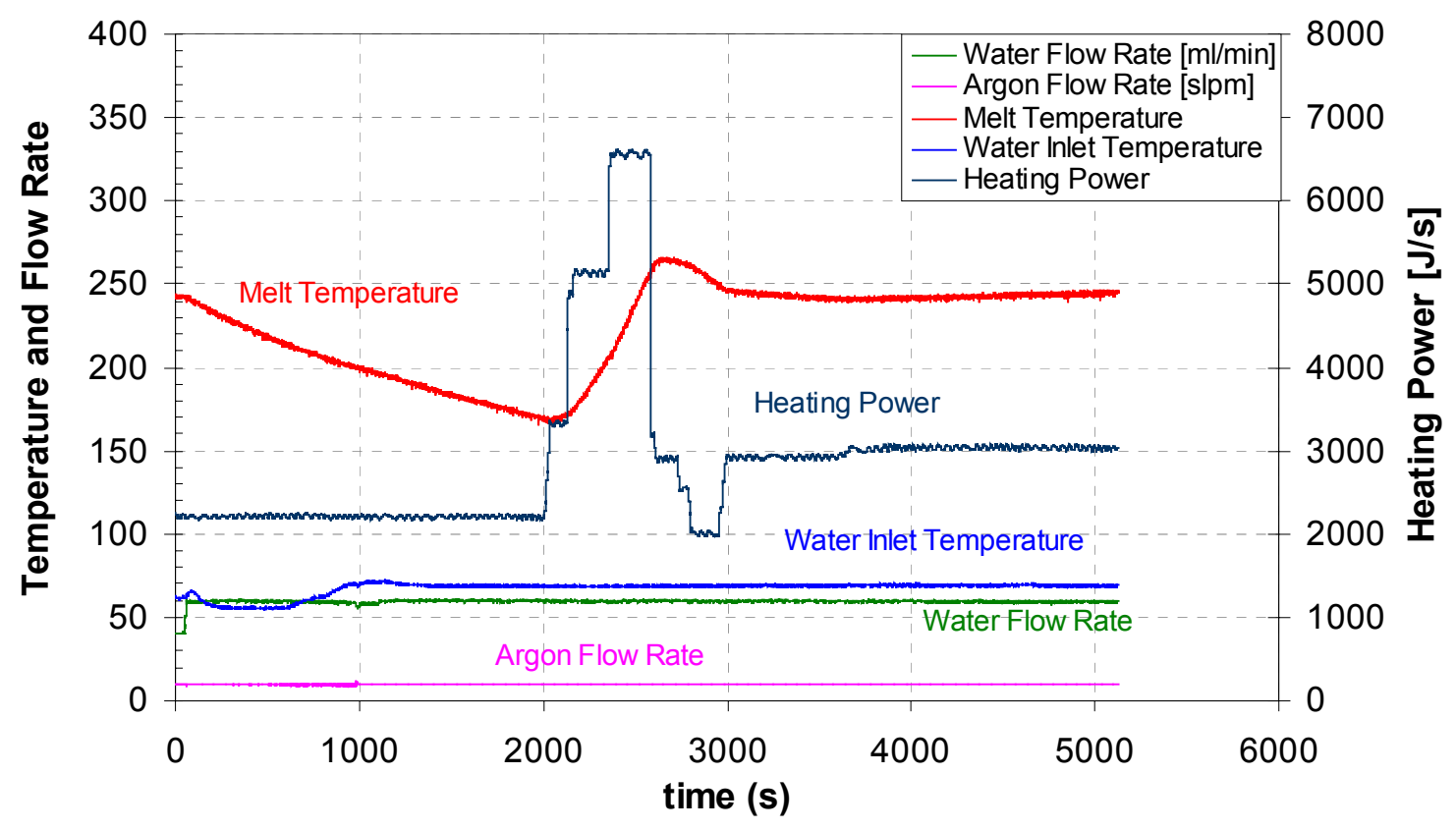

Figure 7. Time Histories for INERI-4.2.

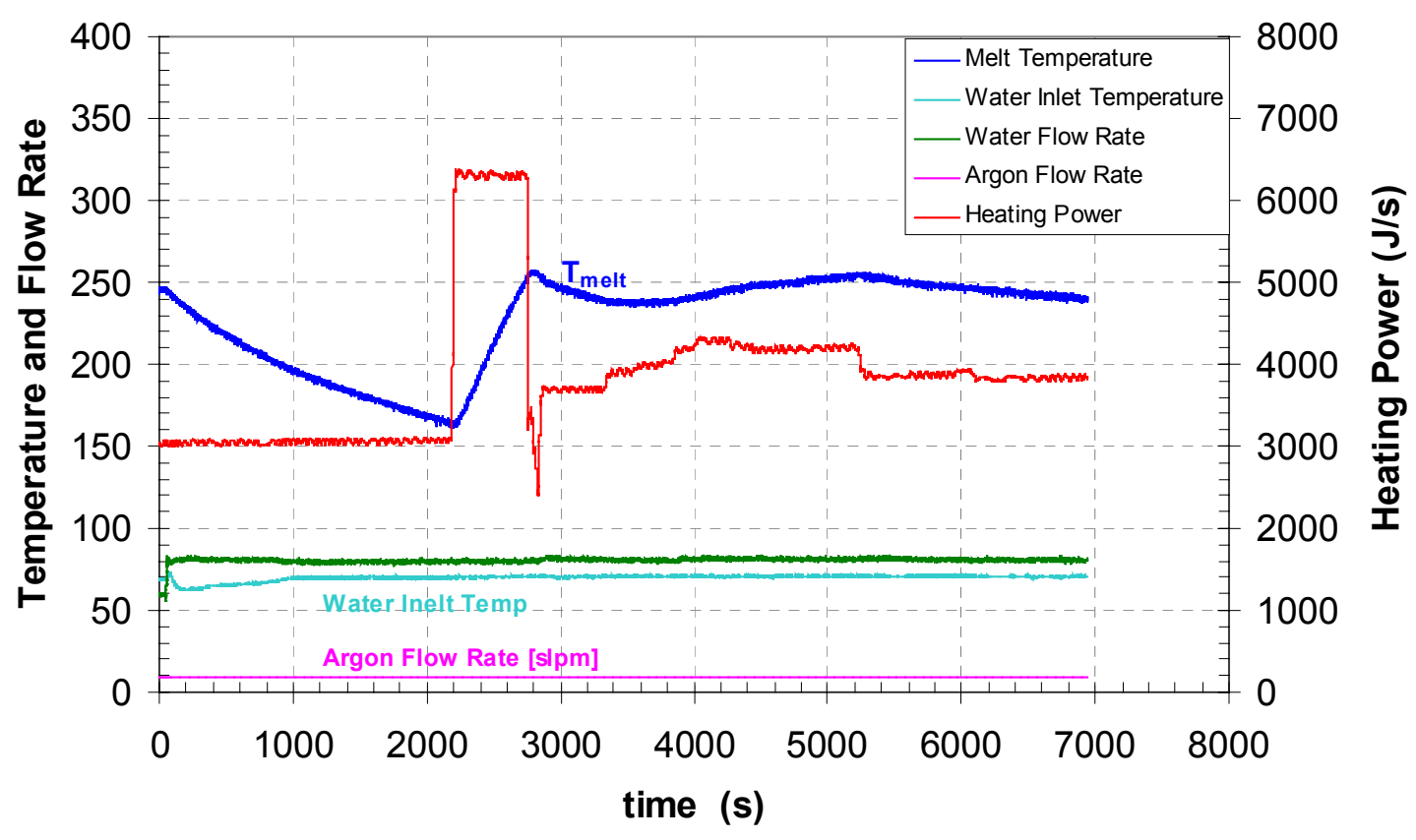

Figure 8. Time Histories for INERI-4.3. 


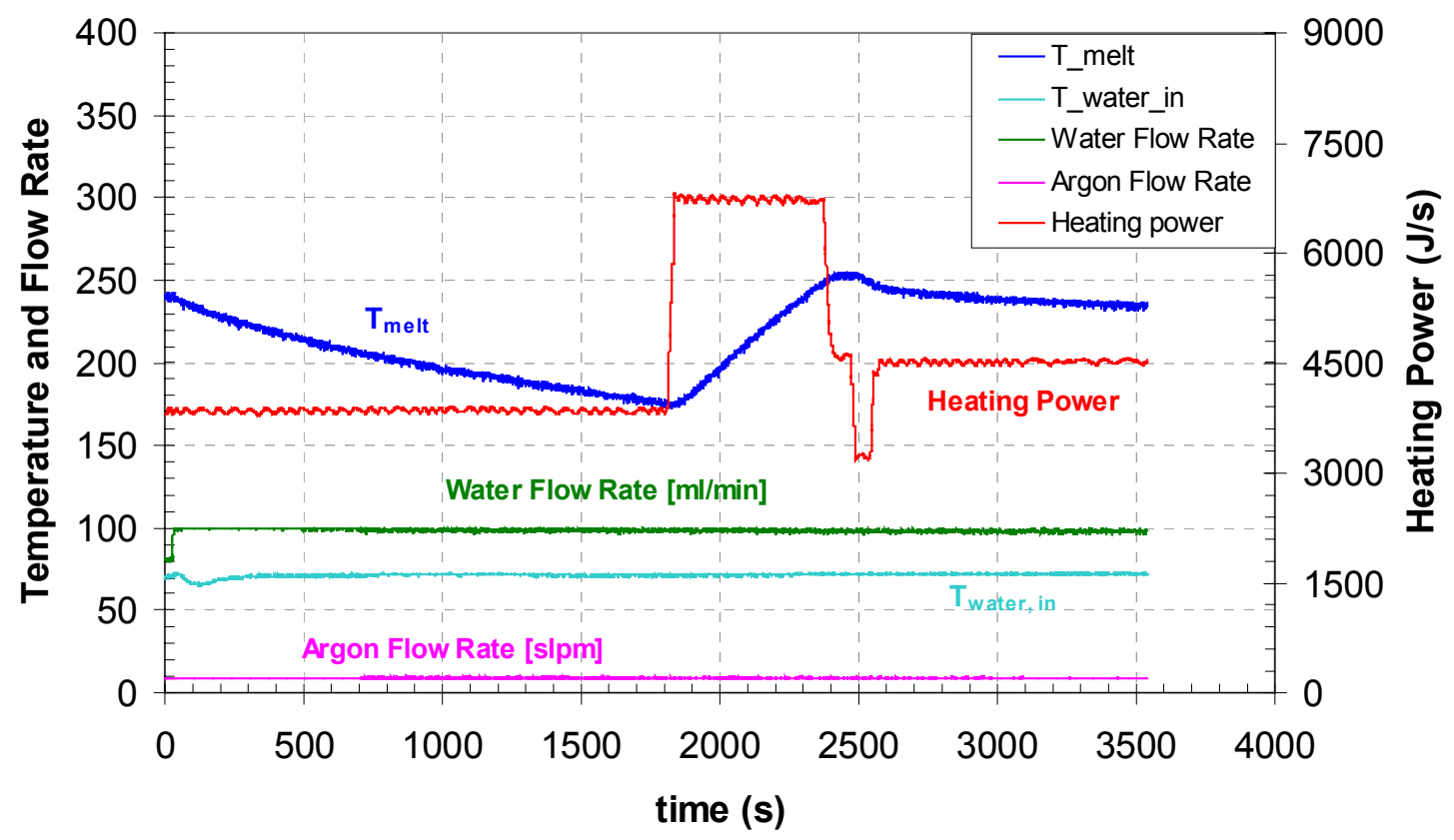

Figure 9. Time History for INERI-4.4.

INERI-5: In this test, which lasted about six hours, the water injection flow was varied from 100 to $200 \mathrm{ml} / \mathrm{min}$ while the melt temperature was maintained near $250^{\circ} \mathrm{C}$. Most of the data was collected at atmospheric pressure, although limited data was obtained at about 3 bars when the water flow rate was $200 \mathrm{ml} / \mathrm{min}$. An inadvertent transient of partial solidification and remelting of the metal took place during the test. Selected portions of the time histories of the power input, melt temperature and water and Argon flows for INERI-5 are shown in Figs. 10-11. 


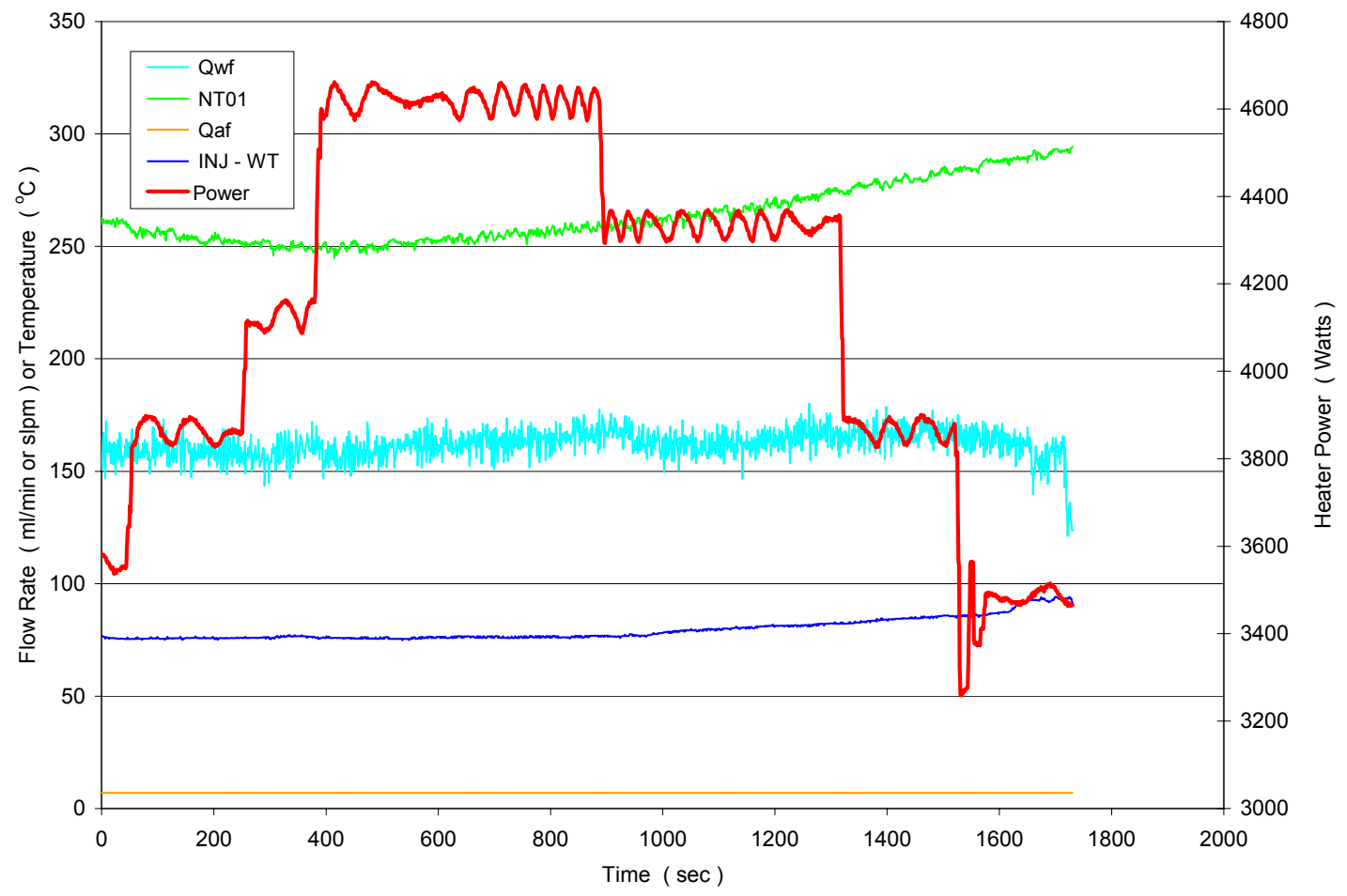

Figure 10. Time History for INERI-5.3.

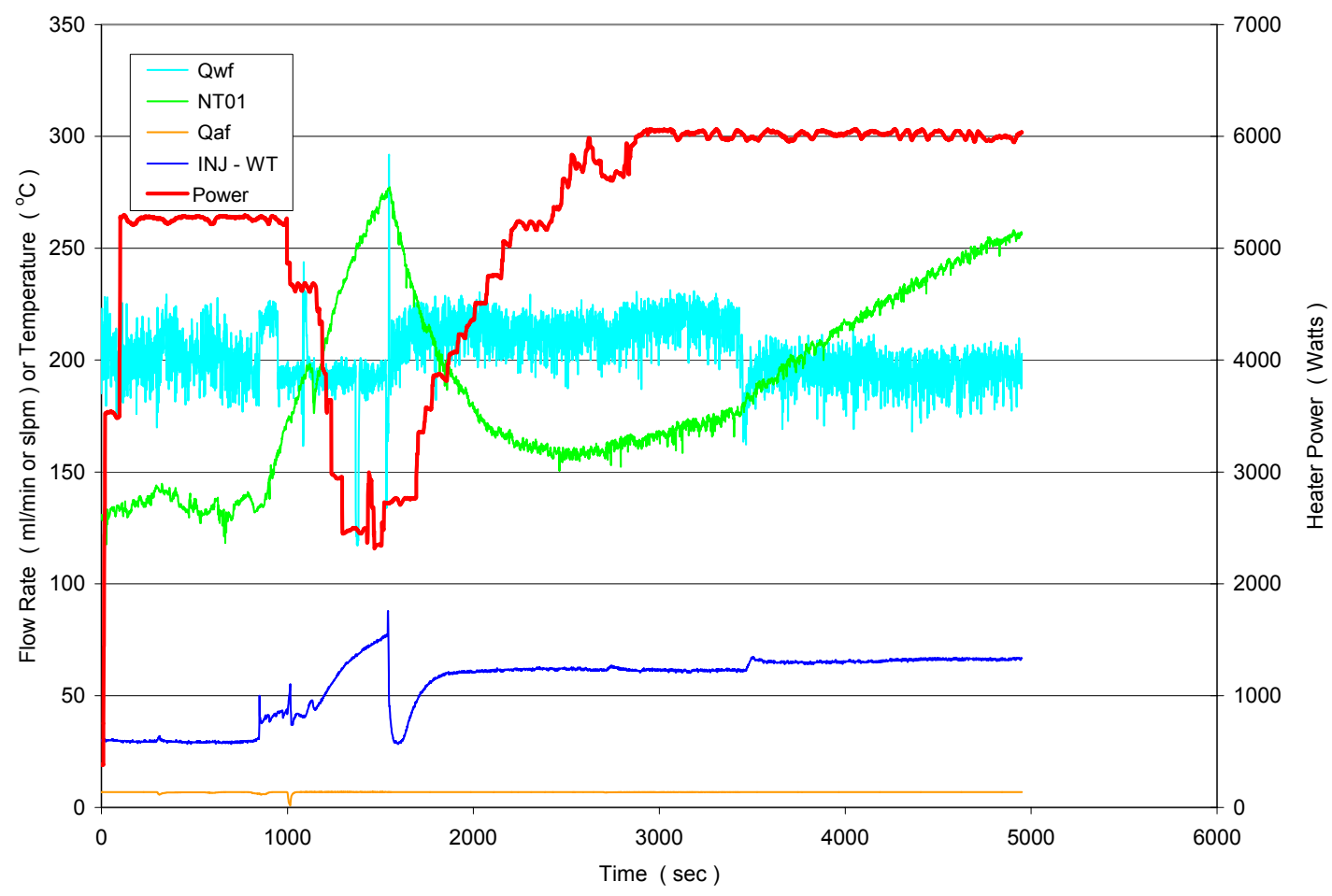

Figure 11. Time History INERI-5.5. 
INERI-6: This test run lasted about 4 hours. Throughout the run the Argon flow rate was about $10 \mathrm{slpm}$ and the temperature of the injected water about $60^{\circ} \mathrm{C}$. The initial melt temperature was about $210^{\circ} \mathrm{C}$ at a power input of $4000 \mathrm{~W}$. Upon injection of water at a flow rate of $150 \mathrm{ml} / \mathrm{min}$, the melt temperature decreased to about $150^{\circ} \mathrm{C}$ over a period of $12 \mathrm{~min}$. Then the power input was increased to $5000 \mathrm{~W}$. At this power level, the melt temperature remained more or less stable at $150^{\circ} \mathrm{C}$ for about 14 min while the water injection rate fluctuated between 150 and $170 \mathrm{ml} / \mathrm{min}$. The rest of the run consisted of stepwise increases both in power input and in water injection rate. Eventually the power input reached $8200 \mathrm{~W}$ (which was the maximum level for the band heaters employed) while the water injection rate was increased to about $300 \mathrm{ml} / \mathrm{min}$. During the entire run, the melt temperature remained in the range of $150^{\circ}-200^{\circ} \mathrm{C}$. The system pressure was atmospheric except for the last $30 \mathrm{~min}$ period of the run during which the system pressure was increased to about 3 bars by pressurized Argon gas. The time-histories of the power input, melt temperature and water and Argon flows for INERI-6 are shown in Fig.12.

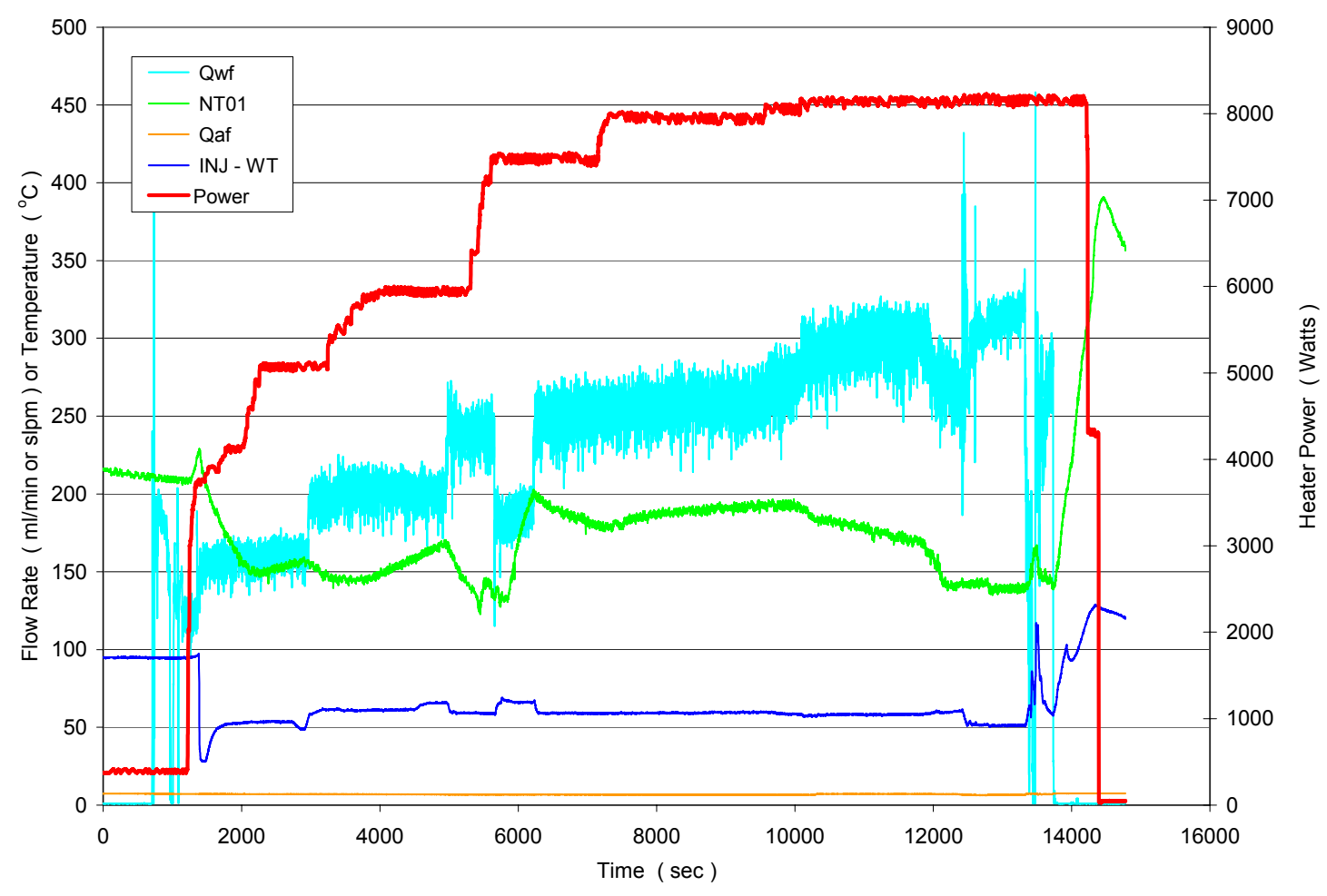

Figure 12. Time History of INERI-6. 
INERI-7: This test run lasted over 3 hours. Throughout the run, the Argon flow rate was about $10 \mathrm{slpm}$ and the temperature of the injected water ranged from 60 to $70^{\circ} \mathrm{C}$. The initial power input was about $6 \mathrm{KW}$ and increased in steps to about $7.5 \mathrm{KW}$ while the water injection rate was increased from 150 to $260 \mathrm{ml} / \mathrm{min}$. The system pressure was initially 1 bar and then varied between 1 and 3 bars during the run. During the entire run, the melt temperature remained in the range of $200-300^{\circ} \mathrm{C}$. Towards the end of the run, when the system pressure was increased to 4 bars, a leak developed in the steam vent line and the test was terminated. The time-histories of the power input, melt temperature and water and Argon flows for INERI-7 are shown in Fig.13.

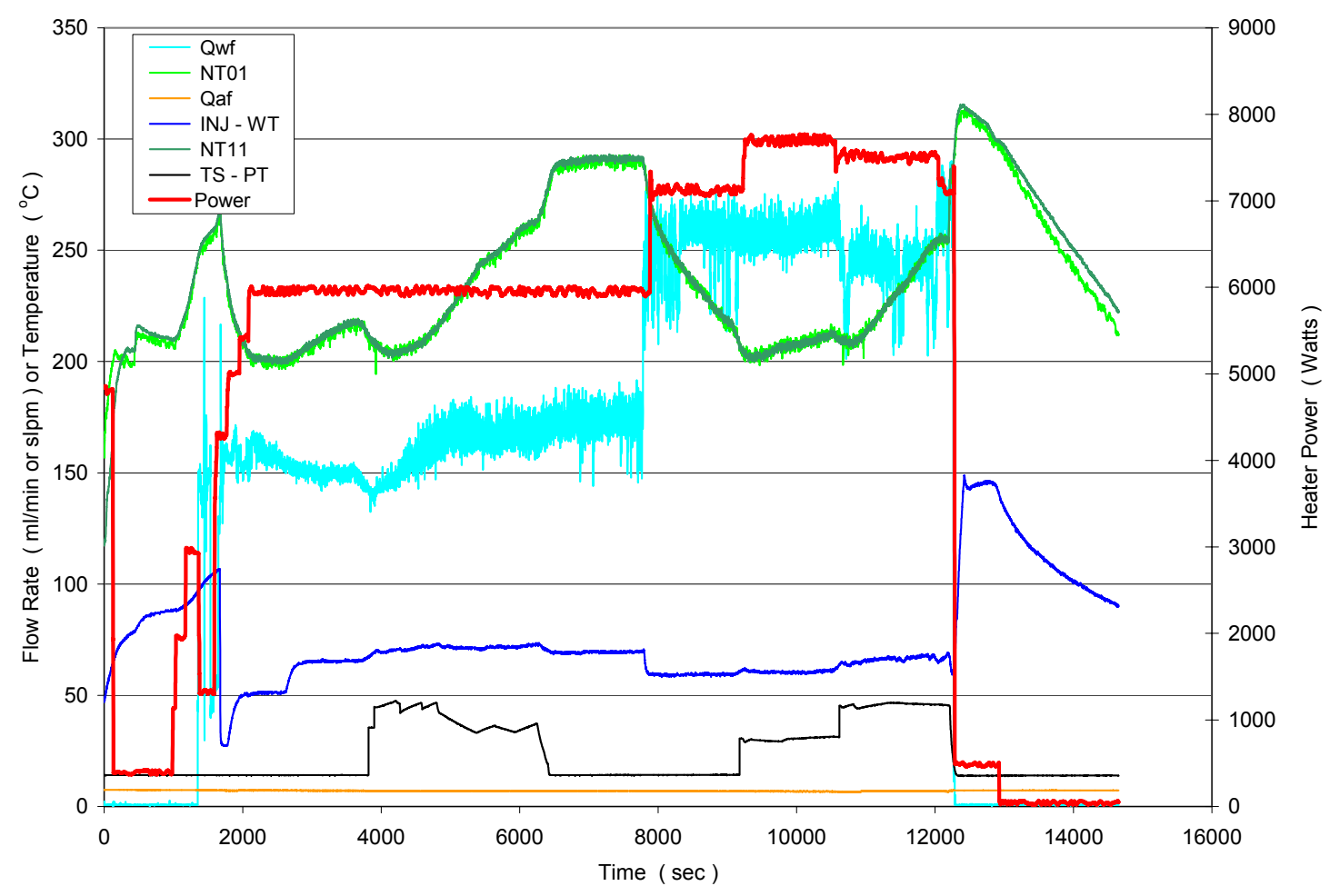

Figure 13. Time History INERI-7.

INERI-8: This test run involved the following sequences. The initial melt temperature was about $200^{\circ} \mathrm{C}$. At a water injection flow rate of $100 \mathrm{ml} / \mathrm{min}$, the system pressure was increased in steps from 1 bar to 4 bars, data being taken at each of these pressures. Power distribution was adjusted so as to avoid overheating near the top of the test section. The power was initially $4 \mathrm{KW}$ and gradually increased up to $5.5 \mathrm{KW}$. The water injection flow rate was increased to about $200 \mathrm{ml} / \mathrm{min}$ while keeping the pressure at 4 bars and the 
power at $5.2 \mathrm{KW}$ (at this tine, the melt temperature was about $400^{\circ} \mathrm{C}$ ). At the water flow rate of $200 \mathrm{ml} / \mathrm{min}$, the system pressure was decreased in steps from 4 bars to 1 bar. The melt temperature continued to increase, exceeding $500^{\circ} \mathrm{C}$. An attempt was made to increase the water flow rate to $400 \mathrm{ml} / \mathrm{min}$, but it went up only to $300-350 \mathrm{ml} / \mathrm{min}$ for a short period of time before it was interrupted. The Argon gas flow was also interrupted. At this point, the test was terminated. Apparently, local pressurization events took place, as evidenced by a series of small pops coming from the test section. It was later found that the steam vent line along with the cyclone collectors was partially filled with frozen metal. Also, the injector nozzle was plugged up with frozen metal. The time-histories of the power input, melt temperature, water and Argon flows for INERI-8 are shown in Fig. 14.

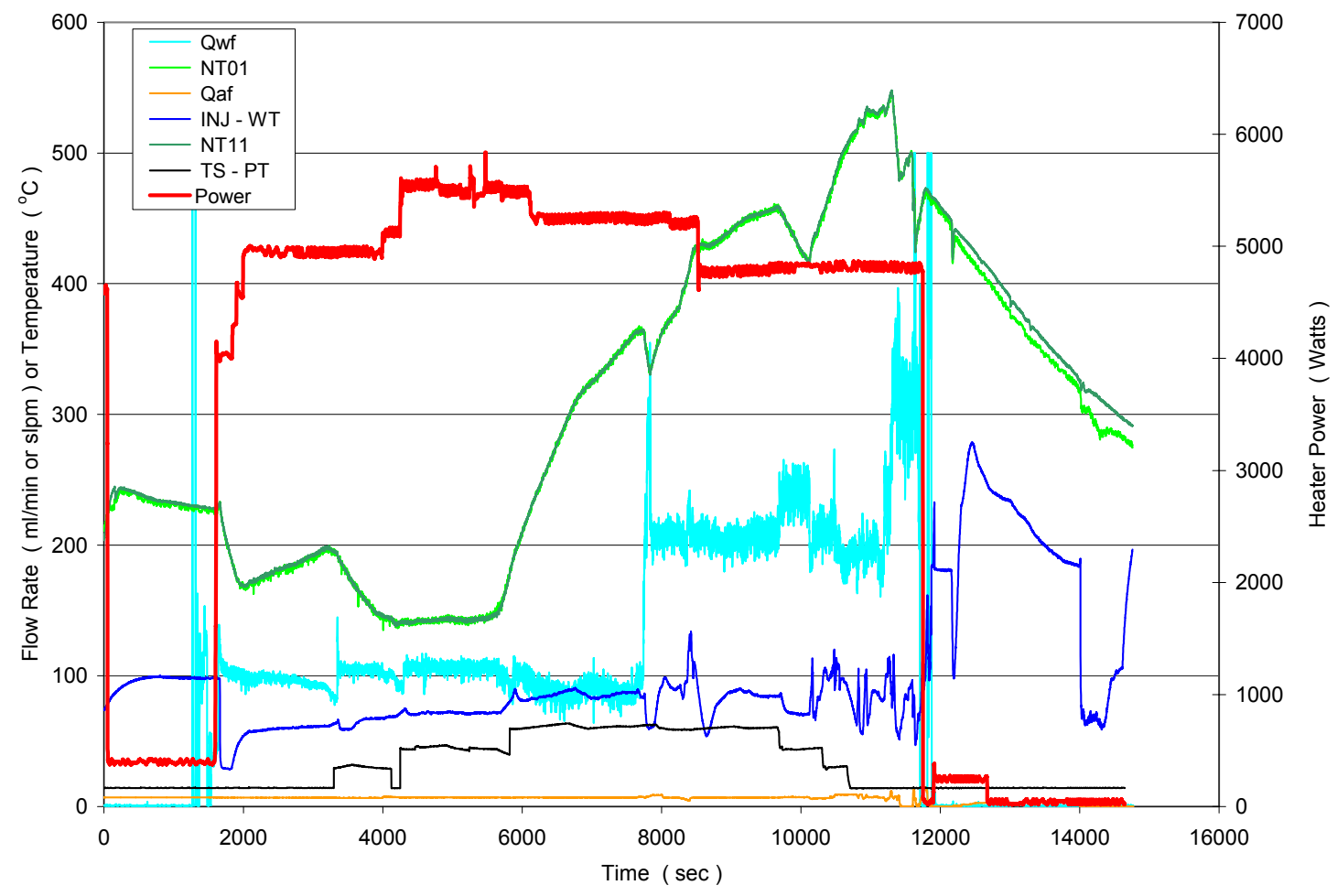

Figure 14. Time History INERI-8.

INERI -9: The primary purpose of this text was to investigate the heat transfer and flow stability behavior at high water mass flow rates using the maximum power input available for the test section. The initial metal temperature was about $200^{\circ} \mathrm{C}$ and the test started at a water flow rate of $150 \mathrm{ml} / \mathrm{min}$. The input power was gradually increased 
from $4500 \mathrm{~W}$ to about $7000 \mathrm{~W}$ over a one-hour period. During this period, the melt temperature increased to about $240^{\circ} \mathrm{C}$. After this heat up period, the water flow rate was gradually increased to over $400 \mathrm{ml} / \mathrm{min}$ while the input power increased to the maximum available (about $8500 \mathrm{~W}$ ). With the increased water flow rate, the melt started to cool down and the temperatures at the various locations of the test section went down below the freezing point. Cooling of the apparently solid mass of metal in the test section continued at the maximum power level. Then the water flow was reduced to $150 \mathrm{ml} / \mathrm{min}$, causing re-melting of the frozen mass of metal. As the power level was reduced to about $7000 \mathrm{~W}$, the operation seemed to stabilize while the melt temperature was slowly increasing with time. When the melt temperature reached about $250^{\circ} \mathrm{C}$, the water flow was increased to over $400 \mathrm{ml} / \mathrm{min}$ but the melt temperature continued to increase. When the melt temperature increased to over $400^{\circ} \mathrm{C}$, booming noises was heard and the water and Argon gas flow rates fluctuated erratically, indicative of partial plugging of the injector nozzle. At this point, the test was terminated. This test seems to indicate that seemingly similar experimental conditions produced significantly different results in terms of the heat removal rate. The time-histories of the power input, melt temperature, water and Argon flows for INERI-9 are shown in Fig. 15.

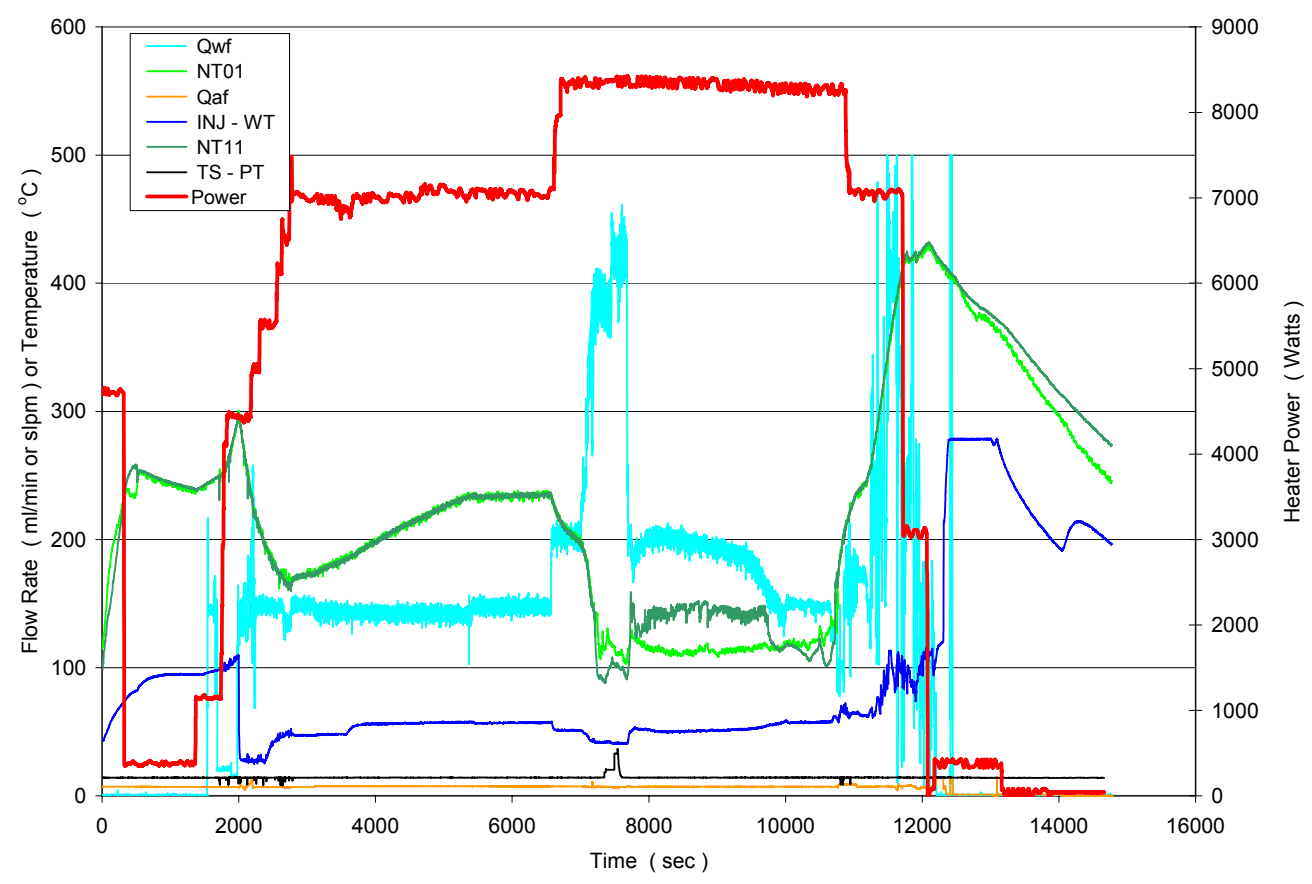

Figure 15. Time History INERI-9. 
INERI-10: This test was more or less a repeat of INERI\#9 with the same objective, namely, to investigate the heat transfer and flow stability behavior at high water mass flow rates using the maximum power input available. The main difference between this test and INERI\#9 was the flow rate of Argon gas mixed with the injected water. In this test the Argon flow rate was $20 \mathrm{slpm}$, which was twice that of INERI\#9. It appears that the increased Argon flow rate stabilized the operation. The water injection rate was increased in steps from $150 \mathrm{ml} / \mathrm{min}$ to $400 \mathrm{ml} / \mathrm{min}$ while the power input was increased from $6000 \mathrm{~W}$ to about $8300 \mathrm{~W}$ (maximum available). The melt temperature mostly remained in the range of $200-300^{\circ} \mathrm{C}$. The test run was terminated as planned. There were no flow instabilities causing the injector plugging. The time-histories of the power input, melt temperature, water and Argon flows for INERI-10 are shown in Fig. 16.

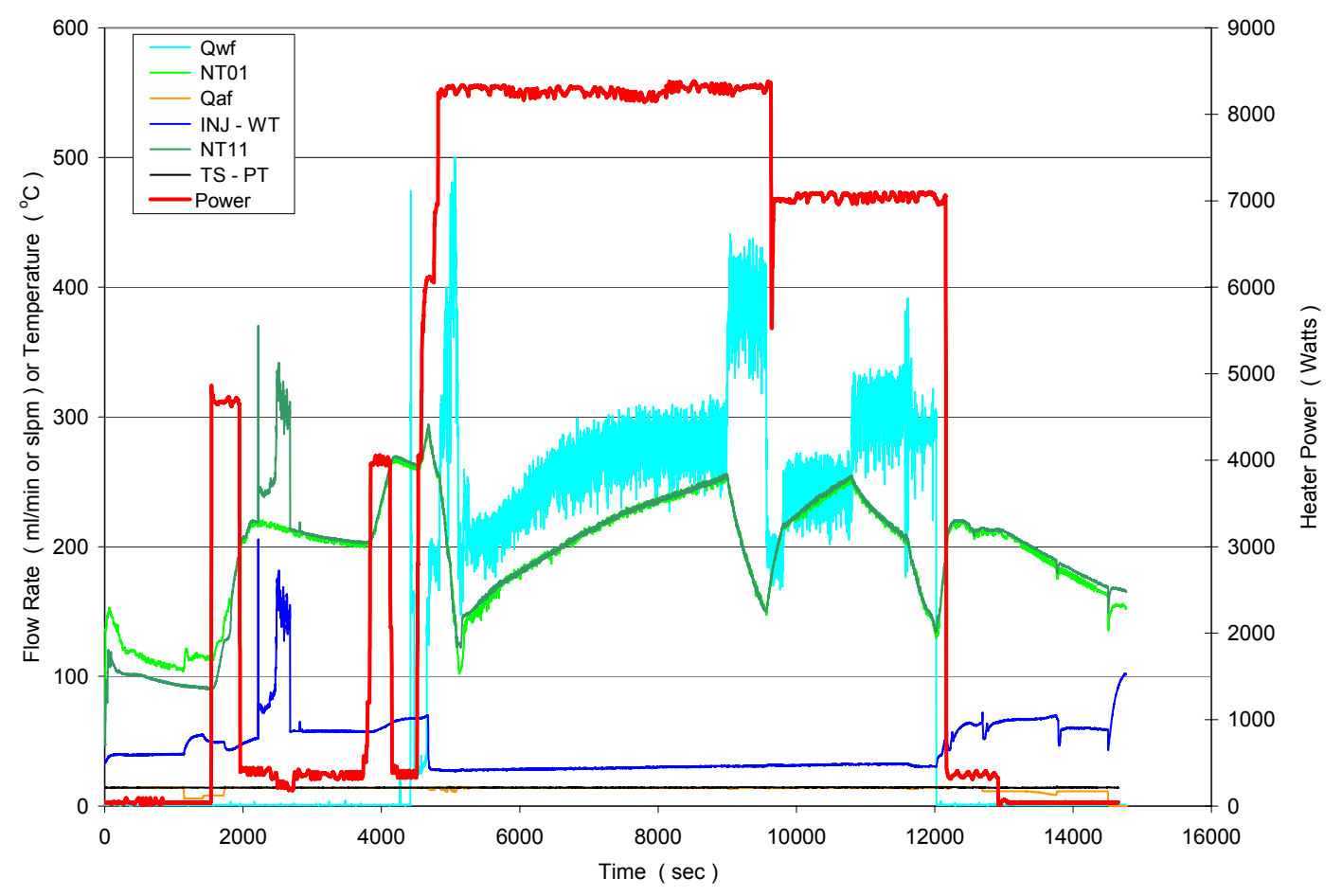

Figure 16. Time History INERI-10.

\section{Heat Removal Rate Estimates}

The rate of heat removal from the melt by the injected water was estimated by the energy balance: [Heat Removal Rate=Power In $-10^{4}\left(\mathrm{dT}_{\text {melt }} / \mathrm{dt}\right)-$ Heat Loss Rate], where the 
units of the heat removal rate, power input and heat loss are given in Watts and the rate of melt temperature change with time, $\left(\mathrm{dT}_{\text {melt }} / \mathrm{dt}\right)$, is given in ${ }^{\circ} \mathrm{C} / \mathrm{sec}$. The above energy balance takes into account a combined thermal mass of the melt and test section. At steady state, the thermal mass plays no role. The heat loss rate was estimated by the following expression: [Heat Loss Rate $=0.8 \mathrm{~T}_{\text {melt }}-20$ ], where the heat loss rate is given in Watts and the melt temperature, Tmelt, is given in ${ }^{\circ} \mathrm{C}$. This heat loss expression takes into account the thickness and thermal conductivity of the insulation surrounding the test section. The time interval chosen for an estimate of the heat removal rate was typically 300 to $600 \mathrm{sec}$, which was considered to be sufficiently large compared to the relaxation time of the thermal mass. The estimated heat removal rates for the tests conducted are plotted as a function of the water injection flow rate. This plot is shown in Fig. 17.

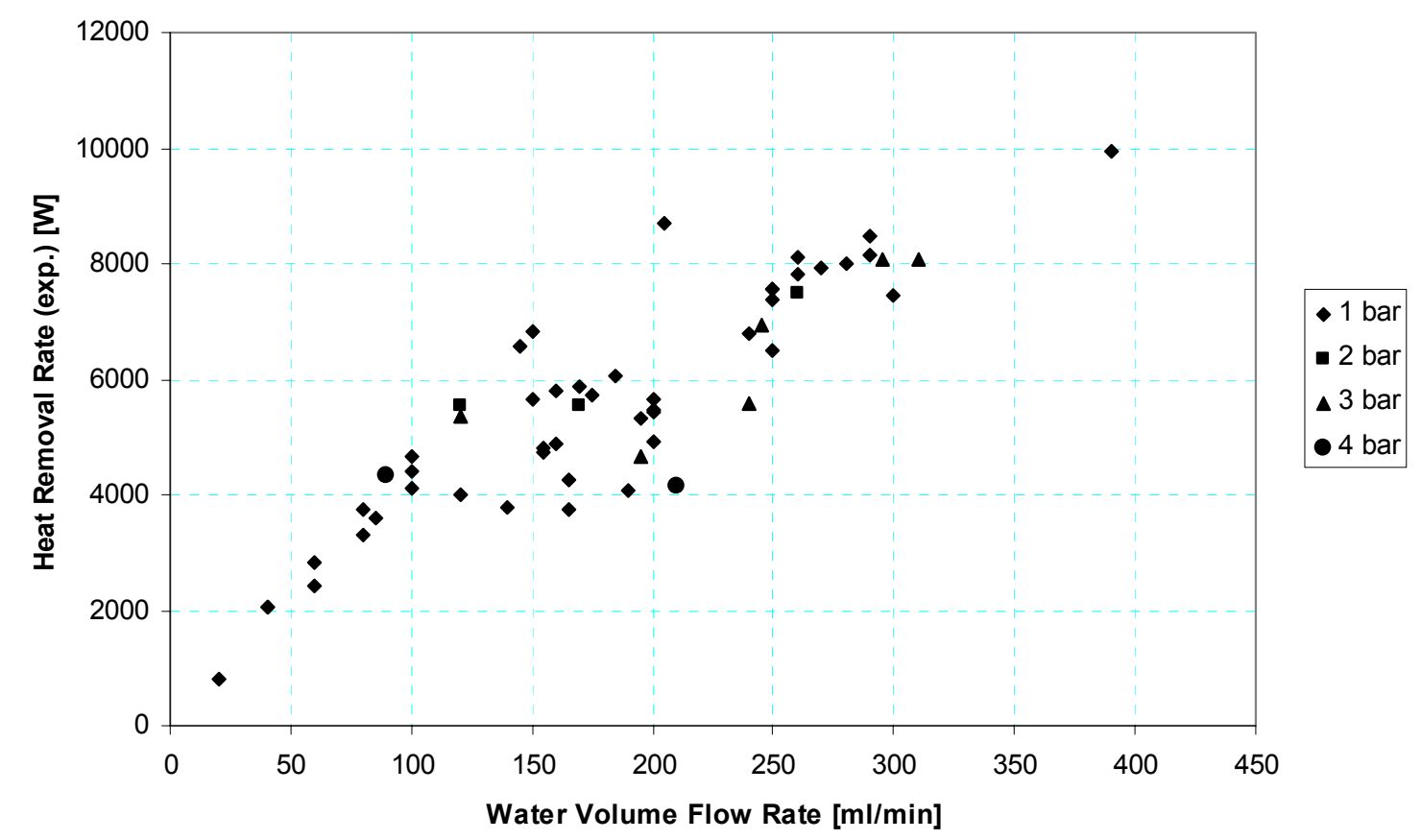

Figure 17. Heat Removal Rate vs. Water Injection Flow Rate for conducted Tests.

\section{$\underline{\text { Discussion }}$}

(1) The figure shows that for low water flow rates (say, less than $100 \mathrm{ml} / \mathrm{min}$ ), the heat removal rate increased in direct proportion to the water flow rate. For high water flow rates, however, there was a large amount of data scatter and the heat 
removal rate deviated greatly from the direct proportimality to the water flow rate. In fact, it would appear that the heat removal rate was reaching an upper limit at very high water flow rates $(\sim 400 \mathrm{ml} / \mathrm{min})$.

(2) To gain insight into the extent of heat removal from the melt, the maximum possible heat removal rate was calculated assuming that the injected water vaporized $100 \%$ to steam and that the steam produced was heated to the melt temperature, viz.

Maximum Heat Removal Rate $($ Watts $)=n w_{v}\left[4.2\left(\mathrm{~T}_{\mathrm{bp}}-\mathrm{T}_{\mathrm{w}}\right)+\mathrm{h}_{\mathrm{fg}}+2\left(\mathrm{~T}_{\text {melt }}-\mathrm{T}_{\mathrm{bp}}\right)\right]$

where $n \&_{V}=$ water injection rate, $\mathrm{g} / \mathrm{s}$

$\mathrm{T}_{\mathrm{bp}}=$ boiling point of water, ${ }^{\circ} \mathrm{C}$

$\mathrm{T}_{\mathrm{w}}=$ temperature of injected water, ${ }^{\circ} \mathrm{C}$

$\mathrm{h}_{\mathrm{tg}}=$ heat of vaporization of water, $\mathrm{j} / \mathrm{g}$

$\mathrm{T}_{\text {melt }}=$ melt temperature ${ }^{\circ} \mathrm{C}$

In the above expression for the maximum heat removal rate, the heating of the Argon gas co-injected with the water was ignored, since its contribution was insignificant.

Fig. 18 shows the ratio of the estimated heat removal rate to the maximum calculated as a function of the water flow rate. It is seen that for water flow rates less than $100 \mathrm{ml} / \mathrm{min}$, this ratio is unity within the experimental uncertainty. Thus for low water flow rates, the injected water vaporized $100 \%$ in the melt and the maximum possible heat removal from the melt occurred. For higher water flow rates, the ratio is significantly lower than unity, indicating that the injected water vaporized only partially in the melt. For the tests conducted here, there was no evidence of water accumulating on the top of the melt. It is believed that the unvaporized water was probably dispersed in the steam flow. 


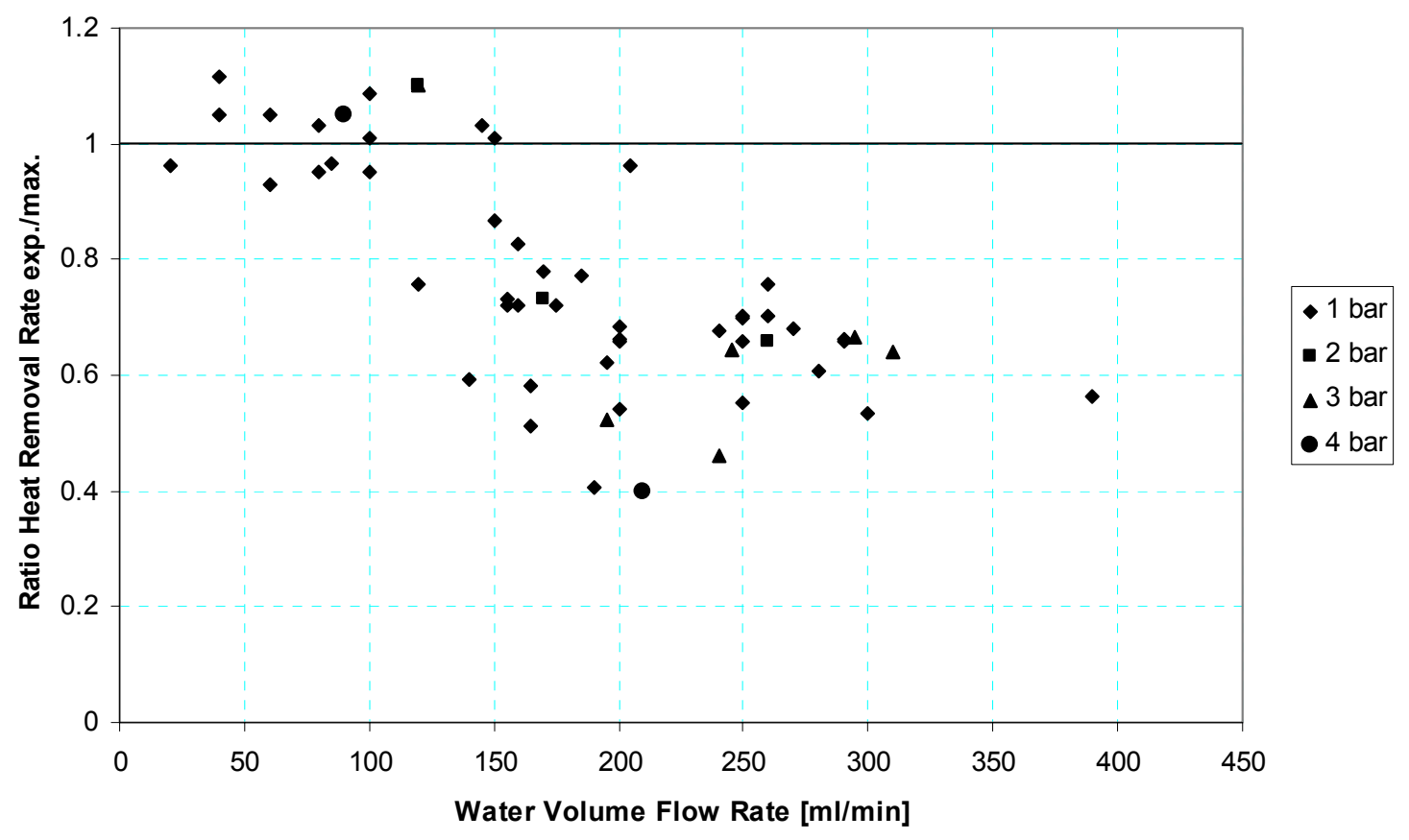

Figure 18. Ratio of Test to Maximum Heat Removal Rate vs. Water Injection Flow Rate.

(3) As long as the injected water vaporizes $100 \%$ in the melt, the rate of heat removal from the melt would be directly proportional to the water injection flow rate. No direct information on the structure of the evaporation zone in the melt is available. For low water mass fluxes where the evaporating drops/steam bubbles would be in the bubbly flow regime with minimal interactions between them, there may be a steam superheating zone above the evaporation zone with a clear boundary between the two zones. However, it may be difficult to define the evaporation zone for high water mass fluxes resulting in churn turbulent flows in the melt/water mixture. In a situation like this, it seems likely that evaporating water drops and superheated steam bubbles would co-exist over a significant portion of the entire mixing zone height, leading to overlapping of the evaporation zone and the steam superheating zone. Nevertheless, an analysis of previous experiments seems to suggest that the evaporation zone height would increase with increasing water flow rate. Once the evaporation zone height becomes equal to the expanded melt height, the injected water would not likely vaporize $100 \%$ in the melt. Then, the heat removal rate stops being directly proportional to the water injection rate. 
(4) Both Figs 17 and 18 show that the data scatter is very large for water flow rates higher than $100 \mathrm{ml} / \mathrm{min}$, where the ratio of the estimated heat removal rate to the maximum calculated is significantly below unity. For these water flow rates, the steam/water flow in the melt would be in the churn turbulent flow regime, which involves unsteady and chaotic flow patterns including channeling and recirculation. It is believed that the large data scatter observed is related to this chaotic nature of the steam/water flow. In a highly churn turbulent flow, the interfacial area for melt-water heat transfer would vary in a chaotic and unsteady manner with time. As a result, the heat removal rate as well as the amount of water vaporization in the melt would vary with time. Even at water flow rates lower than $100 \mathrm{ml} / \mathrm{min}$, the steam/water flow could be unsteady and chaotic. However, the heat removal rate would not be affected as long as the injected water vaporizes $100 \%$ in the melt.

(5) The present data for water flow rates of $100 \mathrm{ml} / \mathrm{min}$ or less, which was obtained in the presence of non-condensable gas in the injected water, was compared to earlier data obtained with water flow alone, i.e. in the absence of non-condensable gas. It was found that the overall heat removal rate was not affected by the presence of non-condensable gas in the injected water. This finding is not surprising in view of the fact that the gas flow rates used were only a small fraction of the steam flow rates produced in the tests. Consider, for example, the water injection rate of $100 \mathrm{ml} / \mathrm{min}$. Assuming 100\% vaporization of the injected water, the water flow rate would correspond to a steam superficial velocity of above $40 \mathrm{~cm} / \mathrm{sec}$, which, incidentally, is well above the velocity for the bubbly-tochurn turbulent flow transition. In contrast, the Argon flow rate of 10 slpm only corresponds to a superficial gas velocity of about $2 \mathrm{~cm} / \mathrm{sec}$. Thus, the presence of non-conderable gas in the injected water did not affect the flow regime produced in the melt and consequently, had little impact on the heat removal process.

The present findings regarding the co-injection of water and non-condensable gas are significant for the following two reasons. First, the findings suggest that the heat removal from the melt would be controlled by melt-water mixing, primarily 
caused by the steam flow produced, rather than material properties or local heat transfer barriers such as gas/steam film. Secondly, adding non-condensable gas to the injection flow of water would stabilize the subsequent melt-water mixing. With the injection of water alone, it was observed that small steam explosion events occasionally occurred, depending on the melt temperature and the water flow rate. These events often caused the plugging of the injector as well as the expulsion of a mass of melt from the test section. Experiments have shown that the presence of non-condensable gas in the injected water flow would suppress such explosive events. Thus, it seems likely that adding non-condensable gas to the injection flow of water would minimize steam explosion risk while not impairing the heat removal capability of the injected water. In the context of exvessel coolability, it should be noted that non-condensable gases would be expected to be produced from erosion of concrete upon contact of the melt with the basemat. The superficial gas velocities resulting from such concrete erosion are known to be mostly in the range of a few $\mathrm{cm} / \mathrm{sec}$, which are comparable to those of the argon flows employed in the present tests.

(6) A limited number of tests at elevated pressures up to 4 bars were conducted. The results of these tests were found to be within the data scatter observed at atmospheric pressure. It thus appears that for an ambient pressure range relevant to the LWR containment (i.e. 1-5 bars), the system pressure has little effect on the heat removal rate from the melt by the injected water.

(7) For comparison to other test data such as COMET, Fig. 17 was re-plotted using normalized quantities, namely in terms of the heat removal rate per unit cross section $\left(\mathrm{MW} / \mathrm{m}^{2}\right)$ vs. the water mass flux $\left(\mathrm{kg} / \mathrm{m}^{2}-\mathrm{s}\right)$. This normalized plot is shown in Fig. 19. It may be noted that in the COMET U2 test, the heat removal rate for a water mass flux of $3.2 \mathrm{~kg} / \mathrm{m}^{2}$-s was about $2.0 \mathrm{MW} / \mathrm{m}^{2}$. This heat removal rate appears to be comparable to the highest heat removal rate observed in the present tests, which was about $1.4 \mathrm{~kg} / \mathrm{m}^{2}$-s at a water mass flux of 0.9 $\mathrm{kg} / \mathrm{m}^{2}-\mathrm{s}$. 


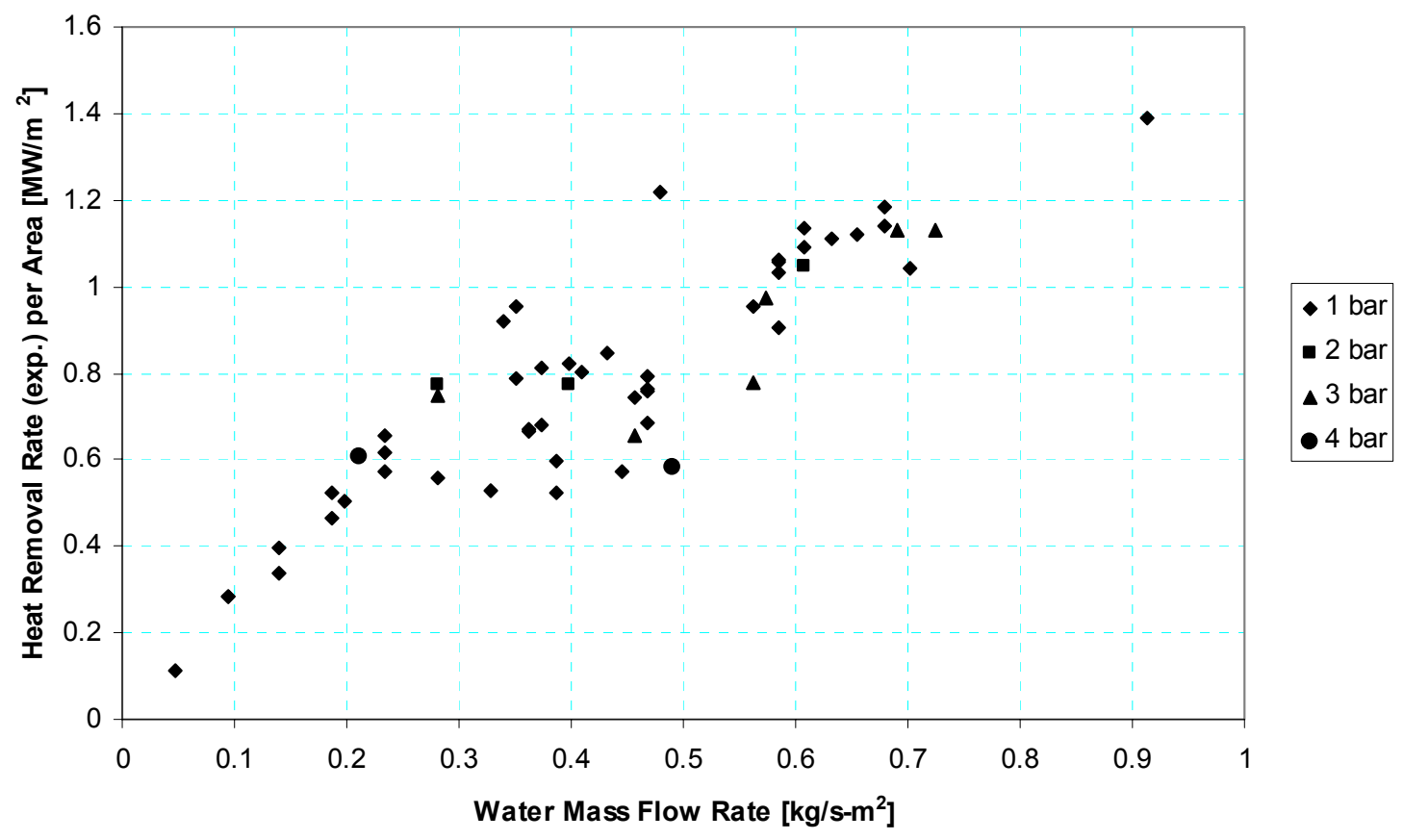

Figure 19. Heat Removal Rate (expt.) per Unit Area vs. Water Mass Flux.

(8) As indicated earlier, it appears that for a given melt height, the heat removal rate would reach an upper limit at a certain water injection rate and would not increase further with increasing water injection rate. This upper limit may depend on the melt height. It is expected, however, that regardless of the melt height, there would likely be a maximum heat removal rate. This expectation is based on consideration of the flow regime of steam produced in the melt. The maximum heat removal rate would likely occur before the steam flow velocity becomes sufficiently high to cause onset of the dispersed droplet flow regime, i.e. melt droplets dispersed in a continuous steam flow. For purposes of illustration, suppose the maximum heat removal rate corresponds to the minimum fluidization velocity of steam in the melt. According to Wallis (p. 385), the minimum fluidization velocity is given by

$$
(j)_{m f}=0.2 \rho_{1}^{-1 / 2}\left[g \sigma\left(\rho_{2}-\rho_{1}\right)\right]^{1 / 4}
$$


Where $\rho_{1}=$ steam density

$\rho_{2}=$ melt density

$\sigma=$ surface tension of melt

$\mathrm{g}=$ gravitational constant

The steam mass flux would then be given by

$\rho_{1}(j)_{m f}=0.2 \rho_{1}^{1 / 2}\left[g \sigma\left(\rho_{2}-\rho_{1}\right)\right]^{1 / 4}$

The corresponding heat removal rate per unit

cross section is given by

$\underset{\text { (max) }}{\&}=0.2 h_{f g} \rho_{1}^{1 / 2}\left[g \sigma\left(\rho_{2}-\rho_{1}\right)\right]^{1 / 4}$

For the present melt-steam system at $1 \mathrm{bar}$, the maximum heat removal rate per unit cross section is found to be $4.89 \times 10^{3} \mathrm{KW} / \mathrm{m}^{2}$. The cross section of the present test section is $7.1 \times 10^{-3} \mathrm{~m}^{2}$, so the maximum heat removal rate for the test section would be $(4.89 \mathrm{x}$ $\left.10^{3}\right) *\left(7.1 \times 10^{-3}\right)=34.7 \mathrm{KW}$. This maximum heat removal rate may be compared to the highest heat removal rate observed in the tests, which was about $10 \mathrm{KW}$. 
Task II:Molten Pool Quench Phenomena with Real-Time X-ray Imaging (UW Lead)

II.1 Objectives: In collaboration with Task I, our goal is to help answer these questions:

1. What is the volumetric heat removal rate, $q^{\prime \prime}$, and the volumetric heat transfer coefficient, $U_{\mathrm{v}}$, for melt-water mixtures in past experimental conditions?

2. Is $U_{\mathrm{v}}$ of the same order of magnitude for different contact modes between melt and water?

3. Is the measured $q^{\prime \prime}$ or $U_{\mathrm{v}}$ a strong function of melt properties?

4. Is the heat removal rate sufficient to quench and cool the melt, resulting in a stable coolable multiphase system?

Questions 1, 2 and 3 have already been answered in our earlier investigations for this study (see INERI US-ROK Annual Reports for Years $1 \& 2$ ). Previous tests from the MACE, FARO and COMET series have been analyzed and the volumetric heat transfer coefficient has been calculated. All volumetric heat transfer coefficients are of the same order of magnitude. This indicates that the heat transfer is primarily limited by the resistance of the vapor separating the liquid water and the melt. Melt properties and contact mode are secondary effects. In order to evaluate sufficient heat transfer and stability for the system in the case of bottom injection, additional research is required.

As discussed below, a test section is designed to solve the remaining question. Several parameters were presented, some of which will be held constant and some of which will be allowed to vary in order to study their effects on the physics. The constant parameters are:

- Liquid Metal Temperature: $500{ }^{\circ} \mathrm{C}\left(450{ }^{\circ} \mathrm{C}\right)$

- Injection Temperature: $75^{\circ} \mathrm{C}-85^{\circ} \mathrm{C}$

- Collapsed Liquid Metal Height: $45 \mathrm{~cm}$

- Injector I.D.: $2 \mathrm{~mm}$ 
At lower flow rates $(1 \mathrm{~g} / \mathrm{s}, 2.5 \mathrm{~g} / \mathrm{s}$, and $3 \mathrm{~g} / \mathrm{s})$ a liquid metal temperature of $500{ }^{\circ} \mathrm{C}$ could be maintained. However, due to elevated cladding temperature of the heaters it had to be lowered to $450{ }^{\circ} \mathrm{C}$ for flow rates of $5 \mathrm{~g} / \mathrm{s}$ and $6 \mathrm{~g} / \mathrm{s}$.

The variable parameters are:

- Pressure: 0, 1, 2.5, 3.5, 5 bar

- $\quad \&_{\text {Vater }}: 1,2.5,3,5,6 \mathrm{~g} / \mathrm{s}$

- $k_{\text {Gas }}: 0,5,10,15,20,30 \mathrm{slpm}$

Analysis of the resulting test matrix will show data for

- Void Fraction;

- Heat Removal Rate, and

- Flow Stability.

\section{II.2 EXPERIMENTAL APPROACH:}

This section discusses the experimental apparatus constructed for studying the stability and heat transfer characteristics of combined injection of water and inert gas into a corium simulant under single and multi nozzle configurations. The apparatus consists of five main components, namely, the liquid metal reservoir, test section, suppression tank (condenser), pumping and preheating system, and X-ray imaging system (Abdulla, 2003; Liu, 2003; Klockow, 2004). The apparatus is equipped with diagnostics to measure the following parameters:

- Inlet water injection rate.

- Inlet inert gas injection rate.

- Inlet mixture temperature.

- Liquid metal reservoir pressure.

- Liquid metal reservoir inventory.

- Liquid metal pool temperature.

- Test section operating pressure.

- Condenser pressure.

- Exiting steam temperature.

- Time evolution of void fraction. 
- Heater power input.

Due to safety considerations and ease of control, the experimental apparatus is equipped with pneumatically actuated valves to control the flow of the working fluids used in the experiment, for example: the liquid metal flow from the reservoir to the test section and vice versa, the water flow to the test section and the pressurized inert gas flow to both the test section and the liquid metal reservoir. Temperature and computer controlled electrical heaters are used both to melt the metal and to keep it in the liquid state. Figure 21 schematically represents the test apparatus.

Liquid Metal Reservoir: The liquid metal reservoir is a cylindrical tank of $0.08 \mathrm{~m}^{3}$ volume (see Figure 22) made of type 410 stainless steel, which is a general purpose heat and corrosion resistant stainless steel with low nickel content. Liquid lead, the corium simulant in the current experiment, reacts with nickel in austenitic stainless steel above $700^{\circ} \mathrm{C}$. A type 410 stainless steel was chosen to avoid lead corrosion (Clifford, 1960). Two identical Omega, model: CRWS-2418/240-A, clamshell heaters with a rated heat output of $16,400 \mathrm{~W}$ surround the reservoir. The heaters are controlled with a temperature controller so that the metal can be heated to a predetermined temperature and to mitigate overheating of the reservoir vessel. The heaters can withstand temperatures of up to 980 ${ }^{\circ} \mathrm{C}$ while the required liquid metal temperature in most of the test is only $500{ }^{\circ} \mathrm{C}$. The reservoir is cantilevered on an Omega force transducer, model: LC 304-1K, to allow continuous monitoring of the liquid metal transferred to the test section. This helped to achieve the same static liquid metal level in the test section every time the experiment was conducted. Two pneumatically actuated valves are connected to the reservoir. One of the valves is used for venting the reservoir while the other valve is connected to the inert gas (argon in the current experiment) supply to pressurize the reservoir to allow the liquid metal transfer from the reservoir to the test section. A $2.54 \mathrm{~cm}$ diameter transfer line connects the liquid metal reservoir to the test section and is equipped with another pneumatically actuated valve to control the liquid metal transfer. In addition to the valve, a cooling device is employed to prevent back flow of liquid metal when there is a high pressure difference between the test section and the liquid metal reservoir. 


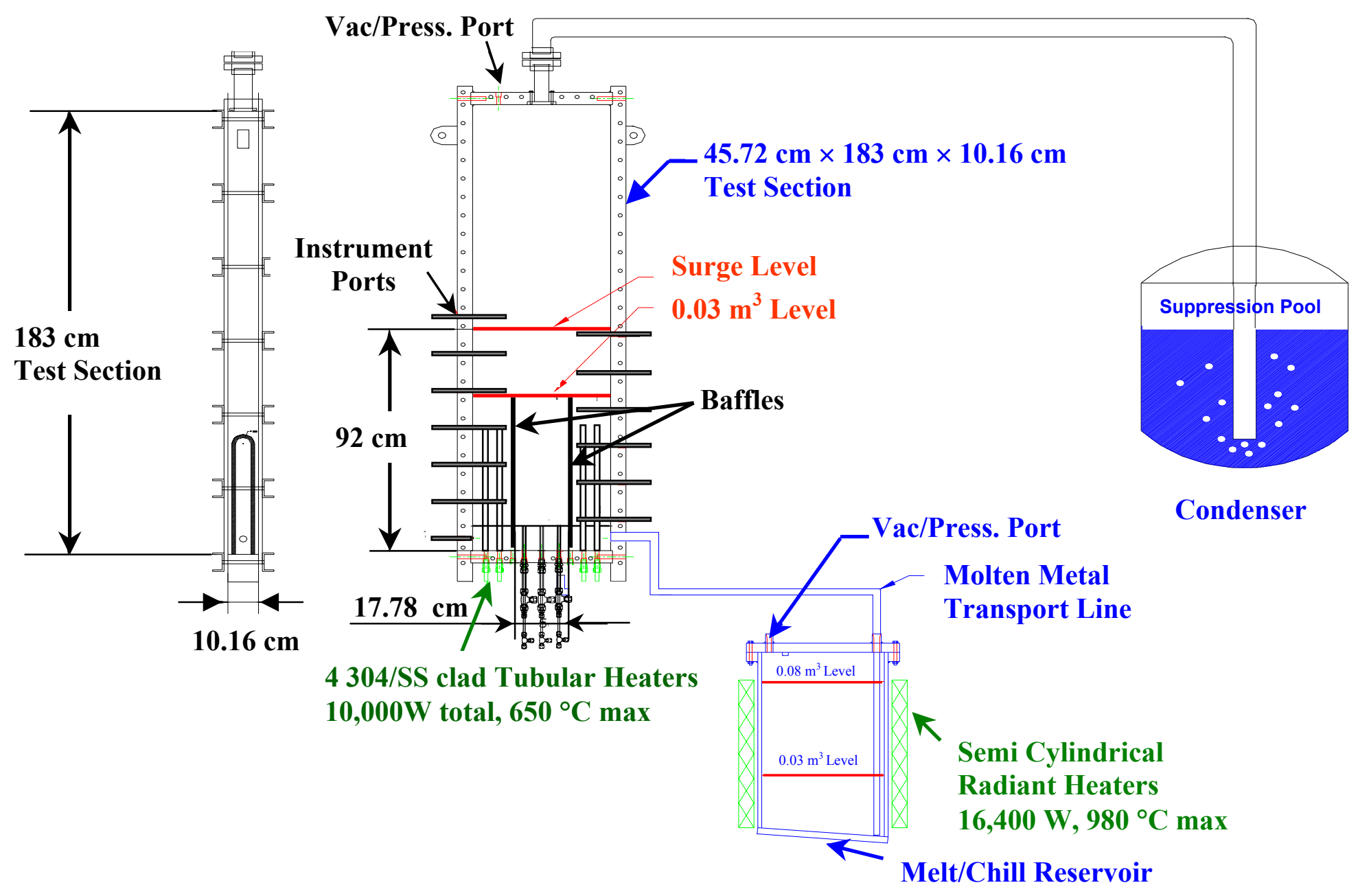

Figure 21: Schematic of the Experimental Setup 


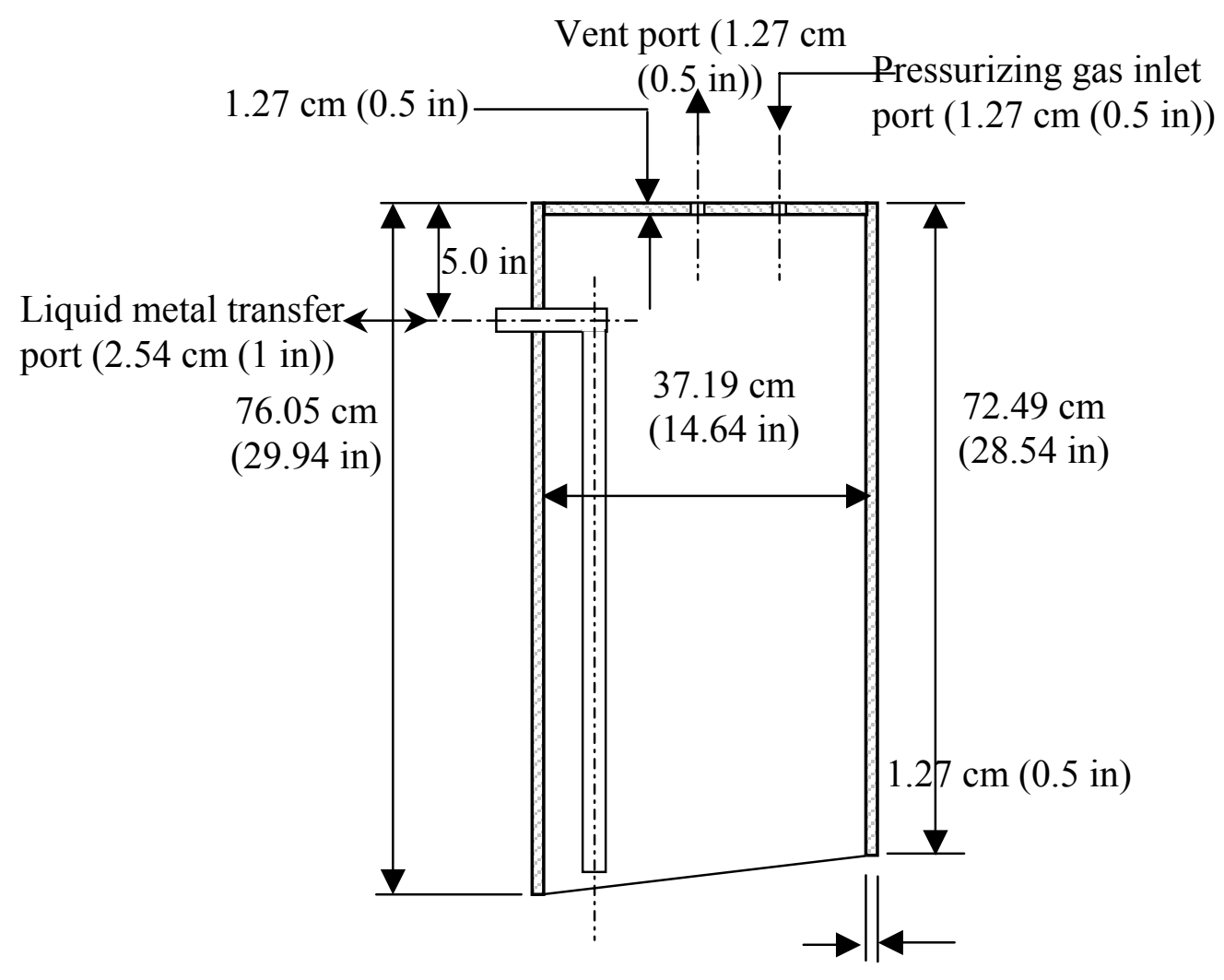

Figure 22: Dimensions of the liquid metal reservoir (drawn to scale)

Test Section: Figure 21 shows the schematic of the test section. A frame made of $5.08 \mathrm{~cm}$ $\times 10.16 \mathrm{~cm}$, type 410 stainless steel plate forms an interior volume of $45.72 \mathrm{~cm}$ wide, $10.16 \mathrm{~cm}$ deep and $183 \mathrm{~cm}$ tall. Two 410 stainless steel plates $1.27 \mathrm{~cm}$ thick, were used for the front and the back of the rectangular box. The test section is bolted at the top and the bottom to a supporting structure. Eight support beams made by $5.08 \mathrm{~cm} \times 15.24 \mathrm{~cm}$, $0.64 \mathrm{~cm}$ thick rectangular tubing are used to reinforce the test section. These beams are necessary for the test section to be able to hold high pressures (as high as 10 bar) at operating temperatures of $500{ }^{\circ} \mathrm{C}$. As shown in Figure 23, the bottom $45.72 \times 10.16 \mathrm{~cm}$ plate of the test section has openings for the injectors, immersion heaters, and the support tubes for the baffles. The injectors are connected to the pumping system. The spacing between the injectors is $6.35 \mathrm{~cm}$. The injectors can be moved up and down for different flow configurations. In the current setup the injector tip is $10.16 \mathrm{~cm}$ above the bottom of the test section in order to have a view area at the liquid metal free surface unobstructed by the supporting structure. The top of the test section has openings for the steam exit, a 
gas vent and an inert gas supply port. The steam exit port is connected to the condenser via a $5.08 \mathrm{~cm}$ I.D. pipe. The test section vent line and gas supply line (both are $1.27 \mathrm{~cm}$ diameter) are controlled via two separate pneumatically actuated valves. This valve arrangement provides the means to pressurize the test section, when needed, to pressures higher than atmospheric pressure. The valves are either controlled by the operator or feedback from the pressure transducers and predetermined pressure limits.

In order to observe different flow configurations, baffles are installed in the test section. The spacing between the baffles is $20.23 \mathrm{~cm}$. The baffles are $76.2 \mathrm{~cm}$ high, $9.65 \mathrm{~cm}$ wide, $0.64 \mathrm{~cm}$ thick type 316 stainless steel plates and can be raised an additional $30.48 \mathrm{~cm}$. In the current experiments the baffles are as low as possible to achieve a 1-D type pool configuration, but allow filling of all spaces. Each baffle is supported by two $1.27 \mathrm{~cm}, 14$ gauge tubes made out of type 316 stainless steel. Thermocouples are welded in the wall of the support tubes to measure the pool temperature distribution.

Preliminary calculations based on a total vaporization of the maximum water flow rates, around $6 \mathrm{~g} / \mathrm{s}$, justified the need of $18 \mathrm{~kW}$ of heat input in order to maintain a steady state operation. Four type 304 stainless steel clad immersion heaters $2.5 \mathrm{~kW}$ each, model: TrSS-5465, were placed inside the test section, as shown in Figure 23, to avoid any metal solidification inside the test section and to maintain a constant liquid metal temperature during water/gas injection. The heaters' on/off operation was controlled by measurement of the liquid metal temperature near the baffle support tubes. If the temperature drops below a user-specified minimum temperature, the heaters are turned on. If the temperature goes above a user specified maximum temperature, the heaters are turned off. The heaters are controlled in pairs to ensure symmetry in the test section. It should be mentioned that the heaters are offset to the side of the test section to allow for at least $20.23 \mathrm{~cm}$ clear, unobstructed view for the water/gas injection with the high energy X-ray imaging system. Later in the experimental series the two pairs were replaced with seven pairs of cartridge heaters manufactured by the Gordon Hatch Company (1/2 inch diameter, 14 inch total length, $240 \mathrm{~V}, 2000 \mathrm{~W}, 8$ inch heated, 6 inch cold with built in TC style III, K-type, standard 12 inch leads) installed vertically in the previous heater ports 
and the two ports initially planned for additional nozzles. Two groups of four cartridge heaters also by Gordon Hatch (3/8 inch diameter, 8 inch total length, $240 \mathrm{~V}, 650 \mathrm{~W}$, 4 inch heated, 4 inch cold with built in TC style III, K-type, standard 12 inch leads) installed horizontally in the ports previously used for thermocouples (see Figure 27). In addition to the immersed heaters, four temperature controlled groups of four Watlow strip heaters, model: MS1J18AS2, were mounted on the exterior front, rear and sides of the test section to preheat the test section prior to the liquid metal transfer to the test section.

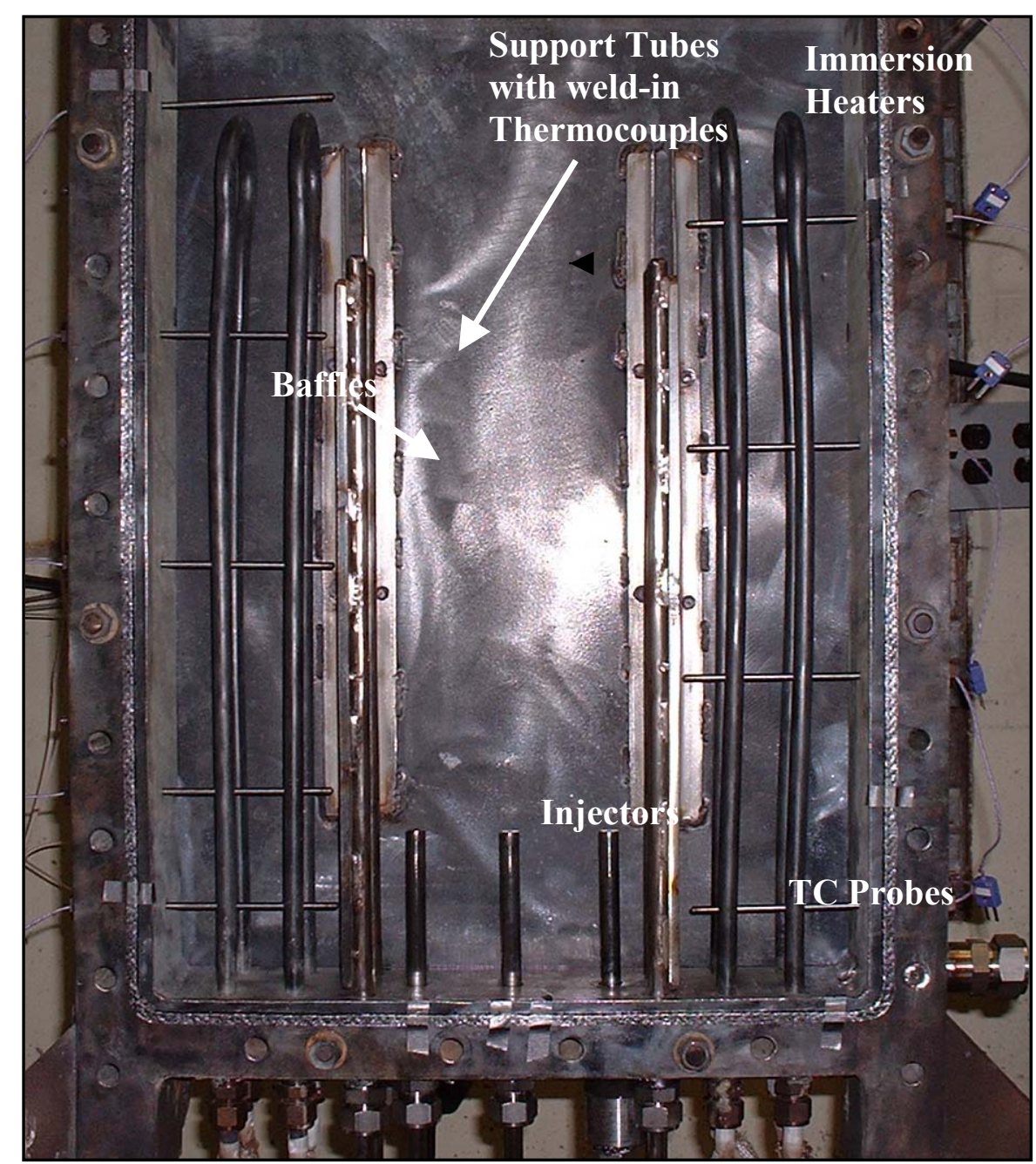

Figure 23: Photo of the test section internal components (Note: Only 18 inch baffles shown without the additional 12 inch extension)

These heaters are also used to add heat to the system. The test section is insulated with layers of alumina wool insulation (about $4 \mathrm{~cm}$ thick), Thermal Ceramics: Kaowool S, to 
reduce the heat loss during the operation. It should be mentioned that the high thermal conductivity of the liquid metal $(\sim 16 \mathrm{~kW} / \mathrm{m}-\mathrm{K})$ resulted in a nearly uniform pool temperature.

Suppression Tank (Condenser): The suppression tank (condenser), shown in Figure 24, is a 350 liter pressure vessel in which the steam generated during the experiments condenses. Almost half of the tank volume is pre-filled with water at room temperature. The steam exit line carries the steam generated in the test section to the condenser and discharges the steam inside the tank below the pre-filled water free surface. The tank is equipped with an Omega pressure transducer, model: PX 302-200 AV, to monitor its pressure during the operation. It is also equipped with a vent valve to relieve the system when the pressure increases above the operator predetermined upper pressure limit. The valve closes automatically when the preset pressure is attained. For safety purposes, the tank was equipped with a mechanically operated relief valve that opens if the condenser pressure reaches 165 psia. A pneumatically actuated valve was installed in the line connecting the test section and condenser to isolate the two components when necessary.

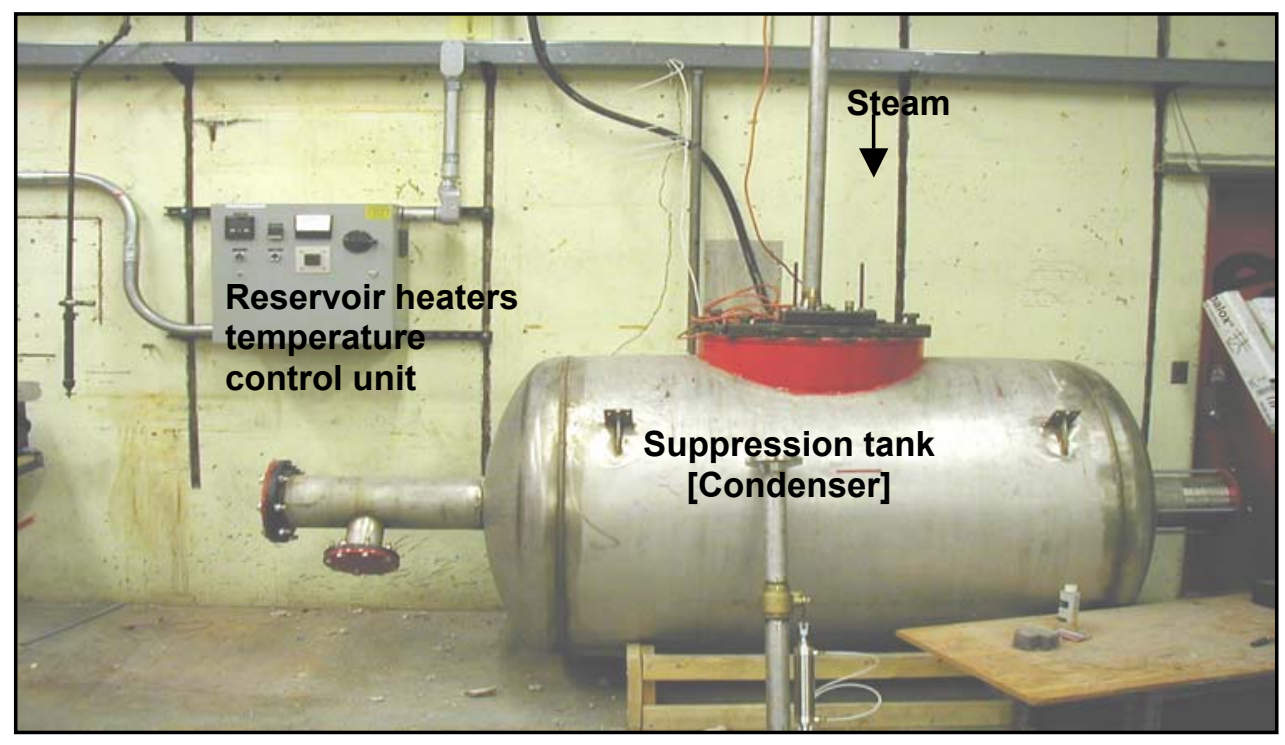

Figure 24: Suppression Tank (condenser)

Pumping System: One of the challenges in the current experiment was the necessity to inject a constant, relatively low water flow rate through the injector, 1-6 g/s, at pressures up to 5 bar. In order to achieve this mandatory requirement, a pumping system was 
designed. The pumping system consists mainly of a water supply tank, an electrically driven variable speed drive plunger pump, HYDRO model: Powerline Plus 2330B-P, and a set of control valves and measuring devices. Figure 25 shows a photo of the pumping system and Figure 26 is a schematic of the pumping system.

The system works by setting the pump discharge pressure $\left(\mathrm{P}_{2}\right)$ to a predetermined value, up to $500 \mathrm{psig}$, using the adjustable regulator. The pump recirculates water at a flow rate much greater than what is required by the experiment. Pressure $\mathrm{P}_{1}$ is used to determine the water level in the tank. Valves $V_{2}$ and $V_{3}$ are needle valves used to adjust the water flow rate to the desired value. $\mathrm{V}_{2}$ (Swagelok ${ }^{\mathrm{TM}}$ needle valve, model: SS-SS2) is used for lower flow rates from 2.5-3 g/s, while $\mathrm{V}_{3}$ (Swagelok ${ }^{\mathrm{TM}}$ needle valve, model: $\mathrm{SS}-2 \mathrm{MG}$ ) is used for higher flow rates from 5-6 g/s. $V_{1}$ is used to direct the water either to $V_{2}$ or $V_{3}$. $\mathrm{V}_{4}$ is a manual shut-off valve, while $\mathrm{V}_{7}$ is a pneumatic computer controlled shut-off valve. $\mathrm{V}_{5}$ is used as a bleed valve. The water flow rate is monitored by an Omega flow meter, model: FTB9503 and an Omega signal conditioner, model: FLSC-61. For flow rates of 1 g/s or less, a High performance Liquid Chromatography (HPLC) was employed.

In addition, the time averaged flow rate could also be calculated from the measured hydrostatic head in the water column supplying water to the pump. The water is circulated through a $6.1 \mathrm{~m}$ long $0.64 \mathrm{~cm}$ diameter copper tube submerged in a water bath to preheat the water to the desired temperature. The water bath heater can add up to $6 \mathrm{~kW}$ to the temperature-controlled bath. The heating capacity was chosen so that at the maximum flow rate water could be preheated from $20^{\circ} \mathrm{C}$ to $75^{\circ} \mathrm{C}$. On the inert gas side of the injection system, argon gas is supplied by pressurized, gas bottles. A computer controlled pneumatic valve $\mathrm{V}_{6}$ is used to shut the flow on or off, while a needle valve ( $\mathrm{V}_{8}$, Swagelok ${ }^{\mathrm{TM}}$ model: SS-SS4) is used to adjust the flow rate to the desired value. A gas flow meter by Aalborg, model: GFM-47, is used to measure the gas flow rate. Before mixing water and gas stream, two Swagelok ${ }^{\mathrm{TM}}$ check valves, model: SS-CHS4-10, are employed to prevent backflow to protect either of the flow meters. 


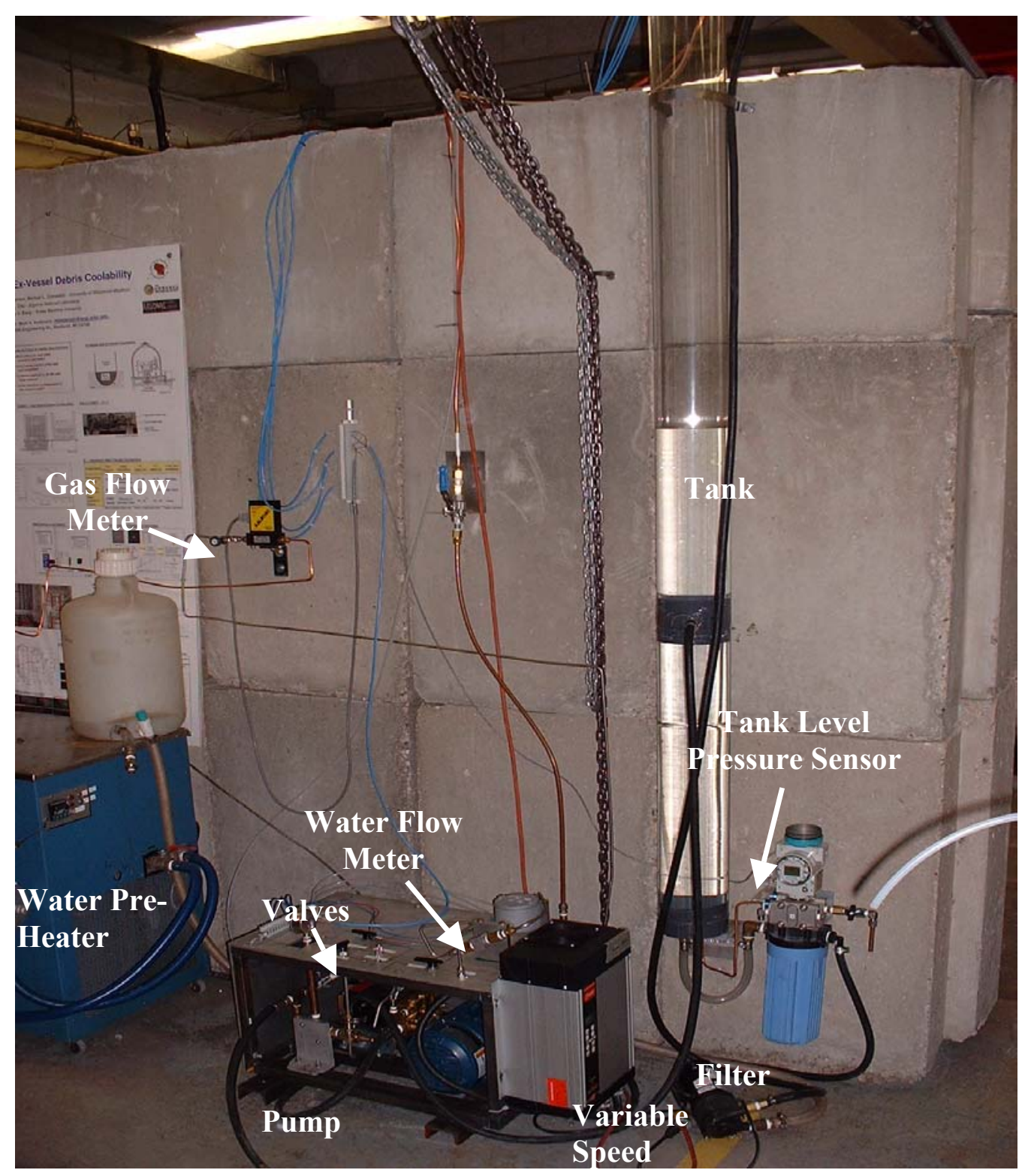

Figure 25: Photo of the pumping system.

\section{II.3 Diagnostics:}

\section{Pool Temperature Distribution:}

In order to determine the liquid metal temperature distribution in the test section, 35

thermocouple probes were installed inside the test section as shown in Figures 21, 23, and 27. Twenty of those thermocouples are used to measure the liquid metal 


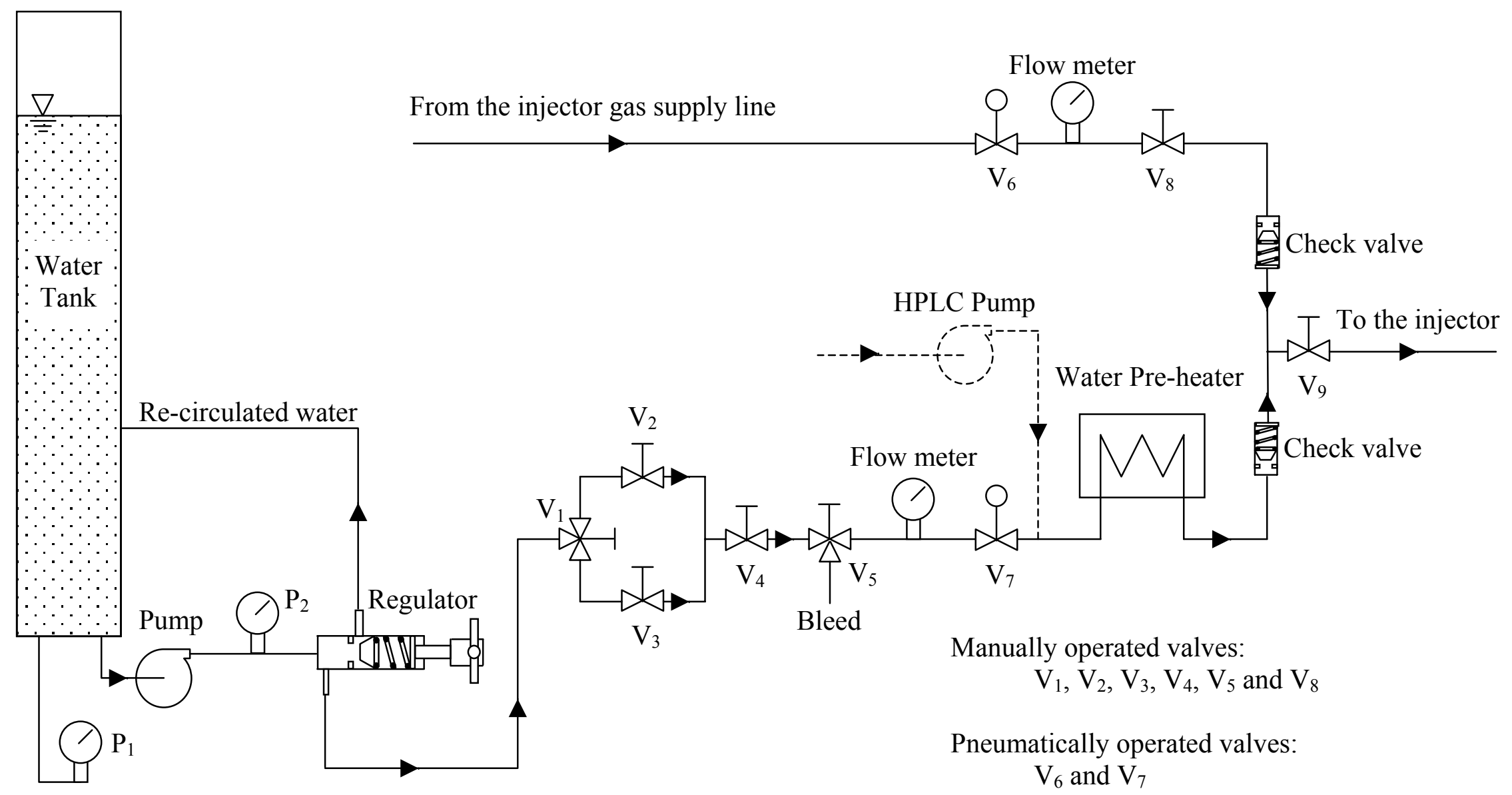

Figure 26: Schematic of the pumping system. 
temperature in the pool, 11 thermocouple probes are used to measure the liquid metal temperature around the immersed heaters, and four thermocouple probes are used to get an additional measurement of the steam exit temperature.

It was found by Abdulla (2003) that the liquid metal temperature distribution is very uniform in the horizontal direction. Twenty thermocouple probes were placed to measure the temperature in the vertical direction with $3.8 \mathrm{~cm}$ spacing. However, for the analysis only the average temperature of the thermocouples were used. A temperature drop of about $1-4^{\circ} \mathrm{C}$ is expected in the vertical direction of the pool.

In order to protect the thermocouple wires and bring them up into the pool, they were located inside the baffle support tubes. The wires are guided to the outside through small holes where the junction is welded on the outside surface of the tubes. Details of the junction location of the different probes are shown in Figure 28 and Table II-1. E-Type thermocouple wire HH-E-24 SLE from Omega was used.

The 14 thermocouple probes inserted from the side can be divided into two different groups: A short version to measure the liquid metal temperature around the immersed heaters and a long version to measure the steam exit temperature. Each short thermocouple probe houses a single thermocouple to measure the liquid metal temperature between the heaters and the baffles $(\sim 9 \mathrm{~cm}$, from the wall) using Omega HH-E-24 SLE thermocouple wire. Tubing and plugs are made of Type-304 stainless steel. A short probe is schematically shown in Figure 29. The long thermocouple probes are used to measure the steam exit temperature above the liquid metal free surface and will be described in next section. 


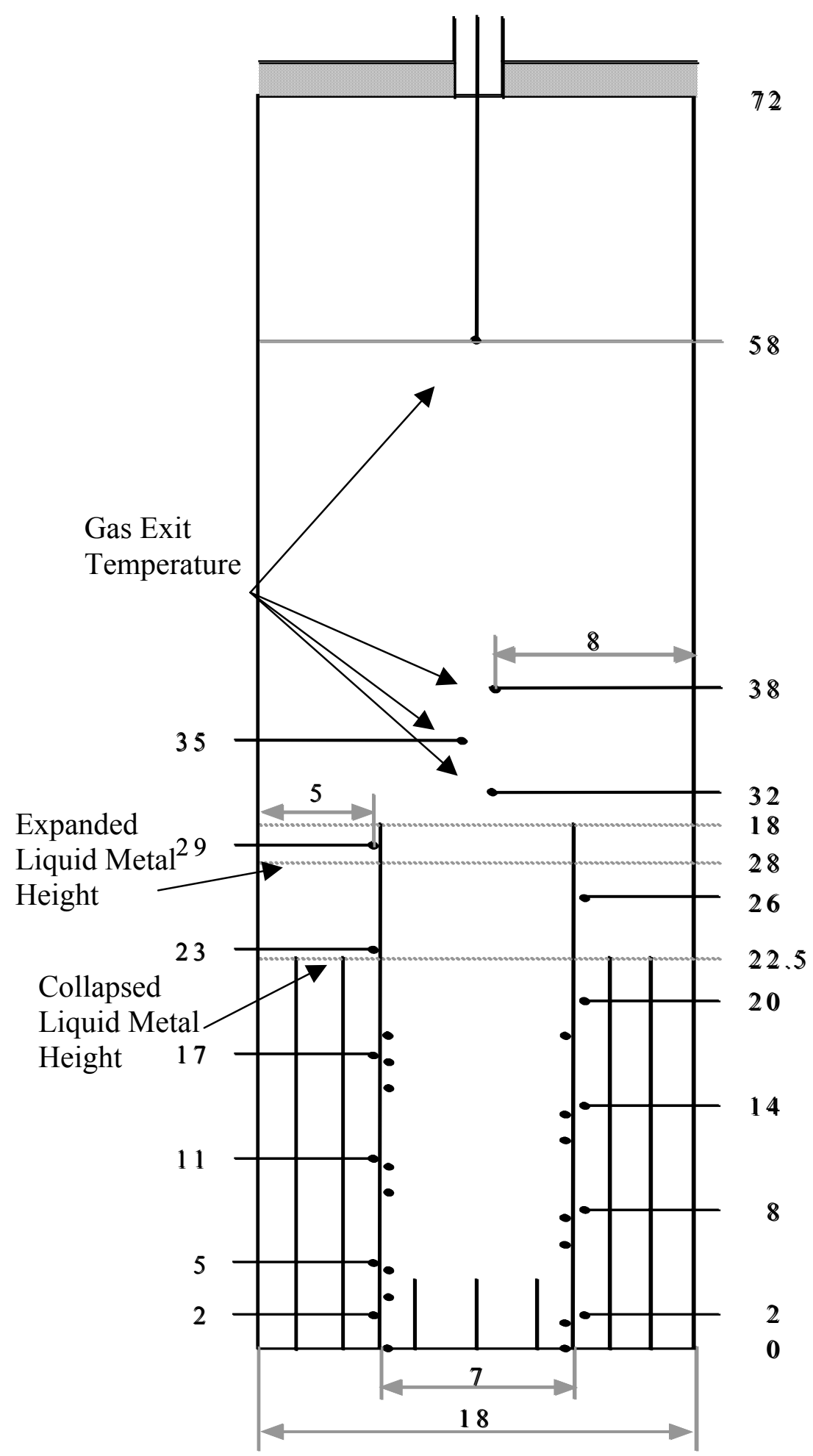

Figure 27: Schematic of the Thermocouple Probe distribution within the Test Section 

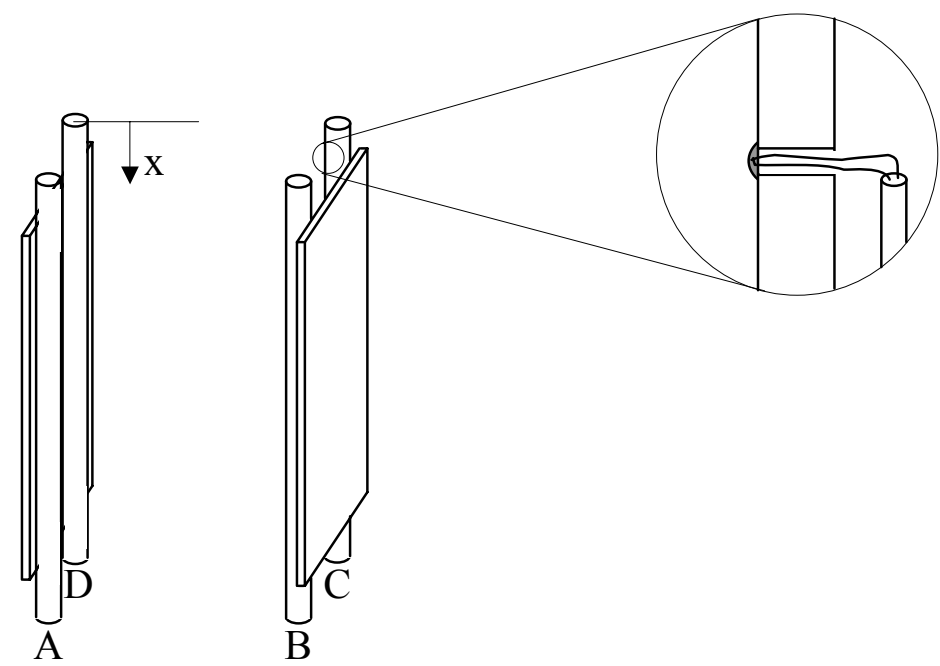

Figure 28: Pool thermocouple probes in baffle support tubes.

Table II-1 Thermocouple locations in baffle support tubes*.

\begin{tabular}{|l|l|l|l|l|}
\hline \multirow{2}{*}{$\begin{array}{l}\text { Thermocouple } \\
\text { No. }\end{array}$} & \multicolumn{4}{|l|}{ Distance $\mathrm{x}$ from top of tube to thermocouple junction in cm (inch) } \\
\cline { 2 - 5 } & A & B & C & D \\
\hline 1 & $1.3(0.5)$ & $1.3(0.5)$ & $1.3(0.5)$ & $5.1(2.0)$ \\
\hline 2 & $8.9(3.5)$ & $12.7(5.0)$ & $16.5(6.5)$ & $20.3(8.0)$ \\
\hline 3 & $24.1(9.5)$ & $27.9(11.0)$ & $31.8(12.5)$ & $35.6(14.0)$ \\
\hline 4 & $39.4(15.5)$ & $43.2(17.0)$ & $47.0(18.5)$ & $47.0(18.5)$ \\
\hline 5 & $52.1(20.5)$ & $52.1(20.5)$ & $52.1(20.5)$ & $52.1(20.5)$ \\
\hline
\end{tabular}

*For naming combine the thermocouple number and the tube label, e.g. "A1". For more details see Figure 4.8.

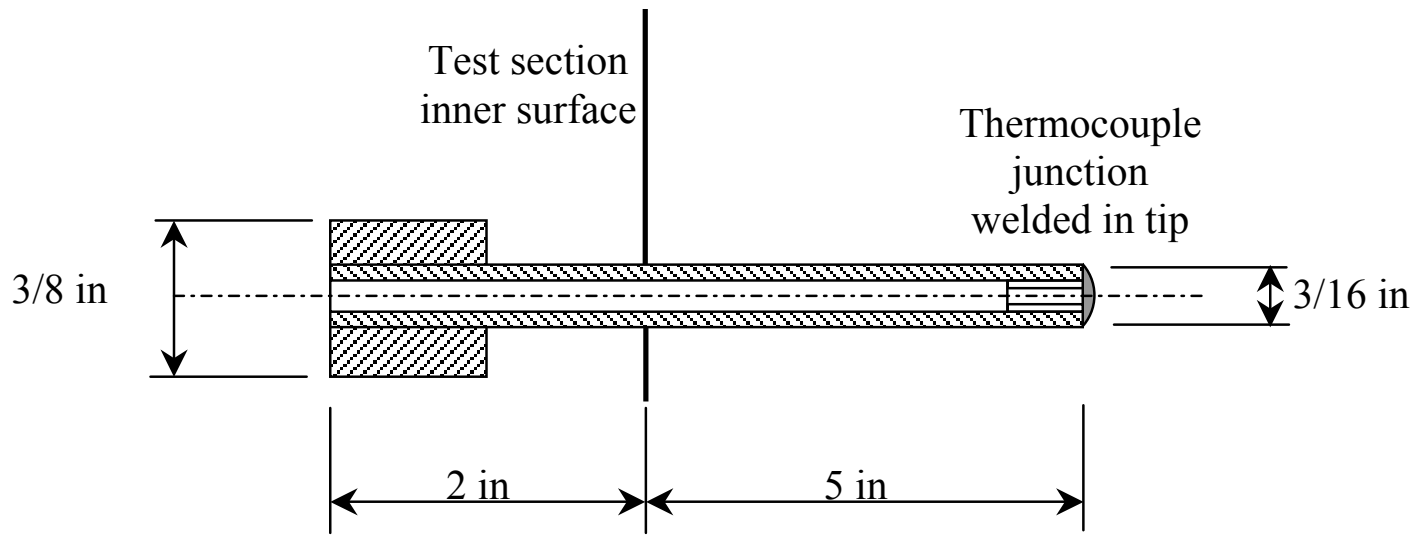

Figure 29: Schematic of the Short Side Thermocouple Probe 


\section{Steam Exit Temperature:}

The steam exit temperature is an essential parameter along with the system pressure to fix the thermodynamic state of the generated steam. It is measured with the previously mentioned long side thermocouple probes and the steam exit thermocouple probe. The long side thermocouple probes are used to measure the steam exit temperature above the liquid metal free surface. The design and materials employed are similar to the short side thermocouple probes mentioned above, but the thermocouple junction had to be protected against energy transport by thermal radiation and conduction in order to achieve an accurate measurement of the gas temperature. To limit conduction effects, a ceramic $\left(\mathrm{Al}_{2} \mathrm{O}_{3}\right)$ two hole round insulator (1/8 inch O.D.), Omega: TRX-13218-12, was used to separate the thermocouple junction thermally from the stainless steel tube. A piece of 3/16 stainless steel tubing was designed as thermal radiation shield. Part of this tube was slotted to enable vertical convection to occur while protecting the bead from the main radiation sources, i.e., the front and the back plate. The surface of the radiation shield is not enhanced (e.g., coating) to minimize thermal radiation energy transfer, due to expected buildup of lead oxide on the surface. A schematic of a long side thermocouple probe is shown in Figure 30.

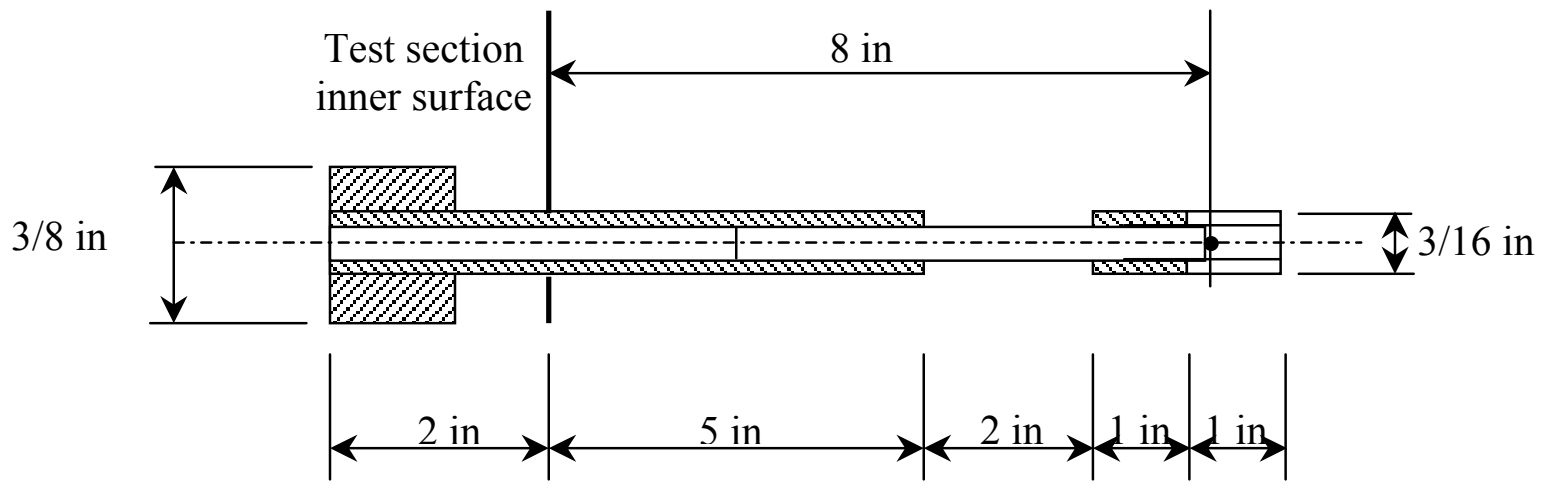

Figure 30: Schematic of the Long Side Thermocouple Probe

The steam exit thermocouple probe is a thermocouple protected against radiation and conduction, which is inserted into the test section from the top as can be seen in Figure 27. It is made out of $1 / 2$ inch tubing about $1 \mathrm{~m}$ long. The thermocouple junction is thermally insulated using the same two hole round insulator as the long side thermocouple probes. The radiation shield is made out of $1 / 2$ inch stainless steel tubing. However, due to the 
vertical position of the tube, several holes are drilled above the thermocouple junction to ensure sufficient gas circulation. A schematic of the steam exit temperature thermocouple probe is shown in Figure 31.

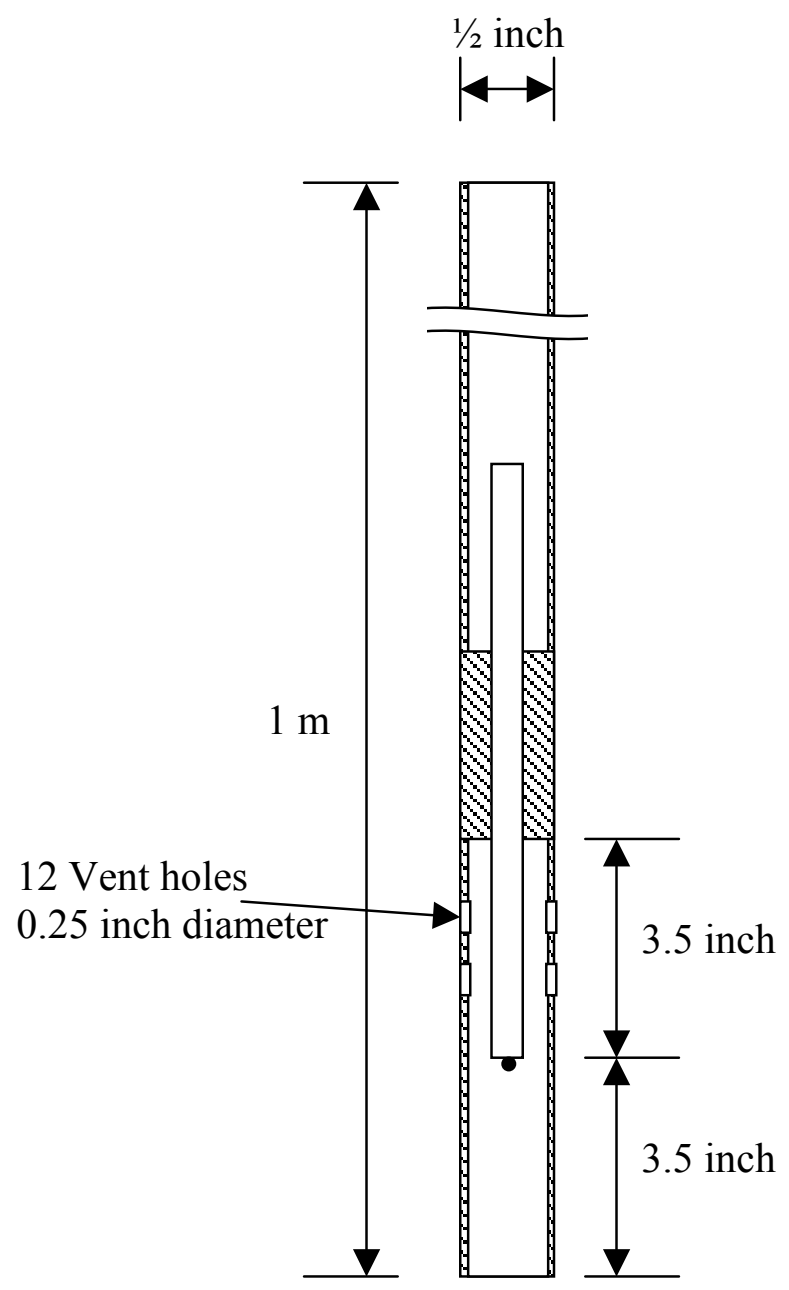

Figure 31: Schematic of the Steam Exit Thermocouple Probe

The measurement of the previously mentioned parameter is essential to characterize the liquid-metal/water direct contact heat transfer rate. However, with these measurements, only the overall heat transfer characteristics can be identified (e.g. an average heat transfer coefficient). In order to obtain detailed information on the complex two-phase flow with phase change phenomenon local measurements of void fraction and pool swell are required. To accomplish this, a non-intrusive X-ray imaging system is used. The Xray system has the advantage of obtaining real time images of the interactions taking place between the injected cold water and the hot liquid metal inside the pool. It also has 
the capability of instantaneous identification of the liquid metal free surface needed for a void fraction calculation.

\section{Water Injection Temperature:}

A water injector was designed to inject supply water into the test section liquid metal pool. The injector is schematically shown in Figure 32. The outer tube serves as an air insulator for the water flowing through the inner tube. The purpose of the air insulation is to avoid excessive heating of the flowing water due to direct conduction as the injector comes into contact with molten metal. Design calculations show that without this insulating tube, water may vaporize before it enters the liquid metal pool. Adding this tube results in reducing the heat transfer and allows more control on the injection temperature to avoid vaporization before the injection. A type E Omega clad 304 stainless steel sheathed and magnesium oxide insulation, model: 304-E-MO-032, thermocouple was inserted from the bottom of the injector to measure the water injection temperature (near the tip) immediately before injection into the liquid metal pool. The measured temperature is used, with the pressure at the exit of the injector (calculated as the system pressure plus the liquid metal head), to fix the thermodynamic state at the injector tip. In order to be able to move the nozzle, the Swagelok ${ }^{\mathrm{TM}}$ connection between the injector and the test section has been modified. The normal ferrule has been replaced with a graphite gasket and a compression tube. The nozzle can be moved up and down and tightening the connection seals the gap between the Swagelok ${ }^{\mathrm{TM}}$ and the injector.

\section{Water Flow Rate:}

Different techniques have been used to measure the injected water flow rate. When using a HPLC pumps, LabAlliance model: Prep 200, $\pm 2 \%$ flow accuracy, $\pm 2 \%$ pressure accuracy of full scale pressure, water flow is preset on the pumps and they automatically adjust the pressure to maintain the flow. The flow rate was monitored on the pump display screen to make sure it stays the same throughout the experimental campaign. The HPLC pump can only produce up to $2 \mathrm{~g} / \mathrm{s}$. Thus for experiments with an injection rate higher than $1 \mathrm{~g} / \mathrm{s}$ the plunger pump system was used. 


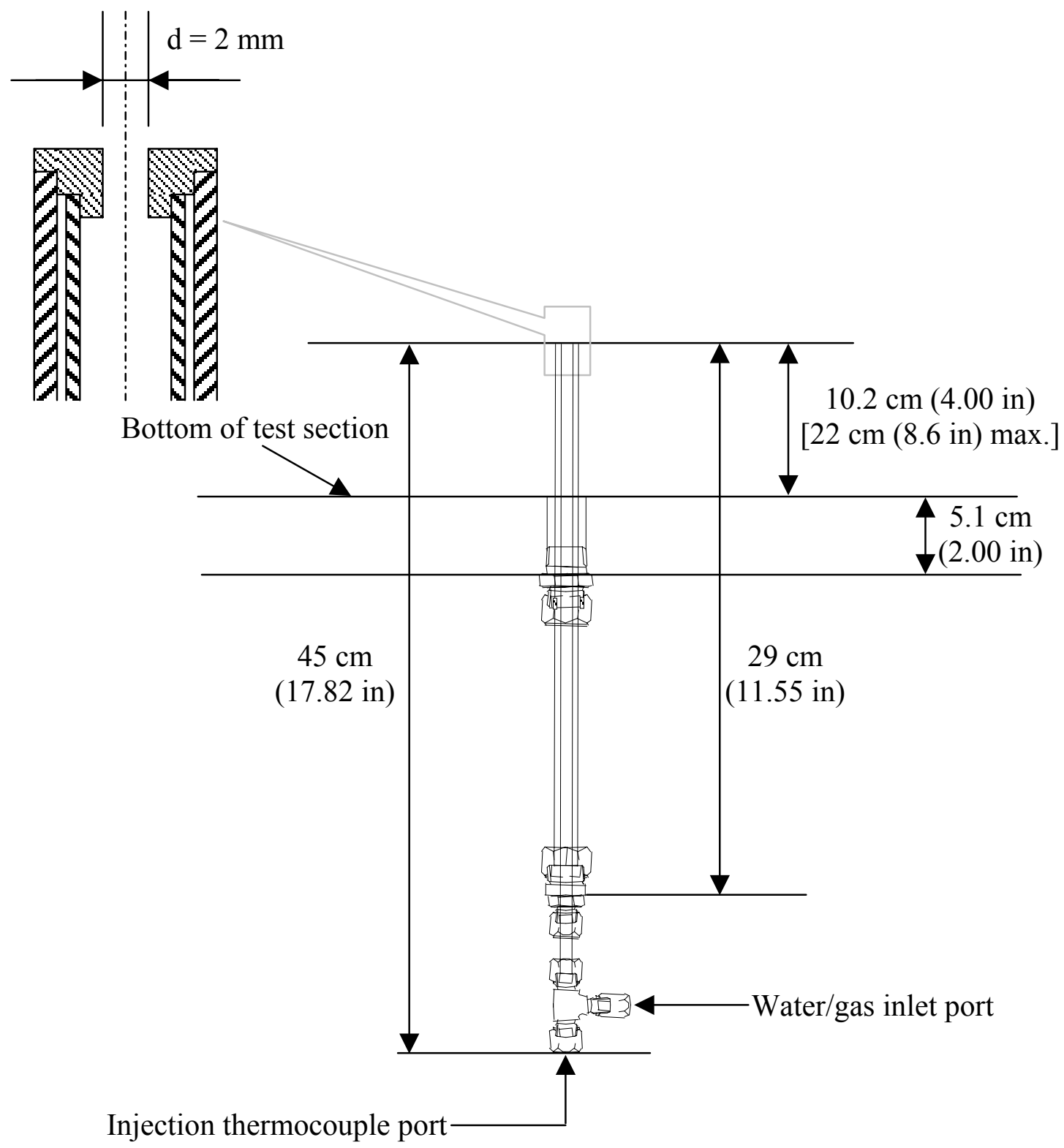

Figure 32: Injector as installed in the test section.

A calibrated Omega turbine flow meter, model: FTB 9503, with an Omega signal conditioner, model: FLSC-61, was used to measure the water flow rate. Swagelok ${ }^{\mathrm{TM}}$ needle valves model SS-SS2 and SS-2MG are used to control and adjust the flow rate. In addition to the electronic flow meter, the time average water flow rate can also be calculated from the measured level (hydrostatic pressure measurement) in the water supply column. 


\section{Gas Flow Rate:}

The gas flow rate is measured with an Aalborg Instruments \& Control, Inc. mass flow meter model: GFM-47. The range of the flowmeter is $0-100 \mathrm{slpm}$. The accuracy is $1.5 \%$ of full scale. To control and adjust the flow, a Swagelok ${ }^{\mathrm{TM}}$ needle valve (SS-SS4) is used.

\section{Pressure Measurement:}

The test section pressure was measured with a strain gage pressure transducer installed on the test section vent line. The transducer is a corrugated stainless steel diaphragm gage, Omega model: PX 302-300AV, with a range from 0 to 200 psig (14.6 bar). Another similar pressure transducer was used at the top of the liquid metal reservoir to measure the reservoir pressure. An absolute pressure gage, Omega model: PX 302-200AV, installed on top of the condenser measured the condenser pressure. The fill level of the water supply tank is determined by a Siemens pressure transducer: Sitrans P, 7MF4432.

\section{X-ray Imaging System:}

A high energy Linatron 3000A X-ray is used as the photon source to image the liquidmetal/water interactions in the test section. The X-ray imaging system arrangement is shown schematically in Figure 33 (Liu, 2003). The system consists of an X-ray head, screen, image intensifier, CCD camera, and computer. The X-ray is a Varian Linatron 3000A with selectable peak energies of 6, 9 and $11 \mathrm{MeV}$. An X-ray sensitive screen (Industrial Quality type 301, $12 \mathrm{~mm}$ thick, high density $\left(3.8 \mathrm{~g} / \mathrm{cm}^{3}\right)$ ) with a terbium activated glass screen and an aluminized coating is used to convert X-ray photons to visible light. The screen dimension is $20.32 \mathrm{~cm}$ wide and $15.24 \mathrm{~cm}$ high. The image intensifier is a $25 \mathrm{~mm}$ GenIII image intensifier, BeMeyers model: MX-11620/UV. The lens of the image intensifier is coupled to a CCD camera. Different CCDs can be used based on the required degree of spatial resolution, contrast and framing rate.

The imaging system has many components and optimization of the system was necessary in order to get the clearest possible images of the liquid-metal/water interactions. It should be mentioned that a clear image is crucial in the current experiment because the 
calculations are related to the instantaneous liquid metal free surface behavior. A clear picture reduces the error associated with the measurement of these quantities and consequently reduces the error in the heat transfer coefficient calculation, which is based on these quantities. Liu (2003) discusses the optimization of the imaging system by considering the different parameters affecting the image. For example, the distance between the X-ray head and the test section, the distance between the scintillator screen and the back of the test section, the use of an X-ray collimator along with different coupling techniques. A list of parameters used in the current experiments is provided in Table II-2. Figure 34 shows the experimental facility with different components arranged all together.

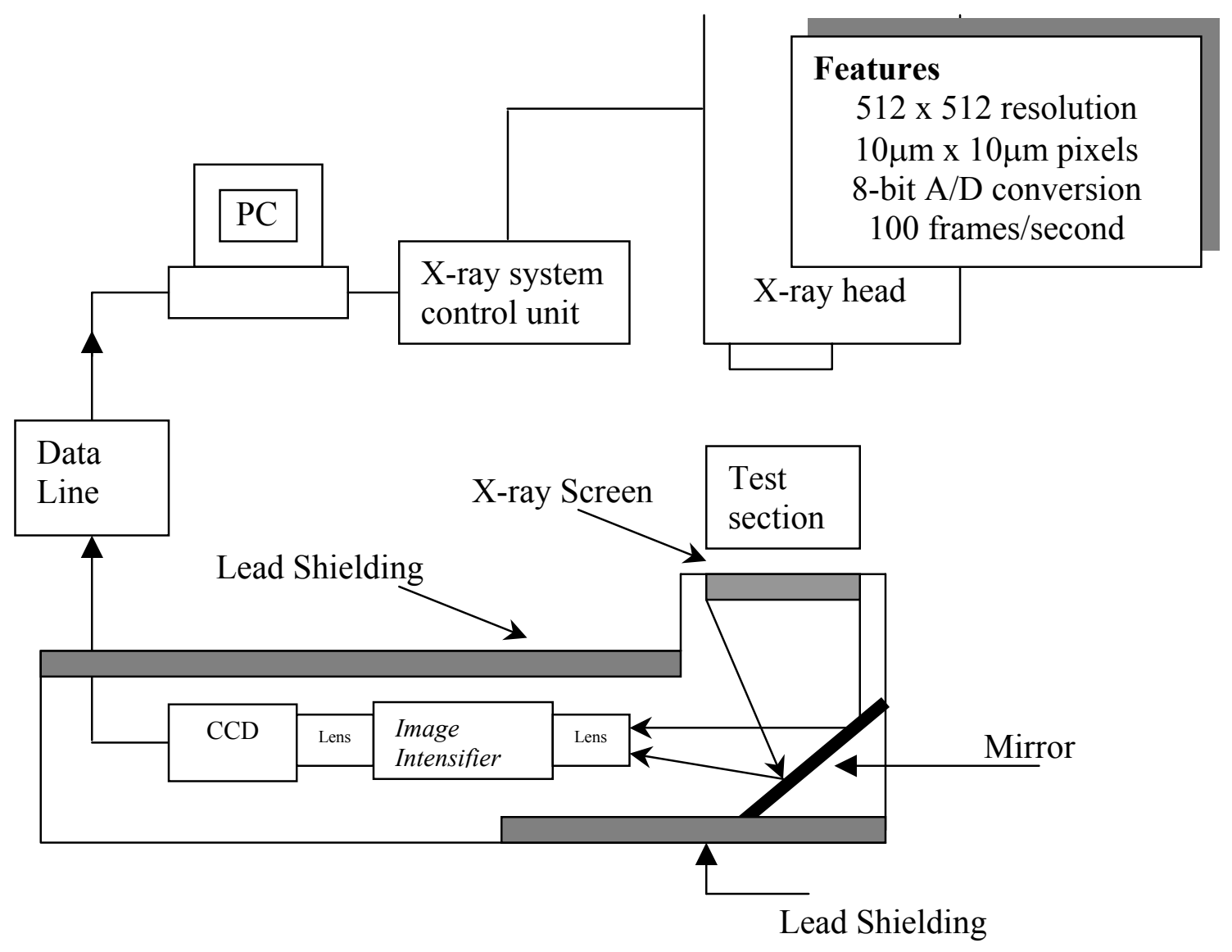

Figure 33: X-ray imaging system setup. 
Table II-2: Summary of Optimized X-ray imaging system Parameters for Experiments.

\begin{tabular}{|l|l|}
\hline Parameter & Specifications \\
\hline Collimator & $\begin{array}{l}1 \mathrm{~m} \text { long and } 13 \times 13 \mathrm{~cm} \text { inner square } \\
\sim 2 \mathrm{~cm} \text { thick filled with lead to reduce the X-ray } \\
\text { scatter }\end{array}$ \\
\hline $\begin{array}{l}\text { Distance from X-ray head to } \\
\text { the test section front surface }\end{array}$ & $113 \mathrm{~cm}$ \\
\hline $\begin{array}{l}\text { Distance from the back } \\
\text { surface of the test section to } \\
\text { the screen }\end{array}$ & $10 \mathrm{~cm}$ \\
\hline Camera & $\begin{array}{l}\text { Dalsa } 8 \text { bit (CA-D1-0512) } 512 \times 512 \text { pixel array } \\
\text { Dalsa } 8 \text { bit (CA-D1-0256A) } 256 \times 256 \text { pixel array }\end{array}$ \\
\hline Image intensifier & 25 mm, Gen III, BeMeyers, model: MX-11620/UV \\
\hline X-ray/Camera puling rate & Synchronized \\
\hline
\end{tabular}

\section{II.4 Experiment Control:}

The experiment involves many control steps and different valve arrangements. Moreover, the possibility of having uncontrolled strong vapor explosions inside the $320 \mathrm{~kg}$ of liquid lead at $500{ }^{\circ} \mathrm{C}$ as well as the use of the high energy X-ray system, necessitated a remotely controlled experiment. To achieve this mandatory requirement, a program was written using commercial data acquisition software (LabVIEW ${ }^{\mathrm{TM}}$ ). The program consists of two main routines: the measuring/display routines (measurement/display and graph routines) and the control routines (heater control and pressure control). The measuring/display routines consist mainly of virtual channels, mounted on terminal blocks NI-SCXI-1303, connected to National Instruments (NI) 32-channel analog input multiplexer amplifier module SCXI-1100 (range: \pm 10 Volt, temperature drift: $0.002 \%$ of reading $/{ }^{\circ} \mathrm{C}$ ) and 32 channel thermocouple amplifier SCXI-1102 (range: \pm 10 Volt mounted, temperature drift: $0.001 \%$ of reading $/{ }^{\circ} \mathrm{C}$ ) on a NI 12 -slot chassis, SCXI-1001. The thermocouples and other measuring devices (e.g. pressure transducer, force transducer, flow meter, etc.) are 
all connected to the hardware channels on NI-SCXI-1303 terminal blocks and the measurements are read and displayed by the measuring/display routines through the NI data acquisition card (DAQ), PCI-6052E (16 inputs, 16 bits, sampling rate: $333 \mathrm{kS} / \mathrm{s}$ ). Control is accomplished with two units of general-purpose relay modules; the module is NI-SCXI-1160, which has 16 independent SPDT electromechanical latching relays. The modules are connected to NI-SCXI-1324 terminal blocks. The terminal blocks consist of a series of on/off relays. They communicate with physical relays through the same DAQ.
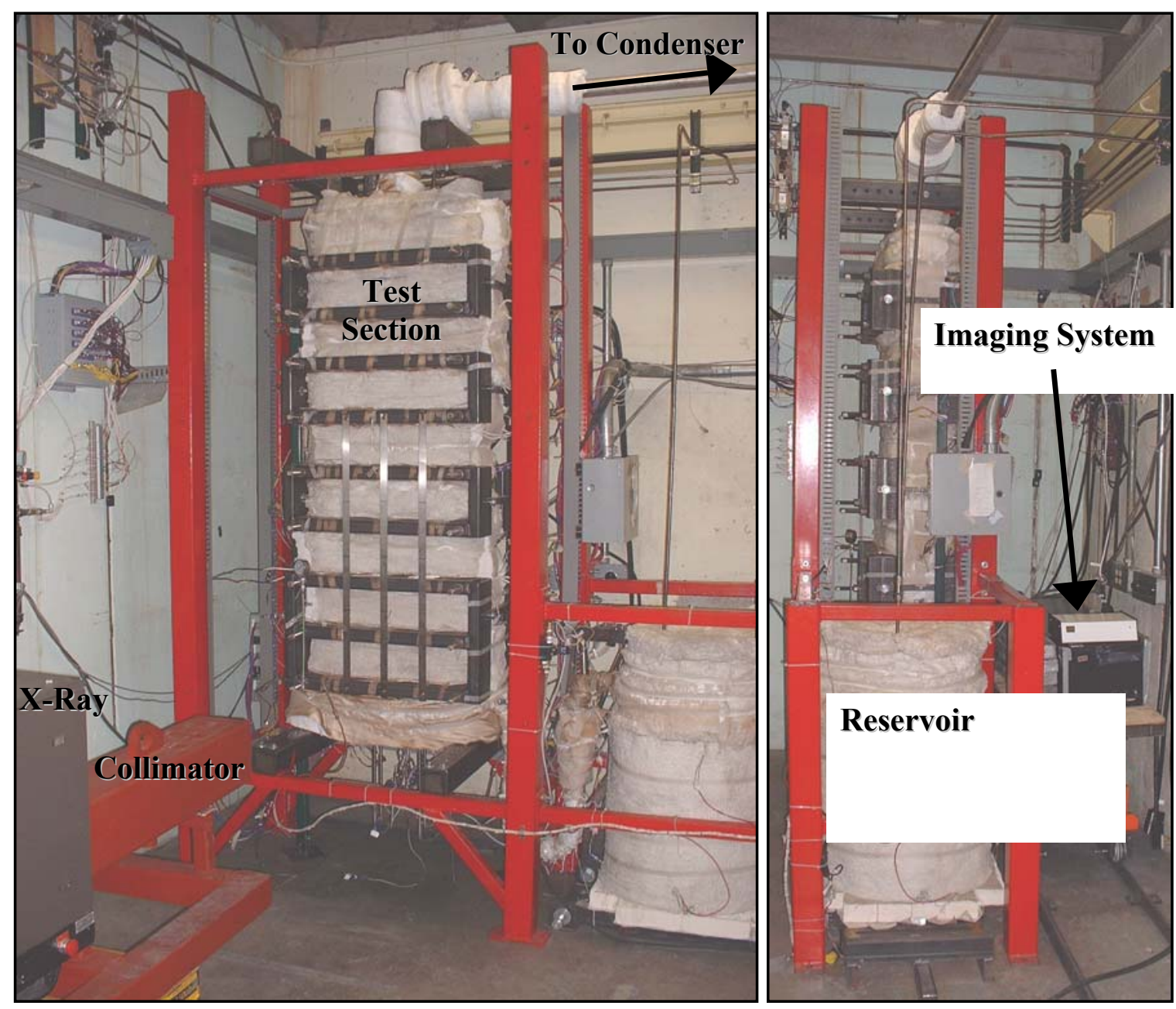

Figure 34: Experimental apparatus arrangement.

The relays are either actuated manually by activating their buttons on the display window (shown in Figure 35) and/or by monitoring the signal from a specified channel. 
Depending on the state of the measured value as compared with a preset condition, the necessary action is initiated. For more information about the DAQ system arrangement the reader is referred to Klockow (2004). The program has been written in a versatile way, for example: the user can choose to run the measuring/display routines only without running the control routines, to control the time between successive data acquisitions, to adjust the heaters preset temperature limits, to adjust the pressure limits, and to save the acquired data to a file or run without saving. The user interface, front panel, is shown in Figure 35. The front panel represents the test section with the relative position of each component, with a display window attached to each measuring element to facilitate online user interpretation of the data. For more information about LabVIEW'TM software the reader is referred to National Instrument (2003).

For ease of operation and control, two computers have been used to control the experiment. The main computer is located near the experiment. It is used to run LabVIEW $^{\mathrm{TM}}$ and it is directly connected to the NI hardware mentioned above. A secondary computer is employed to remotely control the main computer. The secondary computer is located in the control room to ensure the safety of the operator. Microsoft Windows Netmeeting ${ }^{\circledR}$ with its Remote Desktop Sharing feature is used to control the secondary computer. In a similar fashion two different control devices are necessary to operate the imaging system. However, due to a low refresh rate using Microsoft Windows Netmeeting ${ }^{\circledR}$, one computer has been used but with two separate keyboards and two separate pointing devices have been used to control the computer. Also, two monitors have been used. One set of keyboard, mouse and monitor is located near the experiment for convenience during the experiment preparation phase. The other set is placed in the control room to be used whenever the X-ray is in use. Dual PS/2 mouse, PI Engineering model: WHYM-0002, dual keyboard adaptor, PI Engineering model: WHYM-0004, monitors connections were used. Pro series high integrity VGA/SVGA monitor extension cables of $30.5 \mathrm{~m}$ length, Belkin model: F3H981-100, has been used to connect the two monitors, similar cables for the pointing devices and keyboards have also been used. 


\section{Practical Considerations:}

Due to the possibility of liquid metal leaks from the test section it is helpful to to carefully choose the location and insulation of the electric wires supplying power to the heaters. In case of leaks the path of liquid metal flow can be estimated and an appropriate spacing from this area to the wires can be maintained. In addition thin sheets of insulation material or several layers of aluminum foil can be used to protect the leads. A high temperature copper based Anti-Seize (SAF-T-EZE) was used to minimize friction between nuts and bolts used to hold the front and the back plate together. The nuts were tightened down when the test section was cold, first with $20.34 \mathrm{~N}-\mathrm{m}$ (15 lbs-ft), followed by $40.67 \mathrm{~N} \cdot \mathrm{m}(30 \mathrm{lbs} \cdot \mathrm{ft})$. If liquid metal leaks occurred during the experiment, the torque applied to the nut cannot exceed $40.67 \mathrm{~N} \cdot \mathrm{m}$ (30 lbs $\cdot \mathrm{ft}$ ) or the bolt will shear off. Most thermocouples were lost due to mechanical stress where the wire leaves the tube of the thermocouple (see Long Side and Short Side Thermocouple Probe). It is recommended to add structural support in this area using high temperature tape while TC's are assembled.

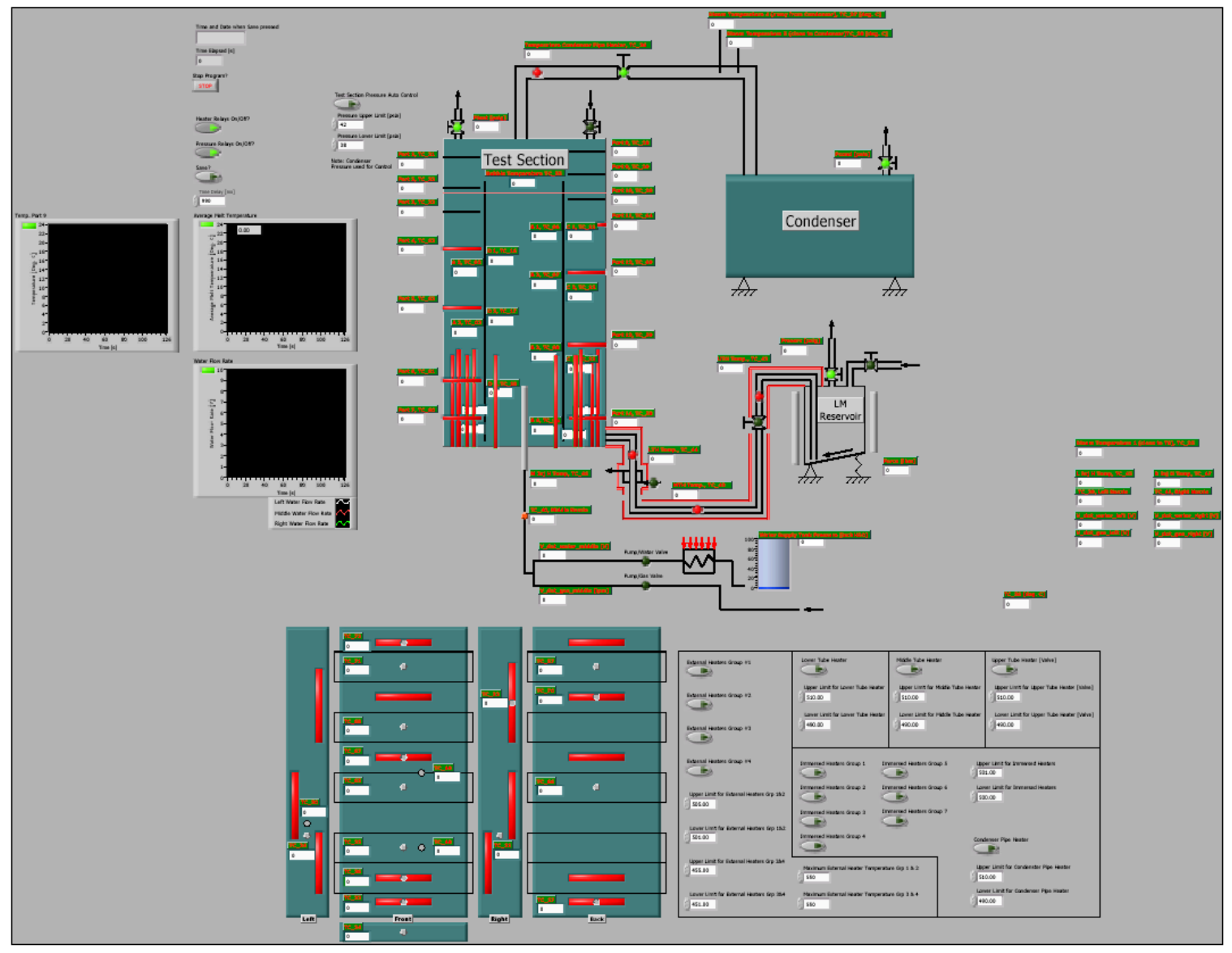


Figure 35: LabVIEW ${ }^{\text {TM }}$ Front Panel user interface

\section{II.5 VOID FRACTION - ANALYSIS AND RESULTS:}

The void fraction is an important parameter in any two-phase flow problem. It is used to determine mixture properties, flow regimes, as well as system hydrodynamics (interactions between fluids). Knowing the collapsed molten core pool volume and the swell level, the void fraction can be estimated. The overall void fraction $\alpha$ of a system can be calculated as stated in the equation below.

$\alpha=\frac{V_{\text {exp }}-V_{\text {coll }}}{V_{\text {exp }}}=\frac{L_{\text {exp }}-L_{\text {coll }}}{L_{\text {exp }}}=1-\frac{L_{\text {coll }}}{L_{\text {exp }}}$

where $V_{\text {exp }}$ and $V_{\text {coll }}$ are the expanded and collapsed pool heights, respectively. With the cross sectional area being constant, the volume can be replaced by the appropriate pool height $L$. A schematic of the pool height definition is shown in Figure 36 .

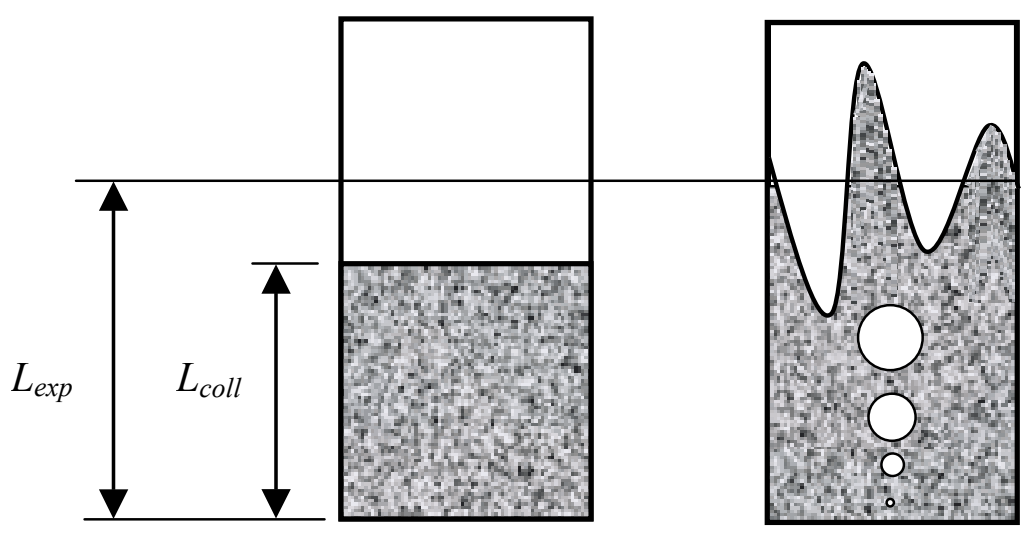

Figure 36: Expanded and Collapsed Pool Height.

The void fraction is measured using an X-ray imaging technique, which makes use of different photon absorption for metal and the liquid/gas void. To calculate the overall void fraction, the X-ray system was used to essentially determine the collapsed pool height as compared to the expanded height due to water injection and steam production. The determination of the collapsed pool height is straightforward, however, the determination of the expanded pool height is complicated by the transient agitation of the surface of the pool. Since the agitation of the pool surface does not allow for a well- 
defined plane free surface, an averaging method must be used to calculate the expanded height of the pool. To estimate the average height, a numerical procedure was developed based on work conducted by Abdulla (2003 b). A series of 500 images is taken for each data point. For each image the contour of the pool free surface is determined and an average pool level is calculated. The representative pool height for each image is time averaged over all 500 images to determine the expanded pool height for a specific combination of experimental parameters. In order to minimize the error, the imaging system was set up to capture the collapsed and expanded pool height simultaneously. A schematic is shown in Figure 37. The view area of the imaging system is set up in a way that half of the expanded pool surface can be observed, while at the same time the collapsed pool surface is visible.

Image Analysis: In order to perform the necessary image analysis, a computer code was developed by Hunter (2004) to preprocess the image (filtering), determine the pool free surface for each image and calculate the average expanded pool height for each image.

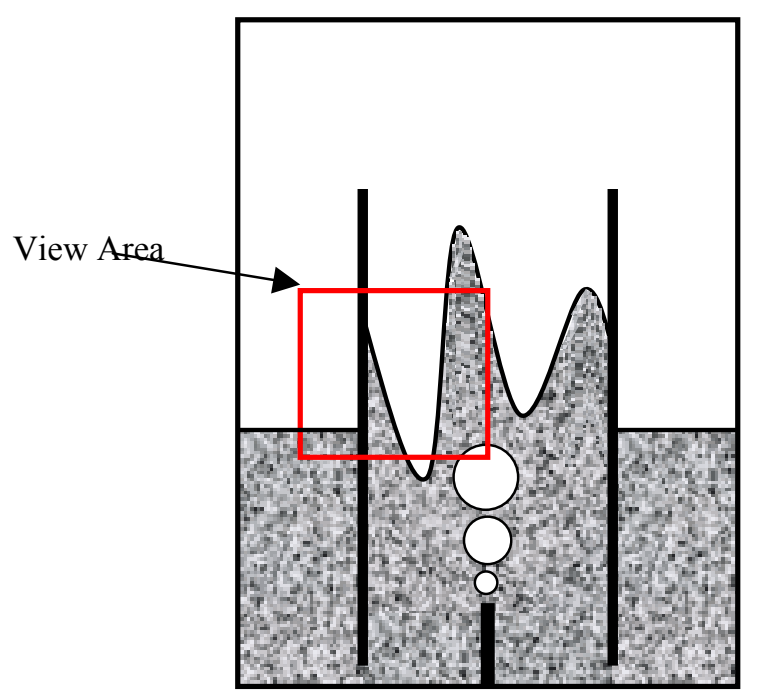

Figure 37: Schematic of the Test Section Interior and the Image View Area.

A digital image is composed of pixels organized in rows and columns. In the case of the given gray scale images from the $\mathrm{X}$-ray imaging system each pixel has an assigned value between 0 and 255, where 0 would represent a black pixel, while 255 is a white pixel. An 
image from the imaging system is shown in Figure 38. This image has already been modified by the first image-processing step: background subtraction. This is necessary since the X-ray system does not provide a uniform beam profile. In the center of the image the intensity is highest and decreases radially. The background image is taken when the test section was filled with simulant material. Subtracting this background image from the original image minimizes the effect of the non-uniform intensity profile. The result can be seen in Figure 38 (A). The collapsed pool level on the left hand side and the expanded (more agitated) pool level on the right hand side of the image are easily recognized. Between those two zones the baffle, a physical barrier, is visible. In order to find the surface of the pool a sudden change in pixel value for each column (line) has to be identified.

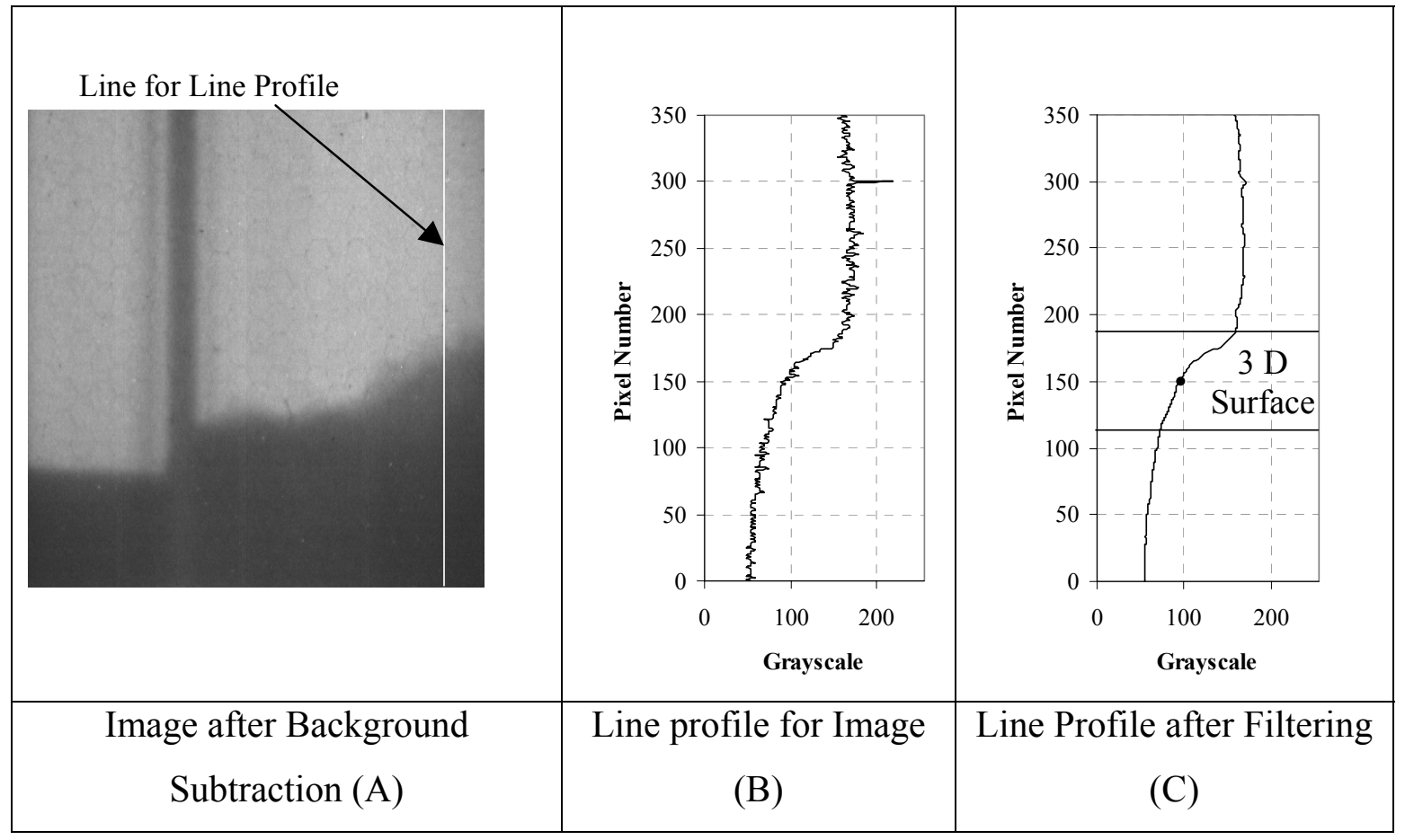

Figure 38: Image Processing Methodology ( $1 \mathrm{~g} / \mathrm{s}, 3.5 \mathrm{bar}, 5 \mathrm{slpm})$.

Before applying the surface detection algorithm, care has to be taken to reduce noise. Figure 38 (B) shows the raw plot of Pixel Number vs. Grayscale for the line shown in the image. A set of filters (median2, Wiener) was applied to minimize the influence of this noise. The median 2 filter re-calculates a pixel value by averaging equally in a 5-by-5 environment, but "pads" the edges with zeros and thereby preserves edges better than the 
median filter. The Wiener filter removes motion blur due to the finite exposure time of $10 \mathrm{~ms}$ maximum per image. The line profile after filtering is shown in Figure 38 (C). This plot shows a much smoother contour than the line profile before filtering and enables successful surface detection. In order to find the pool surface, each column of each picture has to be investigated. Each pixel is compared against a manually chosen threshold value; if the value is higher than the threshold the pixel is set to 255 , if lower the pixel value is set to zero. In a second step the transition from white to black can easily be determined while excluding pixels away from the surface that had the desired threshold value, e.g., due to noise. The pixel value for the local pool level is stored in a matrix for all 500 images of the series.

It has to be mentioned that even though the image is only two-dimensional, the grayscale of the image represents a linearization of the third dimension. As it can be seen in the grayscale profiles for the line in Figure 38, the surface does not show up as a step function, it is a gradual decline from a simulant material free environment to a simulant material rich environment. In early attempts the location of the pool surface was determined by averaging the location of the upper surface boundary (where the transition region starts) and the location of the lower surface boundary (where the transition region ends). However, this process is computationally very expensive. An alternative method is to pick several representative images for one series and choose a threshold value that results in a good representative pool surface. To make it easier for the operator to recognize the detected surface, the grayscale value of the pixels at the surface has been turned white as shown in Figure 39. This process consumes less computational time and the loss in accuracy is small compared to the overall error due to fluctuations in level.

Averaging Processes: The image processing described above resulted in information about the pool surface as a function of position for each image in a series of 500 images taken at 100 frames per second (fps). For each image, the spatially averaged pool level for the collapsed and the expanded levels can be calculated. Figure 40 shows the spatially averaged expanded pool level for a series of 500 images where the abscissa represents the time scale. Each point represents the spatial average for one of the images. For the 
purpose of calculating the expanded pool level, the already spatially averaged values can be time averaged. Images are taken at a frame rate of about 100 frames per second (fps).

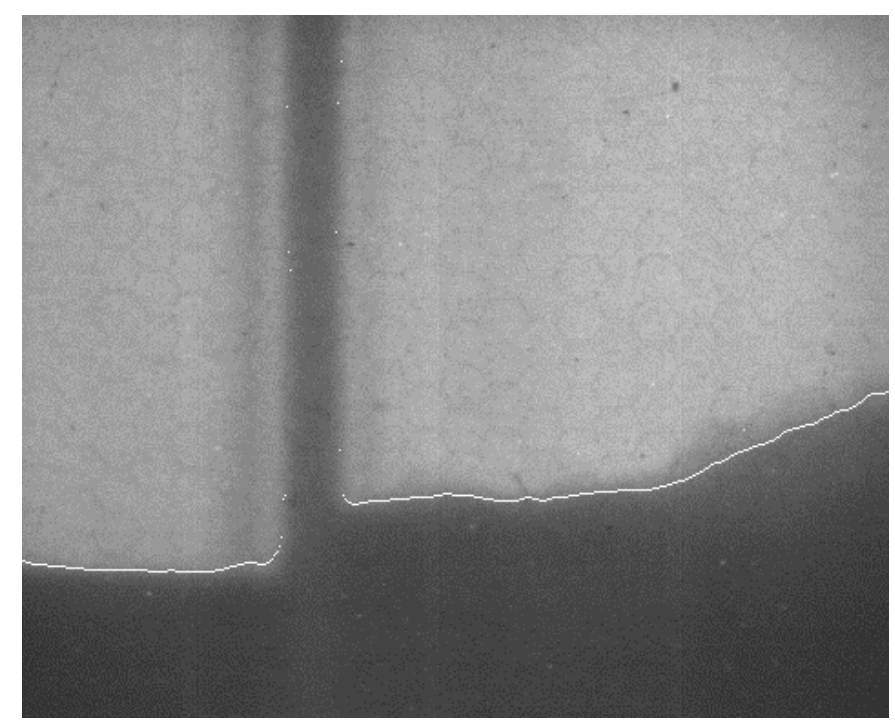

Figure 39: Image with Detected Pool Surface (1 g/s, 3.5 bar, 5 slpm).

Therefore averaging over all 500 images is equivalent to a time average. The time average of the spatial average is the overall average expanded pool level for the duration of the measurement and is shown by a solid black line in Figure 40. It is also of interest to see that the spatially averaged expanded pool height behaves similarly to a sine function of time, however, the frequencies occurring are not dependent on water mass flow rate, gas flow rate or system pressure. The maximum difference between the overall average and spatially averaged only pool height is given in detail by Klockow (2004).

Similar to the expanded pool height, the same principle can be applied to calculate the collapsed pool height. It is obvious from the movie frames that the collapsed pool height has only a slight variation with time, less than $0.5 \%$. 


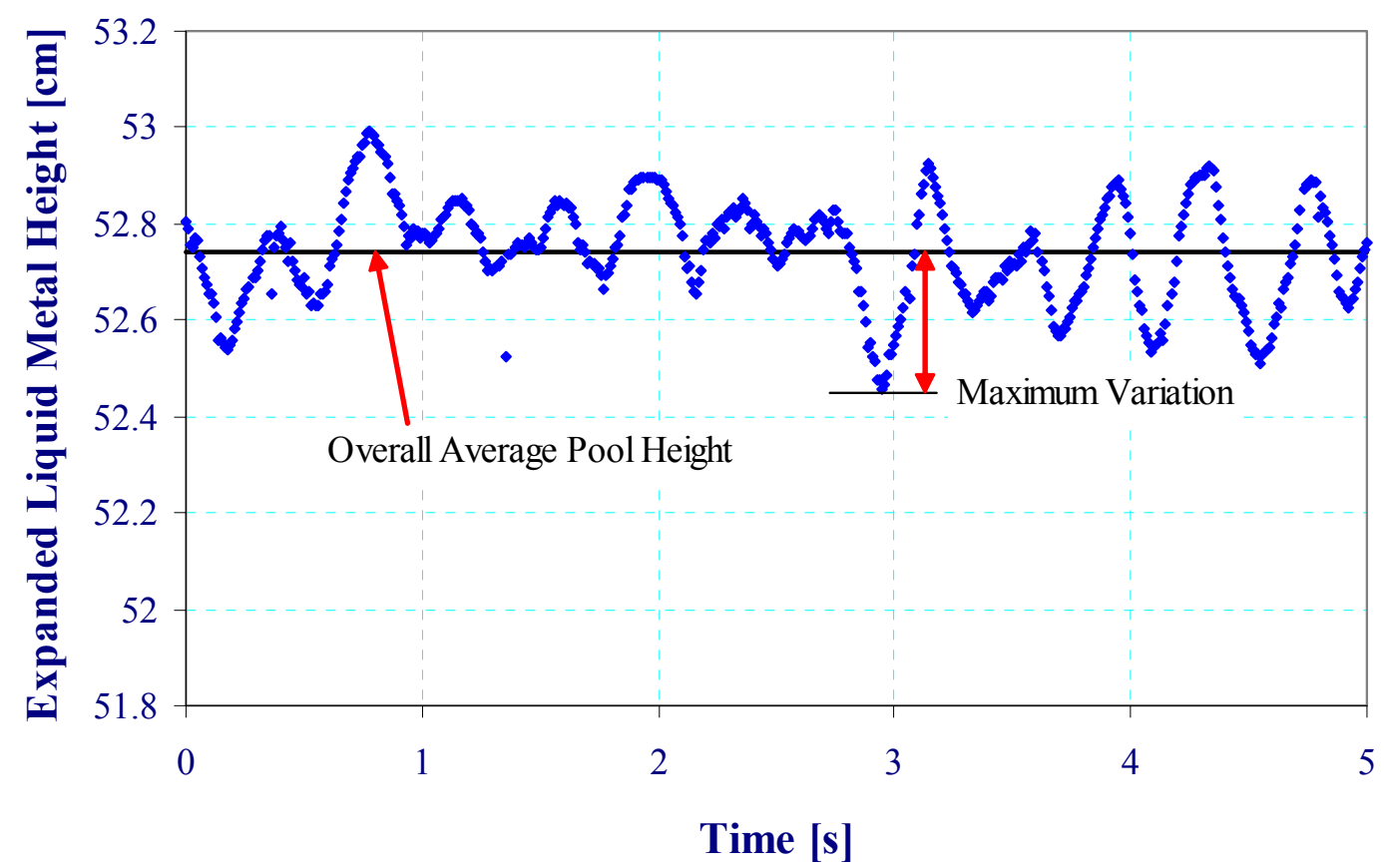

Figure 40: Average Pool Height (per Image) vs. Image Number ( $1 \mathrm{~g} / \mathrm{s}, 3.5 \mathrm{bar}, 5 \mathrm{slpm})$.

Determination of Void Fraction: The previous section explained how the pixel value for the average pool level for both the collapsed and expanded levels was generated. The last step in determining the void fraction is to convert this pixel value to a measurable height. A schematic of the process is shown in Figure 41.

The height of the pool is defined as the distance between the tip of the nozzle and the pool surface (or the average of it). At the beginning of each experimental campaign the imaging system is adjusted to view the injector and the bottom of the test section. The location of the injector tip can be seen in the image and the pixel value of its location can be noted. An alternative is to use the bottom of the test section, knowing that the injector tip is located four inches above this point. During the experiment the vertical position of the imaging system is adjusted to take images of the collapsed and expanded pool surface. The imaging system has an integrated laser system that is used to determine the height difference between the different positions using rulers mounted on the outside of the test section. 


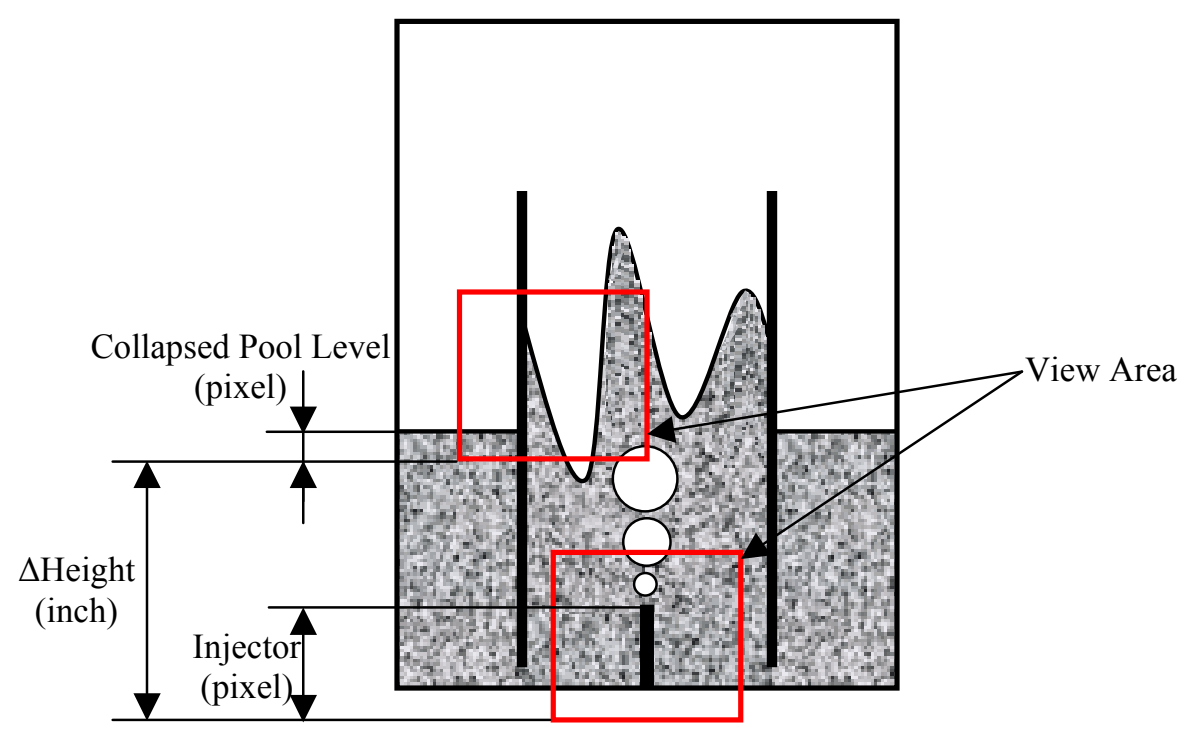

Figure 41: Schematic of Pool Height Calculation.

Knowing the height of the expanded levels (in pixel) from the imaging system, the height of the injector (in pixel) and the height difference the imaging system got shifted between the two image series, the absolute expanded height can be determined. The pool height is calculated in the equation below, where the variables are defined as shown in Figure 41.

Pool Height $=(\Delta$ Height $($ inch $))$ $+($ Pool Level (Pixel) - Injector $($ Pixel $)) \cdot$ Conversion (Pixel,inch $)$

Error Analysis: EES (F-Chart Software, 2004), a program which solves series of coupled equations, was used for the analysis including error propagation. The main portion of the resulting uncertainty is due to the measurement of the height of the imaging system, which has an accuracy between $1.6 \mathrm{~mm}(0.0625$ ”) and $6.4 \mathrm{~mm}(0.25$ ”). The uncertainty for the pool level is determined manually. For the collapsed pool level it is on the order of $1 \mathrm{~mm}(3-5$ pixels), while is up to an order of magnitude larger for expanded pool levels.

Results of the Void Fraction Calculation: Klockow (2004) presents all the detailed void fraction values for the range of tes parameters. Figure 42 shows the void fraction vs. gas flow rate at various pressures (1-5 bar) for water mass flow rates of $1,2.5,3 \mathrm{~g} / \mathrm{s}$. It is 
obvious that the void fraction depends on the water mass flow rate injected into the system, however, with the given error (here one representative error bar is shown) it is hard to determine the influence of the gas flow rate or the pressure. Figure 43 indicates the influence of the pressure on the system. The solid points indicate a measured value. However, in some images the average expanded pool height was located outside the viewing area and it could only be determined as larger then the upper edge of the image. Medium and high pressures are all located in the same range of void fraction (2-7\%), while low pressures result in a significantly higher void fraction (> 10\%). This behavior was also observed at higher flow rates. The flow rate of the co-injected gas does not seem to have a significant effect on the void fraction; however, this is expected comparing the resulting steam volume of the injected water to the volume of co-injected gas.

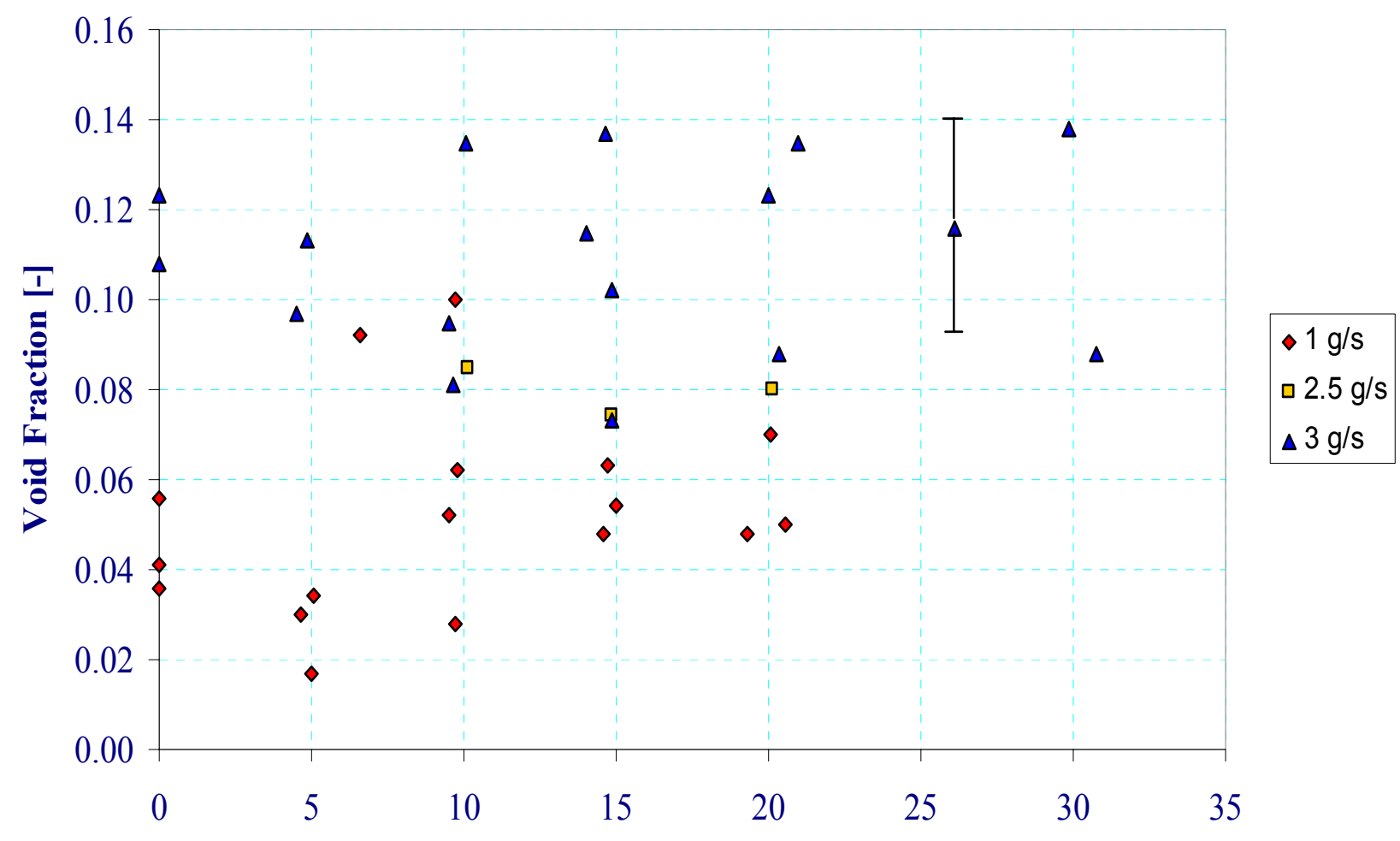

Gas Flow Rate [slpm]

Figure 42: Void Fraction vs. Gas Flow Rate at Various Pressures (1-5 bar) and Water Mass Flow Rates $\left(\mathrm{T}_{\mathrm{LM}}=500{ }^{\circ} \mathrm{C}\right)$. 


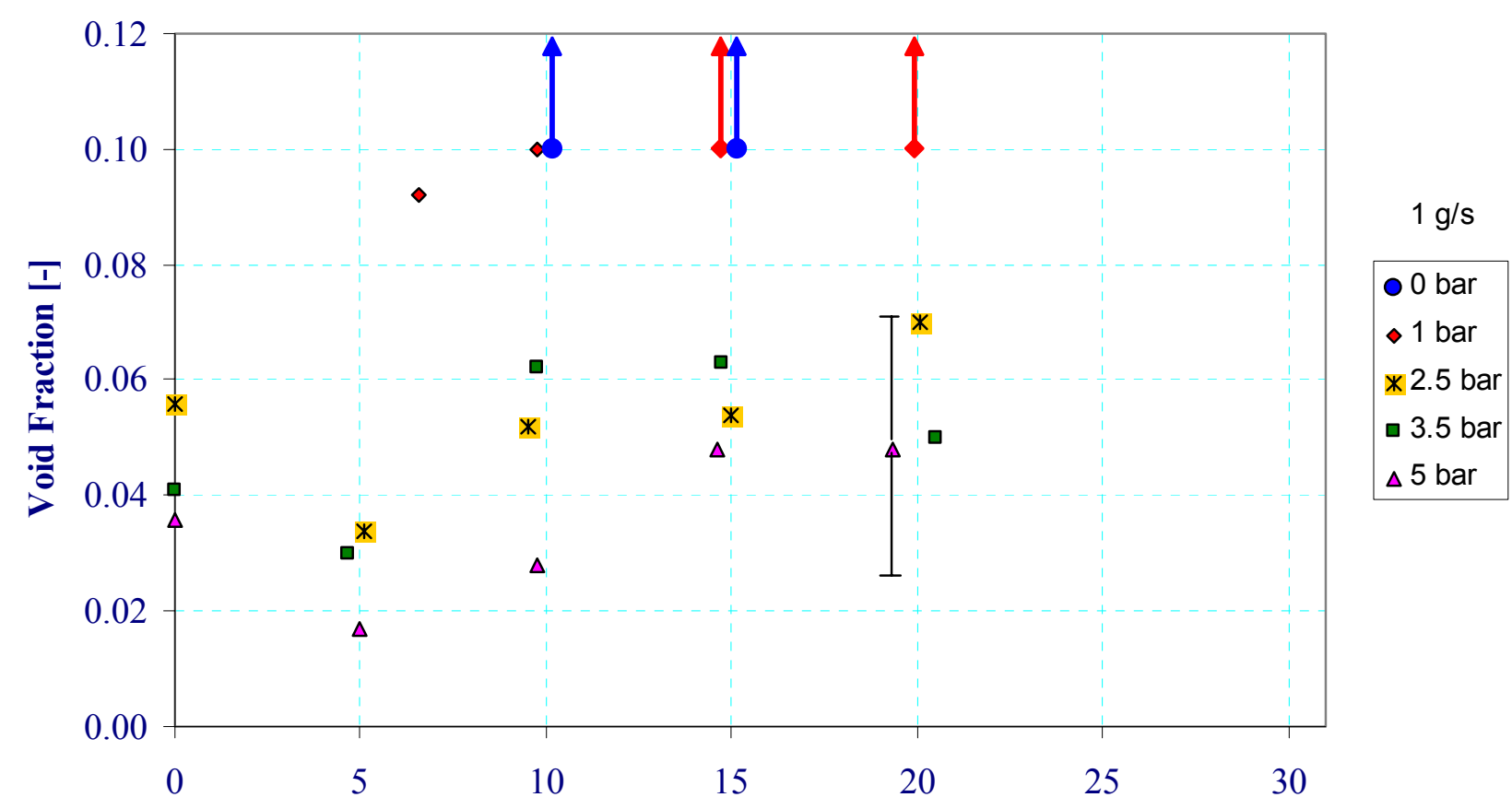

Gas Flow Rate [slpm]

Figure 43: Void vs. Gas Flow Rate at Various Pressures and $1 \mathrm{gm} / \mathrm{s}\left(\mathrm{T}_{\mathrm{LM}}=500{ }^{\circ} \mathrm{C}\right)$.

\section{II.6 HEAT REMOVAL RATE - ANALYSIS AND RESULTS:}

One key question is to quantify the effect of gas injection and ambient pressure on the heat removal rate. Evaluation of the heat transfer and the flow and pressure required to stabilize the quench provides the optimal conditions. To calculate the heat removal rate a simple heat exchanger model is assumed as shown in Figure 44.

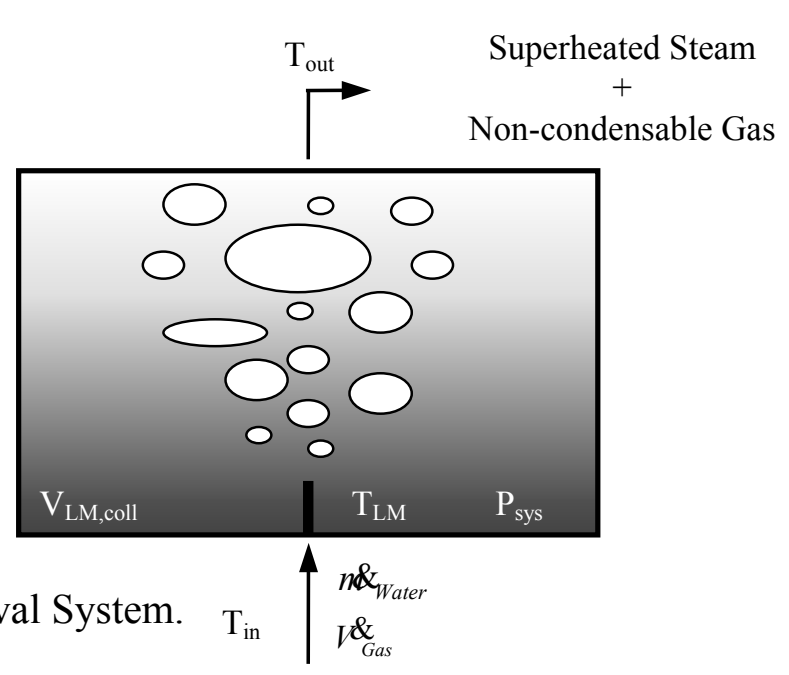

Subcooled Water 
Subcooled water is co-injected with non-condensable gas at a known injection temperature. The mass flow rate of water and the volume flow rate of the noncondensable gas are measured. At the exit, the temperature of the non-condensable gas and superheated steam mixture is known. Inside the test section itself, the average pool temperature, the volume of the pool, and the system pressure is known. With exit temperature and system pressure known, the thermodynamic state of the mixture leaving the heat exchanger can be determined. Knowing the inlet temperature and the system pressure plus the liquid metal head, the enthalpy at the injection point can be determined. In the equation below, the volumetric heat removal rate of the system can be calculated.

$$
q^{\prime \prime \prime}=\frac{n \&_{\text {Vater }}\left(h_{w, \text { out }}-h_{w, \text { in }}\right)+n k_{\text {Gas }}\left(h_{g, \text { out }}-h_{g, \text { in }}\right)}{V_{L M, \text { collapsed }}}
$$

In order to obtain a measurement of the volumetric heat transfer at a given condition, steady state conditions were achieved. This steady state was maintained for about ten minutes in order to have a sufficient time period for averaging the individual measurements. Due to minor issues during operation, the averaging time period varied between five and 20 minutes.

Error Analysis: All the necessary parameters mentioned above are measured directly. In all cases the fluctuation in the measurement was larger than the accuracy of the measuring device given by the manufacturer. Therefore the fluctuation of the specific measurement is used in the error propagation analysis. The fluctuation does not necessarily represent a fluctuation in the measured parameter; it is strongly dependent on noise in the measurement. The only exception is the uncertainty in the collapsed simulant pool volume. The pool height and its uncertainty have been developed in the previous section. All numerical values are presented by Klockow (2004). The major portion of the uncertainty is due to the fluctuation in the measurement of the water mass flow rate. 


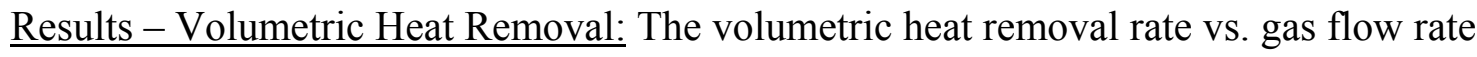
at various pressures and water mass flow rate of 1, 2.5, and $3 \mathrm{~g} / \mathrm{s}$ is shown in Figure 45 (only one representative error bar is shown). As it can be seen, the water mass flow rate has a major impact on the heat removal rate, while system pressure and co-injected gas seem to have secondary effects. Even though the co-injected gas does not seem to alter the heat transferred to the injected water, its influence as a heat transfer fluid itself is measurable, especially at lower flow rates. Figure 46 shows the volumetric heat removal rate as a function of gas flow rate for the lowest water flow rate under investigation (1 $\mathrm{g} / \mathrm{s}$ ). As can be seen, the amount of energy removed increases steadily with the amount of gas injected. A detailed analysis of how much energy is removed by the water and how much energy is removed by the co-injected gas reveals that the increase in energy removal is only due to the increasing mass flow rate of gas.

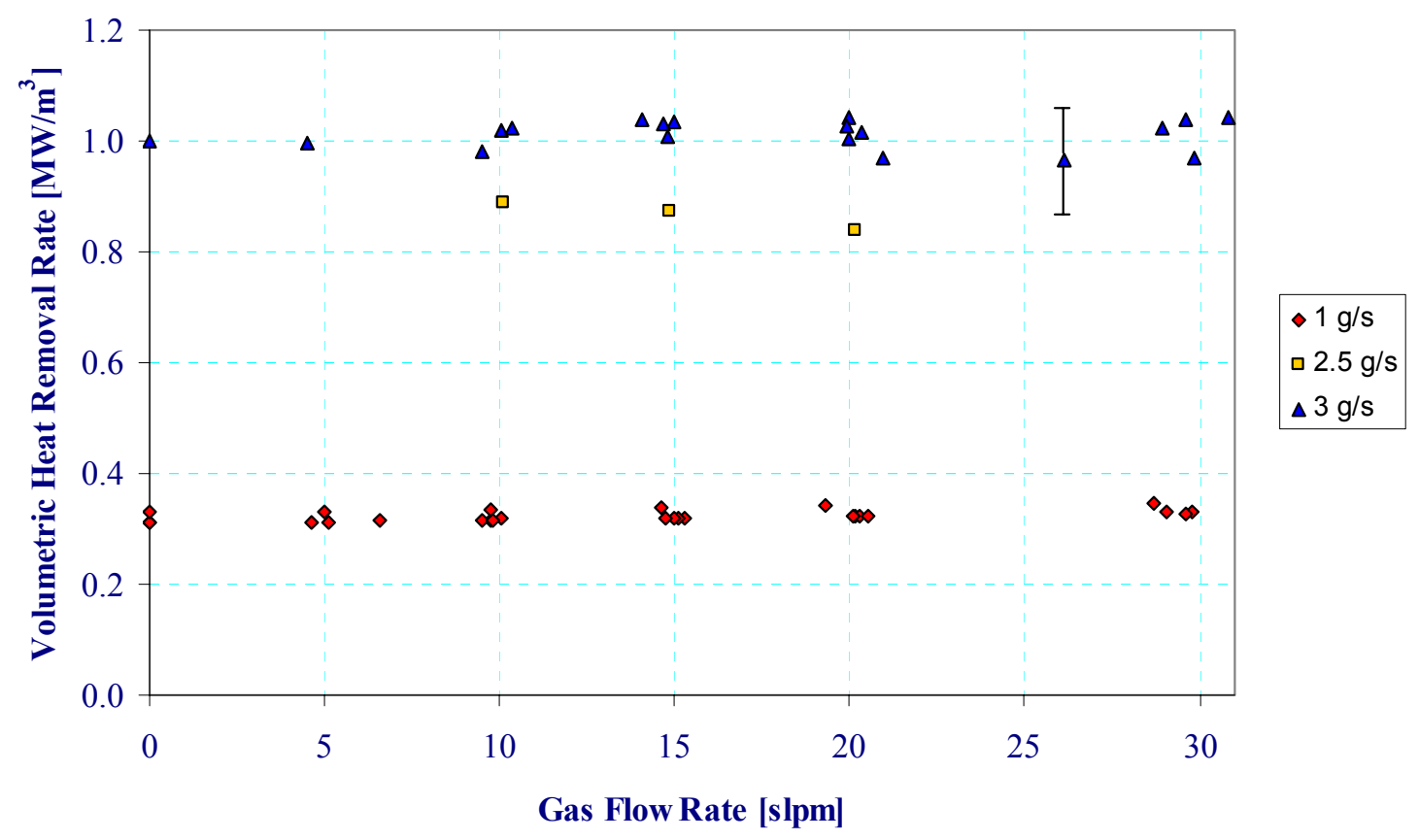

Figure 45: Volumetric Heat Removal Rate vs. Gas Flow Rate at various pressures (15 bar) and Water Mass Flow Rates $\left(\mathrm{T}_{\mathrm{LM}}=500^{\circ} \mathrm{C}\right)$. 


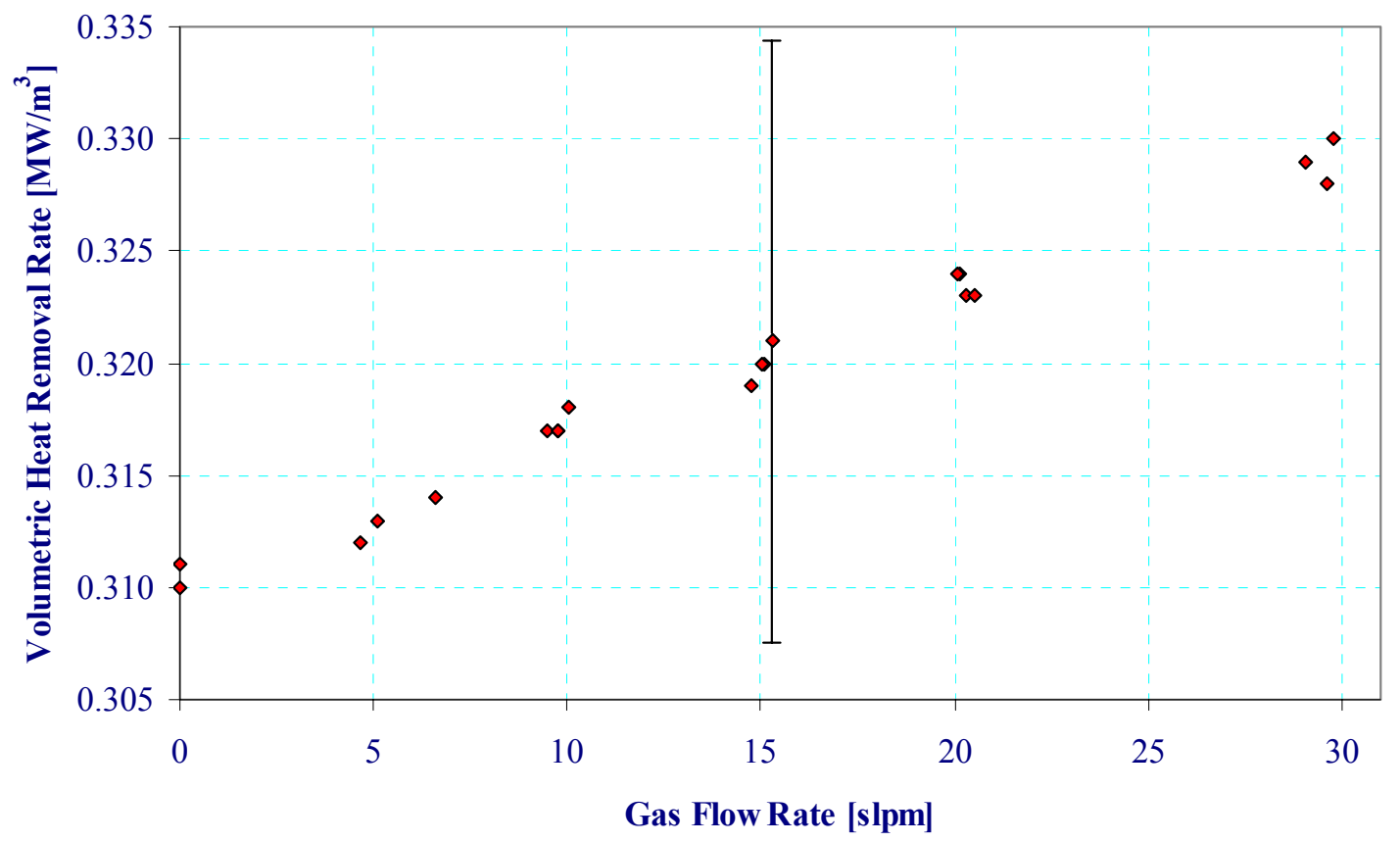

Figure 46: Volumetric Heat Removal Rate vs. Gas Flow Rate at various pressures (1-3.5 bar) and $1 \mathrm{~g} / \mathrm{s}$ Water Mass Flow Rate $\left(\mathrm{T}_{\mathrm{LM}}=500^{\circ} \mathrm{C}\right)$.

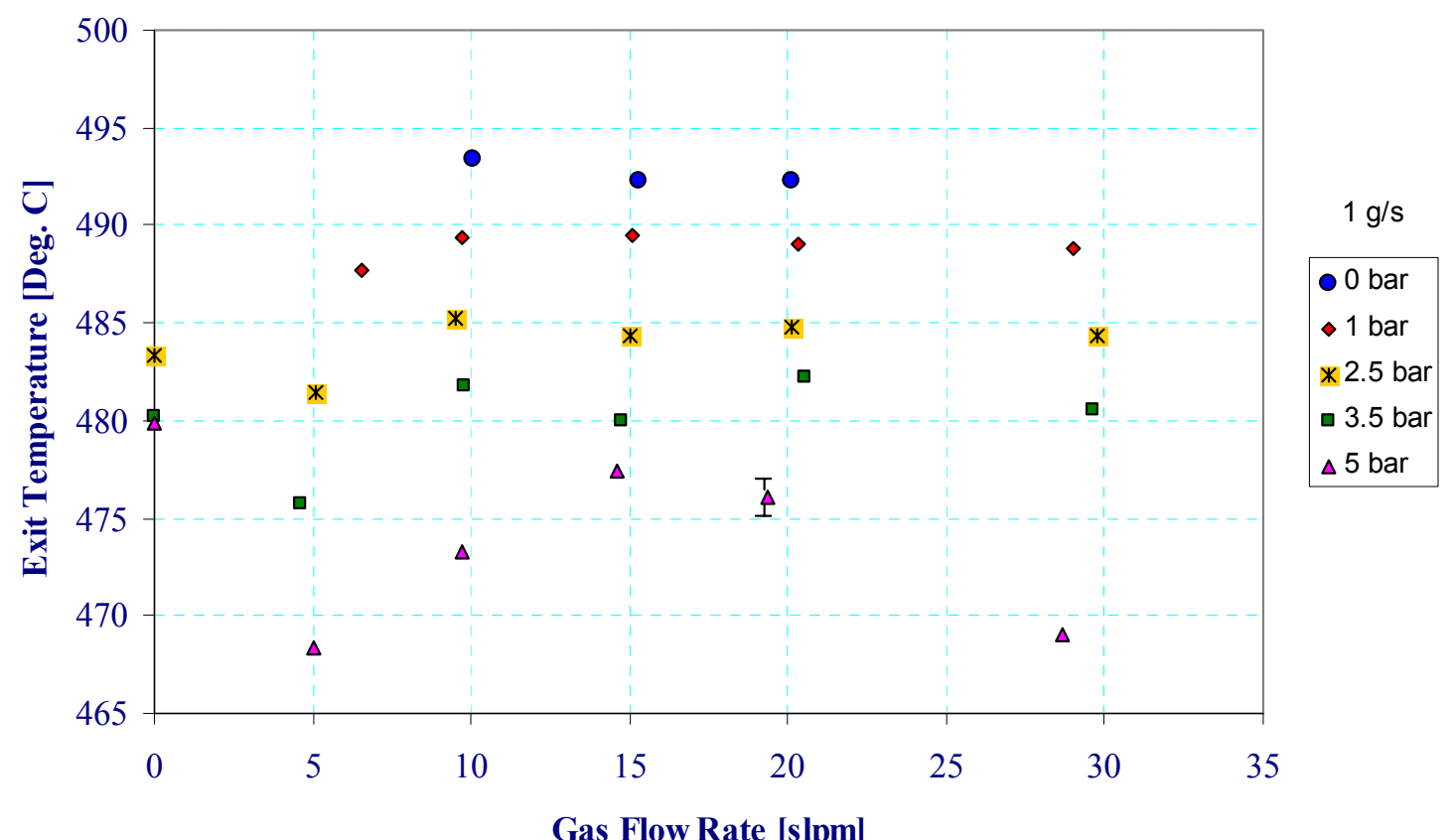

Figure 47: Exit Temperature vs. Gas Flow Rate at various pressures and $1 \mathrm{~g} / \mathrm{s}$ Water Mass Flow Rate $\left(\mathrm{T}_{\mathrm{LM}}=500^{\circ} \mathrm{C}\right)$. 


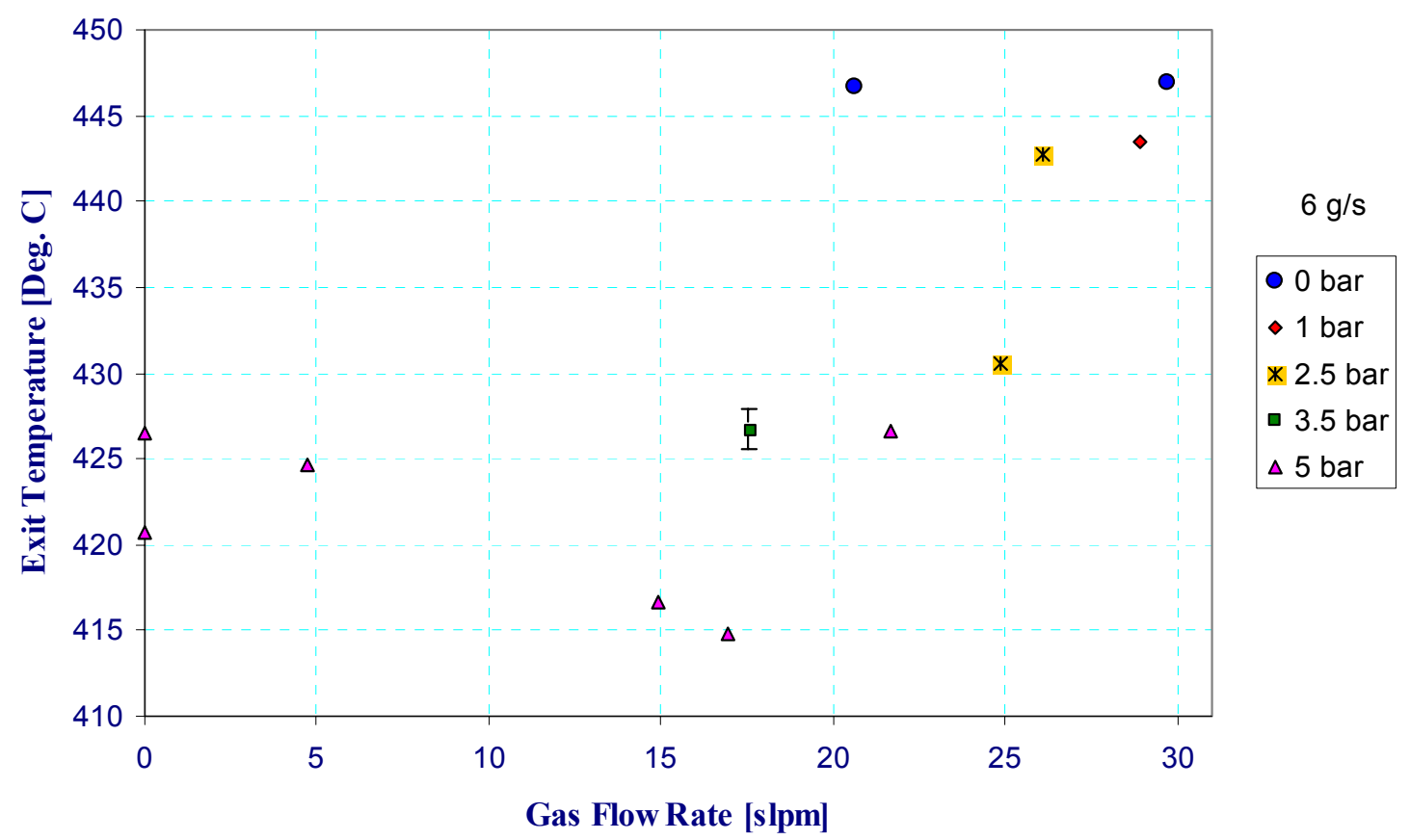

Figure 48: Exit Temperature vs. Gas Flow Rate at various pressures and $6 \mathrm{~g} / \mathrm{s}$ Water Mass Flow Rate $\left(\mathrm{T}_{\mathrm{LM}}=450^{\circ} \mathrm{C}\right)$.

The effect of the system pressure on the heat transfer behavior can be seen in Figure 47 and 48 , where the exit temperature is plotted vs. the gas flow rate. In order to draw a conclusion from the exit temperature concerning the heat removal, it has to be assumed that all other parameters were held exactly constant throughout the different experiments. Figure 47 shows that the system pressure has an effect on the exit temperature. As the system pressure increases the exit temperature of the mixture decreases. The total maximum temperature difference from 0 to 5 bar can be up to $30^{\circ} \mathrm{C}$. In Figure 48 the same plot is shown for $6 \mathrm{~g} / \mathrm{s}$ representing the high flow rate range. Again the effect of pressure on the exit temperature can be seen, with a total temperature decrease of the same order of magnitude. It has to be noted that the decrease in heat transfer results in a lower superheat of the mixture. However, the major part of the energy removed is due to the phase change of the water and therefore these large changes in exit temperature of a superheated gas mixture are only a secondary effect compared to the total energy removed. 
We need to make one note; i.e., one of the experiments performed at $5 \mathrm{~g} / \mathrm{s}, 5 \mathrm{bar}$ and no gas flow significantly deviated from all other tests. The exit temperature of the mixture dropped to about $260^{\circ} \mathrm{C}$ and lead started to solidify on the sidewalls of the test section. All other measurements were investigated for anomalies and there is no difference found compared to other experiments. The combination of these parameters has been repeated several times without being able to reproduce the results. However, the repeated test show reproducibility with an exit temperature of about $430{ }^{\circ} \mathrm{C}$. Therefore, the first test has been disregarded and was not considered in the analysis.

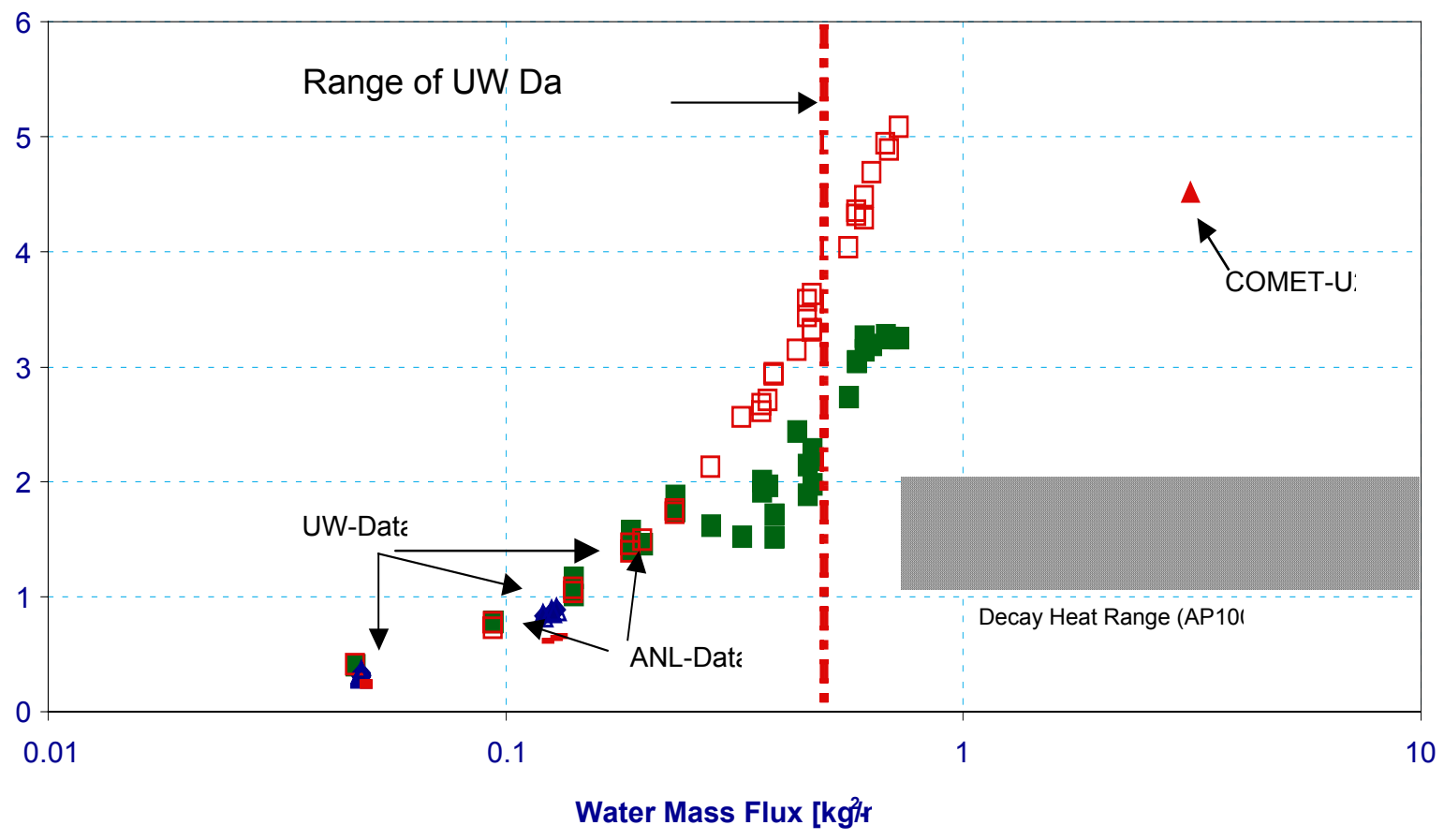

Figure 49: Comparison of ANL and UW Data as Volumetric Heat Removal Rates

One final comparison is given in Figure 49 above. In this case we directly compare the test data from ANL and UW experiments. The Red squares indicate the maximum amount of heat that can be removed via water flux injection and complete evaporation. The Blue and Green squares are the UW and ANL data that show almost perfect heat exchange up to mass fluxes of $0.3 \mathrm{~kg} / \mathrm{m}^{2}$-s, with the heat removal rate approaching a limit. 
Energy Balance: In order to identify possible problems in the system and have an additional check of the analysis, an energy balance has been performed. The heat removal rate can be determined knowing the volumetric heat removal rate, the cross-sectional area, and the collapsed melt heights. The power input from the heaters is known as a function of time. The difference between the input and the heat removal are the losses to the environment.

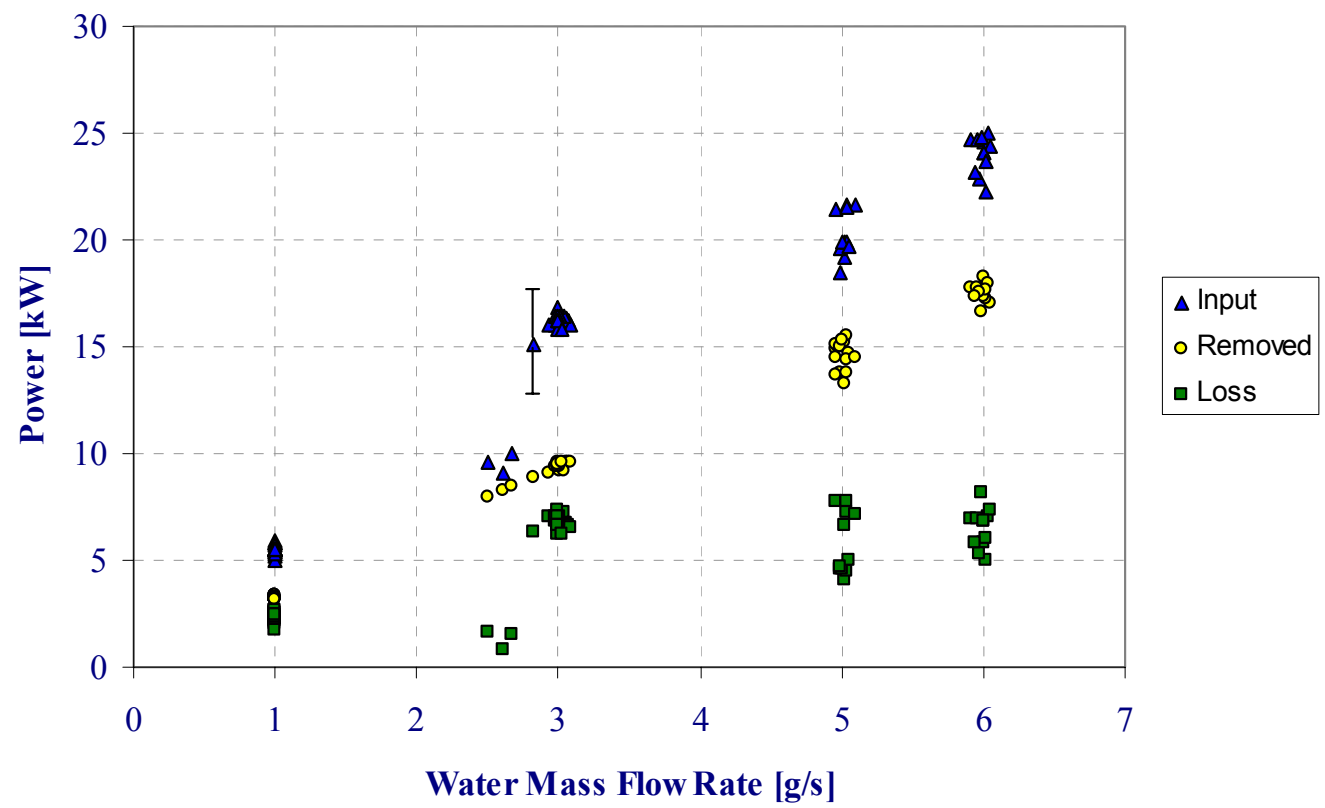

Figure 50: Heat Input, Removal, and Losses from the Energy Balance.

As it can be seen in Figure 50, the energy removed by the injected mixture increases as expected with the increasing water flow rate. Also the energy input increases with water flow rate, however, discontinuities in the required input can be noted, especially for the $2.5 \mathrm{~g} / \mathrm{s}$ data. This result is also visible in the energy losses from the system. The data seems to be split into small groups, each of them representing individual days when experiments were performed. Between some data points with a larger discrepancy, reinsulation of the test section was performed, thus altering the energy loss. Also, comparing the data for the $3-6 \mathrm{~g} / \mathrm{s}$ experiments, external heaters were used more frequently, thus, raising the temperature of the test section surface with higher losses. 


\section{II.7 FLOW STABILITY - ANALYSIS AND RESULTS}

The previous section discussed the effects of gas injection on the heat removal rate. This chapter focuses on the effects of gas injection on the stability of the heat transfer process. Together, these can be used to determine the optimum conditions for cooling by bottom injection.

In order to investigate the flow stability, the system is initially adjusted to a stable flow configuration. The water mass flow rate and the system pressure are held constant while the gas flow rate is initially relatively high. Lowering the gas flow rate will eventually shift the system from a stable to an unstable flow regime. Flow instabilities are recognized by:

- Audible sound;

- Observation using the Imaging System, and

- Nozzle Clogging.

The most common method to detect flow instabilities is to listen for an audible sound emanating from the test section. Using the imaging system requires the use of high energy X-ray equipment and thereby limits the manual control over the injection system. Nozzle clogging is one of the more severe possible results of flow instabilities and it has been observed several times during this experimental series. When flow instabilities were observed, the gas flow rate was increased to return to a stable regime. An alternative method was to decrease the water mass flow rate.

For each combination of system pressure and water mass flow rate, the gas flow rate at which the system exhibited instabilities has been noted as the boundary between a stable and an unstable regime. The parameters are presented in Table II.3. The procedure was repeated several times for some cases to demonstrate reproducibility. It turned out that the stability behavior of the system strongly depends on how the system parameters are changed; e.g., a sudden change in water flow rate showed instabilities earlier compared to a gradual change in that specific parameter. Therefore the system can be seen as metastable. For the data points taken and represented in Table II.3, the change in parameters has been performed as slow as possible. 
Table II.3: Instability Boundary for Gas Injection Flow (slpm) that Stabilizes the test at Constant System Pressure and Constant Water Mass Flow Rate.

\begin{tabular}{|ll|l|l|l|l|}
\hline $\begin{array}{r}\text { System Press. } \\
{[\text { bar }]([\mathrm{psig}])}\end{array}$ & \multicolumn{2}{l|}{ Water Mass Flow Rate $[\mathrm{g} / \mathrm{s}]$} \\
\hline 0 & $(0)$ & $5.5^{+}$ & 6.5 & $3^{*}$ & $6^{* *}$ \\
\hline 1 & $(14.5)$ & 4.5 & 5 & 7.5 & 20 \\
\hline 2.5 & $(36.3)$ & 0 & 0 & 9 & $\mathrm{X}$ \\
\hline 3.5 & $(50.8)$ & 0 & 0 & $\mathrm{x}$ & 19 \\
\hline 5 & $(72.5)$ & 0 & 0 & 0 & 15 \\
\hline \multicolumn{7}{|c|}{$* \mathrm{~T}_{\mathrm{LM}}=500^{\circ} \mathrm{C} ;{ }^{* *} \mathrm{~T}_{\mathrm{LM}}=450^{\circ} \mathrm{C},{ }^{*}$ in slpm, $\mathrm{x}$ No Data } & 0 \\
\hline
\end{tabular}

As it can be seen in Table II.3, pressure, water mass flow rate and gas flow rate have an influence on the stability of the system. For the range of pressure under investigation, flow stability increased with increasing pressure. Also low water flow rates are more favorable than higher water flow rates from a stability point of view. Decreasing the gas flow rate might shift the system from a stable to an unstable regime. It has to be noted that only the boundary from a stable to an unstable regime was under investigation. This quantitative result is in general agreement with the results of Abdulla (2003). In the current experiment, flow instabilities have been experienced multiple times. In most cases, the interactions lead to audible noise and occasionally to nozzle clogging. During the $1 \mathrm{~g} / \mathrm{s}$ test series, flow instabilities were recognized as audible sound only, nozzle clogging did not occur.

Another point of interest is the effect of the system pressure on the flow behavior in the test section. At low pressures the test section is shaking and the movement of the agitated melt is obvious by the sound coming from the test section and by the vibration, which can be felt when touching the test section support. Increasing the system pressure, it results in less agitation and this is also evident by the X-ray. The effect is especially visible when increasing the pressure from 0 bar to 2.5 bar. The effect is also obvious looking at the void fraction. At high pressure the flow in the test section is calm and the vibration coming from the test section decreased drastically. 


\section{Task III: Modeling of Interfacial Phenomena: Separate Effect Tests (KMU Lead)}

The focus of this task is to conduct separate effect tests for key physical models. These include (1) experimental study on dryout heat flux in debris beds, (2) film boiling on spheres in high temperature, and (3) development of simultaneous measurement technique for temperature and flow field.

\section{III.1 Dryout Heat Flux in Volumetrically Heated Debris Beds}

\section{III.1.1 Literature Review}

The dryout heat flux in particle beds is affected by several bed parameters such as particle size, bed height, bed porosity, and pressure in bed, permeability, bed power and boundary conditions. The major controlling factors are known to be particle size, bed height, and cooling modes such overlaid subcooled coolant pool or forced flow below.

The past experiments have shown that the dryout heat flux is changed by the particle size in particle beds. Generally, the dryout heat flux increases as the particle size increases. But the increasing trend is different according to the flow pattern (laminar and turbulent). For the laminar flow approximation as in the models of Dhir-Catton (1976), HardeeNilson (1977), Shires-Stevens (1980), and Jones (1980), the dryout heat flux is proportional to the square of the particle diameter, if the particle sizes are in the range of 0.3 to $1.0 \mathrm{~mm}$. For particle diameters over $1 \mathrm{~mm}$, Ostensen-Lipinski (1981) showed that the dryout heat flux is proportional to the square root of the particle diameter.

Considering the turbulent and capillary attraction, Lipinski (1980) proposed that the relationship between the dryout heat flux and the particle size can be expressed for the bed height $\mathrm{H}$ and the parameter $\lambda_{c}$ which is given by

$$
\lambda_{c}=\frac{\sigma(\varepsilon / \kappa)^{1 / 2}}{\sqrt{5}\left(\rho_{f}-\rho_{g}\right) g}
$$

For small particles ( $1 \mathrm{~mm})$,

$$
\begin{aligned}
& \lambda_{\mathrm{c}}\left\langle\mathrm{H}, \mathrm{q}_{\mathrm{d}} \approx \mathrm{d}^{2}\right. \\
& \left.\lambda_{\mathrm{c}}\right\rangle \mathrm{H}, \mathrm{q}_{\mathrm{d}} \approx \mathrm{d}
\end{aligned}
$$


For large particle ( $>1 \mathrm{~mm})$,

$$
\begin{aligned}
& \lambda_{\mathrm{c}}\left\langle\mathrm{H}, \mathrm{q}_{\mathrm{d}} \approx \sqrt{\mathrm{d}}\right. \\
& \left.\lambda_{\mathrm{c}}\right\rangle \mathrm{H}, \mathrm{q}_{\mathrm{d}} \neq \mathrm{d}
\end{aligned}
$$

The height (or depth) of particle beds does not affect the dryout heat flux if it is regarded as so-called a deep bed. Squarer (1981) reported that the bed was regarded as a deep bed if the bed height was more than $13 \mathrm{~cm}$ for the particle sizes of 0.5 0.6 mm. Dhir (1984) proposed $10 \mathrm{~cm}$ of bed height for the limit of deep bed, above which the dryout heat flux did not change. Hofmann (1984) observed that the limit was about $25 \mathrm{~cm}$ for $3 \mathrm{~mm}$ particles. But in the shallow bed, the dryout heat flux increases as the bed height decreases.

\section{Experimental Work}

The past experimental works on the particle bed dryout heat flux are summarized in Table 5. Dhir and Catton (1977) observed the dryout heat fluxes for inductively heated particle beds cooled from the top. They used two bed configurations, shallow and deep. Different mechanisms for the dryout in these beds were identified. It was concluded that the deep bed primarily dries out at a particular section in the lower region of the bed because gravity can no longer maintain the flow rate necessary to compensate for the evaporation rate. The evaporation rate is greater than the average downward superficial velocity of the coolant. Some semi-theoretical correlations were developed and validated based on the proposed hydrodynamic model.

The dependence of the dryout heat flux for volumetrically heated particle bed on the bed height and particle diameter was experimentally studied by Barleon et al. (1981). The bed was volumetrically heated by induction coil heater and the coolant, water or Freon-113, was added to the top of the bed (top flooding). They reported that the dependence of the dryout heat flux on particle size and bed height was well predicted by the theory but the absolute value was overpredicted. Hu and Theofanous (1991) also conducted dryout heat flux experiment of top-flooded bed. They used one meter deep bed made up with electrically heated aluminum spheres and stone gravel of $\sim 8 \mathrm{~mm}$ in characteristic 
dimension. They reported a new finding of dryout delay time in measuring dryout heat flux and recommended Theofanous-Saito correlation for dryout heat flux in deep beds. Enhancement of dryout heat flux by forced coolant flow from below were experimentally studied by Tsai and Catton (1983), Cha et al. (1986), and Atkhen and Berthoud (2003). The bed heights in the first two experiments above are relatively shallow, $15 \mathrm{~cm}$ and 11 $\mathrm{cm}$. Atkhen used a rectangular bed of $60 \times 10 \mathrm{~cm}$ cross section and $50 \mathrm{~cm}$ height.

Some selected data of dryout heat flux in the form of volumetric power are shown in Figure 51. In the literature the dryout heat flux is typically given in terms of unit cross sectional area of the bed and the volumetric power given in Table 5 is obtained by dividing it by the height of the bed. In this figure the enhancement of dryout heat flux by forced coolant flow from below is quantitatively observed. Wide ranges of particle diameter and coolant mass flux were studied by KAERI (Cha et al., 1986), but their data showed limited usefulness due to shallow bed height $(11 \mathrm{~cm})$ and bed diameter $(5 \mathrm{~cm})$.

Table 5: Dryout heat flux data from some selected past work

\begin{tabular}{|l|c|c|c|c|}
\hline \multicolumn{1}{|c|}{ Authors } & $\begin{array}{c}\text { Particle Size } \\
(\mathrm{mm})\end{array}$ & $\begin{array}{c}\text { Bed Height } \\
(\mathrm{m})\end{array}$ & $\begin{array}{c}\text { Mass Flux } \\
\left(\mathrm{kg} / \mathrm{m}^{2} \mathrm{~s}\right)\end{array}$ & $\begin{array}{c}\text { Dryout Heat } \\
\left(\mathrm{MW} / \mathrm{m}^{3}\right)\end{array}$ \\
\hline $\begin{array}{l}\text { Barleon et al. } \\
(1981)\end{array}$ & $0.06-16$ & $<0.4$ & 0 & $0.7 \sim 6$ \\
\hline $\begin{array}{l}\text { Tsai \& Catton } \\
(1983)\end{array}$ & $0.6-4.8$ & $<0.15$ & $0-0.56$ & $3 \sim 4$ \\
\hline $\begin{array}{l}\text { Hu \& Theofanous } \\
(1991)\end{array}$ & $7-9$ & 1.02 & 0 & $0.6 \sim 1$ \\
\hline $\begin{array}{l}\text { Cha et al. } \\
(1986)\end{array}$ & $1.5-5$ & 0.11 & $0-3.5$ & $9 \sim 26$ \\
\hline $\begin{array}{l}\text { Atkhen \& Berthoud } \\
(2003)\end{array}$ & $2-7.2$ & 0.5 & $?$ & $1.6 \sim 5.4$ \\
\hline
\end{tabular}






Figure 51: Comparison of selected dryout heat flux data

Also drawn in Figure 51 is the possible range of decay heat of core debris for typical LWRs, 2 4 MW/ $/ \mathrm{m}^{3}$. It is noted that in actual reactor cases, the anticipated debris size may be a few millimeter or larger and the debris bed can be deeper than $30 \mathrm{~cm}$.

Considering these debris bed parameters of reactor cases, it is obvious to note that the existing dryout heat flux data for these ranges of particle size and bed height do not show a margin for assuring stable coolable state of core debris in reactor cavity.

\section{$\underline{\text { Dryout Heat Flux Models }}$}

Dhir-Catton (1976) developed a dryout heat flux model based on the assumptions of deep bed, natural convection flow, and spherical particles.

$$
q=c_{1} \frac{\varepsilon^{3}(\bar{d})^{2}}{(1-\varepsilon)^{2}} \frac{\rho_{f} h_{f g}\left(\rho_{f}-\rho_{g}\right) g}{\mu_{f}}
$$

They experimentally investigated the cooling in inductively heated particle beds. Water, methanol, and acetone were used as coolants. Based on the experimental result, they 
proposed $c_{1}=10^{-4}$. Gabor and Sowa obtained the dryout heat flux data in the low heated region and proposed $c_{1}=5 \times 10^{-5}$ for the equation (12).

Ostensen-Lipinski (1981) obtained the dryout correlation on the basis of flooding criterion in particle beds. The particle size was over $1 \mathrm{~mm}$ and the flow was assumed turbulent. For uniform particle size,

$$
q_{d}=\frac{0.245 h_{f g}\left[\rho_{f} \rho_{g} g d \varepsilon^{3} /(1-\varepsilon)\right]^{1 / 2}}{\left[1+\left(\rho_{g} / \rho_{f}\right)^{1 / 4}\right]^{2}}
$$

Ostensen-Lipinski model shows that the dryout heat flux is proportional to the square root of particle diameter. Equation (13) shows a good agreement with the experimental results for large size particles.

Lipinski (1984) developed one-dimensional model and it included the turbulent flow and the effect of capillary pressure. The correlation also included the upward and downward boiling. Two-phase fluids are passing through particle beds and the two fluids have an opposite direction.

$$
\begin{aligned}
& \frac{\sqrt{150} \sigma \cos \theta(1-\varepsilon)}{\varepsilon d} \frac{d J}{d s} \frac{d s}{d z} \\
& +\sqrt{150} \sigma \cos \theta J \frac{d}{d z}\left(\frac{1-\varepsilon}{\varepsilon d}\right) \\
& -\left(\rho_{f}-\rho_{g}\right) g+\frac{0.175(1-\varepsilon) q^{2}}{h_{f g}^{2} \varepsilon^{3} d}\left[\frac{1}{\rho_{g}(1-s)^{5}} \pm \frac{1}{\rho_{f} s^{5}}\right] \\
& +\frac{150(1-\varepsilon)^{2} q}{h_{f g} \varepsilon^{3} d^{2}}\left[\frac{\mu_{g}}{\rho_{g}(1-s)^{3}}+\frac{\mu_{f}}{\rho_{f} s^{3}}\right]+\frac{(1-\varepsilon) \omega}{\rho_{f} \varepsilon^{3} d} \\
& \times\left[ \pm \frac{1.75 \omega}{s^{5}} \mu \frac{3.5 q}{s^{5} h_{f g}}-\frac{150(1-\varepsilon) \mu_{f}}{s^{3} d}\right]=0
\end{aligned}
$$

Here, $\mathrm{q}>\omega \mathrm{h}_{\mathrm{fg}}$ is applied to the upper sign and $\mathrm{q}<\omega \mathrm{h}_{\mathrm{fg}}$ is applied to the lower sign.

\section{III.1.2 Experimental Apparatus}

An experimental setup for long-term coolability in volumetrically heated particle beds with coolant injected from below was constructed. The experimental apparatus consists 
mainly of an induction heater, a quartz tube test section containing particle bed, a condenser, and a water circulator. A schematic diagram of the apparatus is shown in Figure 52.

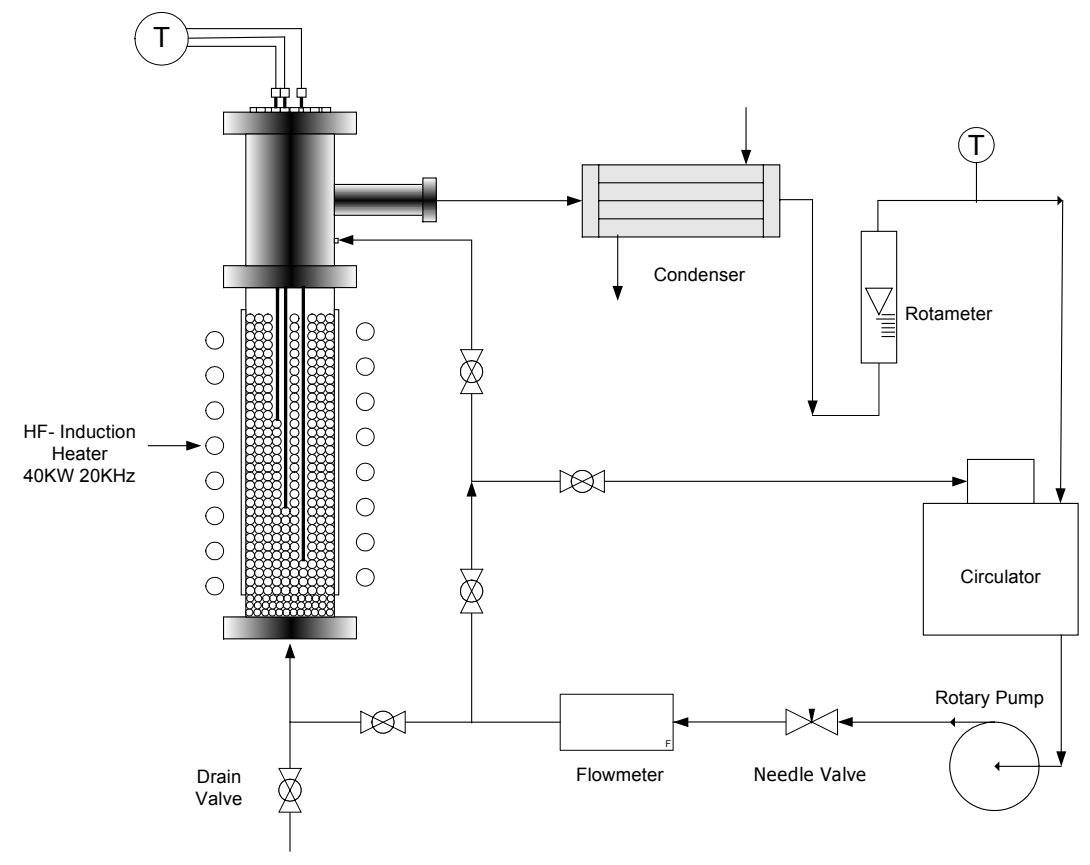

Figure 52: Experimental setup of dryout heat flux measurement

\section{Test Section and Induction Heater}

The particle beds were composed of steel particles in a quartz tube. The shape was spherical and the size was uniform in the bed. Two particle sizes were tested, $3.2 \mathrm{~mm}$ and $4.8 \mathrm{~mm}$. The bed height was $300 \mathrm{~mm}$ and the bed diameter was $100 \mathrm{~mm}$. The measured porosity for the $4.8 \mathrm{~mm}$ particles was 0.38 and 0.37 for the $3.2 \mathrm{~mm}$ particles.

The steel balls were charged in a double-walled quartz tube. The tube was fabricated with $3 \mathrm{~mm}$ thick quartz and it can contain up to $300 \mathrm{~mm}$ high particle bed. The lower part of the test section was filled with glass balls in order to separate the steel particle bed and the joining flange and also to distribute the water coolant uniformly over the cross section of the bottom of the particle bed when the coolant was injected from below. The doublewall sidewall was intended to minimize heat loss. The double-wall annulus was open to the atmosphere. 
The volumetric heating of the bed was given by an induction heater. The induction heater system consists of power supply and control unit ( $40 \mathrm{~kW}, 30 \mathrm{kHz})$, an induction coil and a cooling unit (Figure 53). The brine coolant of the cooling unit is also directed to the condenser unit to condense the steam produced in the test section. The heating up rates of the bed filled with stagnant water measured at different spatial positions were used to calculate the power density distribution within the bed.

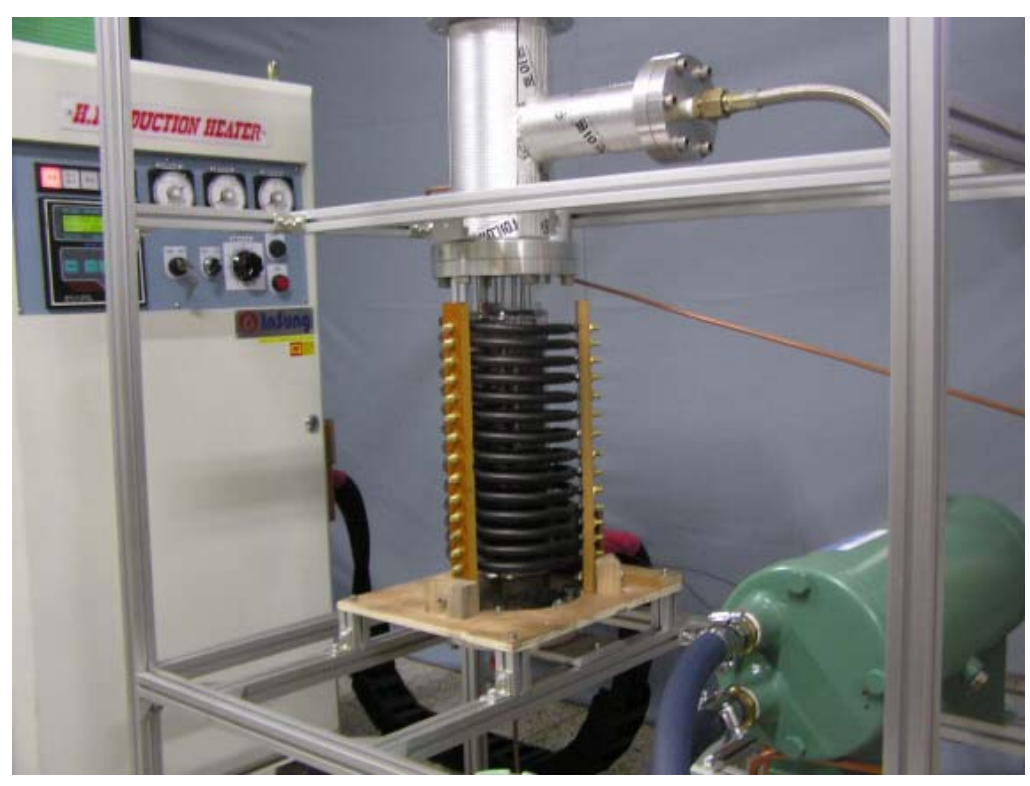

Figure 53: Induction Heater

Good homogeneity of power input can be achieved by electrically insulating the particles mutually. The electrical insulation was offered by oxide surface layer. The oxide coating was made naturally, that is, it occurred during the preliminary boiling tests. As far as the beads are oxidized, the magnetic field penetrates more and more within the bed. The heat produced in the bed was removed either only from the top water pool or by the injected water from below.

Water was flooded at the top of the bed in the atmospheric pressure or injected at the bottom of the bed. The generated steam was passed to a condenser and the collected liquid was redirected to the bed through the water circulator at a controlled temperature. The steam condenser was a shell-and-tube type heat exchanger and the coolant of the 
induction heater unit was used for the condenser coolant. The heat transfer surface area of the condenser was $1.31 \mathrm{~m}^{2}$. The condensate liquid flow rate was. The water circulator supplies water coolant to the test section at a predetermined temperature either to the top of the test section (top-flooding test) or from below of the test section (bottom injection test). The water coolant flow rate was controlled by use of a constant-speed pump and a needle valve.

\section{$\underline{\text { Instrumentations }}$}

Twenty three chromel-alummel (K-type) thermocouples (sheathed, $1.6 \mathrm{~mm}$ diameter) were located at different positions within the bed (Figure 54). Thermocouples were located in five vertical levels inside the bed (Figure 55). The radial distribution of the thermocouples is also shown in the Figure 56. A coriolis-type mass flow meter was used to measure the coolant injection rate and a rotameter was used for condensate liquid flow rate measurement. The thermocouples and flow meter signals were processed, monitored, and recorded in a PC-based data acquisition system (Labview).

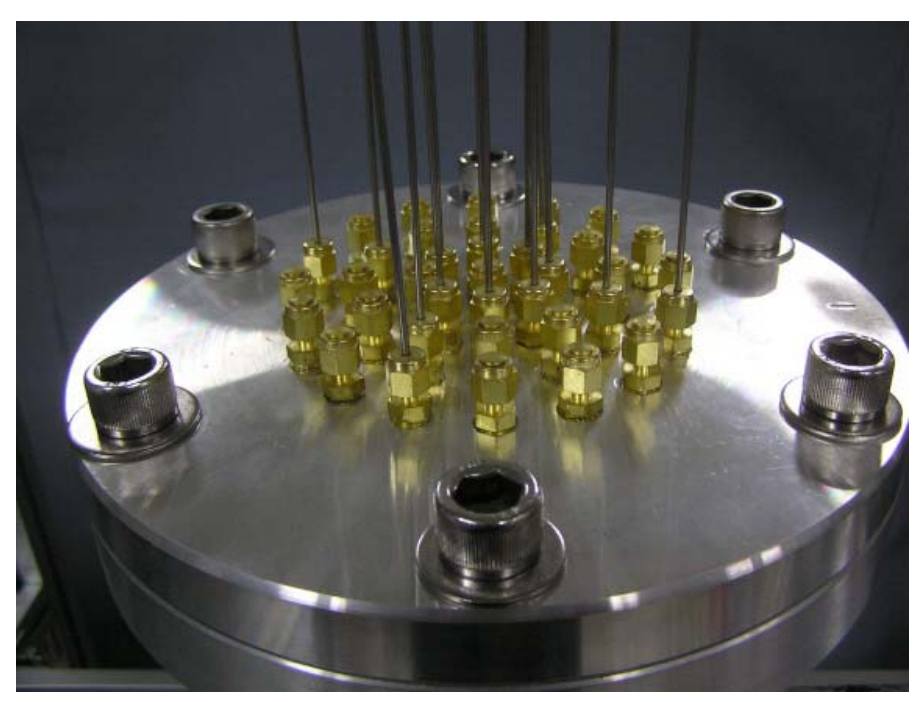

Figure 54: Thermocouples on the top plate 


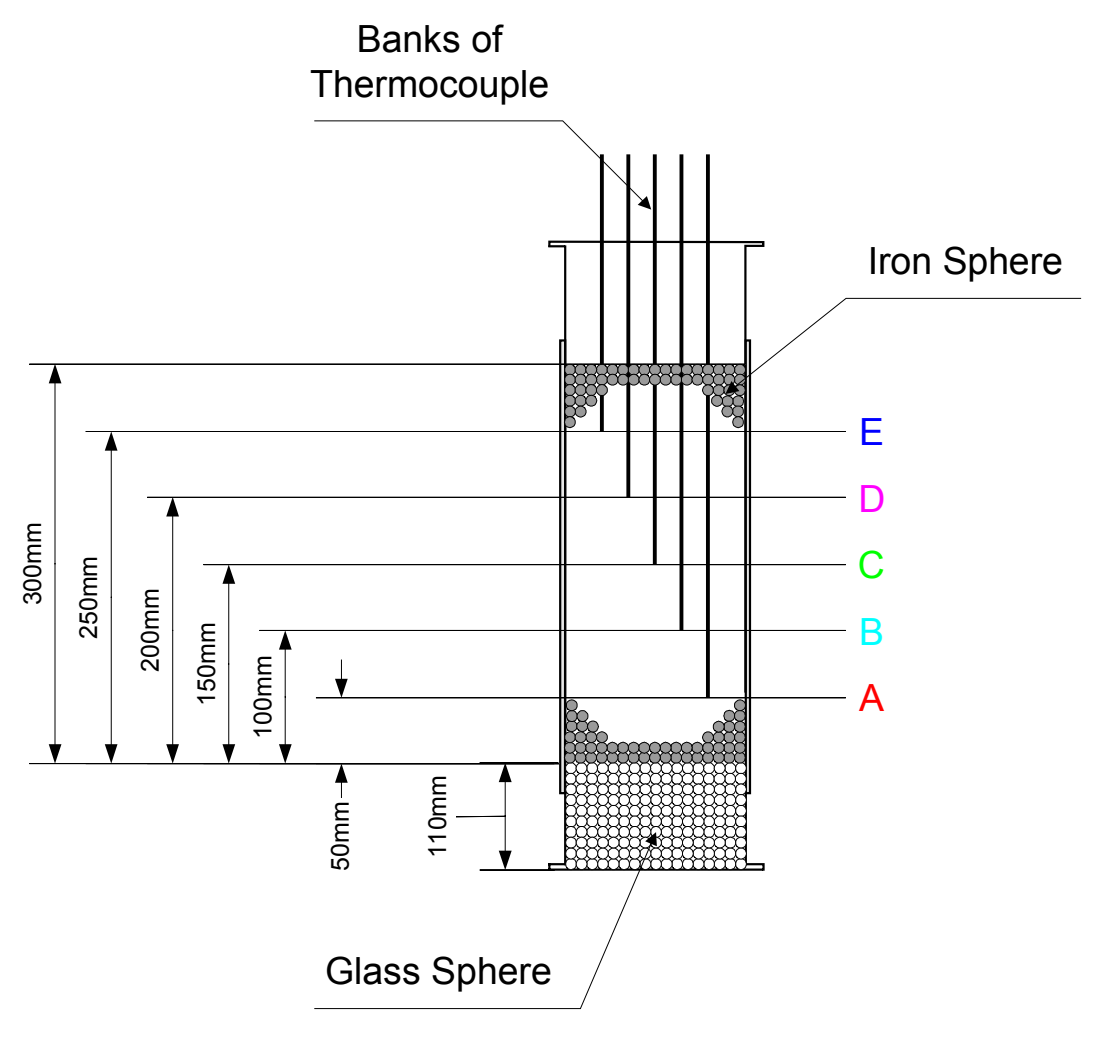

Figure 55: Location of thermocouples

\section{Experimental Procedure}

For the first test series, a mono-disperse bed with pre-oxidized $4.8 \mathrm{~mm}$ spheres (height $300 \mathrm{~mm}$ ) was used under the atmospheric conditions. The measured bed porosity was 0.38 for clean steel balls and varied up to 0.42 depending on the level of rust. For the second test series, pre-oxidized $3.2 \mathrm{~mm}$ particle spheres (height $300 \mathrm{~mm}$ ) were used under the atmospheric conditions. The bed porosity was 0.37 . The experimental setup allows pool boiling experiments (counter-current-flow) with condensate from the condenser fed to the top of the bed, as well as experiments with water injection from the bottom (co-current-flow).

The tests were conducted according to the following procedure.

(1) Turn on the pump and heat the coolant in the circulator to a preset temperature (normally $95^{\circ} \mathrm{C}$ )

(2) Adjust the valves for a desired coolant flow rate while the induction heater turned on for warming-up. 


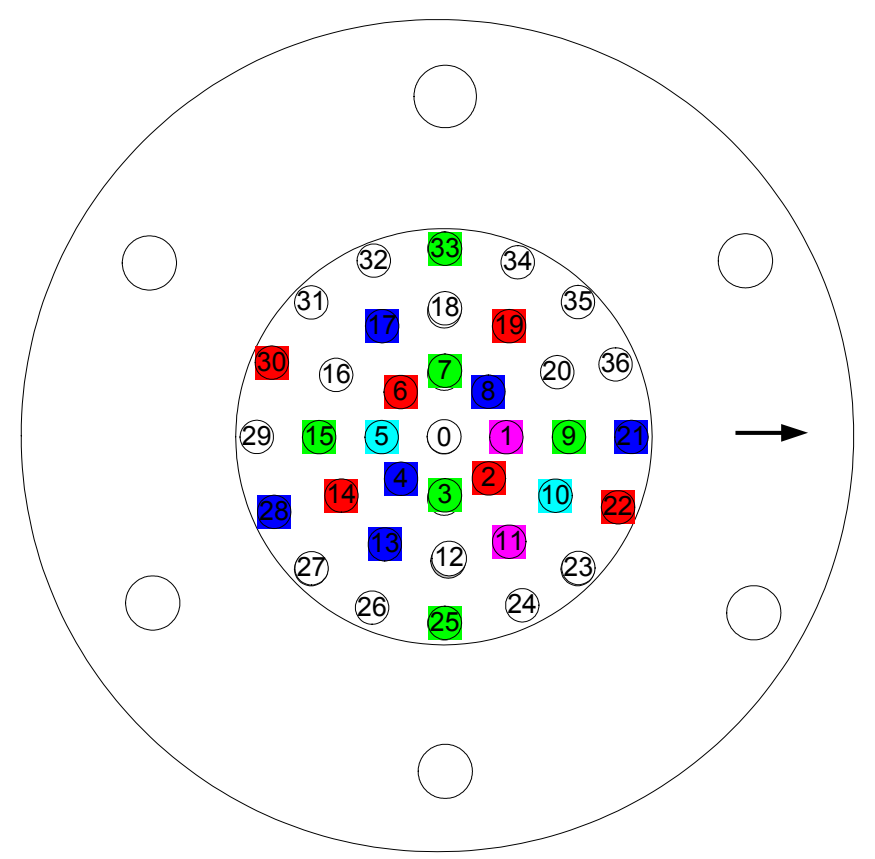

Location of Thermocouples in the Banks

$$
\begin{aligned}
& \text { A }-2,6,14,19,22,30 \\
& \text { B - } 5,10 \\
& \text { C - } 3,7,9,15,25,33 \\
& \text { D - } 1,11 \\
& \text { E - } 4,8,13,17,21,28 \\
& \# 0 \text { is located on the bottom of Tube }(0 \mathrm{~mm}) \\
& \# 12 \text { is located on the top of Tube }(300 \mathrm{~mm})
\end{aligned}
$$

\section{Figure 56: Radial distribution of thermocouples}

(3) The induction heater power button turned on and the power is increased in steps.

(4) At each power level, the test is running for 15 30 minutes or longer to obtain a steady-state condition and to allow any delayed dryout events.

(5) The dryout of the bed is observed visually by monitoring the sharp rise in the temperature of one or more of the thermocouples in the bed. 
(6) The power is turned off as soon as dryout is observed. The bed is cooled by the natural convection for about 20 minutes.

(7) Repeat the test at least once more under the same test conditions.

(8) For a different set of test conditions, repeat step 1 through step 7.

\section{Measurement of Volumetric Heat Input Distribution}

In order to measure the volumetric power density in the bed by induction heating, liquid coolant was filled up to the top of the bed and induction power was applied at a predetermined level. The liquid water temperature was allowed to rise to the boiling temperature. The volumetric power density is related with the rate of temperature rise.

$$
q^{\prime \prime \prime}=\frac{Q}{V}=\left(\frac{m}{V}\right) \bar{c}_{p} \frac{d T}{d t}=\bar{\rho} \bar{c}_{p} \frac{d T}{d t}
$$

Here, $\bar{\rho}, \bar{c}_{p}$ are the average density and specific heat of the bed including steel spheres and water coolant and can be expressed using the porosity $\phi$ for uniform-size particle bed.

$$
\begin{aligned}
& \bar{\rho}=\frac{m}{V}=\rho_{\text {steel }}(1-\phi)+\rho_{\text {water }} \phi \\
& \bar{c}_{p}=\frac{1}{\bar{\rho}}\left[\rho_{\text {steel }}(1-\phi) c_{p, \text { steel }}+\rho_{\text {water }} \phi c_{p, \text { water }}\right]
\end{aligned}
$$

The twenty-two thermocouple signals were used to calculate the power density distribution.

\section{III.1.3 Results and Discussion}

Experiment of dryout heat flux measurement for particle beds of $100 \mathrm{~mm}$ in diameter and $300 \mathrm{~mm}$ in height has been conducted. The water coolant was supplied either from the top of the bed or from below. The bed was composed of steel particles in uniform size (two cases of $4.8 \mathrm{~mm}$ diameter and $3.2 \mathrm{~mm}$ diameter) and volumetrically heated by induction heater coil. In this experiment achievement of uniform heat input throughout the bed is crucial and for this purpose the particles composing the bed must be electrically isolated or completely conducted. Complete conductance between the steel 
particles was not plausible in this case, however the natural rusting of steel particles after several repeated boiling had built sufficient oxide coating over the particle surface and this provided complete electrical insulation between the particles.

\section{Volumetric Power Density}

In order to measure the volumetric power density in the bed with induction heating, liquid coolant was filled up to the top of the bed and induction power was applied at a predetermined level. The liquid temperature was allowed to rise until it reached the boiling temperature. The twenty-two thermocouple signals gave sensible heating of liquid and these values were converted to power density distribution. The typical temperature rise of coolant is shown in Figure 57. Natural circulation of the coolant in the bed caused nonlinear rise of temperature, particularly in the upper part of the bed (Figure 58). Using the equation (15), the local power density was calculated. The average power density at each axial level is shown in Figure 59. Although the middle of the bed showed higher power and the top and the bottom parts of the bed were lower, the power density was uniform within $10 \%$. The average volumetric heat input over the five axial values at various power level of the induction unit is shown in Figure 60 and it shows good linearity with the unit power level. The best-fitted linear function was used to read the power density in the experiment.

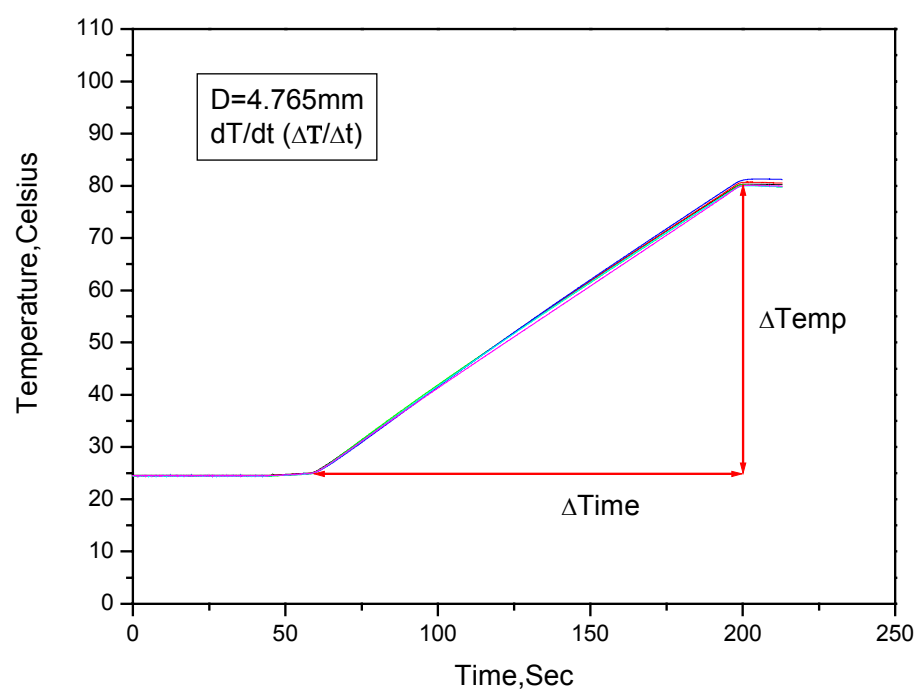

Figure 57: Coolant heatup rate in bed 


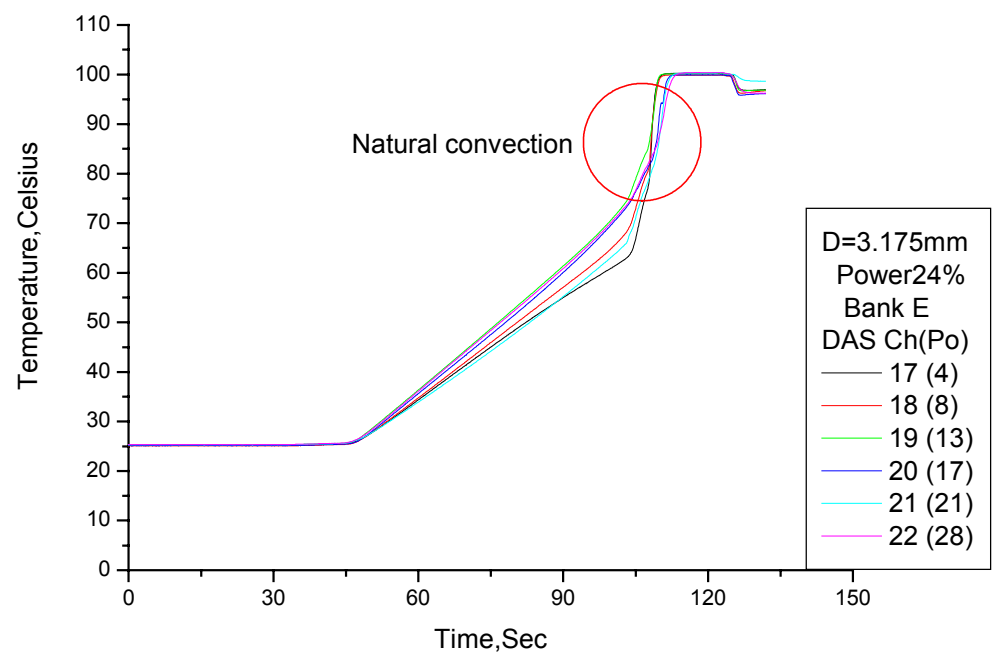

Figure 58: Distortion of linear temperature rise due to natural convection in bed

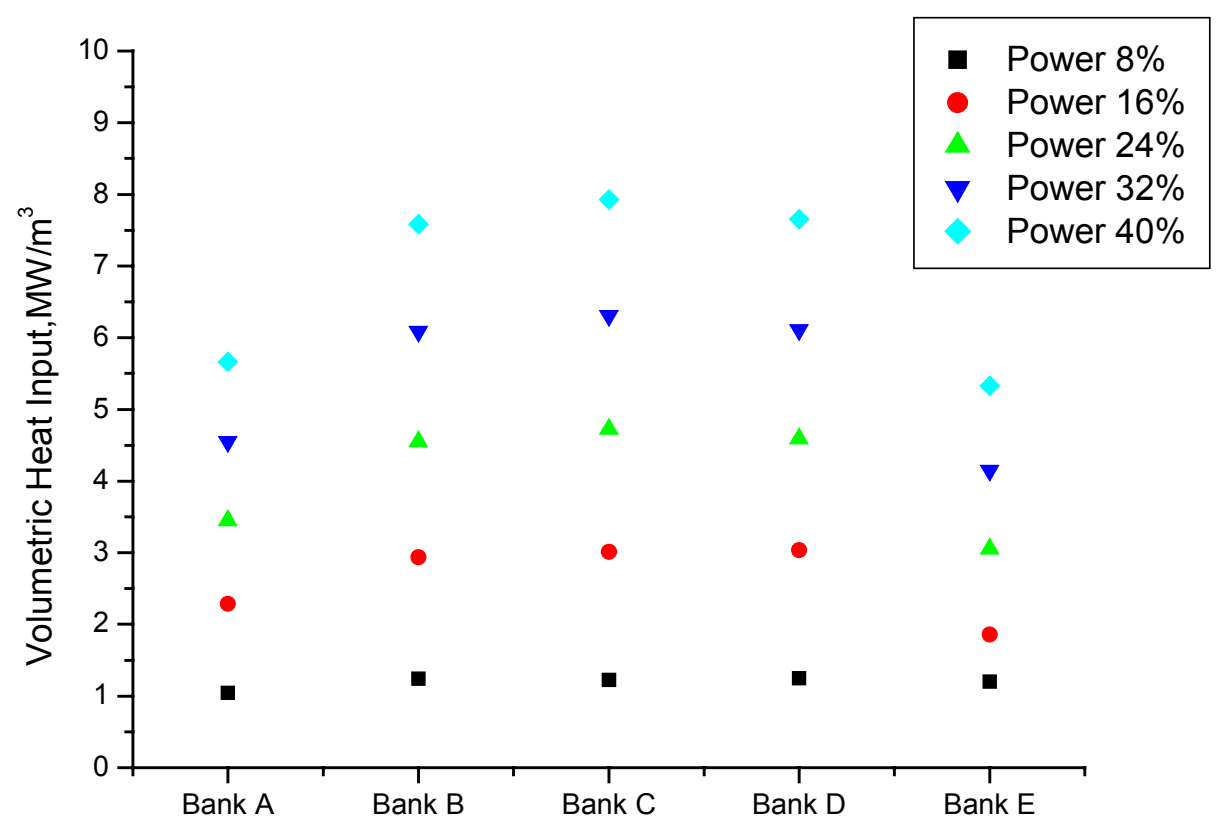

Figure 59: Volumetric power densities at each bank $(\mathrm{Dp}=4.8 \mathrm{~mm})$ 


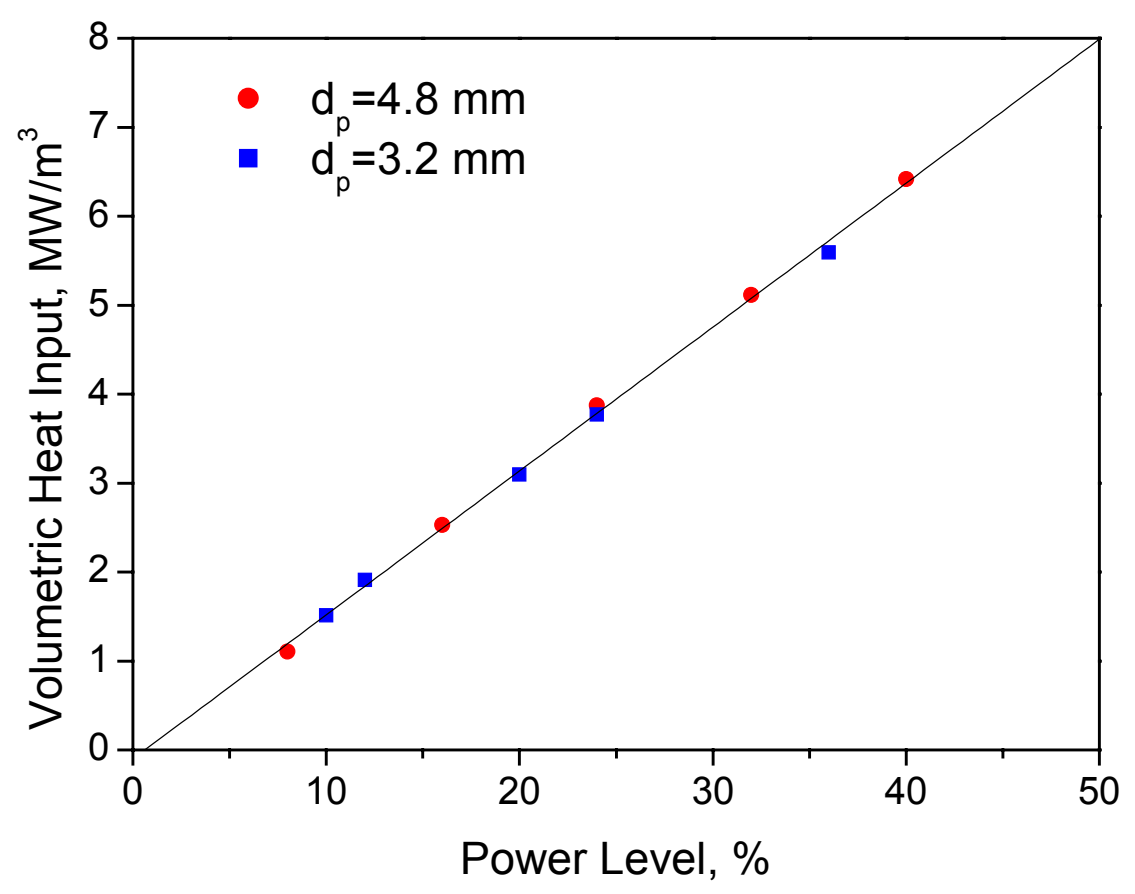

Figure 60: Average volumetric heat input

The volumetric power density was also verified by comparing it with the condensation heat removal rate of the steam produced. A stable steady-state operation of the boiling in the test section and condensation in the condenser of the loop was achieved. The condensate water was returned to the water circulator by gravity-driven so a rotameter was used to measure the condensate liquid flow. The rotameter reading was corrected according to the measured condensate water temperature to get correct flow rate. This correction table was built from a set of calibration process with various water temperatures.

The reading of condensate liquid flow rate multiplied by the latent heat of vaporization is equal to the heat added in the test section to boil the liquid coolant. The comparison between the power input and latent heat of the condensate is shown in Figure 61 and it shows a fairly good agreement. 


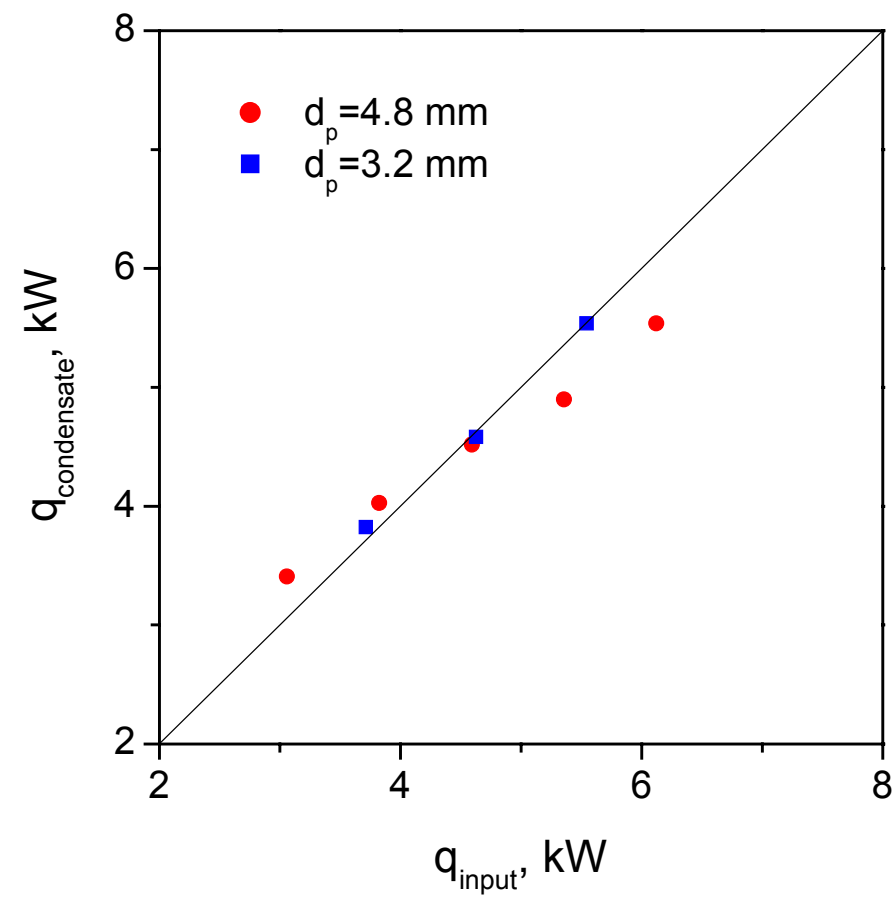

Figure 61: Energy balance between heat input and steam condensation rate

\section{Dryout Heat Flux}

The first set of tests was top flooding case to obtain the top-flooding data for the present bed composition and geometry and also to verity the present experimental method by comparing with the past data of similar geometry. The nearly saturated liquid coolant, in this case, was continuously added to the top of bed to refill the amount of boil-off coolant. The induction heating power was increased by a step from a lower level until one of thermocouples showed a sharp increase. The typical thermocouple signals when dryout occurred are shown in Figure 62. In top-flooding cases the dryout occurred always near the bottom of the bed.

In case of bottom injection experiments, the nearly saturated liquid coolant was continuously injected from the bottom of the test section at a preset flow rate. The induction heating power was increased by a step from a lower level until one of thermocouples showed a sharp increase. It is noted that there was a layer of $110 \mathrm{~mm}$ 
height containing glass beads between the bottom of the test section and the steel bead particle bed to distribute the injected coolant over the cross section of the test section. Table 6 and 7 summarize the test conditions and the measured dryout heat rate.

Figure 63 presents the measured dryout heat rate for both top flooding and coolant injection from below. Here the volumetric dryout heat rate is defined by the total heat input at which dryout occurred divided by the bed volume. For $4.8 \mathrm{~mm}$ particle bed, the top-flooding dryout heat rate was $\sim 4.0 \mathrm{MW} / \mathrm{m}^{3}$ and this value falls within the range of the past experimental data as compared with the past data in Figure 64. The coolant boiling rate corresponding to this amount of heat input is about $0.5 \mathrm{~kg} / \mathrm{m}^{2} \mathrm{~s}$ in terms of coolant mass flux. Therefore, when the coolant is injected only from below of the bed, the dryout occurs whenever the power input is greater than the heat required to evaporate all the coolant injected from below. For $3.2 \mathrm{~mm}$ particle bed, the top-flooding dryout heat rate was $\sim 2.8 \mathrm{MW} / \mathrm{m}^{3}$. In the range of coolant injection rate of $0.25 \sim 1.5 \mathrm{~kg} / \mathrm{m}^{2} \mathrm{~s}$, the dryout heat rates were shown in Figure 63. Also is plotted a line of evaporation heat of complete vaporization of the coolant flow.

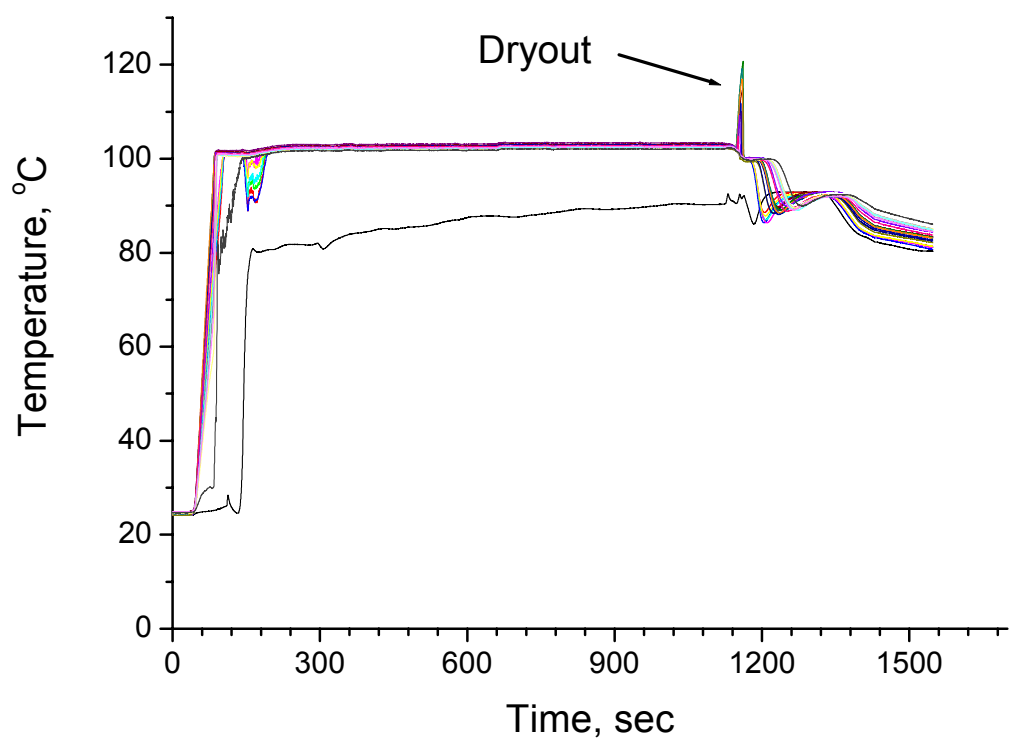

Figure 62: Typical temperature responses at dryout 
Table 6: Measured dryout heat rate $(D p=4.8 \mathrm{~mm})$

\begin{tabular}{|c|c|c|c|}
\hline Test \# & $\begin{array}{l}\text { Mass Flux } \\
\left(\mathrm{kg} / \mathrm{m}^{2} \mathrm{~s}\right)\end{array}$ & $\begin{array}{l}\text { Vol. Heat Input } \\
\qquad\left(\mathrm{MW} / \mathrm{m}^{3}\right)\end{array}$ & $\begin{array}{l}\text { Time to dryout } \\
\text { (min) }\end{array}$ \\
\hline 1 & 0 & 4.22 & 6 \\
\hline 2 & 0 & 3.90 & 29 \\
\hline 3 & 0 & 3.90 & 21 \\
\hline 4 & 1.0 & 6.82 & 2 \\
\hline 5 & 1.0 & 6.49 & 19 \\
\hline 6 & 1.0 & 6.11 & 9 \\
\hline 7 & 1.0 & 6.82 & 14 \\
\hline 8 & 1.25 & 7.71 & 15 \\
\hline 9 & 1.5 & 7.91 & 18 \\
\hline 10 & 0.75 & 6.33 & 8 \\
\hline 11 & 0.75 & 6.33 & 11 \\
\hline 12 & 0.5 & 4.87 & 5 \\
\hline 13 & 0.5 & 4.38 & 21 \\
\hline
\end{tabular}


Table 7: Measured dryout heat rate $(\mathrm{Dp}=3.2 \mathrm{~mm})$

\begin{tabular}{|c|c|c|c|}
\hline $\begin{array}{l}\text { TEST } \\
(\mathrm{No})\end{array}$ & $\begin{array}{l}\text { Mass Flux } \\
\left(\mathrm{kg} / \mathrm{m}^{2} \mathrm{~s}\right)\end{array}$ & $\begin{array}{l}\text { Vol. Heat Input } \\
\qquad\left(\mathrm{MW} / \mathrm{m}^{3}\right)\end{array}$ & $\begin{array}{l}\text { Time to dryout } \\
\text { (min) }\end{array}$ \\
\hline 1 & 0 & 3.13 & 6 \\
\hline 2 & 0 & 2.74 & 7 \\
\hline 3 & 0 & 2.74 & 4 \\
\hline 4 & 1.0 & 5.07 & 13 \\
\hline 5 & 0.5 & 4.29 & 2 \\
\hline 6 & 0.25 & 2.74 & 10 \\
\hline 7 & 0.75 & 5.46 & 15 \\
\hline 8 & 1.0 & 6.24 & 14 \\
\hline 9 & 0.25 & 2.97 & 1 \\
\hline 10 & 0.5 & 4.37 & 9 \\
\hline 11 & 0.75 & 5.46 & 4 \\
\hline
\end{tabular}

The dryout heat rate increases as the coolant injection rate is increased; $\sim 5.0 \mathrm{MW} / \mathrm{m}^{3}$ at the coolant mass flux of $0.5 \mathrm{~kg} / \mathrm{m}^{2} \mathrm{~s}$ and $7.91 \mathrm{MW} / \mathrm{m}^{3}$ at the coolant mass flux of 1.5 $\mathrm{kg} / \mathrm{m}^{2} \mathrm{~s}$ for $4.8 \mathrm{~mm}$ particle bed. For $3.2 \mathrm{~mm}$ particle bed, the dryout heat rate is about 3.0 $\mathrm{MW} / \mathrm{m}^{3}$ at the coolant mass flux of $0.25 \mathrm{~kg} / \mathrm{m}^{2} \mathrm{~s}$ and $6.3 \mathrm{MW} / \mathrm{m}^{3}$ at the coolant mass flux of $1.0 \mathrm{~kg} / \mathrm{m}^{2} \mathrm{~s}$.

The present dryout data for $300 \mathrm{~mm}$ bed height and $100 \mathrm{~mm}$ bed diameter are compared with the past studies in Figure 64. The present data of dryout heat rate of zero flow case (top-flooding) agrees well with the past data. Comparing the present data with KAERI data of $100 \mathrm{~mm}$ bed height shows the effect of bed height. 


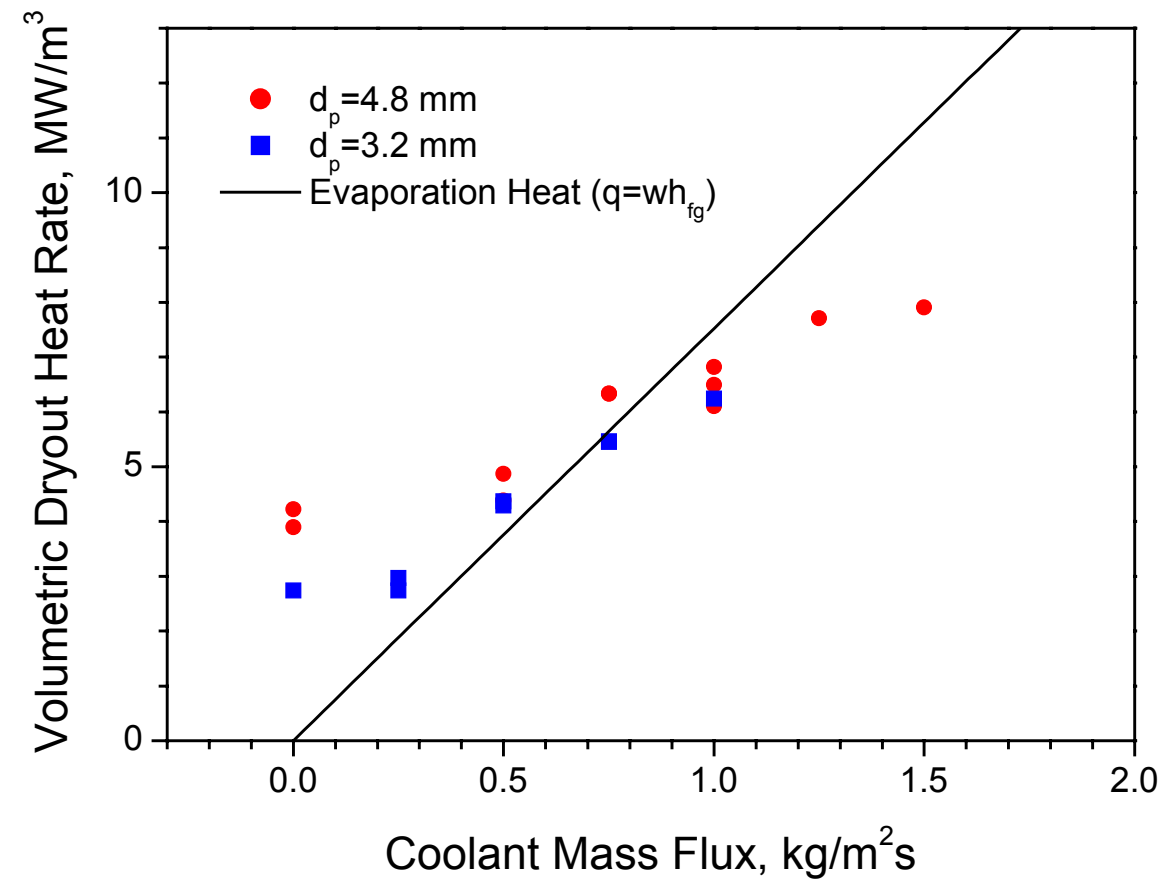

Figure 63: Volumetric dryout heat rate for $300 \mathrm{~mm}$ deep particle beds

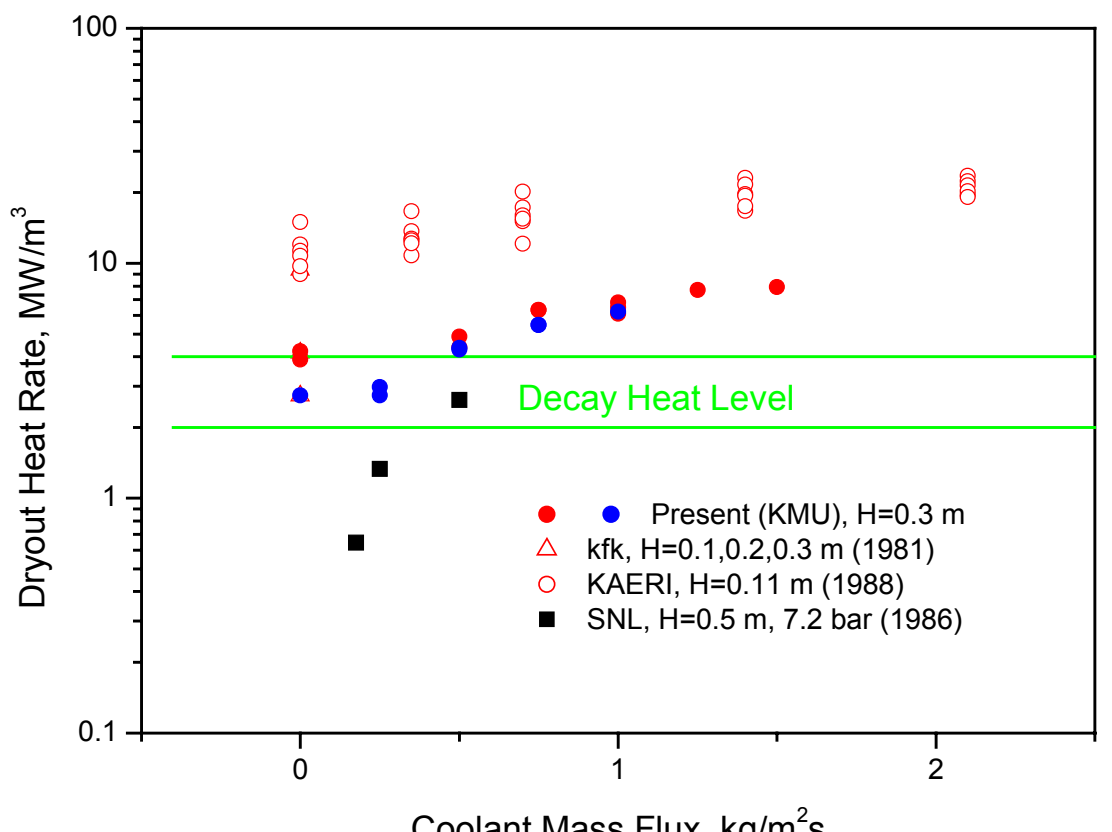

Figure 64: Comparison of present data with the past experimental data 
Assuring ex-vessel coolability of degraded core requires sufficient cooling rate for both molten and quenched phases, i.e., the cooling rate should be greater than the decay heat within the degraded core. The estimated decay heat per volume can be approximately in the range of $2 \sim 4 \mathrm{MW} / \mathrm{m}^{3}$ for a $1400 \mathrm{MWe}$ reactor (APR1400). This value is marked on Figure 64 in comparison with the maximum volumetric heat removal rate for quenched debris bed (dryout heat rate). For debris beds of $300 \mathrm{~mm}$ in height and 3 5 mm uniform particle sizes, ex-vessel coolability can not be assured if the coolant is only added to the top of the bed (top flooding). Figure 64 indicates that forced coolant flow from below greater than $0.5 \mathrm{~kg} / \mathrm{m}^{2} \mathrm{~s}$ is required to assure ex-vessel debris coolability. Figure 65 presents the prediction of dryout heat rate by Lipinski's 1-D model for top-flooded case and the present data are compared with the predictions. The figure shows that the dryout heat flux is proportional to the square root of particle diameter as reported in the past study for deep debris beds $\left(\mathrm{H}>\lambda_{\mathrm{c}}, \mathrm{Dp}>1 \mathrm{~mm}\right)$. The present data for top flooded cases are in good agreement with the model predictions.

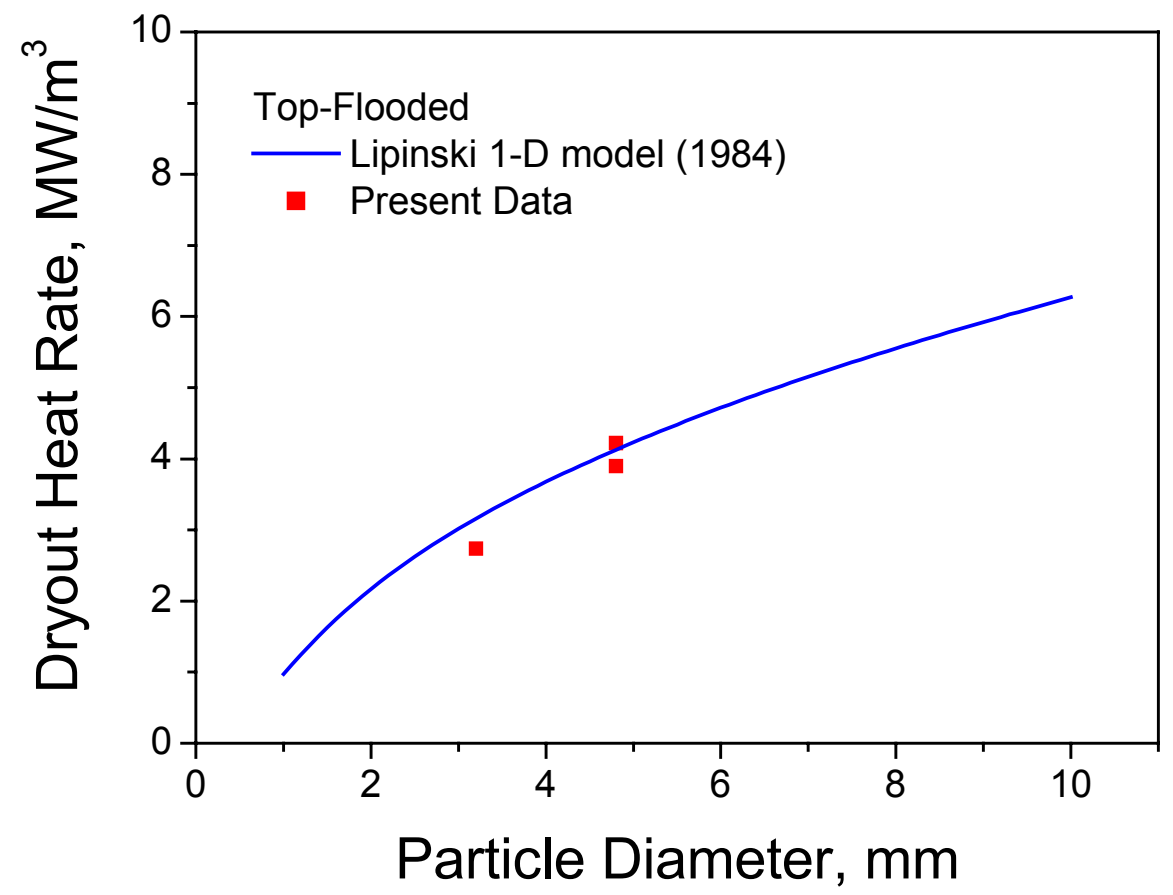

Figure 65: Comparison of present data with prediction of Lipinski 1-D model 


\section{Summary}

Enhancement of dryout heat flux in debris beds with forced coolant flow from below has been experimentally studied. A fairly uniform volumetric heating of particle bed was achieved by induction heating. Dryout heat rate data were obtained for both top-flooding case and forced coolant injection from below with the injection mass flux up to 1.5 $\mathrm{kg} / \mathrm{m}^{2} \mathrm{~s}$. For the top-flooding case, the volumetric dryout heat rate was about $4.0 \mathrm{MW} / \mathrm{m}^{3}$ in $4.8 \mathrm{~mm}$ particle bed and about $2.8 \mathrm{MW} / \mathrm{m}^{3}$ in $3.2 \mathrm{~mm}$ particle bed. At the coolant injection mass flux of $1.5 \mathrm{~kg} / \mathrm{m}^{2} \mathrm{~s}$, the volumetric dryout heat rate was enhanced to about $8.0 \mathrm{MW} / \mathrm{m}^{3}$ in $4.8 \mathrm{~mm}$ particle bed. In $3.2 \mathrm{~mm}$ particle bed, the volumetric dryout heat rate was about $6.3 \mathrm{MW} / \mathrm{m}^{3}$ at the coolant injection mass flux of $1 \mathrm{~kg} / \mathrm{m}^{2} \mathrm{~s}$.

The present experimental data show that for debris beds of $300 \mathrm{~mm}$ in height and $3 \sim 5$ mm uniform particle sizes, ex-vessel coolability can not be assured if the coolant is only added to the top of the bed (top flooding) and that forced coolant flow from below greater than $0.5 \mathrm{~kg} / \mathrm{m}^{2} \mathrm{~s}$ is required to assure ex-vessel debris coolability. 


\section{III.2 High Temperature Film Boiling on Spheres}

\section{III.2.1 Visualization of High Temperature Film Boiling}

Film boiling heat transfer is regarded as the dominant heat transfer mode in high temperature melt (up to $3000 \mathrm{~K}$ ) and coolant interactions and even in the coolable state of the core debris this mode of heat transfer can be sustained until the surface temperature drops below the minimum film boiling temperature, which is typically in the range of $200 \sim 300^{\circ} \mathrm{C}$ depending on the water subcooling. Despite the fact that film boiling data are needed for the wide range of temperature up to $3000 \mathrm{~K}$, most film boiling correlations are based on the data of relatively low temperature $(<1200 \mathrm{~K})$ due to the experimental difficulty of high temperature film boiling. As Figure 66 shows, there is large difference in estimating film boiling heat transfer coefficient using three flow film boiling correlations in terms of sphere velocity and temperature. The difference is more significant as the temperature increases up to $3000 \mathrm{~K}$.
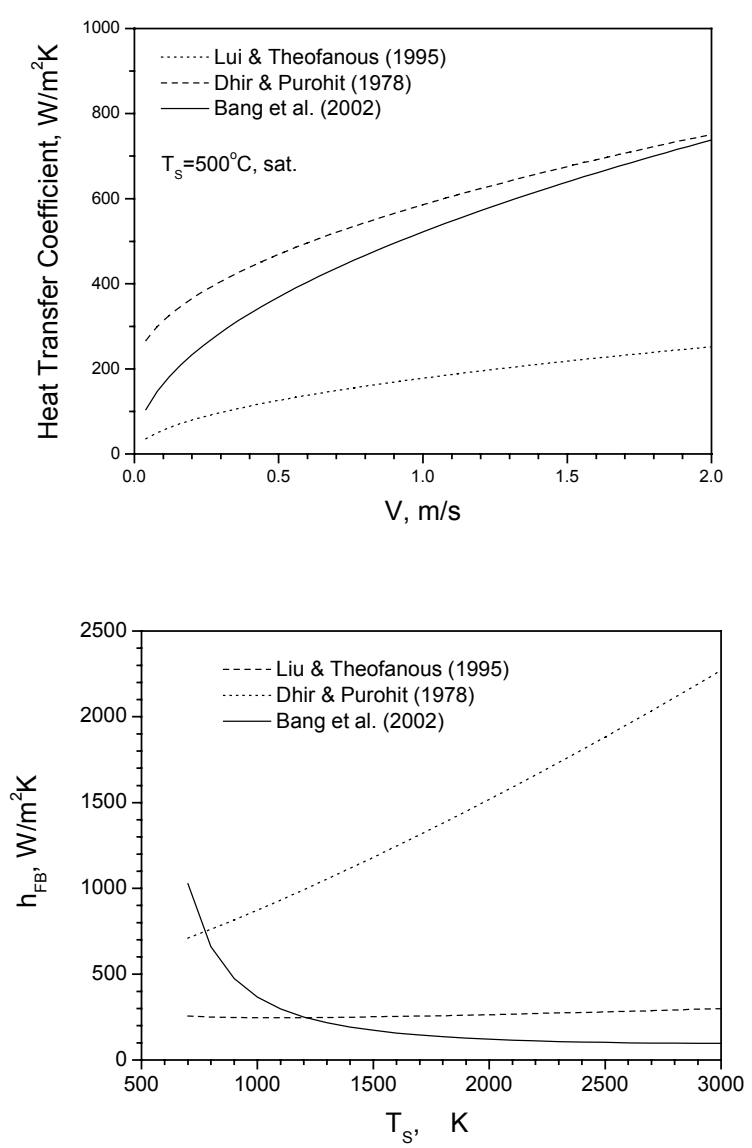

Figure 66: Film boiling correlations in terms of velocity and temperature 
In the present work, visualization of high temperature film boiling has been carried out up to $2000 \mathrm{~K}$, although direct measurement of heat transfer coefficient is not made due to the difficulty of instrumentation for high temperature. A solid sphere heated in a Kanthal furnace up to $2000 \mathrm{~K}$ is dropped into a long transparent tube filled with water. The lower half of $1.6 \mathrm{~m}$-long test tube is made of stainless steel round tube and insulated. The upper half of the test tube is rectangular and made of double-sided glasses for better thermal insulation. An electric heater is installed at the bottom of the test tube so that the water temperature can be raised up to saturation temperature of $100^{\circ} \mathrm{C}$. An alumina $\left(\mathrm{Al}_{2} \mathrm{O}_{3}\right)$ solid sphere is placed on the top of the lower cover piece of the furnace and heated inside the furnace. When it is heated to a desired temperature, the lower cover is lowered and the ball is pushed through a guide and dropped into the water-filled test tube. A CCD camera and video recorder are used to capture the film boiling of the falling sphere in water. Figure 67 shows the experimental apparatus.
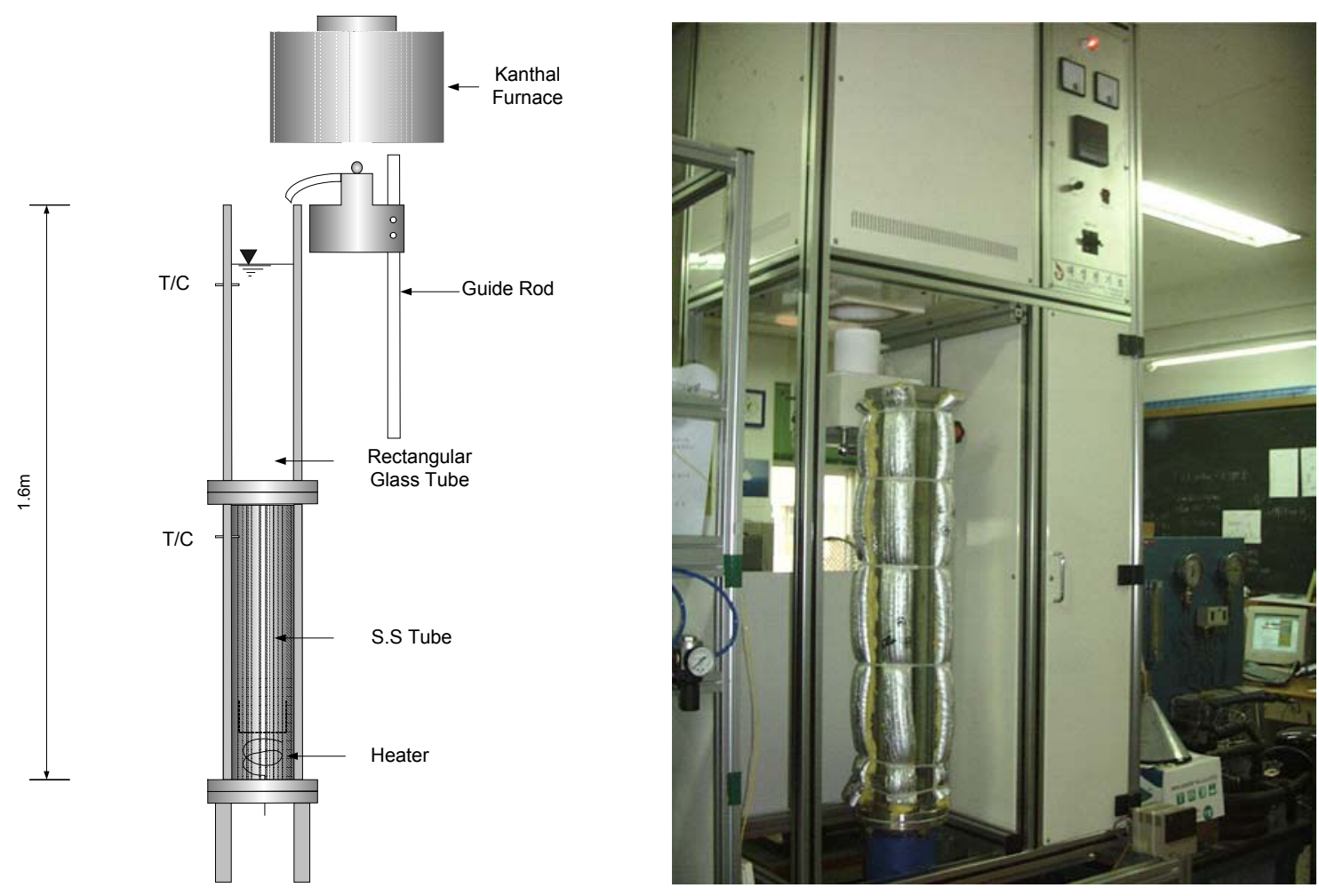

Figure 67: Experimental Apparatus of High Temperature Film Boiling 
In scoping tests, $19 \mathrm{~mm}$-diam. alumina ball was heated and dropped in saturated $\left(100^{\circ} \mathrm{C}\right)$ and also subcooled $\left(80^{\circ} \mathrm{C}\right)$ water. The sphere temperatures were $1500^{\circ} \mathrm{C}, 1000^{\circ} \mathrm{C}$ and $500^{\circ} \mathrm{C}$. The analysis of video images as shown in Figure 68 to Figure 72 shows that the sphere fall speed is $1.8 \pm 0.1 \mathrm{~m} / \mathrm{s}$ in all cases, indicating that it reached its terminal velocity.
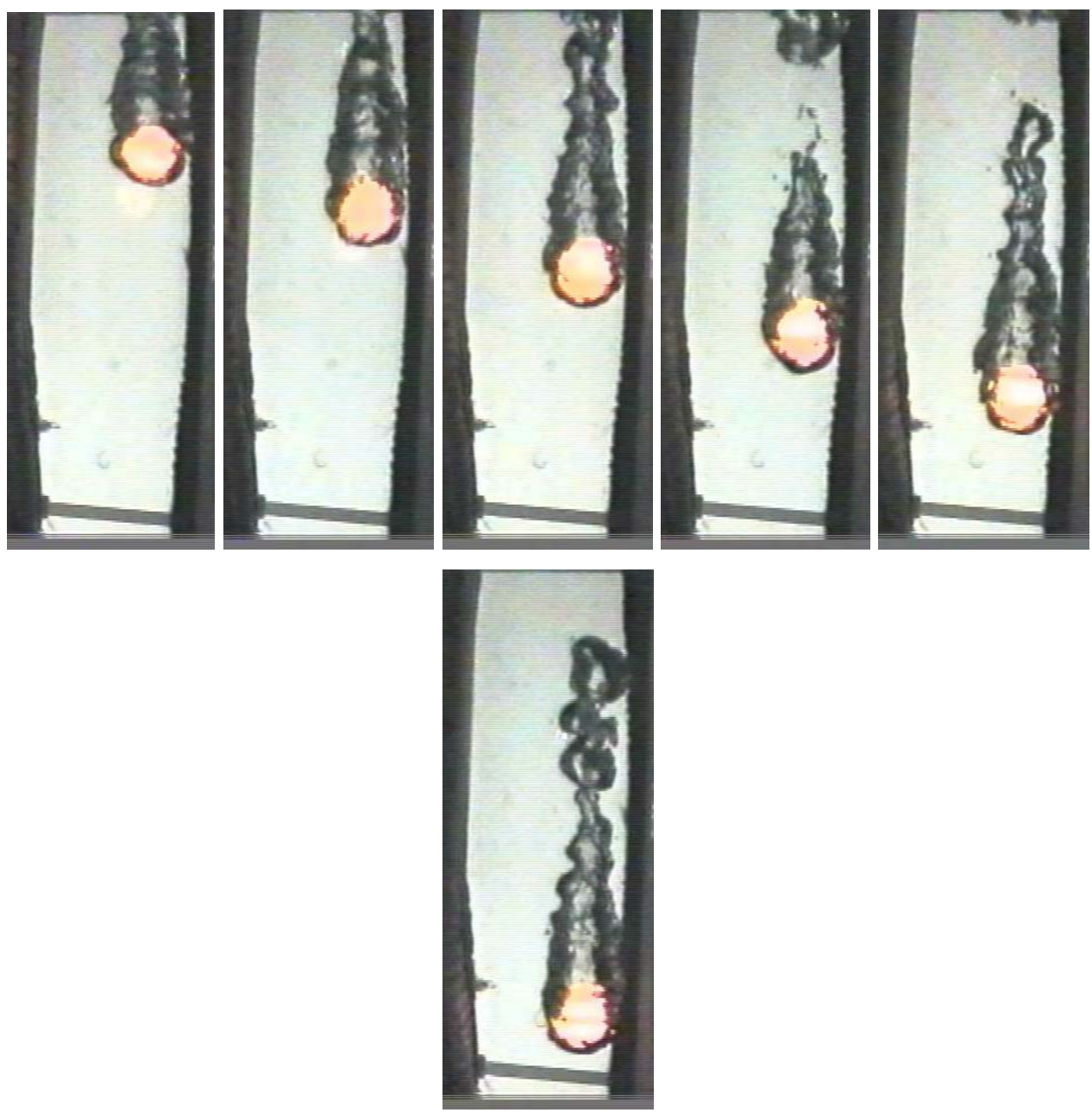

Figure 68: Film boiling $\left(V=1.8 \mathrm{~m} / \mathrm{s}, \mathrm{T}_{\mathrm{S}}=1500^{\circ} \mathrm{C}, \mathrm{T}_{\mathrm{W}}=100^{\circ} \mathrm{C}\right)$ 

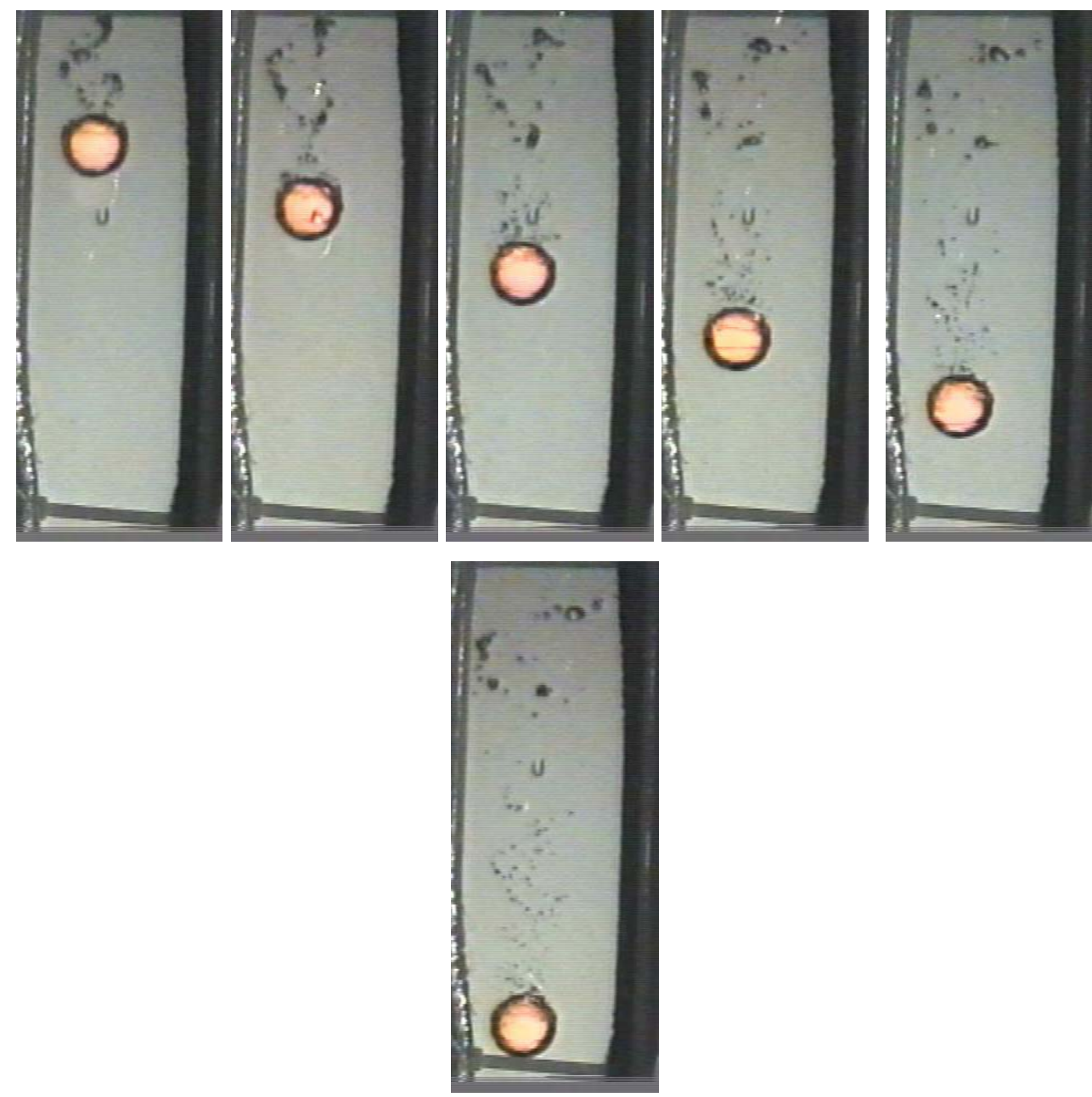

Figure 69: Film boiling $\left(\mathrm{V}=1.8 \mathrm{~m} / \mathrm{s}, \mathrm{T}_{\mathrm{S}}=1500^{\circ} \mathrm{C}, \mathrm{T}_{\mathrm{W}}=80^{\circ} \mathrm{C}\right)$ 

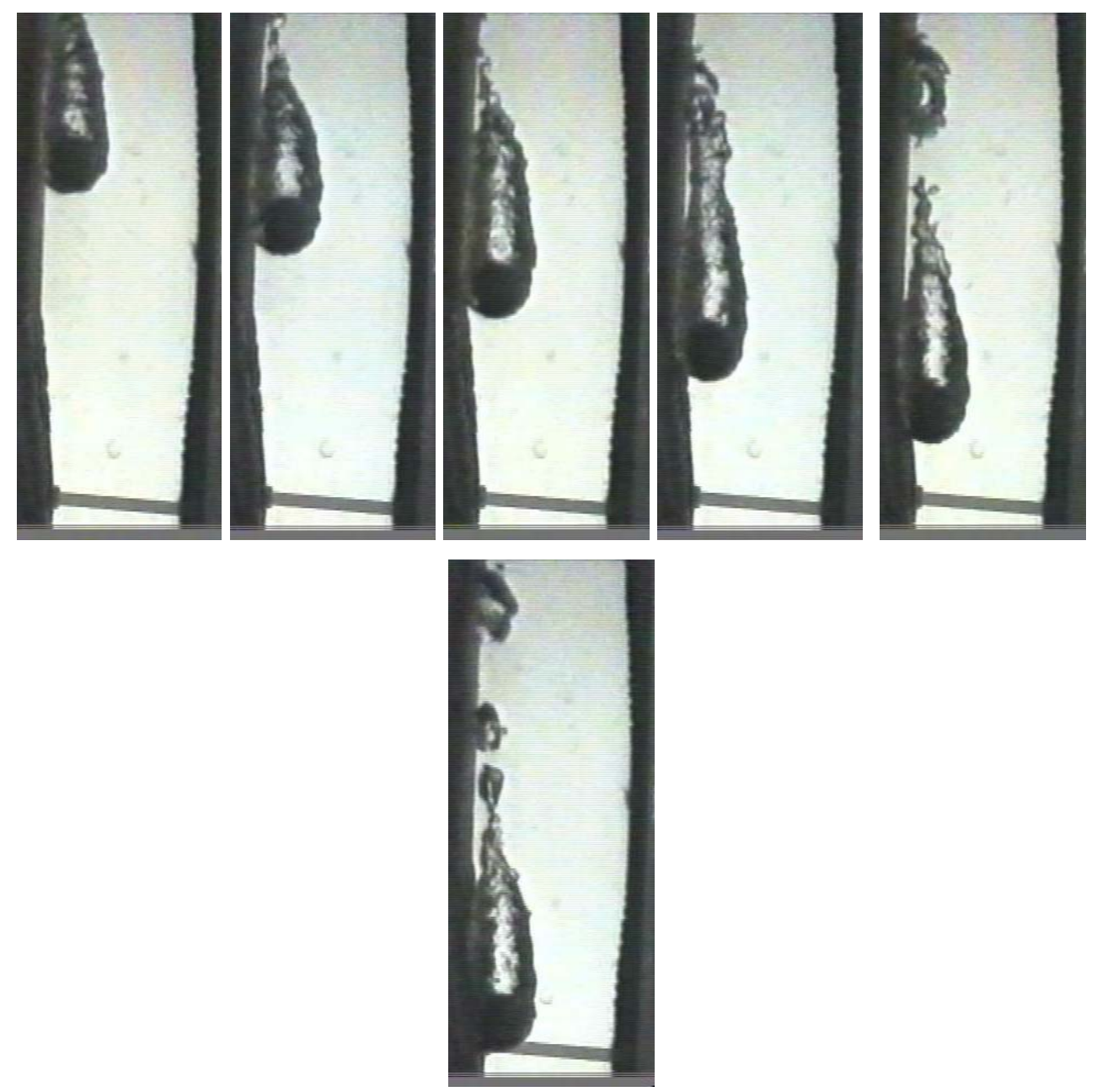

Figure 70: Film boiling $\left(V=1.8 \mathrm{~m} / \mathrm{s}, \mathrm{T}_{\mathrm{S}}=1000^{\circ} \mathrm{C}, \mathrm{T}_{\mathrm{W}}=100^{\circ} \mathrm{C}\right)$ 

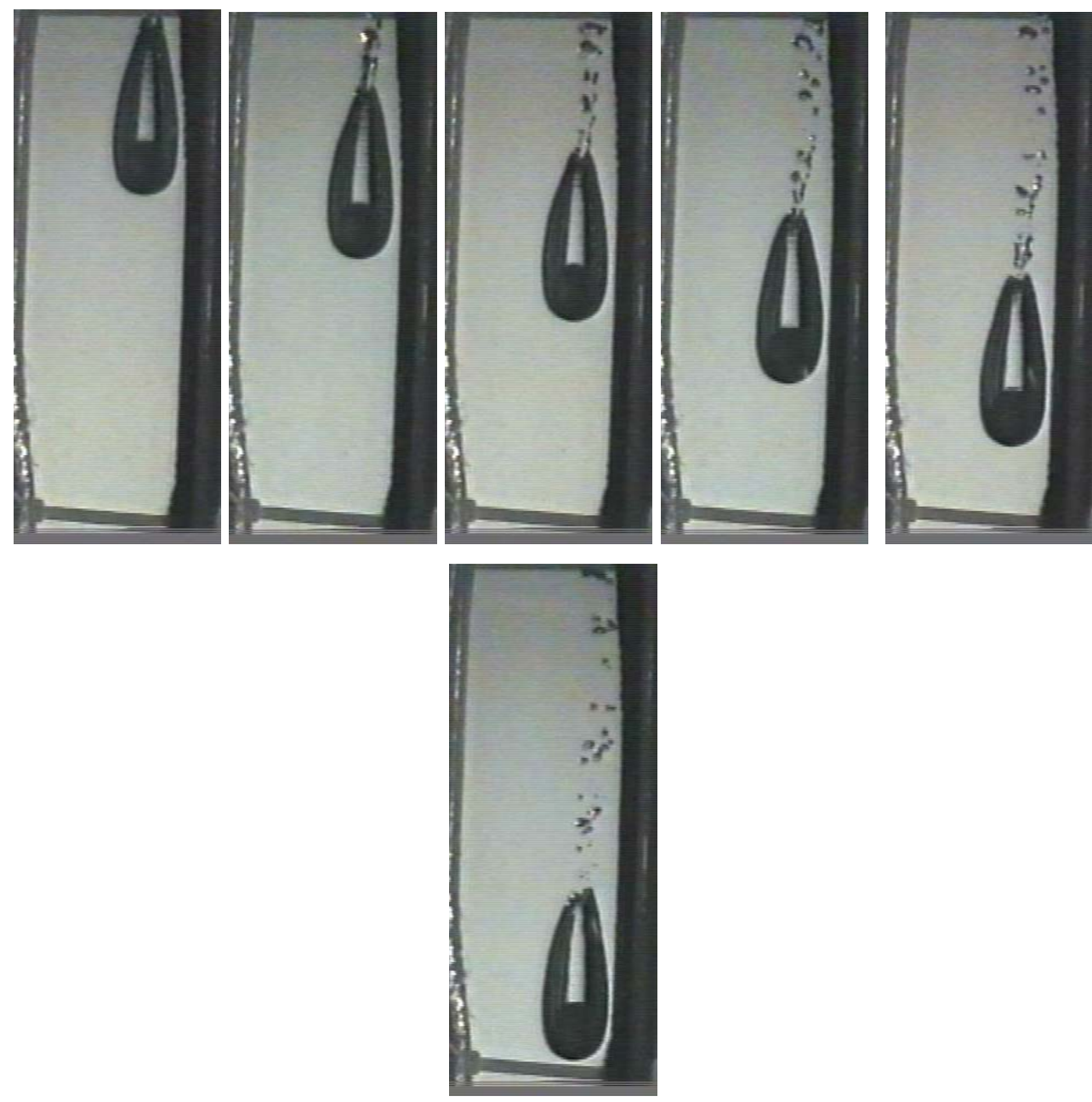

Figure 71: Film boiling $\left(V=1.8 \mathrm{~m} / \mathrm{s}, \mathrm{T}_{\mathrm{S}}=1000^{\circ} \mathrm{C}, \mathrm{T}_{\mathrm{W}}=80^{\circ} \mathrm{C}\right)$ 

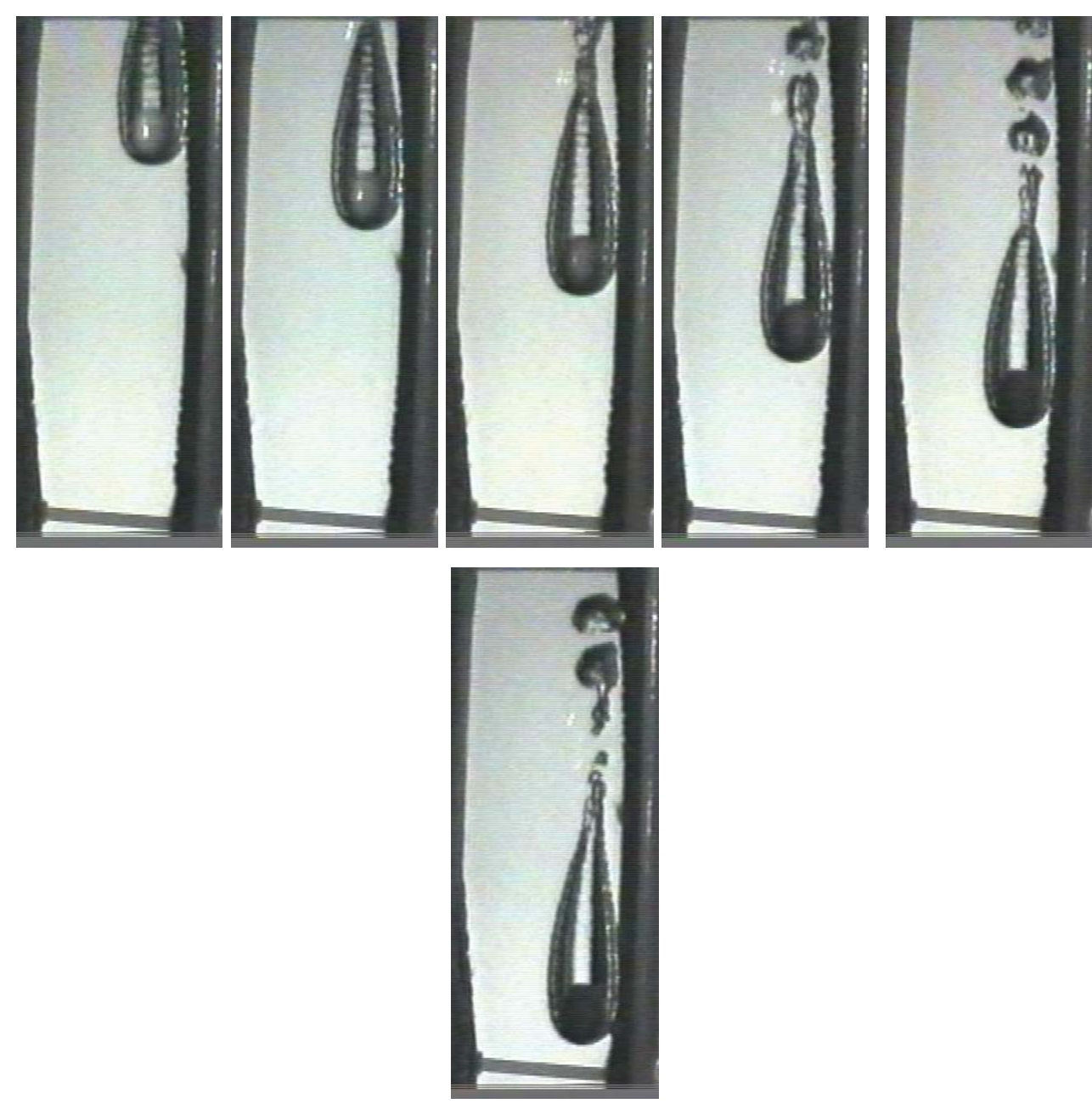

Figure 72: Film boiling $\left(\mathrm{V}=1.8 \mathrm{~m} / \mathrm{s}, \mathrm{T}_{\mathrm{S}}=500^{\circ} \mathrm{C}, \mathrm{T}_{\mathrm{W}}=100^{\circ} \mathrm{C}\right)$

Several notes are made from these visualization of film boiling. The long vapor dome behind the moving sphere is a typical picture of film boiling. The wavy interface of vapor film is also observed in high temperature sphere with saturated water and the level of waviness is an indication of vapor generation rate. However, it is a unique observation that the vapor dome is not observed in the case of $1500^{\circ} \mathrm{C}$ sphere and $80^{\circ} \mathrm{C}$ water, while the case of $1000^{\circ} \mathrm{C}$ sphere and $80^{\circ} \mathrm{C}$ water has vapor dome. More systematic observation will be made to identify the subcooling effect of high temperature film boiling. Figure 73 shows comparisons for the effects of sphere superheat and water subcooling. 


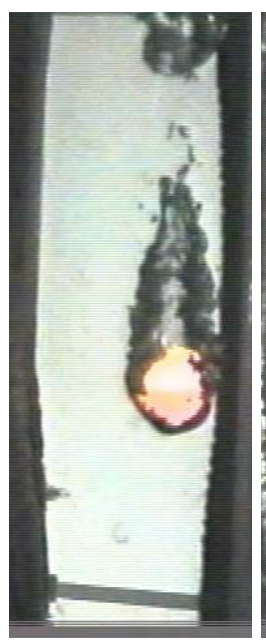

$\mathrm{T}_{\mathrm{W}}=100^{\circ} \mathrm{C}$

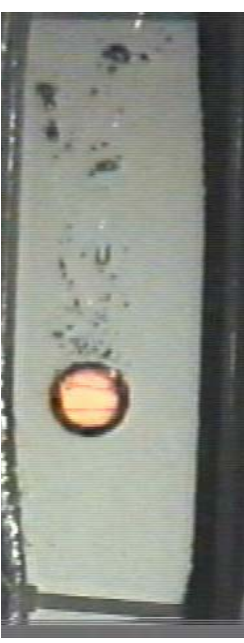

$80^{\circ} \mathrm{C}$

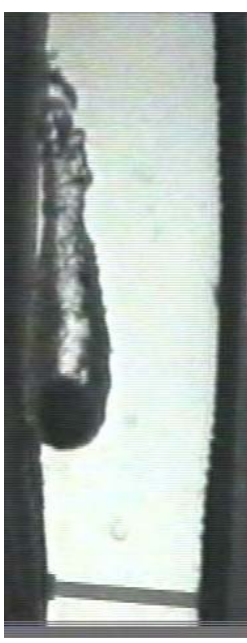

$\mathrm{T}_{\mathrm{W}}=100^{\circ} \mathrm{C}$

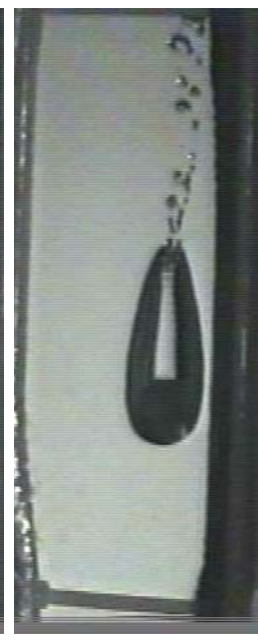

$80^{\circ} \mathrm{C}$

$$
\mathrm{T}_{\mathrm{S}}=1500^{\circ} \mathrm{C}
$$

$$
\mathrm{T}_{\mathrm{S}}=1000^{\circ} \mathrm{C}
$$

\section{Figure 73: Comparisons for the effects of sphere superheat and water subcooling}

\section{III.2.2 Forced Convection Saturated Film Boiling}

One useful information obtained from the visualization was the falling speed of the spheres under film boiling. The viewing area of the photography was about $0.55 \mathrm{~m}$ below the water surface and at this location the spheres were observed to reach its terminal velocity, i.e., constant speed. The measured sphere velocities are shown in Figure 74. For spheres reaching its terminal velocity, the body force is counter-balanced with the drag force so the drag coefficient can be calculated from the following relation.

$$
g\left(\rho_{b}-\rho_{w}\right)\left(\frac{\pi d^{3}}{6}\right)=\frac{1}{2} C_{D} \rho_{w} U^{2}\left(\frac{\pi d^{2}}{4}\right)
$$

Using the density of alumina ball, $\rho_{b}=3970 \mathrm{~kg} / \mathrm{m}^{3}$, the drag coefficients were calculated from the measured sphere velocity and shown in Figure 74. Comparing with the known drag coefficients of sphere under no boiling condition (White, 1974), the drag coefficients of spheres under film boiling appear, in general, to be close to the case of no boiling. Given the uncertainty of the measurement, however, it is noted that for $19 \mathrm{~mm}$ diameter sphere the drag coefficient appears to increase as the sphere temperature increases and it is larger than the non-boiling case. For $12.7 \mathrm{~mm}$-diameter sphere, drag coefficients smaller than the non-boiling case are observed when the sphere temperature is lower than $1300 \mathrm{~K}$. 

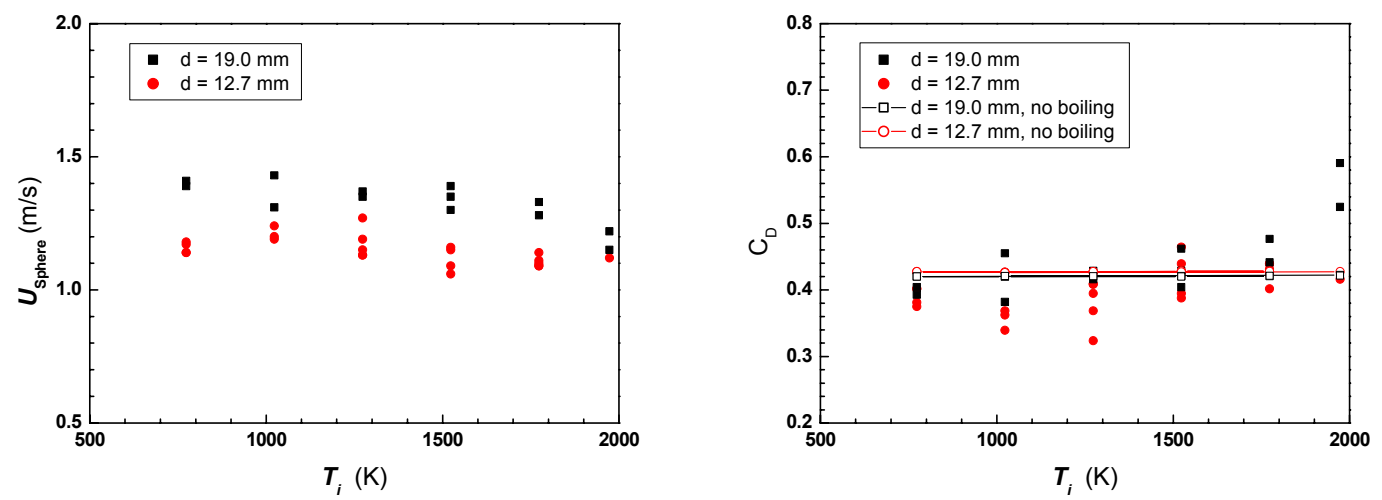

Figure 74: Fall Velocity of Spheres in Saturated and Drag Coefficient for Spheres

The high temperature and the ceramic material of test spheres make it difficult to instrument the sphere to measure temperature trace for the heat transfer coefficient. For saturated film boiling, however, the heat transfer from the film interface to bulk liquid is negligible so that the heat transferred from the sphere is all used in producing steam vapor in the film and the vapor is released in the wake region as seen in the visualization. Therefore, the estimation of heat transfer coefficient for saturated film boiling was attempted by measuring the released steam bubble volume and release period in the visual images. By measuring the volume of the released bubbles and the release period, the saturated flow film boiling heat transfer coefficient can be calculated using the following relations.

$$
\begin{aligned}
& Q=\frac{1}{\tau} \rho_{v} V_{b}\left[h_{f g}+0.5 c_{p v}\left(T_{s}-T_{w}\right)\right] \\
& h=\frac{Q}{\pi d^{2}\left(T_{s}-T_{w}\right)}
\end{aligned}
$$

Here, $V_{b}$ is the released bubble volume, $\tau$ is the bubble release period, $h$ is heat transfer coefficient. The typical pictures of the bubbles and release period are shown in Figure 75. 


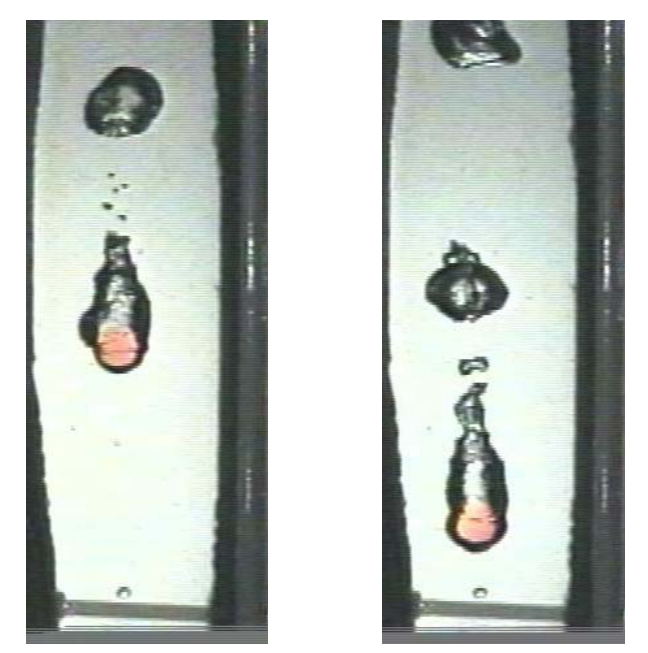

Figure 75: Illustration of bubble volume and release period

From each recorded video image, the released bubble diameter and the release period were measured. The released bubble diameters are shown in Figure 76. The bubble size shows an increasing tendency as the sphere temperature increases. However, for $19 \mathrm{~mm}$ diameter sphere, the variation of bubble size for the same sphere temperature is large compared to the $12.7 \mathrm{~mm}$-diameter sphere. The bubble release period was 50 millisecond for all tests of $12.7 \mathrm{~mm}$-diameter sphere, but for $19 \mathrm{~mm}$-diameter spheres it varied in the range of 34 66 millisecond.

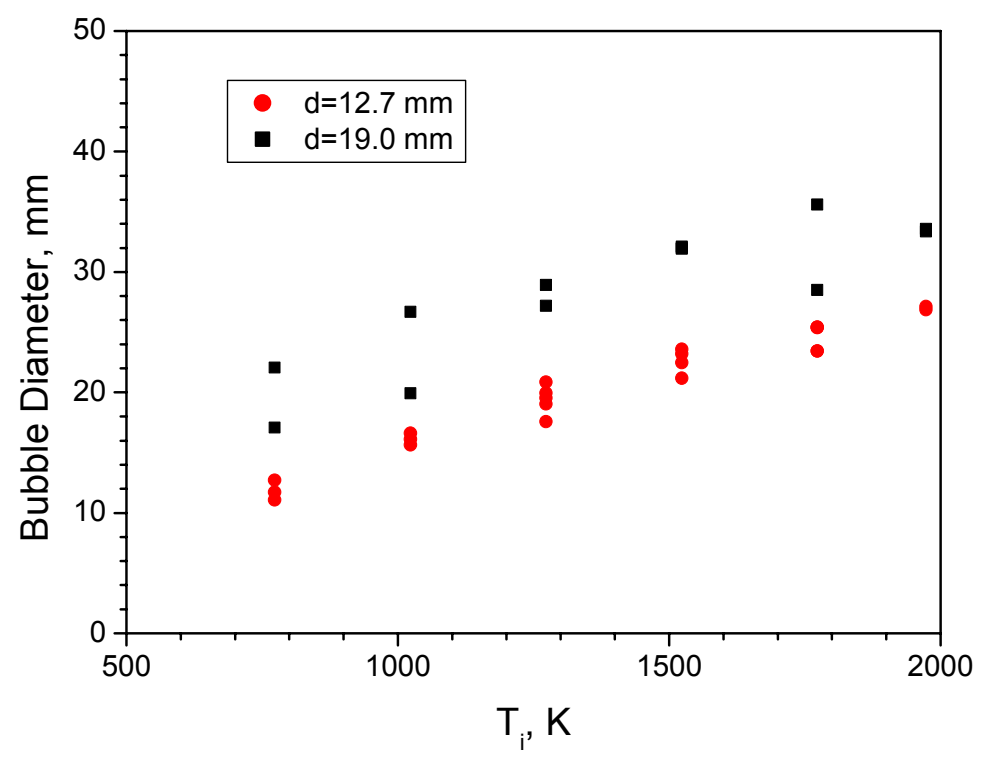

Figure 76: Released bubble diameter v.s. sphere temperature 


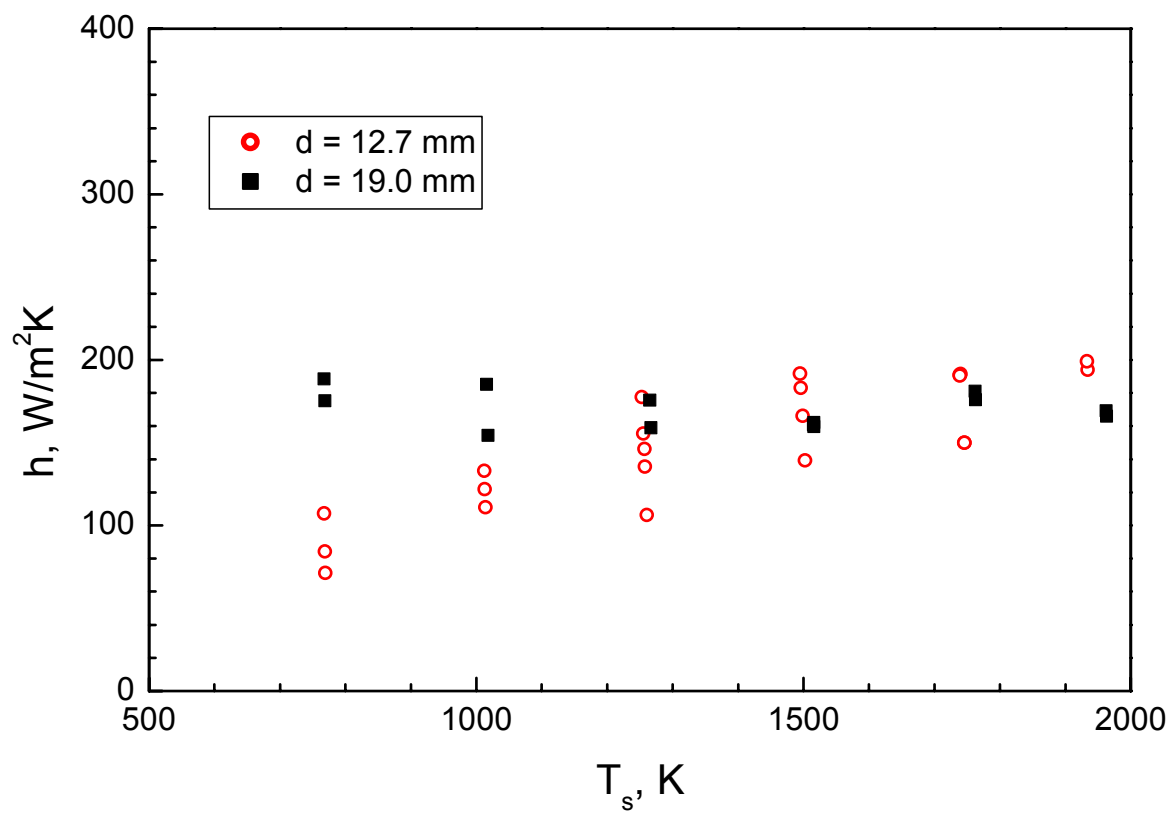

Figure 77: Saturated flow film boiling heat transfer coefficients

In order to complete the calculation of the heat transfer coefficient using Eqs. (19) and (20), the actual surface temperature of the sphere is required. Since direct measurement of the surface temperature was difficult, an approximate value was obtained by inversely solving the transient conduction equation for sphere with the assumptions of (1) onedimensional, and (2) constant heat transfer coefficient (Mills, 1992).

$$
\frac{1}{\alpha} \frac{\partial T}{\partial t}=\frac{1}{r^{2}} \frac{\partial}{\partial r}\left(r^{2} \frac{\partial T}{\partial r}\right)
$$

Given the measured bubble volume and release period, Eqs. (19), (20), and (21) are iteratively solved, beginning with $\mathrm{T}_{\mathrm{s}}=\mathrm{T}_{\mathrm{i}}$, until the heat transfer coefficient converges. As for the material properties, superheated steam properties at film temperature $\left(\mathrm{T}_{\mathrm{f}}=0.5\left(\mathrm{~T}_{\mathrm{s}}+\mathrm{T}_{\mathrm{w}}\right)\right)$ were used for Eq. (19) under the assumption that the heat loss from the vapor dome to the liquid water during the bubble release period is negligible due to the short release period of about 50 millisecond. 
The measured heat transfer coefficients are shown in Figure 77 for the two sphere diameters. It ranges $70 \sim 200 \mathrm{~W} / \mathrm{m}^{2} \mathrm{~K}$ for the sphere surface temperature $750 \sim 1950 \mathrm{~K}$ and it increases slightly as the sphere temperature increases. It is noted, however, that the slopes of the heat transfer coefficients versus sphere temperature are different for the two sphere diameters. At lower sphere temperature, $12.7 \mathrm{~mm}$-diameter sphere shows lower heat transfer coefficient than $19 \mathrm{~mm}$-diameter sphere. Noting that the existing correlations are expressed as $N u_{d} \sim R e_{d}^{0.5}$, the heat transfer coefficient can be proportional to $\sim 1 / d^{0.5}$, i.e., larger diameter sphere has lower heat transfer coefficient. The present data shows opposite trend in the sphere temperatures lower than $\sim 1300 \mathrm{~K}$, implying that the data for $19 \mathrm{~mm}$-diameter sphere at lower temperature might have large measurement error.

Figure 78 and 79 show the comparisons with three existing correlations separately for the two sphere diameters. The correlation of Dhir and Purohit overestimates the data significantly and the correlation of Bang et al. shows an opposite trend in terms of sphere temperature. Liu and Theofanous' correlation shows the best estimation among the three correlations, although it overestimates the data by up to $100 \%$.

The data are also compared with the predictions of boundary layer analysis of flow film boiling proposed by Bang (1994). In this model, boundary layer equations for momentum and energy are solved separately for vapor film and liquid flow, including radiation contribution to the vapor generation at the vapor-liquid interface. In the present analysis, it is assumed that $15 \%$ of black body radiation is contributed to vapor generation. The results are plotted with the data in Figure 80. As seen in this figure, the predictions are in good agreement with the data except the points of $19 \mathrm{~mm}$-diameter sphere at lower temperatures. 


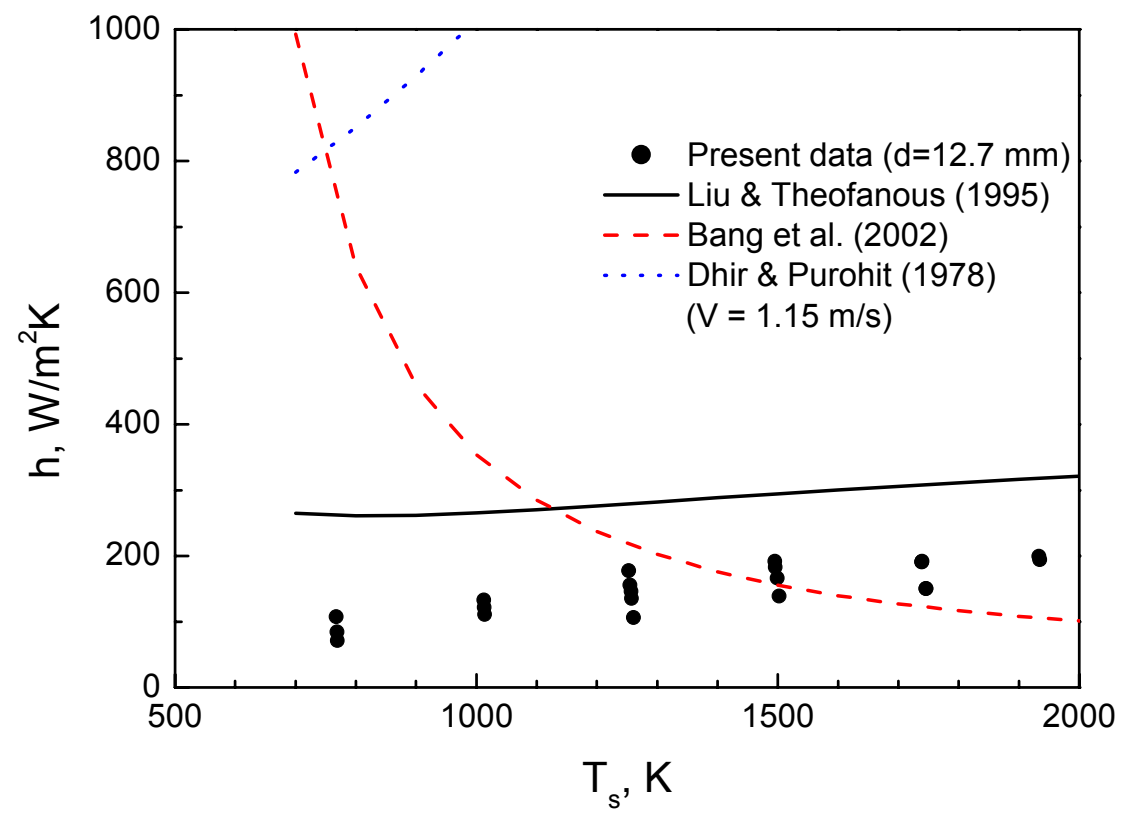

Figure 78: Saturated flow film boiling heat transfer coefficients $(d=12.7 \mathrm{~mm})$

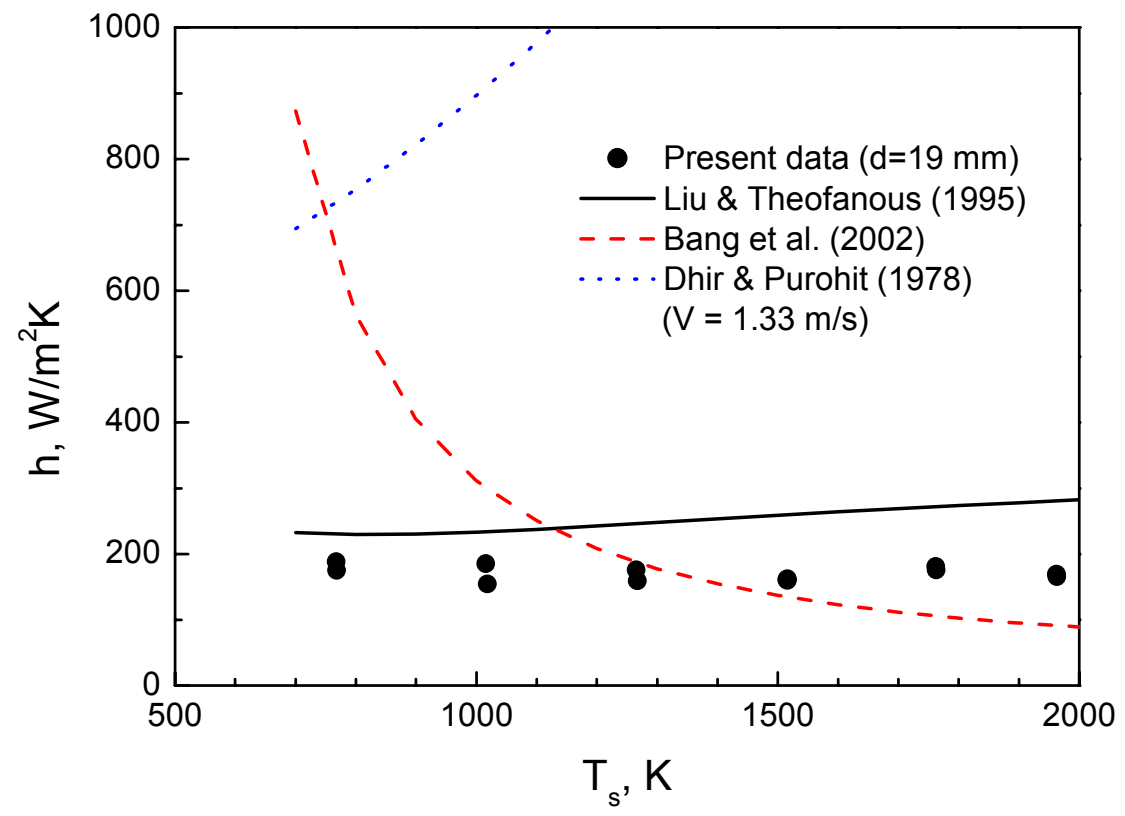

Figure 79: Comparisons of saturated flow film boiling heat transfer coefficients $(\mathrm{d}=19 \mathrm{~mm})$ 


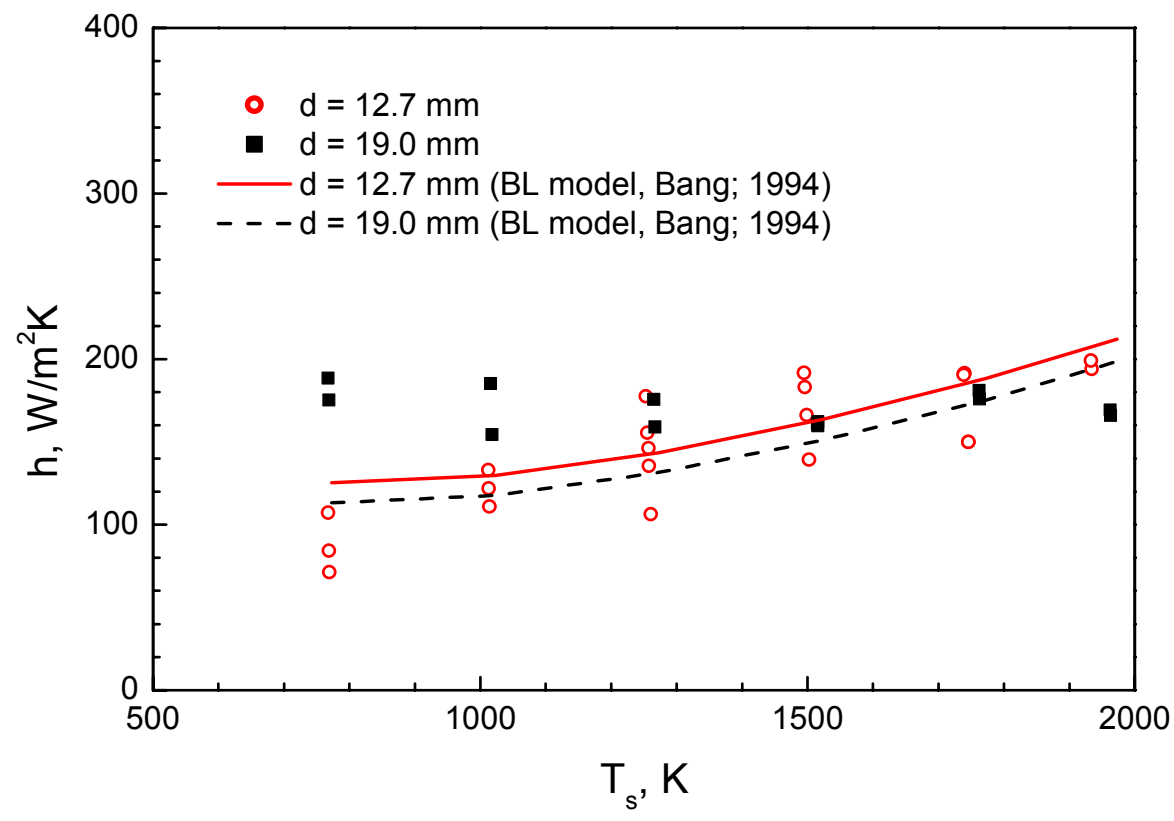

Figure 80. Comparisons with predictions of boundary layer analysis of film boiling

The correlation of saturated flow film boiling heat transfer coefficient has been proposed in the general form given as

$$
\begin{aligned}
& N u_{s}=\frac{h d}{k_{v}}=C_{O} \operatorname{Re}^{0.5} \frac{\mu_{l}}{\mu_{v}}\left(\frac{K R^{4}}{S_{p}}\right)^{1 / 4} \\
& \operatorname{Re}=\frac{\rho_{l} U d}{\mu_{l}}, K=\frac{\rho_{l}}{\rho_{v}}, R=\sqrt{\frac{(\mu \rho)_{v}}{(\mu \rho)_{l}}}, S_{p}=\frac{c_{p v}\left(T_{s}-T_{w}\right)}{h_{f g}^{\prime} \operatorname{Pr}_{v}}
\end{aligned}
$$

When the constant $\mathrm{C}_{\mathrm{o}}$ in this equation is obtained using the present data for $12 \mathrm{~mm}$ diameter sphere, 

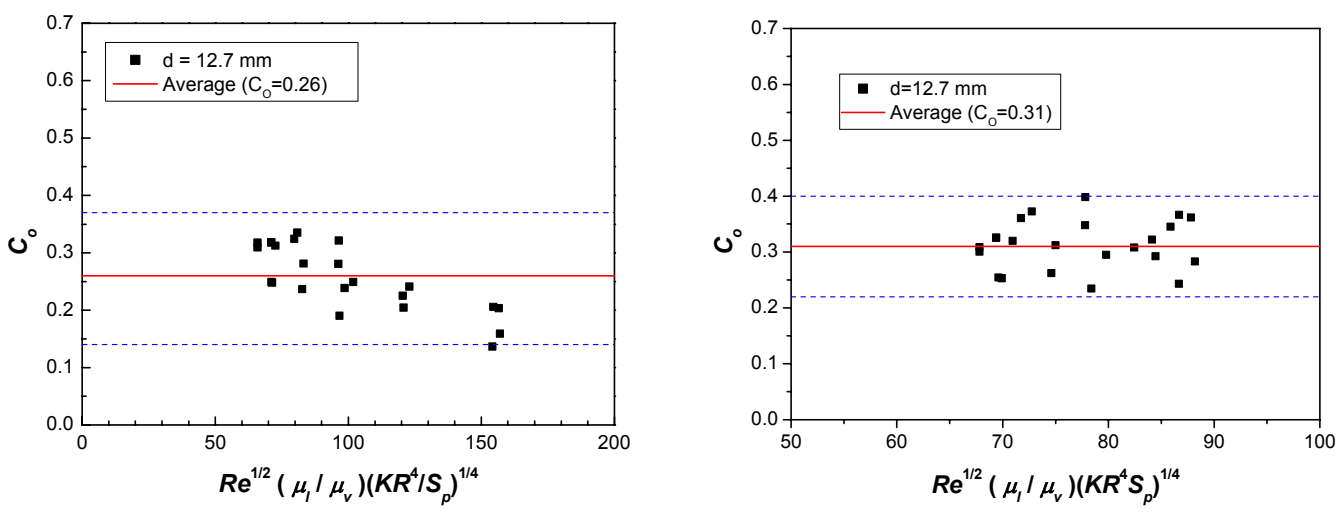

Figure 81: Effect of wall superheat $\left(S_{p}\right)$ in correlation constant

the dependency on wall superheat parameter $S_{p}$ exists as shown in Figure 81. The data fitting analysis to find the best-fit exponent for the parameter $S_{p}$ showed that the present data are better fitted with $\mathrm{Nu} \sim \mathrm{S}_{\mathrm{p}}{ }^{1 / 4}$ than $\mathrm{Nu} \sim \mathrm{S}_{\mathrm{p}}{ }^{-1 / 4}$, as shown in Figure 82. Based on this data analysis, a new correlation for saturated flow film boiling heat transfer coefficient for sphere is proposed as

$$
N u_{s}=0.31 \operatorname{Re}^{0.5} \frac{\mu_{l}}{\mu_{v}}\left(K R^{4} S_{p}\right)^{1 / 4}
$$

and the prediction of the proposed correlation is compared with the data in Figure 82 . 


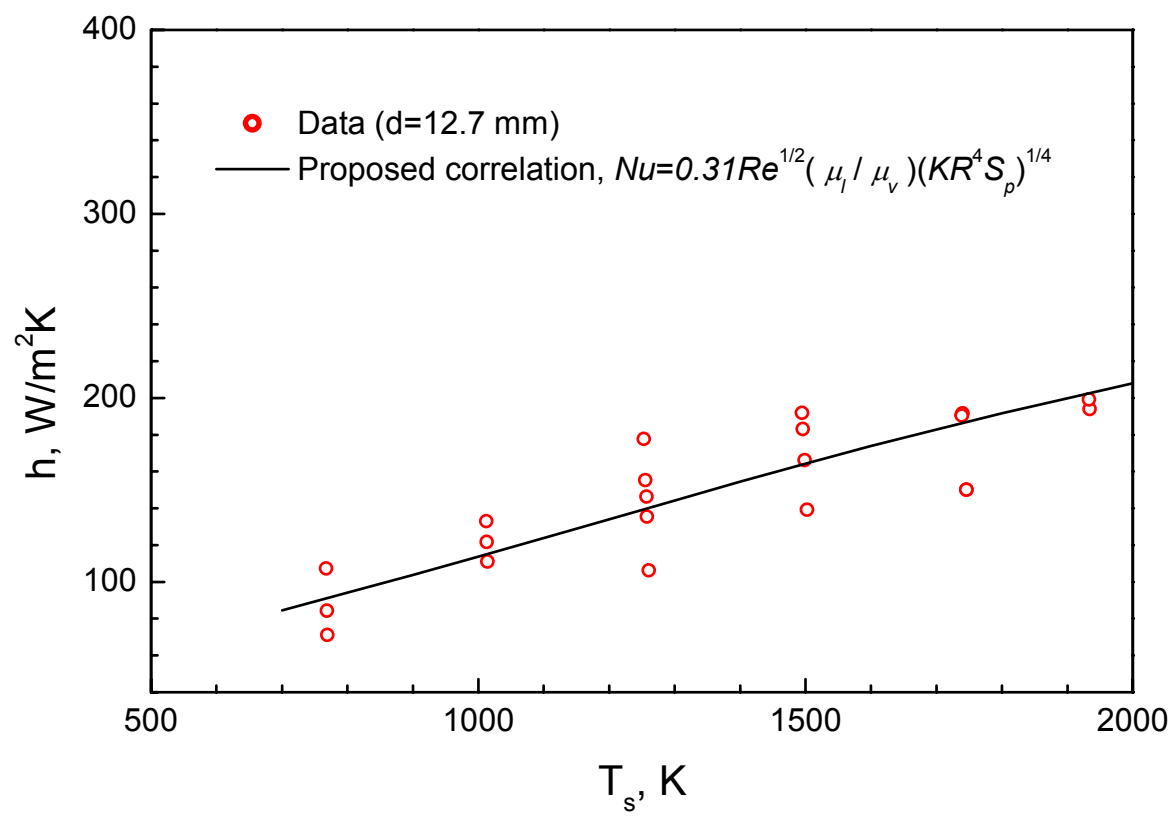

Figure 82. Proposed correlation for saturated flow film boiling heat transfer coefficient

\section{Summary}

High temperature film boiling experiment has been carried out up to $2000 \mathrm{~K}$ of sphere temperature. Direct measurement of heat transfer coefficient is not possible due to the difficulty of instrumentation for high temperature, but the estimation of heat transfer coefficient for saturated film boiling can be made by estimating the steam bubble volume and release period in the visual images. The experimental parameters are: sphere diameters of $19 \mathrm{~mm}$ and $12.7 \mathrm{~mm}$, water temperature of $50 \sim 100^{\circ} \mathrm{C}$, sphere temperature of $500 \sim 1700^{\circ} \mathrm{C}$. The saturated flow film boiling heat transfer coefficient ranges 70 200 $\mathrm{W} / \mathrm{m}^{2} \mathrm{~K}$ for the sphere temperature $750 \sim 1950 \mathrm{~K}$ and it increases slightly as the sphere temperature increases. The existing heat transfer correlations for saturated flow film boiling overestimate the present data. A new correlation has been proposed and this correlation can be extended to the temperature range beyond $2000 \mathrm{~K}$. 


\section{III.3 Simultaneous Measurement of Temperature and Velocity Fields}

\section{III.3.1. Background}

Visualization of the thermal field in a fluid may be as important as visualization of the velocity field for those working in mechanical, civil, aerospace, chemical, and many other engineering and scientific fields related to fluid mechanics and heat transfer. Knowledge of the temperature distribution in a flow field is very useful for understanding not only the convective heat transfer mechanism but also the structure of the flow field itself. If information about the local wall temperature distribution is available, along with the local wall heat flux, the local heat transfer coefficient can be calculated, and the local friction factor is estimated based upon the analogy between momentum and heat transfer.

Various temperature-measuring devices, such as mercury thermometers, thermocouples, resistance thermometers, and infrared thermometers, have already been developed and applied in a variety of situations. However, the data obtained by these measurement methods do not provide simultaneous information on temperature and velocity fields of a thermal flow, which is inevitable to quantify the turbulent heat flux. Recently, a new technique utilizing a thermo-sensitive liquid crystal has been developed for measuring the temperature field. The liquid crystal technique has been accepted as a legitimate temperature-measuring method in fluid mechanics and heat transfer.

Klein (1968) was the first to report the use of liquid crystals for flow visualization in wind-tunnel experiments. He applied an unencapsulated liquid crystal to his test model, and qualitatively studied the steady-state boundary-layer temperature distributions of the model. Lemberg (1971) used the same technique to visualize the unsteady boundary-layer on a model surface. Since the color play of the liquid crystal is sensitive to shear stress, the above techniques did not allow for accurate qualitative or quantitative temperature measurements. However, McEldery (1970) solved this problem by using encapsulated liquid crystals in an experimental technique similar to Klein's technique. Orden and Hendricks (1984) further advanced this technique for surface analysis in water tunnels by using liquid crystals covered with a layer of acrylic polymer and polyuretane coating. This not only shielded the crystals from shear stresses but also prevented chemical 
contamination of the crystals by the water. Rhee et al. $(1984,1986)$ expanded the use of encapsulated liquid crystals to study temperature fields in flow structures rather than on model surface. By mixing the encapsulated liquid crystals within the flow and illuminating a two-dimensional cross-section of the flow with a white sheet of light, Dabiri and Gharib (1991) were able to study heated vortex-ring. Color photographs showed pathlines, flow structures, and temperature distributions which otherwise would not have been deducible. Efforts have been made to quantify the temperature field through the use of liquid crystals. Cooper et al. (1975) used encapsulated liquid crystals to measure the variation of the Nusselt number on a circular cylinder placed in a crossflow of air.

Temperature visualization was made quantitatively by calibrating the color of the liquid crystal versus temperature using various approaches (TLC technique: Thermochromic Liquid Crystal Technique). Wilcox, et al. (1985) proposed a color photography technique, and Akino, et al. $(1986,1988)$ performed calibration of the wavelength of the color against temperature using a monochrome CCD camera and interference filters. Instead of calibrating temperature against location in R, G, B color space, Dabiri and Gharib (1991) proposed the use of $\mathrm{H}, \mathrm{S}, \mathrm{I}$ color space with hue as the single calibration variable. Thus, they showed that a usable relationship could be established between the hue and the temperature. The Hue-value calibration has been successfully adopted to the studies of thermal phenomena by Ozawa, et al. (1992), Nozaki, et al. (1995). In a rather different approach, Kobayashi, et al. (1995) extended the TLC technique to the PIV (Particle Image Velocimetry) for a quantitative simultaneous temperature and velocity measurement. In the study, two tracers were used for simultaneous probing of temperature and velocity fields. The encapsulated liquid crystals were used as temperature tracer and the nylon particles were used as velocity tracer. In TLC technique, a color-to-temperature calibration is necessary to obtain the temperature distribution. However, it is not so easy to obtain the exact calibration because the characteristic curve of temperature and color shows very strong non-linearity. Kimura et. al. (1993) and Doh et. al. (1994) adopted a neural network to solve this problem. The neuron number of the hidden layer of their neural network was only three. 
In this study, a neural network having more than 50 was used to enhance the accuracy of the temperature probing. Further, the gray level cross-correlation method (Utami, 1991) was used for velocity field measurements. For the last goal of measuring the quantities of the radiation from a heated ball at high temperature, the neural network and the crosscorrelation algorithms were tested on a horizontal thermal jet.

\section{III.3.2 Enhancements of Measurement Accuracy}

The color images of TCLC usually contain noises due to signal jittering or nonuniformity of the incident light. This noise enhanced the uncertainty of the true color that corresponded to the temperature of TCLC temperature. A median filter was introduced to overcome this problem. Introducing the median filter onto the contaminated images, Thompson's Tau Method (ANSI/ASME,1983) was introduced to get higher purity of color at the corresponded temperature. It is the equation of Thompson's Tau from Eqn 24 to Eqn 26. In this method, if $\left(\delta \geq \tau \cdot S^{*}\right)$, then $x_{j}$ is eliminated. If $\left(\delta \tau<\tau \cdot S^{*}\right)$, then $x_{j}$ is not eliminated during the process of the median filtering. Here, $x_{j}$ is the intensity of the colors of the pixels. Other letters represent as the below equations, such as the mean intensity and the standard deviation of the intensity. Figure 83 shows a median filter and the equation. Using this median filter, the relative error was reduced to less than $5 \%$. Figure 84 shows the experimental apparatus for error validations of the temperature measurements. For temperature measurements, liquid crystal slurry was put into the Polycarbonated square water vessel $(60 \mathrm{~mm} * 60 \mathrm{~mm} * 350 \mathrm{~mm})$. The water temperature in the vessel was maintained about $86^{\circ} \mathrm{C}$. A cartridge heater was installed at $20 \mathrm{~mm}$ height from the tip of the heater and the heat was controlled by a voltage controller (slidacs). The measurement area was set near the boundary of the surface of the cartridge heater. Calibration of color-to-temperature (Doh et al., 1994) for the liquid crystal in the water was carried our by changing the temperature in stepwise. A neural network shown in Figure 85 was used for color-to-temperature calibration. The color image obtained by a 3plate-CCD color camera (512 x 512 pixel) was converted into digital image information, R (red), G (green) and B (blue) thorough an image grabber (512 x 512 pixel) installed on the host computer. These color information were used as the input for the neural network 
with the Hue (H) value expressed in Eqn 27. Figure 86 (a) and (b) show color-totemperature calibration curves for the cases obtained by using the median filter and not using, respectively.

$$
\begin{aligned}
& \bar{x}=\sum_{i=1}^{N} \frac{x_{i}}{N} \\
& S^{*}=\sqrt{\sum_{i=1}^{N} \frac{\left(x_{i}-\bar{x}\right)^{2}}{N}} \\
& \delta=\left|x_{j}-\bar{x}\right| \\
& H=\cos ^{-1}\left\{\frac{1 / 2[(R-G)+(R-B)]}{[(R-G) 2+(R-B)(G-B)]^{1 / 2}}\right\}, \quad \text { at } \quad B \leq G \\
& H=2 \pi-\cos ^{-1}\left\{\frac{1 / 2[(R-G)+(R-B)]}{\left[(R-G)^{2}+(R-B)(G-B)\right]^{1 / 2}}\right\}, \quad \text { at } \quad B>G
\end{aligned}
$$

\begin{tabular}{|l|l|l|}
\hline$f 1$ & $f 2$ & $f 3$ \\
\hline$f 4$ & $f 5$ & $f 6$ \\
\hline$f 7$ & $f 8$ & $f 9$ \\
\hline
\end{tabular}

$$
x 5=\frac{x 1+x 2+x 3+x 4+x 5+x 6+x 7+x 8+x 9}{9}
$$

Figure 83: Median filter. 


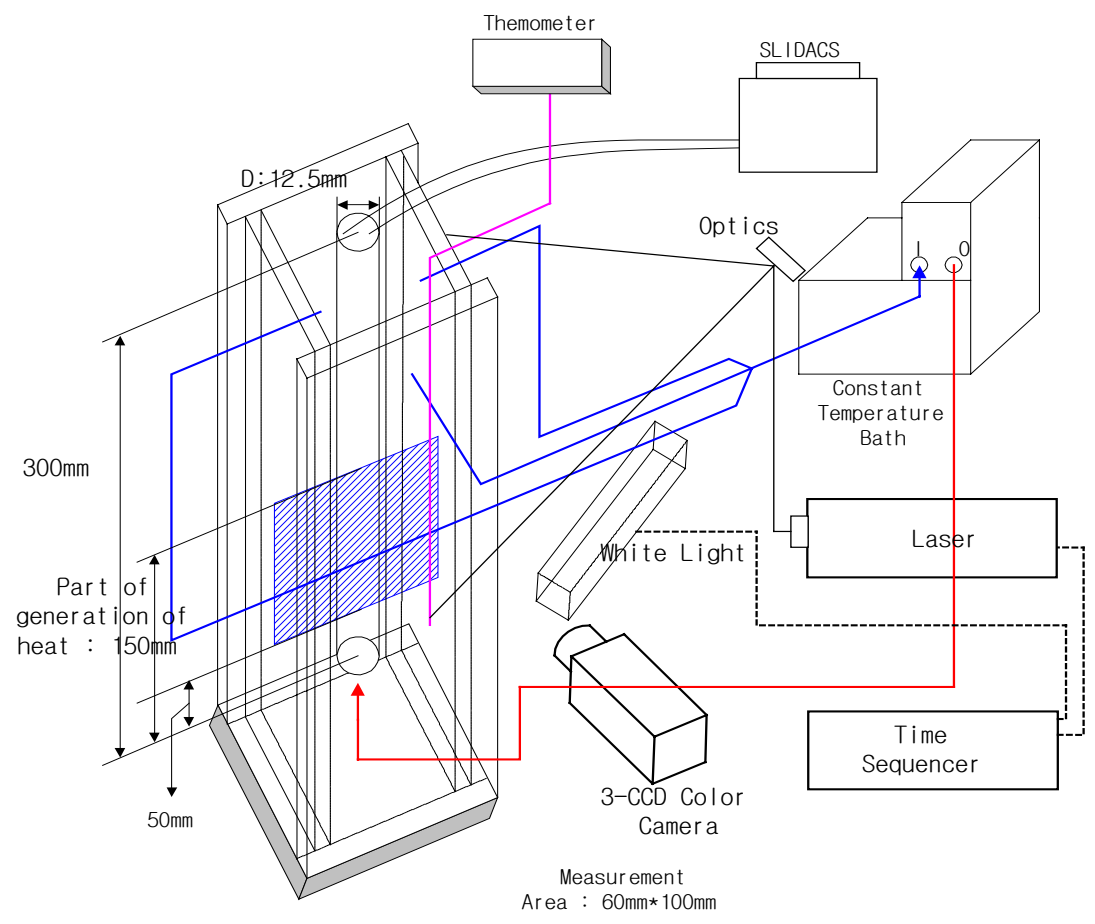

Figure 84: Simultaneous measurement system for temperature and velocity fields.

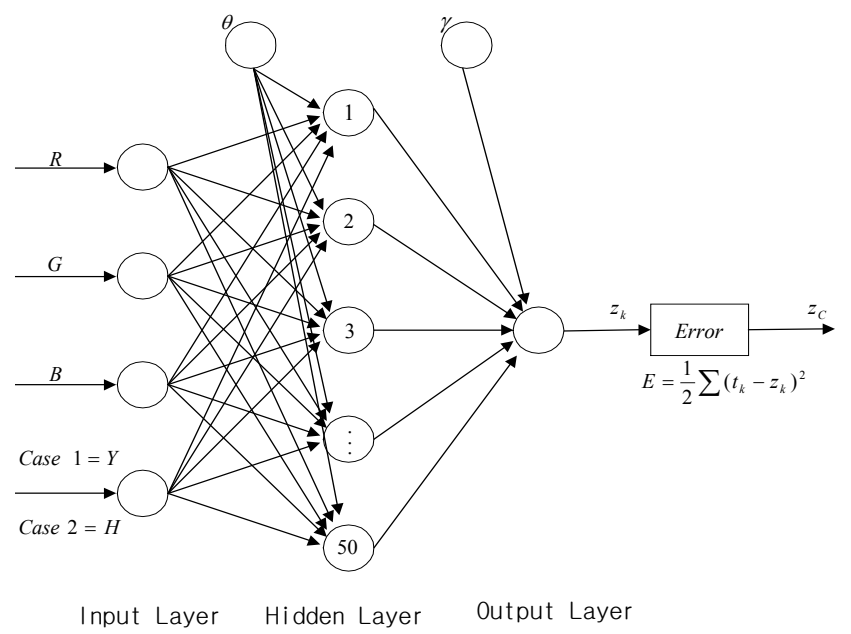

Figure 85: Structure of used neural network. 


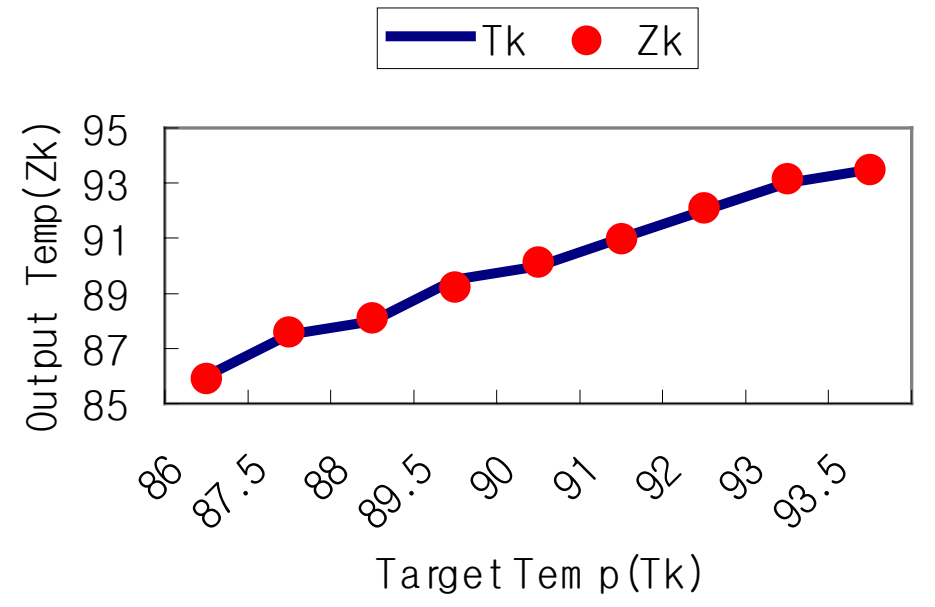

Figure 86 (a): Calibration results with Median filter

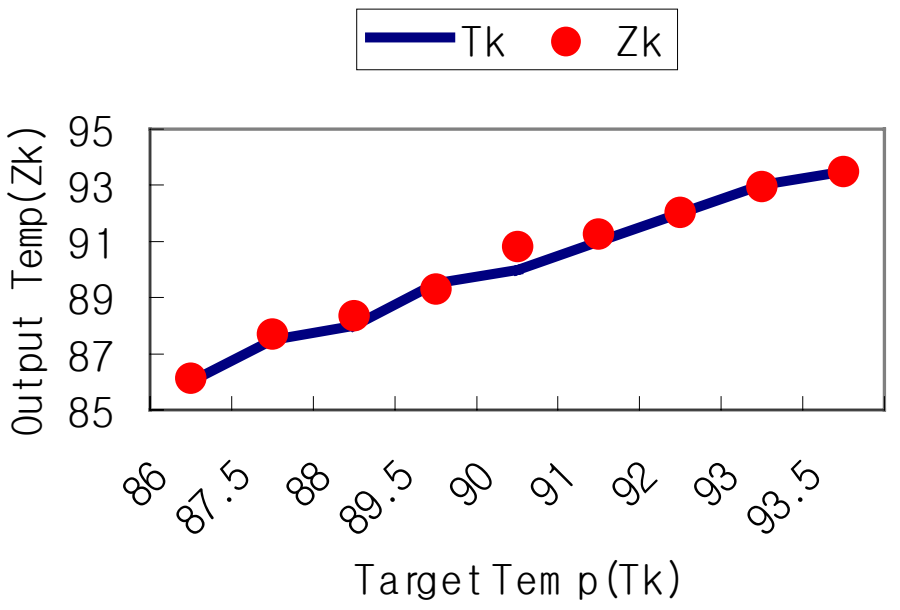

Figure 86 (b): Calibration results without Median filter

It was verified that the relative measurement error obtained was reduced to within 5\% from $7 \%$ for the temperature range, $86^{\circ} \mathrm{C}$ to $94.5^{\circ} \mathrm{C}$. Here, $\mathrm{Tk}$ implies the temperature of thermocouples and $\mathrm{Zk}$ implies recovered temperature obtained by the neural network. Figure 87 shows one of the captured original image of the thermal flow field where the fluid is maintained stratified by the cartridge heater. Figure 88 shows the temperature distribution obtained by the constructed system and software. From this experiment, it was verified that the temperature field could be quantified clearly up to $1.5 \mathrm{~mm}$ from the surface of the cartridge heater by introducing the image enhancements. Without 
introducing the Median filter in the previous test, the error was relatively bigger, and further the measurable distance from the boundary of the surface of the heater was about $3 \mathrm{~mm}$ lager two times than present case.

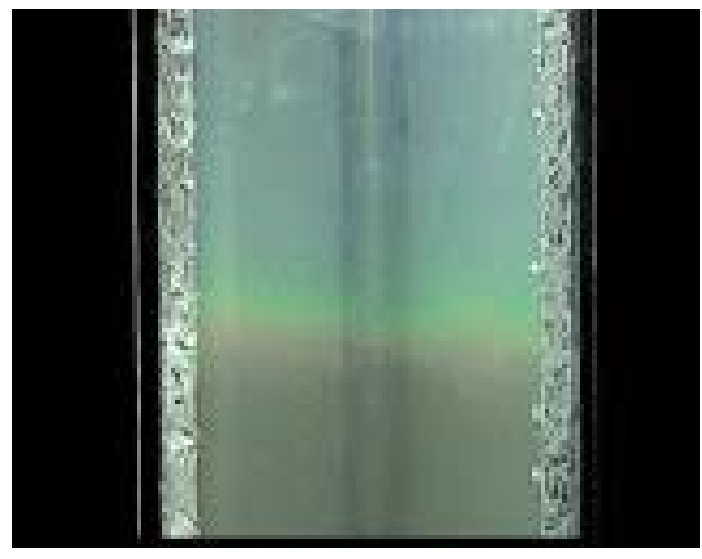

Figure 87: Original image of thermal flow field.

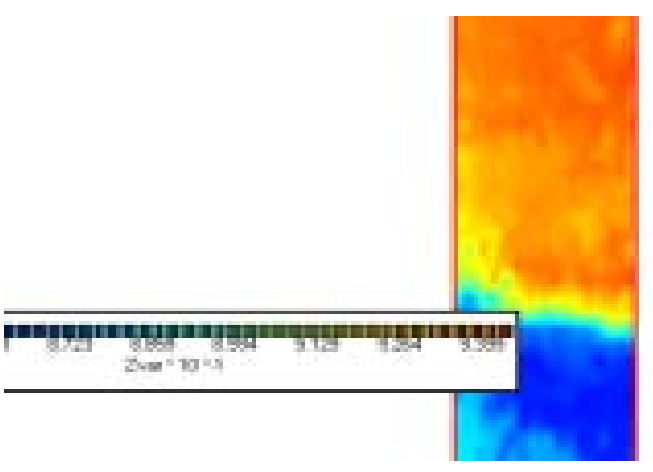

Figure 88: Measured temperature field.

\section{III.3.3 Validations of the Measurement System through a Benchmark Test}

To make validations of the constructed measurement system, a benchmark test was carried out before applying the system into the measurement of radiation heat transfer in which a super heated $(1500 \mathrm{~K} \sim 3000 \mathrm{~K})$ sphere is fallen into a saturated water tank. The Hele-Shaw cell (Hartline, 1977) as shown in Figure 89 was used for the benchmark test. The experimental setup for the Hele-Shaw cell consists of two blocks, the upper and the lower, that produce a natural convection flow in the cell by the temperature differences between the two blocks. The lower and upper part wall temperatures were maintained at $90.3^{\circ} \mathrm{C}$ and $94.7^{\circ} \mathrm{C}$ during the benchmark experiment, respectively. 


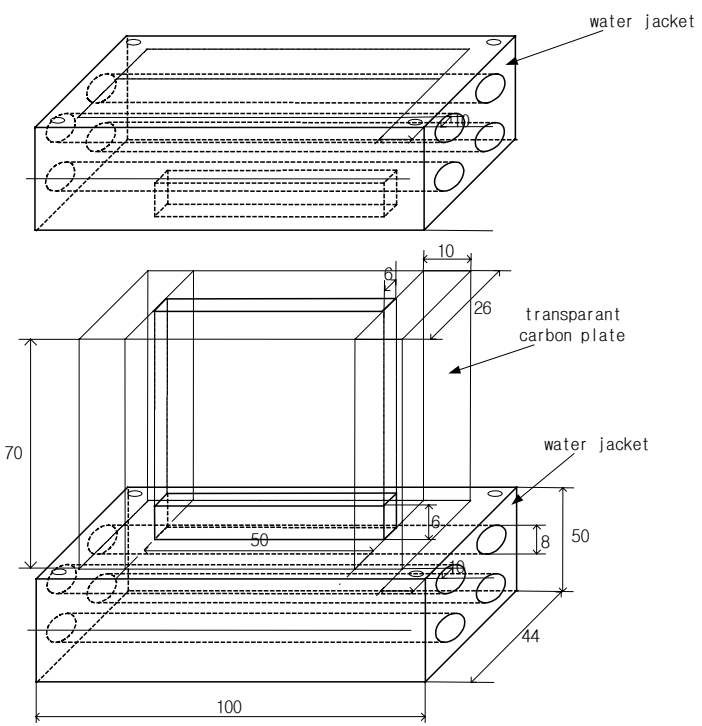

Figure 89: Hele-Shaw Cell

Figure 90 shows the schematics for the benchmark test with the Hele-Shaw cell. The system consists of a color 3-plate-CCD camera (512 x 512), a color image grabber, a light source (white, 30W) and two sets of water heating baths. The upper block's temperature was maintained at $94.7^{\circ} \mathrm{C}$ and the lower block's temperature was $90.3^{\circ} \mathrm{C}$.
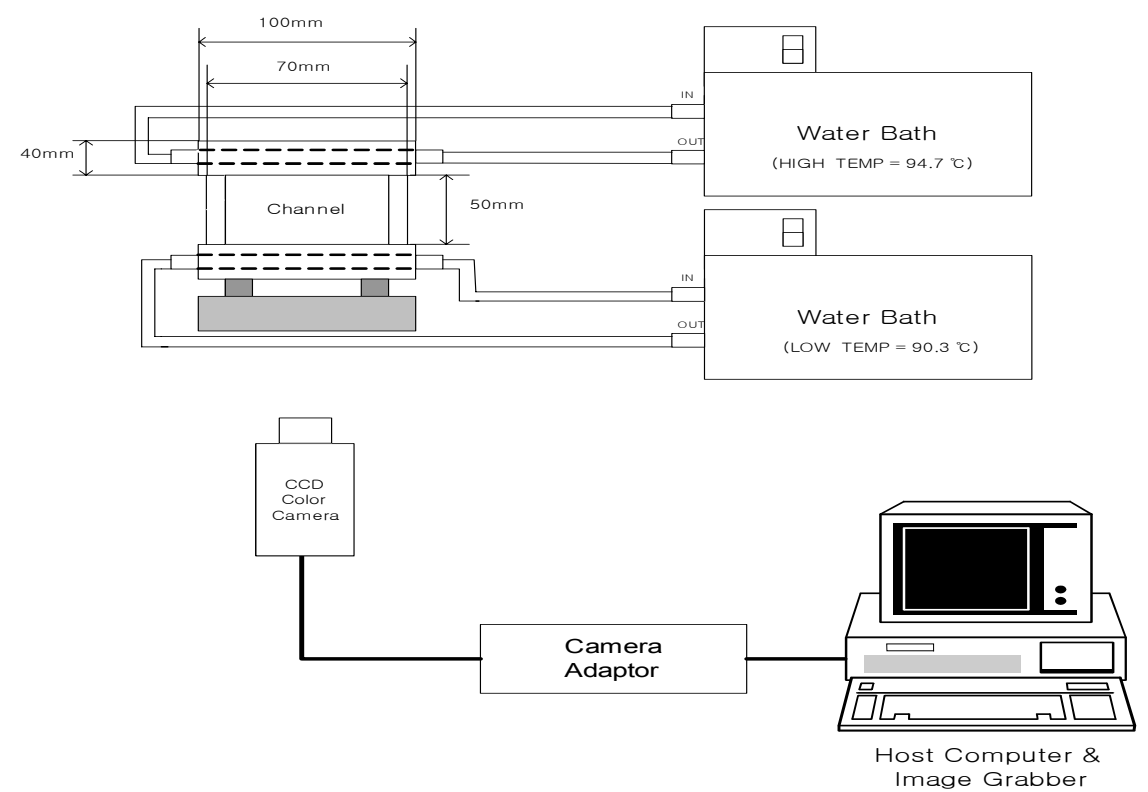

Figure 90: Helle-Shaw Cell for validations of temperature measurements 
Figure 91 shows one of the calibration image at $92.8^{\circ} \mathrm{C}$ and the black square box implies the area used for color-to-temperature calibration. This image was captured when the temperature of the water in the cell was recognized as constant temperature by the thermocouple installed in it. Image capturing for the calibration was carried out at every $0.45^{\circ} \mathrm{C}$ step. With these images, color-to-temperature calibration was made.
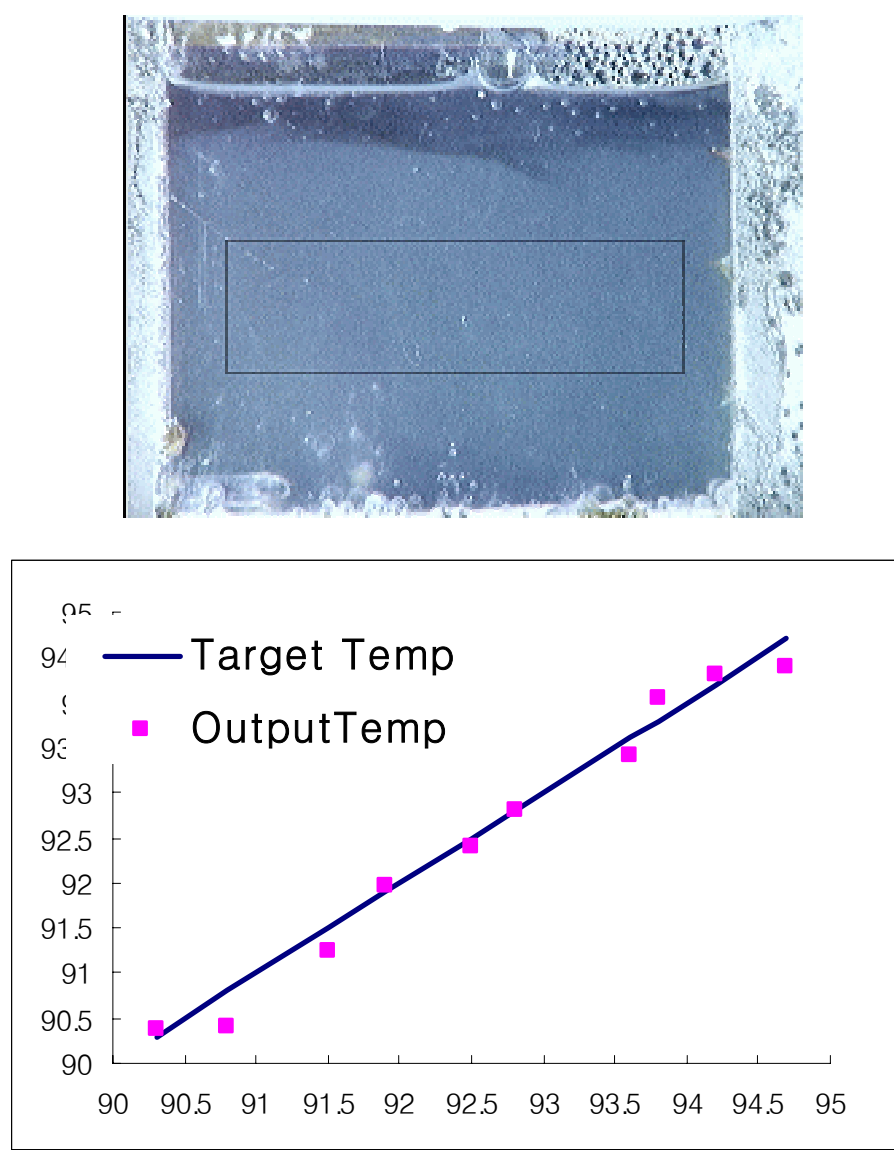

Figure 91a: Calibration image at $92.8^{\circ} \mathrm{C}$

Figure 91b: Calibration curve by neural network

The color information R, G, B and H (Hue) were used for the input of the neural network while the temperatures measured by the thermocouple embedded in the cell were used for the output of the neural network. With this manner, the neural network was trained. Once the neural network is learned, the temperature for unknown colors can be obtained straightforwardly. 
Figure 91 shows the obtained calibration curve recognized by the neural network. Here, $\mathrm{Tk}$ implies the temperature of thermocouples and $\mathrm{Zk}$ implies recovered temperature obtained by the neural network.

Figure 92 shows the original image of the Hele-Shaw cell of which upper wall temperature was maintained with $94.7^{\circ} \mathrm{C}$ and lower wall temperature was maintained with $90.4^{\circ} \mathrm{C}$. A stratified thermal layer was constructed in the cell as expected. And the temperature field obtained by the neural network was just in the range of maintained wall temperature, $90.4{ }^{\circ} \mathrm{C}$ and $94.7^{\circ} \mathrm{C}$, which implies that the constructed measurement system is quite reliable for the measurement of temperature fields of thermal flows. Figure 36 shows the measured temperature distribution with the constructed system. During the calculations, the median filters were also introduced to enhance the measurement accuracy as depicted in the previous section. In Figure 93, non-uniform temperature distribution is seen locally. This is due to the affect of thermal buoyant flows which was generated by the slight difference of the local heat transfer from the lower wall to the working fluids. However, the measured temperature distribution was clearly within the temperature range of the walls enabling the measurability of the constructed system near the saturated water temperature $\left(100^{\circ} \mathrm{C}\right)$.
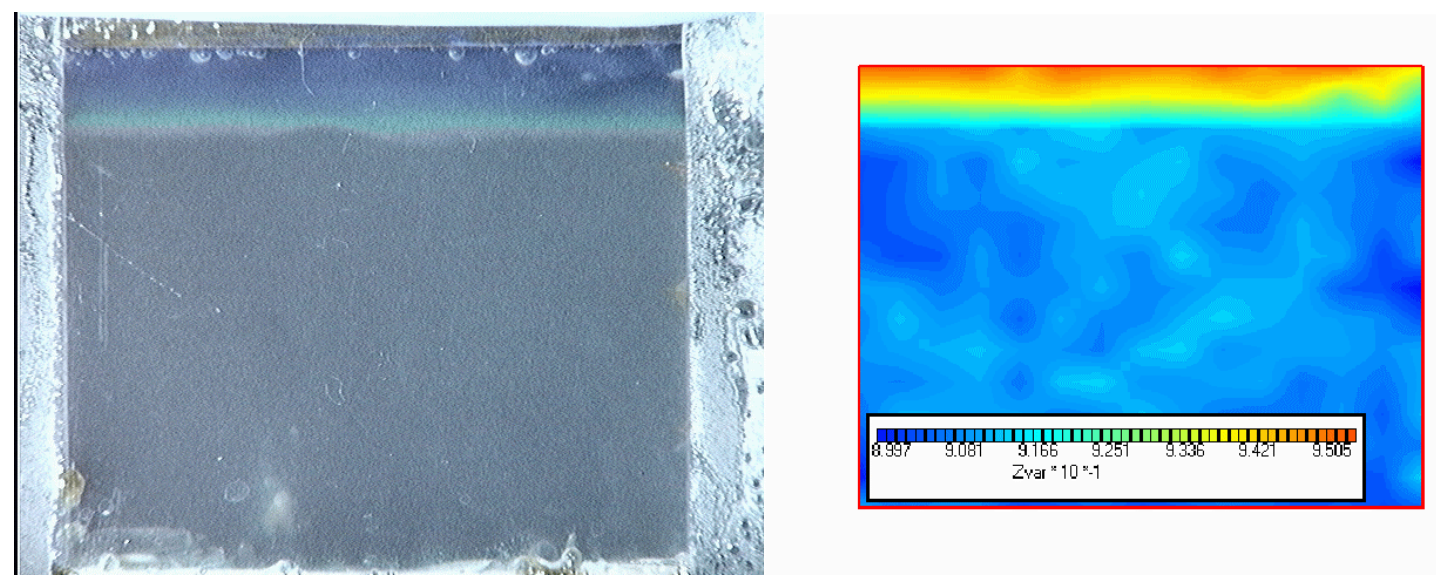

Figure 92: Original image

Figure 93: Temperature field with neural network 


\section{Task IV: Integration of Analytical Models (KMU lead)}

\section{$\underline{\text { IV.1 Background }}$}

The numerical model to be developed in this study is aiming at simulating melt-watersteam multiphase flow behavior encountered in melt coolability by injecting water jet into the melt from its bottom. The problem includes interfacial transfer phenomena of mass, momentum and energy between at least three phases which are water, melt and water-vapor, etc. Mass transfer occurs between water and vapor through boiling. The dimension of the model to be analyzed in this study is a cylinder $0.6 \mathrm{~m}$ high with $0.1 \mathrm{~m}$ diameter with the coolant injection nozzle diameter of $2 \mathrm{~mm}$. The domain is filled with the melt, which is lead in this case, up to $0.3 \mathrm{~m}$ high. Water is injected with $0.5 \mathrm{~m} / \mathrm{sec}$ of velocity through the nozzle. The computational dimension a little bit differs from the experimental dimensions of UW experiment. The inhomogeneous multiphase flow was modeled by mixture model. These models are adapted in CFX5.6 code.

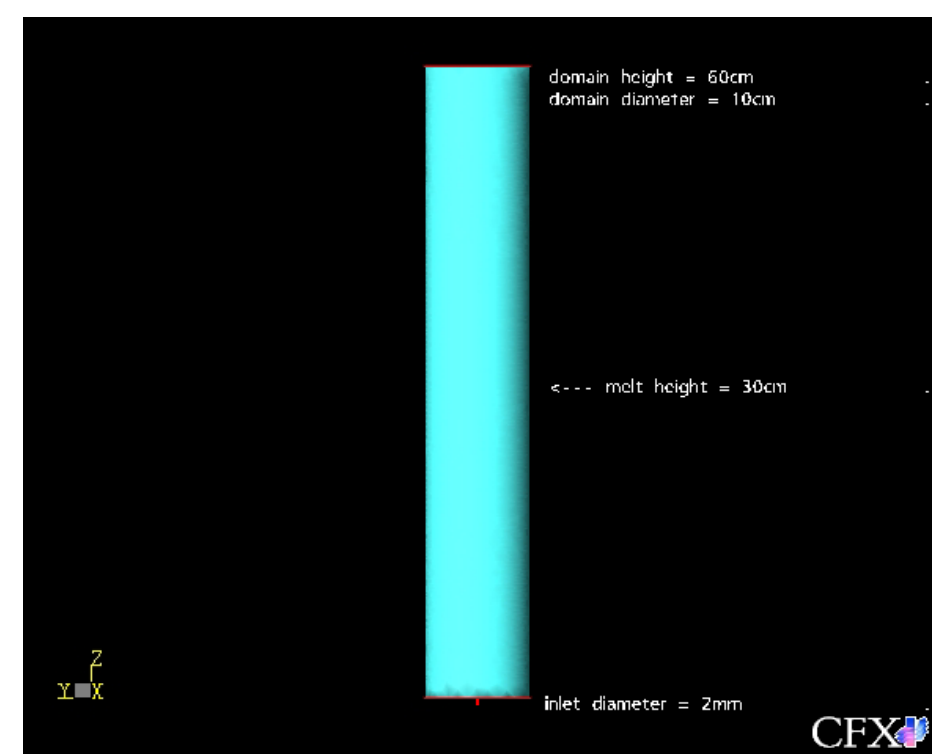

Figure 94: Configuration of the computational domain in this study 


\section{IV.2 Mathematical Model}

Three conservation equations - mass, momentum and energy - are applied to each phase. In addition to these equations, constraints in volume fraction and pressure are added to close the set of equations. The inter-phase transfer quantities such as momentum, heat and mass are calculated by using some relevant models. The conservation equations of mass, momentum and energy are given below:

$$
\begin{aligned}
& \frac{\partial}{\partial t}\left(r_{\alpha} \rho_{\alpha}\right)+\nabla \bullet\left(r_{\alpha} \rho_{\alpha} U_{\alpha}\right)=s_{M S \alpha}+\sum_{\beta=1}^{N_{p}} \Gamma_{\alpha \beta} \\
& \bullet\left(r_{\alpha}\left(\rho_{\alpha} U_{\alpha} \otimes U_{\alpha}\right)\right) \\
& \quad=-r_{\alpha} \quad p_{\alpha}+\bullet\left(r_{\alpha} \mu_{\alpha}\left(\nabla U_{\alpha}+\left(\nabla U_{\alpha}\right)^{T}\right)\right)+\sum_{\beta=1}^{N_{p}}\left(\Gamma_{\alpha \beta}^{+} U_{\beta}-\Gamma_{\beta \alpha}^{+} U_{\alpha}\right)+s_{M \alpha}+M_{\alpha} \\
& \frac{\partial}{\partial t}\left(r_{\alpha} \rho_{\alpha} h_{\alpha}\right)+\nabla \bullet\left(r_{\alpha}\left(\rho_{\alpha} U_{\alpha} h_{\alpha}-\lambda_{\alpha} \nabla T_{\alpha}\right)\right)=\sum_{\beta=1}^{N_{p}}\left(\Gamma_{\alpha \beta}^{+} h_{\beta s}-\Gamma_{\beta \alpha}^{+} h_{\alpha s}\right)+Q_{\alpha}+S_{\alpha}
\end{aligned}
$$

where

$S_{M S \alpha}$ user specified mass sources

$\Gamma_{\alpha \beta}$ the mass flow rate per unit volume from phase $\beta$ to phase $a$

$S_{M \alpha}$ momentum sources due to external body forces, and user defined momentum sources

$M_{\alpha}$ the interfacial forces acting on phase adue to the presence of other phase.

$h_{\alpha}, T_{\alpha}, \lambda_{\alpha}$, the enthalpy, the temperature, and the thermal conductivity of phase $a$.

$S_{\alpha}$ external heat sources.

$Q_{\alpha}$ inter-phase heat transfer to phase a across interfaces with other phase.

$\left(\Gamma_{\alpha \beta}^{+} h_{\beta s}-\Gamma_{\beta a}^{+} h_{\alpha s}\right):$ heat transfer induced by inter-phase mass transfer

$\left(\Gamma_{\alpha \beta}^{+} U_{\beta}-\Gamma_{\beta \alpha}^{+} U_{\alpha}\right):$ momentum transfer induced by inter-phase mass transfer. 
Two constraints exist for volume fraction and pressure in each phase. The volume fractions sum to unity and the pressures in all phases are assumed to be identical. These can be expressed as;

$$
\sum_{\alpha=1}^{N_{p}} r_{\alpha}=1, \quad p_{\alpha}=p \text { for all } \alpha=1, \ldots . ., N_{p}
$$

Interfacial length scale in the mixture model is calculated using the following equation:

$$
d_{\alpha \beta}=\frac{r_{\alpha} d_{\beta}+r_{\beta} d_{\alpha}}{6}
$$

It is used to estimate interfacial area density for drag and heat transfer calculation. The CFX5.6 code does not have any formulation for drag and heat transfer coefficient calculation of the mixture model. The values should be input by users. The drag coefficient and the Nusselt number used here are 0.2 and 15 , respectively.

The particle model deals with the interaction between fluid particles and continuous medium. The Ishii-Zuber drag model is appropriate to calculate inter-phase drag. The following equation is Ishii-Zuber drag model for dense spherical particle regime.

$$
\begin{aligned}
& C_{D}(\text { sphere })=\frac{24}{\operatorname{Re}_{m}}\left(1+0.15 \operatorname{Re}_{m}^{0.687}\right), \quad \operatorname{Re}_{m}=\frac{\rho_{c}\left|U_{d}-U_{c}\right| d_{p}}{\mu_{m}}, \\
& \frac{\mu_{m}}{\mu_{c}}=\left(1-\frac{r_{d}}{r_{d m}}\right)^{-2.5 r_{d} \mu_{*}} \quad, \quad \mu_{*}=\frac{\mu_{d}+0.4 \mu_{c}}{\mu_{d}+\mu_{c}},
\end{aligned}
$$

Here, $r_{d m}$ is the user defined Maximum Packing value.

Both Ranz-Marshall correlation and Hughmark correlation are used for the interphase heat transfer calculation between the continuous fluid and the fluid particle which is dispersed. 
- Ranz-Marshall correlation; $\mathrm{Nu}=2+0.6 \operatorname{Re}^{0.5} \operatorname{Pr}^{0.3}$ for $0<\operatorname{Re}<200, \quad 0<\operatorname{Pr}<250$

- Hughmark correlation; $\mathrm{Nu}=2+0.6 \operatorname{Re}^{0.5} \operatorname{Pr}^{0.33}$ for $0<\operatorname{Re}<776, \quad 0<\operatorname{Pr}<250$

$$
=2+0.27 \operatorname{Re}^{0.62} \operatorname{Pr}^{0.33} \text { for } 776<\operatorname{Re}, \quad 0<\operatorname{Pr}<250
$$

Mass transfer is assumed to arise only by evaporation of water at the water-lead interface, which is called 'thermal phase change model'. The excess heat transferred to water from lead above the saturation temperature causes vapor generation. Interphase species mass transfer is not considered here. The model is explained by the equations below.

Total heat flux to phase $\alpha$ from the interface : $\quad Q_{\alpha}=q_{\alpha}+\dot{m}_{\alpha \beta} H_{\alpha s}$

Total heat flux to phase $\beta$ from the interface : $\quad Q_{\beta}=q_{\beta}-\dot{m}_{\alpha \beta} H_{\beta s}$

where

$\dot{m}_{\alpha \beta}$ : mass flux into phase a from phase $\beta$.

$H_{\alpha s}$ and $H_{\beta s}$ : interfacial values of enthalpy carried into and out of the phases due to phase change.

Since the total heat balance $Q_{\alpha}+Q_{\beta}=0$, the mass flux is determined as;

$\dot{m}_{\alpha \beta}=\frac{q_{\alpha \beta}+q_{\beta \alpha}}{H_{\beta s}-H_{\alpha s}}$

The CFX5.6 code is based on the above equations and correlations for multiphase calculation.

\section{Properties and Model Parameters}

Listed below are the physical properties, initial conditions and program running conditions. The table values are only for sample simulation purposes and can be changed 
for new simulations, for example, use of new materials, new computational domain, new convergence criterion, etc.

Table 8: Physical properties and setup conditions

\begin{tabular}{|l|l|c|c|c|}
\hline & \multicolumn{1}{|c|}{ Material } & lead & water & Water vapor \\
\hline \multirow{5}{*}{$\begin{array}{l}\text { Properties } \\
\text { and } \\
\text { conditions }\end{array}$} & Initial temperature, $\mathrm{K}$ & 690 & 425 & 425 \\
\cline { 2 - 5 } & $\begin{array}{l}\text { Phase change temperature, } \\
\mathrm{K}\end{array}$ & $\begin{array}{c}600 \\
\text { (melting) }\end{array}$ & $\begin{array}{c}425 \\
\text { (boiling) }\end{array}$ & N/A- \\
\cline { 2 - 5 } & Density, $\mathrm{kg} / \mathrm{m}^{3}$ & 11340 & 915 & 2.667 \\
\cline { 2 - 5 } & Specific heat, $\mathrm{kJ} / \mathrm{kgK}$ & 0.127 & 4.272 & 1.926 \\
\cline { 2 - 5 } & $\begin{array}{l}\text { Thermal conductivity, } \\
\text { W/mK }\end{array}$ & 30 & 0.682 & 0.028 \\
\cline { 2 - 5 } & Dynamic viscosity, Ns/m & $5 \times 10^{-8}$ & 0.000183 & - \\
\cline { 2 - 5 } & Surface tension, N/m & 0.076 & 0.02 & - \\
\cline { 2 - 5 } & Injection flow rate, $\mathrm{kg} / \mathrm{s}$ & 0 & 0.01 & 0.00236 \\
\cline { 2 - 5 } & Thermal expansivity, $/ \mathrm{K}$ & - & 0.00104 & N/A- \\
\cline { 2 - 5 } & Heat of vaporization, $\mathrm{kJ} / \mathrm{kg}$ & $\mathrm{N} / \mathrm{A}$ & 2108.47 & - \\
\hline
\end{tabular}

Table 9: List of model parameters

\begin{tabular}{|l|c|}
\hline Number of dimensions & 3-dimension \\
\hline Number of elements & 47661 \\
\hline Maximum number of iteration & 50 \\
\hline Time step size & $0.001-0.0001 \mathrm{sec}$ \\
\hline Grid coordinates & Cartesian coordinates \\
\hline Flow type & Turbulent flow (k-epsilon) \\
\hline Compressibility & Incompressible flow \\
\hline Buoyancy & Buoyant flow \\
\hline Mass transfer & Boiling model \\
\hline Flow state & Transient flow \\
\hline Number of phases & 3 phases \\
\hline
\end{tabular}


Table 10: Initial conditions

\begin{tabular}{|c|c|c|}
\hline \multirow{4}{*}{$\begin{array}{l}\text { Melt } \\
\text { (lead) }\end{array}$} & Temperature, $\mathrm{K}$ & 690 \\
\hline & Pressure, bar & 5.0 \\
\hline & Velocity, $\mathrm{m} / \mathrm{s}$ & 0.0 \\
\hline & Volume fraction & step $(0.3-z)$ in the domain \\
\hline \multirow{4}{*}{$\begin{array}{l}\text { Coolant } \\
\text { (water) }\end{array}$} & Temperature, $\mathrm{K}$ & 425 \\
\hline & Pressure, bar & 5.0 \\
\hline & Injection velocity, $\mathrm{m} / \mathrm{s}$ & $5 \mathrm{~m} / \mathrm{s}$ in $\mathrm{z}$-direction \\
\hline & Volume fraction & $\begin{array}{c}0.0 \text { in the domain } \\
1.0 \text { at the inlet }\end{array}$ \\
\hline \multirow{4}{*}{ Vapor } & Temperature, $\mathrm{K}$ & 425 \\
\hline & Pressure, bar & 5.0 \\
\hline & Velocity, $\mathrm{m} / \mathrm{s}$ & 0.0 \\
\hline & Volume fraction & step(z-0.3) in the domain \\
\hline
\end{tabular}

\section{IV.3 Simulation of UW Experiment}

The computational model described above is modeled to prepare for computing. The total number of nodes and elements are 9167 and 47661, respectively. The pairs for interphase transfer are lead-water, lead-vapor and water-vapor. For the lead-water pair, mixture model has been chosen for interfacial calculation. The interfacial length scale was assumed to be about $5 \mathrm{~mm}$ considering the mean diameter of the water jet. And the Nusselt number of 10 was used which is for the Reynolds number 50000. Ishii-Zuber model was adopted for the interfacial drag calculation in the lead-vapor and water-vapor pairs since vapors are considered as dense fluid particles. The initial temperatures of water and vapor are given to be identical $152^{\circ} \mathrm{C}$ which is the saturation temperature at 5 bar. Temperature of the vapor has been set to be isothermal throughout the calculation. Mass transfer was considered by introducing the boiling model in the water-vapor pair. 
The whole computational domain was assumed to be pressurized with 5 bar. The initialization of the domain for pressure and volume fraction was set by using step function. The initial conditions used in this calculation are given in Table 10.

Figure 95 presents the melt-water interaction in terms of vapor volume fraction distribution for the first 20 seconds of coolant injection. In the first two seconds, the interaction is confined in a single spherical-shape bubble. Then continuing vaporization of the water coolant produced a vapor plume and it rises upward and is widened.

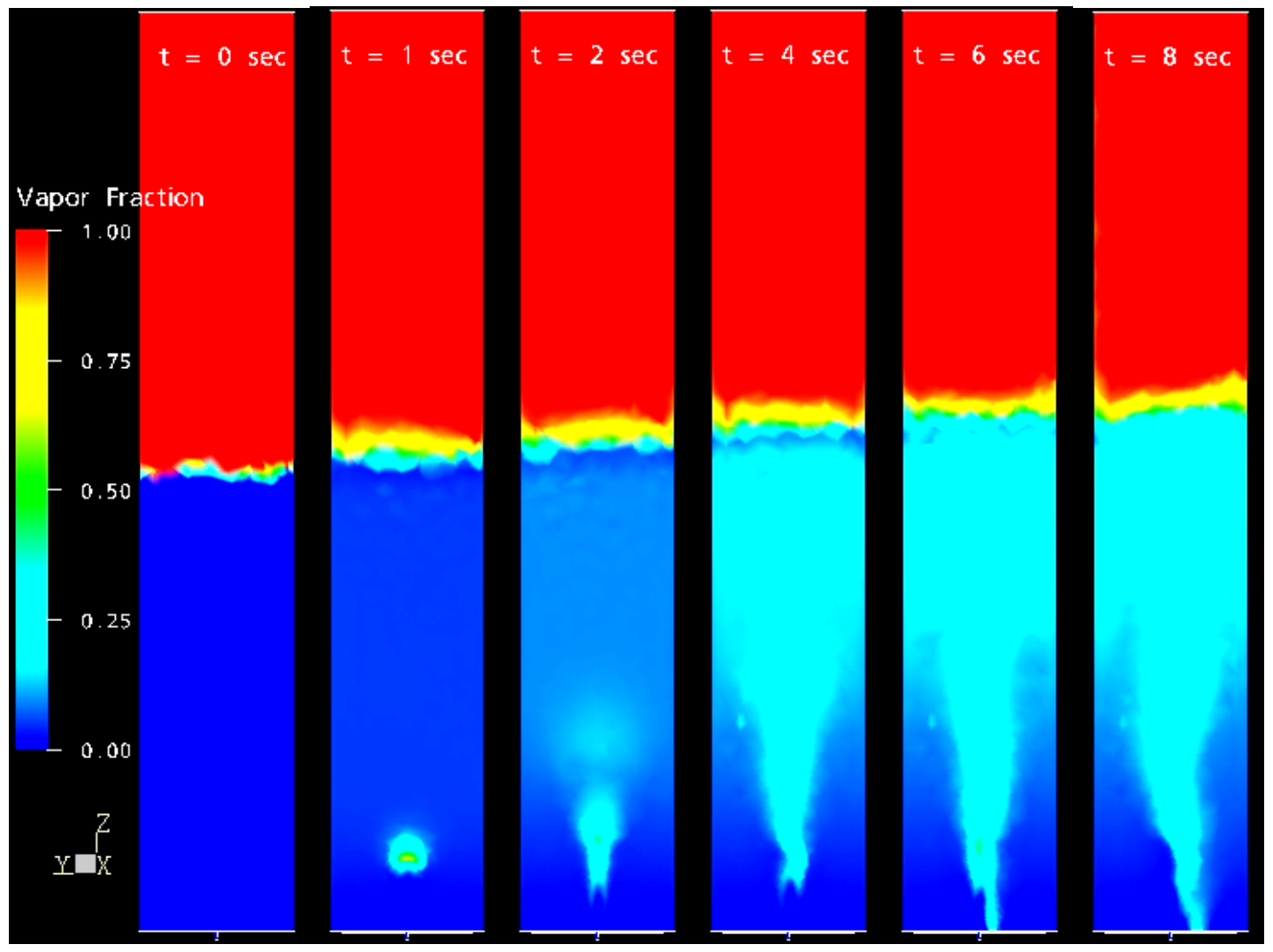

Figure 95: Vapor volume fraction distribution during the first 20 seconds of water injection into melt 


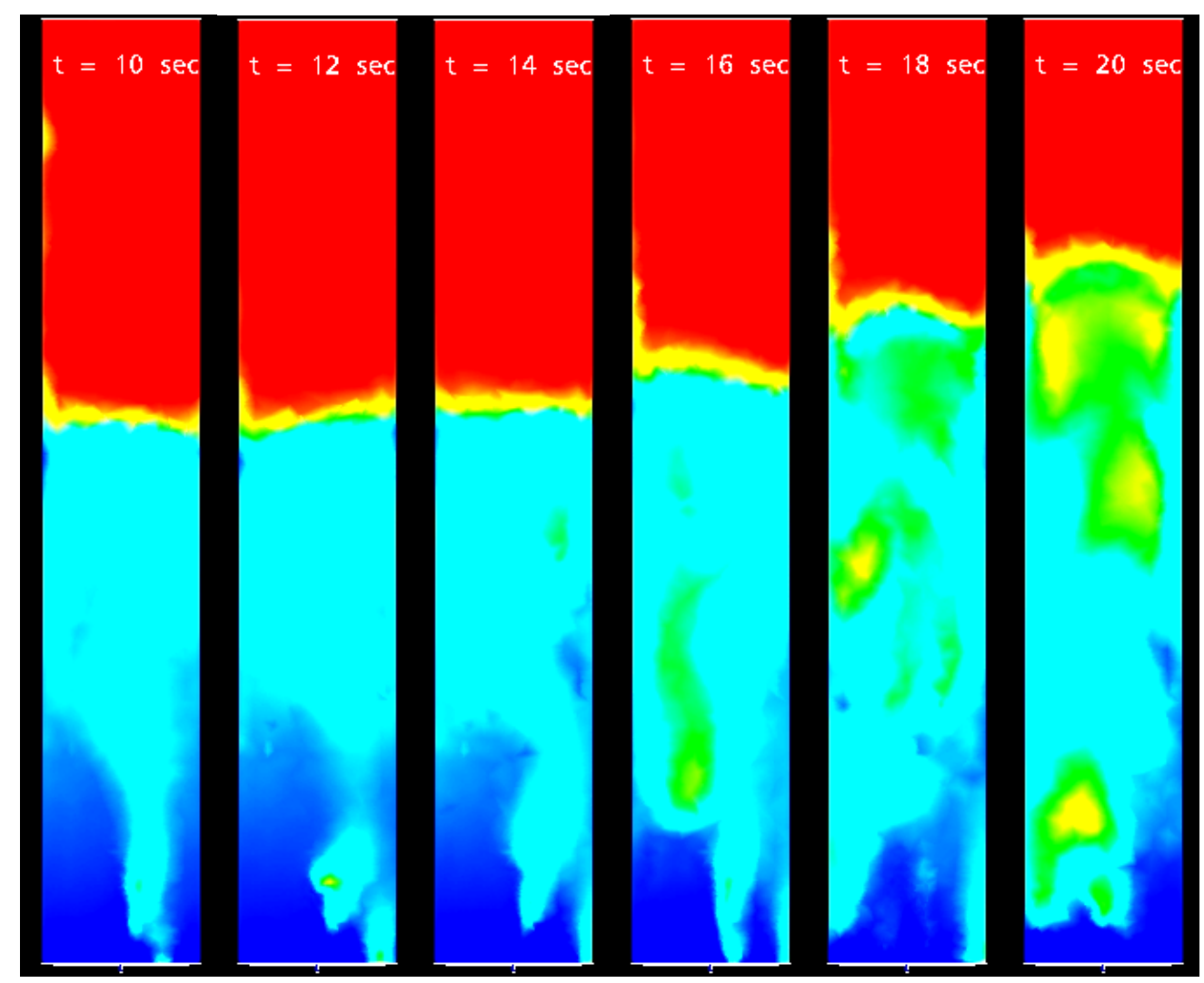

Figure 95 (cont.) : Vapor volume fraction distribution during the first 20 seconds of water injection into melt 


\section{Task V: Development of an Innovative Core Coolability Concept (All Groups)}

\section{V.1 Reactor Safety Background}

Regulatory Framework: In the design of the next-generation of nuclear reactors and in the safety assessment of currently operating nuclear power plants, it is necessary to evaluate the risk from a severe accident and to identify the key strategies to follow in order to mitigate possible consequences. In the unlikely event of a severe accident involving core melt, it is important to identify the processes that would allow the molten core material to cool down and resolidify, to reliably remove core decay heat, and to bring core debris to a safe and stable state - thereby achieving "core coolability". For current nuclear plants, the safety approach taken by plant operators and the US Nuclear Regulatory Commission (USNRC) is to:

- Provide alternative sources of water to arrest progression of the degraded core accident;

- Develop accident management procedures to maximize reactor pressure vessel integrity; - Provide long-term ultimate heat sink paths to remove decay heat from the containment; - Delay any potential containment failure beyond 24 hours for off-site emergency actions.

For next-generation plants seeking final design certification from the USNRC (e.g., AP1000), the approach has been to improve the reliability of each of these actions to reduce the probability of progressing further into a severe accident with required off-site emergency preparedness actions. Nevertheless, safety analyses of next-generation plants indicate that all four types of actions will be necessary to minimize off-site radiological dose; e.g., NRC03-202 indicates that in-vessel retention is not assured, thereby eventually causing containment basemat melt-through and off-site radiological consequences requiring a range of emergency actions - i.e., evacuation.

In contrast to this safety approach, next-generation nuclear plant safety in some developed countries (e.g., Europe) and developing countries (e.g., Korea) have taken a more proactive posture and have a goal to eliminate off-site radiological consequences and the need for off-site emergency actions. For example, the planned nuclear plant for Finland, a Framatome EPR, will incorporate an ex-vessel coolability system with the objective to preclude containment failure and substantial off-site emergency action plans. 
If the next-generation nuclear plants developed by US nuclear vendors (i.e., AP1000, ESBWR) are to be competitive worldwide, the ability to preclude containment failure and off-site emergency actions will need to be incorporated into their future reactor designs. The OECD in collaboration with its members (e.g., USNRC and other reactor safety agencies) worldwide is planning a revised program. One potential objective being considered is to develop a technical basis for ex-vessel coolability concepts independent of any specific reactor design for advanced Light Water Reactors (ALWR).

We would propose that the Department of Energy collaborate with the Nuclear Regulatory Commission in developing and participating in the OECD program with this as the primary objective in the next few years; i.e., develop a technical basis for ex-vessel coolability concepts independent of specific reactor designs for advanced LWR's.

Technical Basis: In a severe accident, core-melt material has the potential to be discharged from the core region and eventually fail the reactor pressure vessel lower plenum wall; e.g., analyses in NRC03-202 indicated the likelihood of reactor vessel failure given a core-melt relocating to the lower plenum was over 1-in-3. Given this scenario, the molten core material pours from the reactor pressure vessel, and accumulates as a molten pool in the reactor cavity below. This molten material, usually called corium, is composed of mainly uranium-dioxide and zirconium-dioxide, as well as some limited quantities of zirconium and stainless steel from the melting of the reactor core internals and lower plenum. The molten corium can thermally attack the concrete underneath and decompose it, producing gases, which agitate the pool, enhancing heat release to the boundaries as fission product decay heat and chemical reactions continue to add mass and energy to containment. It is the production of the gases that pressurize the containment and the attendant erosion can melt-through the containment basemat.

To achieve "core coolability" in the reactor containment cavity and eliminate any threats to containment integrity by overpressurization or melt-through, a number of approaches have been proposed; i.e., water flooding from above or injection of water from below. 
The effectiveness of these techniques to achieve ultimate coolability involves the mixing of high-temperature melt with water, via boiling processes and/or injection.

Because this process occurs at large scales and with materials whose physical properties are not well determined, the phenomenology involved is not completely understood. In addition, many of the current, most widely used models were not specifically developed to simulate this phenomenology and do not always predict the experimental observations. Various attempts have been made to reproduce the problem experimentally by using either prototypic or simulant materials. Some of these are integral experiments that try to reproduce the entire scenario to pinpoint all the processes involved (e.g., EPRI/DoE/NRC supported MACE tests), while others are separate effect studies focused on the more detailed analysis of very specific phenomena (e.g., the current OECD supported MCCI program to examine water-flooding phenomena).

A concept of core-melt quenching and long-term coolability by the bottom injection of water into the melt was originally proposed for application to the European Pressurized Water Reactor (EPR). A number of tests employing simulant melts (COMET) were conducted to demonstrate the viability of this concept. The concept appears promising for the development of innovative safety technologies for next-generation LWRs. However, fundamental data on the transport phenomena involved with prototypic materials are needed for further refinement of the concept and potentially for regulatory acceptance and industry implementation. Our DoE INERI project conducted these experiments to provide fundamental data on the COMET concept.

\section{V.2 Functional Requirements}

The ex-vessel coolability system must have certain attributes:

- Heat removal capabilities in excess of decay-heat generation (e.g., $>2 x$ decay heat),

- Continuous and appropriate amounts of coolant injection with no active actions,

- Minimize the probability of damaging fuel-coolant interactions. 


\section{V.3 Ex-Vessel Reactor Cavity Flooding Concepts}

In the absence of a dedicated device for core-melt retention and heat removal (i.e., core catcher) the only option for achieving ex-vessel coolability is to add water to the reactor cavity so as to remove the decay heat and enthalpy of the corium by vaporizing the water mixed with the corium melt. Three different concepts for water addition have been proposed and experimentally tested:

1. Core molten material falling into a pre-flooded cavity and quenching (FARO tests),

2. Pouring of water onto the top of core molten materials and quench (MACE tests),

3. Injection of water into the bottom of molten pool and quench (COMET tests). These different cavity flooding contact modes have been investigated in past experiments and analytical models have been developed (see figure below). Based on experimental results and evaluation to date, the COMET concept (i.e., bottom injection of water) appears to be the most effective approach. A short summary follows.

Figure 96: Different Types of Contact Mode.

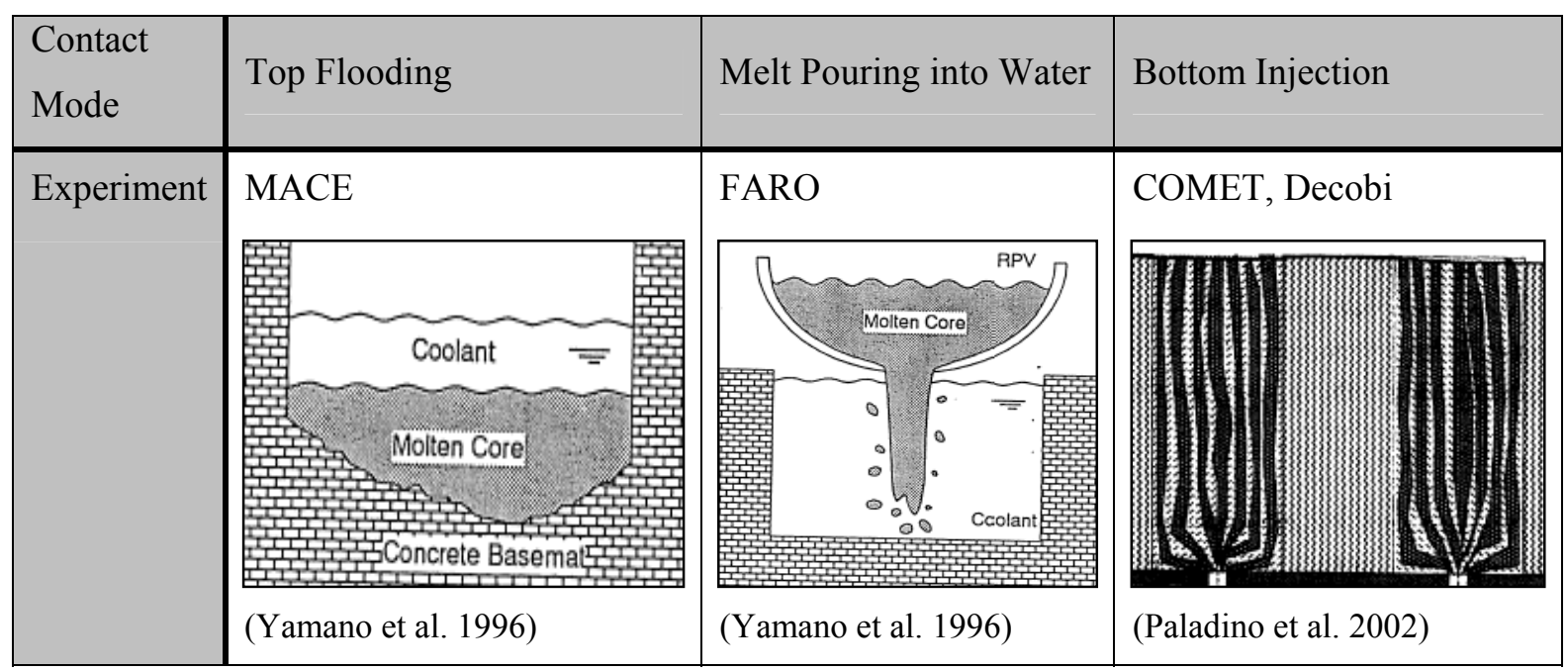

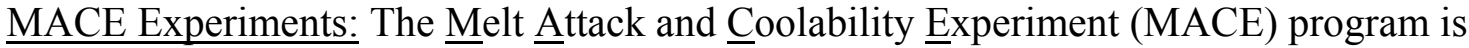
focused on collecting the corium in the reactor cavity and flooding it with water (top flooding). Four major experiments have been performed. A variety of phenomena have been identified through experiments that may contribute to long-term coolability. When 
water is introduced on top of corium, several possible sequences of events may result depending on the initial conditions. In the short term following water addition, the question of whether or not a significant amount of the melt thermal energy is removed may depend upon whether or not a stable crust forms between the cooling water and molten core. If this occurs it would inhibit heat transfer from the corium to the water layer. For a sufficiently high sparging rate (gas generation due to concrete ablation), stable crust formation at the melt/water interface may be precluded. In this regime, film boiling is expected to be the dominant heat transfer mode, due to periodic introduction of high temperature melt at the interface, as the crust segments are broken up. Efficient melt/water heat transfer will thus be encountered due to conduction and, predominantly, radiation across the agitated (i.e., area enhanced) melt/water interface, in addition to the possible entrainment of melt droplets into the overlying water. An illustration of this process is provided in Figure 97. In a purely bulk freezing heat transfer mode, frozen material formed at the interface is mixed back into the melt causing an overall decline in the bulk melt temperature, eventually leading to the development of a slurry mixture of solid chunks and liquid.

As bulk cooling continues, the melt temperature will gradually decrease. If the downward heat transfer rate, which drives concrete ablation with co-current non-condensable gas release, is proportional to the melt temperature, then the melt sparging rate will also decrease. Thus, a point will eventually be reached at which a stable crust is able to form in the presence of the sparging gases. The physical configuration at this point would consist of a corium pool at reduced temperature with a crust on top of the melt. The crust will be characterized by some degree of porosity, or cracks, due to venting the concrete decomposition gases.

After the crust is formed, completion of the quench process can only be achieved if one of two conditions is met. The first condition is that the melt depth is less than the minimum depth at which decay heat can be removed via conduction heat transfer alone (estimated to be $10 \mathrm{~cm}$, Fisher et al. (1991)). The second condition is that water is able to penetrate into the debris by some mechanism to provide a sufficient heat sink to 
remove the decay heat via evaporation. Three potential mechanisms have been identified through experiments, which provide pathways for water to penetrate the debris. The first mechanism, depicted in the figure above, is water ingression through interconnected porosity or cracks.

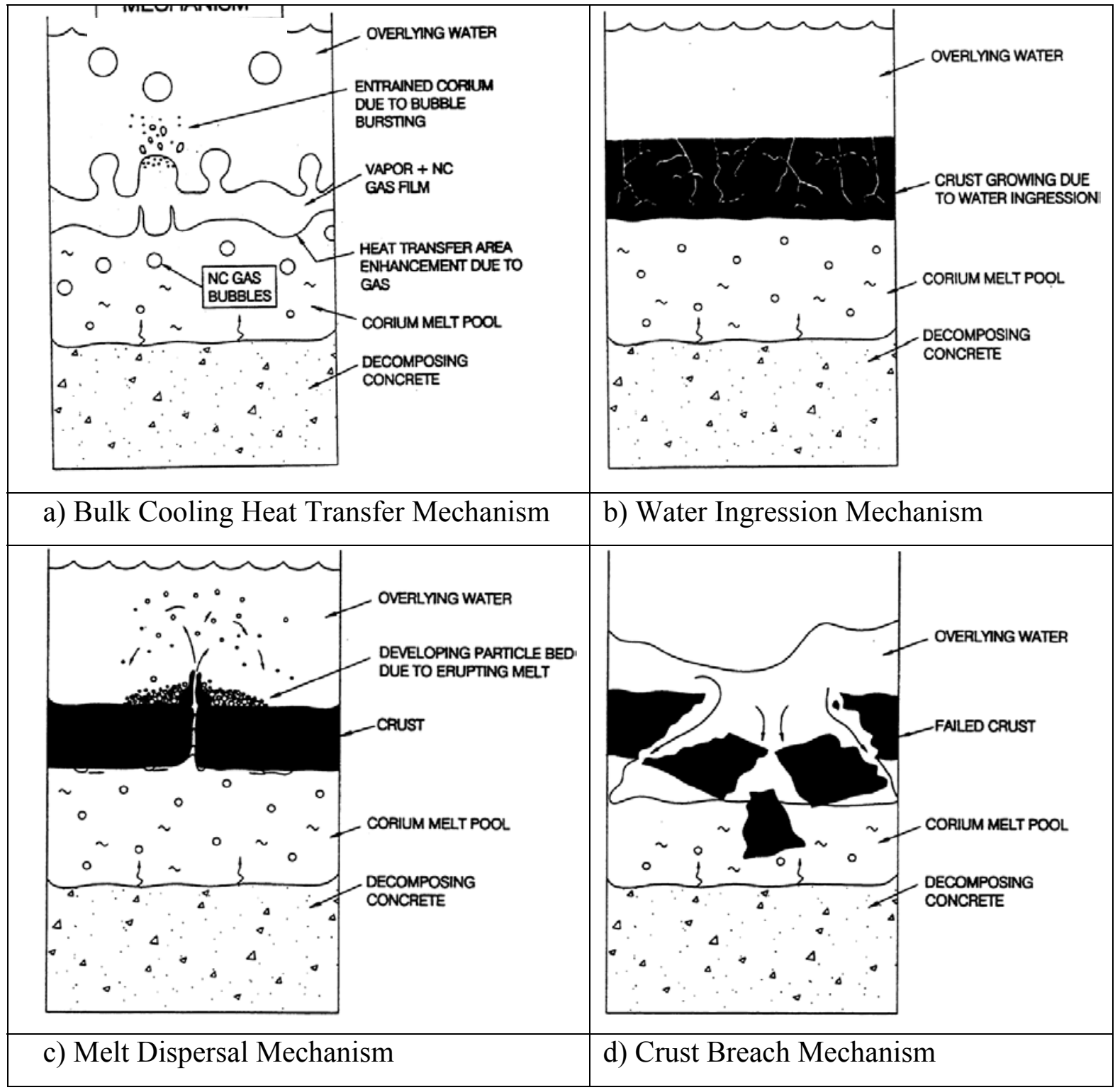

Figure 97: Illustration of different Heat Transfer Mechanisms for MACE

Experiments (Farmer et al., 2000).

For this mechanism to exist, sustained contact between the crust and the underlying molten phase is required. This process relies on crack propagation through the material and, as such, is highly dependent upon the mechanical properties, since thermal stress is a 
key factor. The second potential mechanism, which would yield interconnected porosity is particle bed formation through "volcanic" eruptions. In this case, concrete decomposition gases entrain melt droplets into the overlying coolant as they pass through the crust. The entrained droplets then solidify in the overlying coolant and accumulate as a porous particle bed atop the crust. This cooling process is shown in the figure above.

Another mechanism that may contribute to long-term debris coolability is mechanical breach of a suspended crust. Sustained separation of the crust from the underlying melt due to mechanical bonding of the crust to the reactor cavity walls is not expected in a plant accident, owing to the large lateral span of the drywell/pedestal regions of these structures. However, the thick crust $(\sim 10 \mathrm{~cm})$ that develops may have sufficient mechanical strength to bond to the pedestal walls and temporarily separate from the ongoing MCCI. This configuration is, however, not expected to be stable due to the shear weight of the crust, in addition to the dead weight imposed by accumulating, dispersed material atop the crust and water. Eventually the suspended crust will fail, leading to rapid ingression of water beneath the crust. This sudden introduction of water will provide a pathway for renewed debris cooling by bulk cooling, water ingression, and melt eruption-cooling modes. This transient cooling process is illustrated in the figure above. An excellent description of the above shown mechanisms with examples from the experiments and reference to analytical models is given by Farmer et al. (2000).

FARO Experiments: A different type of contact mode occurs if the molten corium pours into water. This scenario would occur if the corium were still in the reactor pressure vessel when the reactor cavity is flooded with water. When the pressure vessel melts through, a jet of molten corium falls into the water where it, ideally, fragments and solidifies. In the Fuel Melt and Release Oven (FARO) facility, up to $200 \mathrm{~kg}$ of oxide fuel type melts (up to $3000^{\circ} \mathrm{C}$ ) can be produced, possibly mixed with metallic components, and delivered to a test section containing a water pool at initial pressures of up to 50 bar. The FARO experiments were conducted over ten years beginning in 1991. Experiments are focused on the investigation of basic phenomena relevant to the fragmentation and quenching of molten material in the water coolant at different initial pressures and water 
subcooling. Twelve experiments have been performed: Five at 50 bar initial pressure, one at 20 bar and six tests at ambient pressures lower than 5 bar. The experimental data indicated that only partial quench of the molten core materials was possible.

COMET-Experiments: Similar to the MACE experiments, the corium is collected in the reactor cavity in the COolability of $\underline{\mathrm{MElT}}$ (COMET) experiments. At the bottom of the reactor cavity, called the core catcher, a sacrificial layer of concrete with integrated nozzles is installed. Erosion of the sacrificial concrete layer agitates the melt by gas production and lowers the melt temperature. Mixing of concrete components and corium will also lower the solidus temperature of the mixture significantly (Roche at al., 1993).

As the erosion of the sacrificial layer reaches the nozzle and ignites the burnable cap, coolant water starts to enter the melt from below. At first, the inflowing water is evaporated immediately and completely due to the high temperature difference between coolant and melt. The production of steam creates pressure inside the melt and fragments the melt. As long as the melt is in the liquid state, flow channels form. However, they are not stable, but permanently redeveloped in the turbulent melt flow. The direct water contact and its evaporation lead to a rapid cooling of the melt, which then starts to solidify in a solid-liquid mixture. The possibility of long term cooling of the solidified and decay heated debris will depend on the structure of the debris and the distance between the nozzles. If a porous structure is formed as a consequence of the solidification process and if the distance between the nozzles is properly designed, the continuous water inflow will ensure long-term coolability.

Up until now, three major series of COMET experiments have been performed (Alsmeyer et al., 1999). The main focus of these transient tests was qualitative study of the fragmentation of the melt, safe design flooding water pressure, as well as quantitative study of the melt quench process via rapid and complete solidification, different melt compositions, inhomogeneous erosion, presence of zircaloy, steam explosions, hydrogen release during the interaction, aerosol release and long term coolability. In addition to 
these experiments, enhanced designs were under investigation. A schematic of the different cooling stages during the COMET experiments is shown in Figure 98.

a)

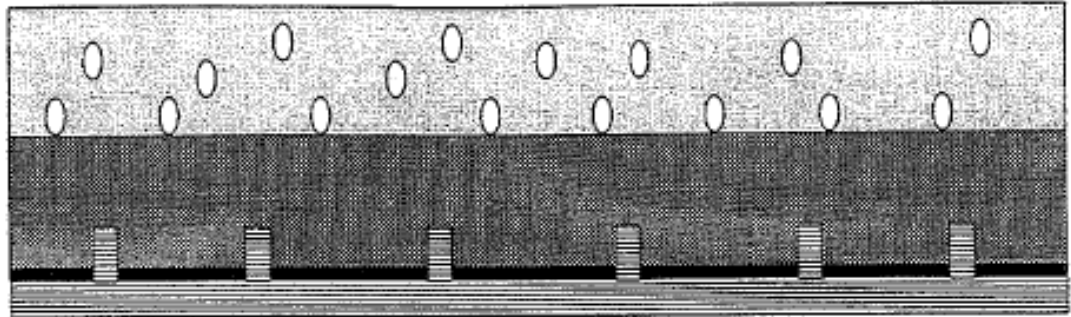

b)

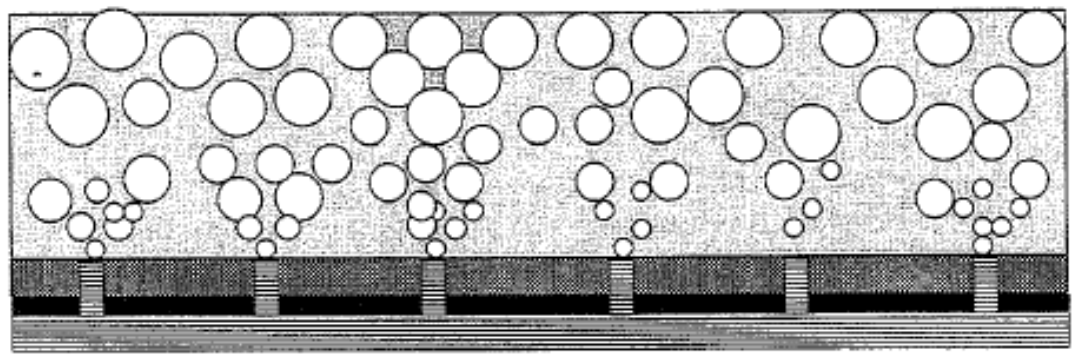

c)

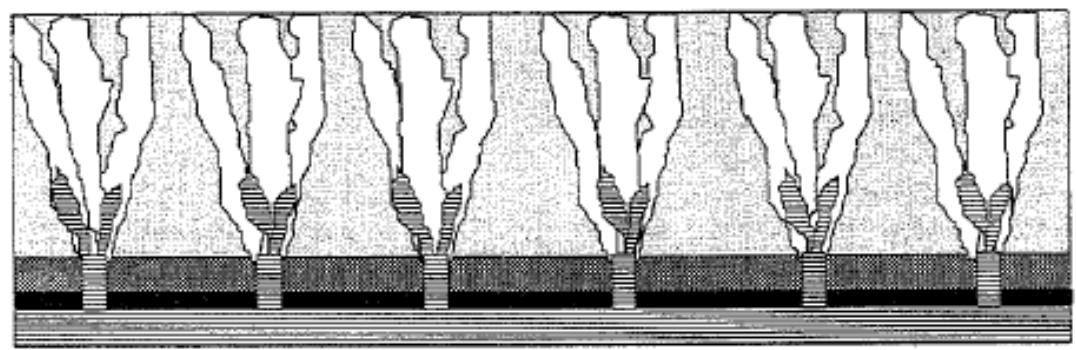

d)

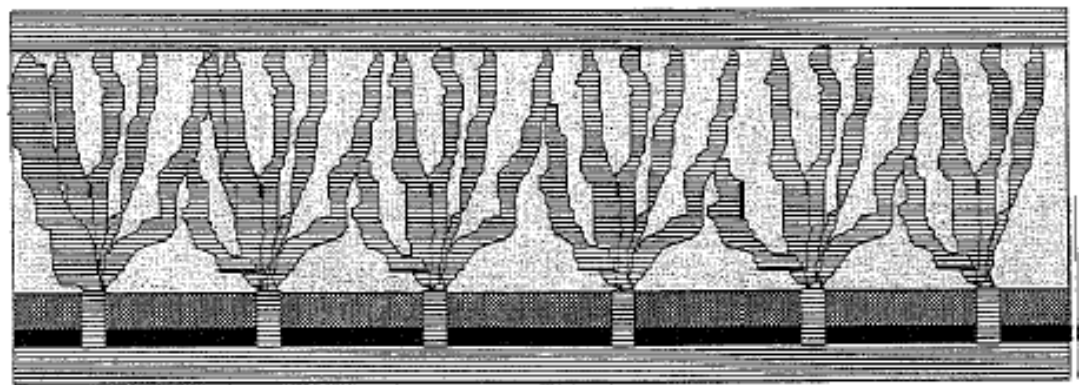

Figure 98: Phenomena during melt quenching process (COMET, Tromm, 1998):

a) Dry concrete erosion

b) Onset of water injection

c) Flooding of the solidified melt

d) Porously solidified and flooded melt 
Fuel Coolant Interactions (FCI): The FCI phenomenon, known as vapor explosion, is a rapid evaporation of the injected coolant which can initiate shock waves, melt explosions, finer melt fragmentation, and possible mechanical damage. Similar to COMET-T Experiment 2.1 and 2.3 also in COMET-T 8.1, about 2-10 seconds after onset of water injection, energetic FCI's were observed. In the water injection lines, pressure peaks up to 2 bar were measured. At this point, the melt had a high temperature due to the energy from oxidizing the added $5 \mathrm{~kg}$ of zirconium. The table below gives three strong measured pressure peaks, the resulting impulses and the kinetic energies. The highest pressure peak occurred at onset of water injection. The calculated impulse is about $118 \mathrm{~N} \cdot \mathrm{s}$. About 70 $\mathrm{kg}$ of the melt participated in this interaction, nearly the total melt mass, resulting in a low kinetic energy of the melt mass of $0.1 \mathrm{~kJ}$. Seven seconds after onset of water injection, the pressure increased again and $5 \mathrm{~kg}$ of melt were ejected from the test section.

Figure 99: Measured Forces during COMET-T 8.1 (Tromm, 1998)

\begin{tabular}{|c|c|c|c|c|c|}
\hline Time $[\mathrm{s}]$ & Force $[\mathrm{kN}]$ & Impulse $[\mathrm{N}-\mathrm{s}]$ & Time $\Delta \mathrm{t}[\mathrm{s}]$ & Mass $[\mathrm{kg}]$ & Kin Energy $[\mathrm{J}]$ \\
\hline 0 & 7.7 & 118 & 33 & 70 & 100 \\
\hline 7 & 3.7 & 95 & 64 & 5 & 880 \\
\hline 8 & 3.2 & 69 & 45 & 5 & 480 \\
\hline
\end{tabular}

\section{V.4 External Cavity Cooling Reactor Concepts}

AP1000 Reactor Design: The current design for the AP1000 does not explicitly have an external cavity-cooling concept as noted previously. Rather, the IVR concept is used exclusively as the mechanism to provide debris coolability within the reactor pressure vessel after a core melt accident has progressed to the point where core material relocates beyond the core region. If the IVR concept is defeated and the molten core materials are released to the cavity and the full range of phenomena need be considered.

ESBWR Reactor Design : The conceptual design for the ESBWR is now being formulated for submission to the NRC for design certification. Thus, many of the details of containment systems that would be employed to handle severe accident phenomena are still not precisely specified. However, it is seems clear that, at this time, the ESBWR does not explicitly have an external cavity-cooling concept incorporated into its design. 
EPR Reactor Design: The current EPR design has an external cavity-cooling concept that utilizes the approach in which the region below the reactor pressure vessel is kept dry. The current conceptual design would achieve coolability by allowing the corium melt to deposit on that cavity floor flow into an adjoining compartment lined with a sacrificial material. In this room the corium would spread over this large sacrificial surface area as it erodes material, dilutes, and radiates to the dry cavity region. After a few centimeters of erosion water channels open up allowing water to be injected into the corium from below. The basic concept is to forcibly quench the core debris by limited fuel/coolant interactions atop the sacrificial layer and steel liner. Eventually the core would cool, solidify and particulate in a manner that would achieve long-term coolability.

\section{V.5 Proposed Concept for Further Study}

A new concept is proposed here for achieving ex-vessel core debris coolability and longterm stabilization. This concept is developed with a view toward accomplishing the following objectives:

1. Totally passive safety measures;

2. Minimal sensitivity to the melt release condition at the time of RPV failure;

3. No energetic fuel-coolant interactions (FCI's);

4. Sufficient debris coolability margin (i.e., the volumetric heat removal rate should be significantly larger than the decay heat with high confidence).

The proposed concept represents a combination of the two existing concepts discussed earlier, namely, the bottom-flooded reactor cavity and the externally-cooled core catcher. As depicted in Figure 100, the reactor cavity would have provisions for side-wall cooling and bottom-injection of water. In addition, it would contain internal structures that would minimize the FCI risk.

To provide the side-wall cooling, a steel cylinder is placed in the reactor cavity. The inner diameter of the steel cylinder would be larger than the outer diameter of the RPV, so the melt released at RPV failure would be $100 \%$ collected in the region within the steel cylinder. The inner wall of the steel cylinder would be lined with a thin layer of refractory material (e.g., zirconia or magnesia) in order to protect the steel cylinder from direct melt contact caused by either jet impingement or melt-coolant mixing as the melt is 
discharged from RPV failure. The annular gap between the reactor cavity wall and the outer wall of the steel cylinder would be filled with water supplied by gravity from an incontainment water reservoir (or overflow from the inner cylinder given water presence from IVR accident management strategies). This water would be available for providing side-wall cooling to the steel cylindrical wall as well as a backup for bottom-flooding into the inner cylinder where the debris is located. The thickness of the annular gap as well as the wall thickness (steel plus refractory material) would have to be determined from detailed design structural and fluid analyses but are expected to be $30-50 \mathrm{~cm}$ for the annular gap and an order of magnitude smaller for the wall respectively.

The bottom of the reactor cavity would be provided with a liner made of sacrificial material, which contains nozzles for the injection of water from below. This water flow would be supplied by another in-containment reservoir specifically dedicated to bottom injection of water. Note that one could also consider for redundancy an alternative water supply by gravity flow from the outer annular space. The steel cylinder would be provided with an internal structure made of sacrificial material, which could be an array of tubes or honeycomb-shaped structure supported at the bottom of the reactor cavity. The primary purpose of the internal structure is to minimize the steam explosion risk if the reactor cavity is pre-flooded with water, as would be the case if the in-vessel retention (IVR) strategy were adopted. In addition, the sacrificial material, when mixed with the core melt, would have a dilution effect reducing the sensible heat and the long-term volumetric heat generation rate due to decay heat.

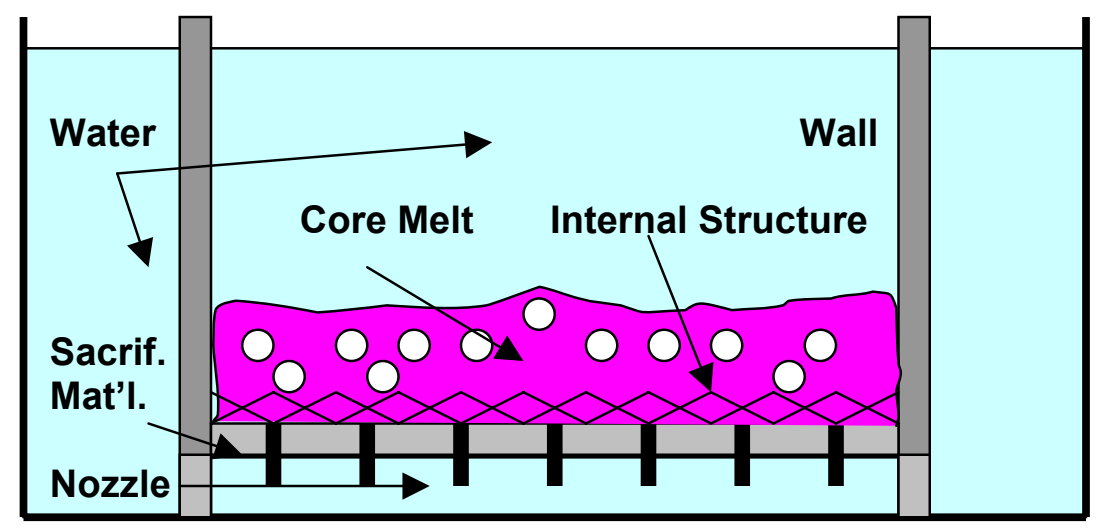

Figure 100: Conceptual Picture of Proposed Ex-Vessel Coolability Scheme 
Let us now discuss how the proposed concept might meet the specific objectives set forth. Passive Safety:

The measures described in the proposed concept are 100\% passive, since the cooling water is supplied by only a gravity feed.

Minimize Sensitivity to Melt Release:

First consider the case where the steel cylinder is dry; i.e., absent of any substantial preexisting water pool. If the melt release at RPV failure is rapid as well as massive, a deep pool of melt would form in the steel cylinder before the injection of water from below begins. However, the annulus gap between the reactor cavity and the steel cylinder walls would be pre-filled with water prior to the melt release as in the IVR strategy, so the steel wall would be at this water temperature and the side-wall cooling would be immediate with a significant time constant. The subsequent erosion of the bottom sacrificial layer and the injection of water from below would provide significant additional cooling, the extent of which would depend on the water injection rate. Also, the water injection process would bring about good mixing of the melt pool and the melt pool temperature would likely be relatively uniform. Thus, some of the key uncertainties associated with the IVR strategy for the side-wall cooling (e.g., melt pool heat flux distributions including the so-called focusing effect) would all be eliminated.

If, however, the melt release is gradual (e.g., in the form of small melt streams), the melt pool formed by the time of water injection would be likely shallow. In this case, depending on the water injection rate, the injected water may not vaporize $100 \%$ in the melt, resulting in a pass-through of some of the coolant injection. The situation, then, would become similar to that of a pre-flooded reactor cavity as additional melt continues to pour into this reactor cavity region.

In the case of a pre-flooded cavity such as is being considered for the INVR strategy, both the steel cylinder and the annular region between the cavity wall and the steel cylinder would be filled with water prior to melt release from the RPV. The melt would be falling into a pool of water within the steel cylinder region. The timing of water 
injection, from the nozzles below the pool, would depend on the interaction of the melt and the debris with the underlying sacrificial material at the bottom of the cavity. Once the water injection starts from below, however, the injected water would remove heat from the melt in a similar manner, whether the cavity is pre-flooded or not. One exception may be that in the case of a pre-flooded cavity, an overlying layer of water would likely exist on the top of the melt. This overlying water layer would not impact the effectiveness of the injected water in the heat removal.

\section{No Energetic FCIs:}

For the case when the steel cylinder is dry, the water injected from the bottom would be the only source of water mixed with the melt. Experimental studies conducted to date (e.g., COMET and ANL/UW experiments) seem to indicate that no energetic and damaging FCI would occur from the bottom injection of water. As a matter of fact, the water injection rate could be controlled and would be kept to a minimum necessary for melt quenching. A simple analysis would show that the amount of injected water mixed with the melt at any time would indeed be very small, minimizing any potential energetics. The water-to-melt mass ratio would so small that if the water were to interact with the melt in a $100 \%$ efficient manner, the resulting work would not be damaging to the reactor cavity or any other containment structures.

A major FCI concern may arise in the case of a pre-flooded cavity. In this case, an optimum mixing condition for melt and water, which would produce an energetic and damaging FCI is a theoretical possibility. This possibility would be minimized by adding an internal structure within the steel cylinder. If FCI's were to occur, the internal structure would be expected to render these events incoherent and benign. The FCI issue is an important consideration for the viability of the proposed concept, especially for the case of a pre-flooded cavity. The effectiveness of this internal structure in reducing the FCI risk deserves careful evaluation. 


\section{Sufficient Margin for Debris Coolability:}

Both COMET and ANL/UW studies have shown that the bottom injection of water alone would be capable of removing the decay heat with sufficient margin. In the proposed concept, a major fraction of the decay heat, could be removed by the side-wall cooling, when no FCI concerns exist. The bottom injection of water would be initially employed to quench the pool and ultimately to significantly enhance the margin of long-term coolability to such a level that no uncertainty analysis would be needed. The water injection rate would be optimized as necessary for this purpose. The optimum split of heat removal capabilities between the side-wall cooling and the bottom injection of water would be one of the prime subjects of future study. 


\section{REFERENCES for TASKS I and II}

Abdulla, S.H., 2003, "Liquid-Metal/Water Direct Contact Heat Exchange", Ph.D. Thesis, University of Wisconsin - Madison, Department of Mechanical Engineering, Madison, Wisconsin.

Abdulla, S.H., 2003 b, Personal Communication, University of Wisconsin - Madison.

Alsmeyer, H., Tromm, W., 1991, "A Core Catcher Concept and Basic Experimental Results", International Topical Meeting on Safety of Thermal Reactors, Portland, Oregon, USA.

Alsmeyer, H., Tromm, W., 1999, "The COMET Concept for Cooling Core Melts: Evaluation of the Experimental Studies and Use in the EPR", FZKA 6186, EXVCSC(99)-D036, Forschungszentrum Karlsruhe, Karlsruhe, Germany.

Alsmeyer, H., Cron, T., Messemer, G., Häfner, W., 2004, "ECOKATS-2: A Large Scale Experiment on Melt Spreading and Subsequent Cooling by Top Flooding", Proceedings of International Congress on Advances in Nuclear Power Plants, Pittsburgh, PA, USA.

Annunziato, A., Leva, G., 1994, "FARO TEST DATA PACKAGE - TEST L-14", Commission of the European Communities, Joint Research Centre, Safety Technology Institute, Thermodynamics and Radiation Physics Unit.

Bürger, M., Widmann, W., Schmidt, W., Buck, M., Pohlner, G., 2001, "Theoretical investigations for the COMET concept - Overview of work at IKE", EUROCORE, Contract FIKS - CT1999 - 20003, Institut für Kernenergetik und Energiesysteme, Universität Stuttgart, Germany.

Cho, D., 2002, Nuclear Engineering Research Initiative, "Interfacial Transport Phenomena and Stability in Liquid-Metal/Water Systems", Final Report, DOEDE-FG03-99SF21928.

Cho, D., 2003, Personal Communication, Argonne National Laboratories, USA.

Cho, D., 2004, Personal Communication, Argonne National Laboratories, USA.

Clifford, J.C., 1960, “A Loop for Circulating Liquid Lead-Bismuth Mixtures: Corrosion Studies and Operations", Ph.D. Thesis, Department of Chemical Engineering, Iowa State University of Science and Technology, Ames, Iowa.

Corradini, 2003, Personal Communication, University of Wisconsin - Madison. 
Esmaili, H., Khatib-Rahbar, M., 2003, "Analysis of In-Vessel Retention and Ex-Vessel Fuel Coolant Interaction for AP1000”, ERI/NRC 03/202 (Revised November 2003).

Esmaili, H., Khatib-Rahbar, M., 2004, "Analysis of In-Vessel Retention and Likelihood of Lower Head Failure", Proceedings of International Congress on Advances in Nuclear Power Plants, Pittsburgh, PA, June 13-17.

F-Chart Software, 2004, EES - Engineering Equation Solver, www.fChart.com, Version 6.738 .

Farmer, M.T., Spencer, B.W., Kilsdonk, D.J., Aeschlimann, R.W., 1998, "Quick Look Data Report for COMET Test U2”, ANL/RE-98-1, Argonne National Laboratory, Argonne, IL, USA.

Farmer, M.T., Spencer, B.W., 2000, "A Review of the Database Pertaining to Ex-Vessel Debris Coolability”, ACEX-TR-C34, Argonne National Laboratory, Argonne, IL, USA.

Fink, J.K., Thompson, D.H., Armstrong, D.R., Spencer, B.W., Sehgal, B.R., 1995, "Aerosol and Melt Chemistry in the ACE Molten Core-Concrete Interactions Experiment”, High Temperature and Material Science, Vol. 33, p. 51-75.

Fisher, M., Farmer, M., 1991, "MACE MCCI Pretest M0 Test Data Report”, MACE-TRC01, Argonne National Laboratory, Argonne, IL, USA.

Hunter, R., 2004, "Melt Quenching and Coolability by Water Injection from Below: Void Fraction Calculation", Summer Undergraduate Research Experience, University of Wisconsin - Madison, Department of Engineering Physics.

Klockow, K., 2004, "Molten Pool Quenching Phenomena: Stability and Heat Transfer with Multiphase Injection", Ph.D. Thesis, University of Wisconsin - Madison, Department of Mechanical Engineering, Madison, Wisconsin.

Liu, X., 2003, "Flow Visualization and Void Fraction Measurement in LiquidMetal/Water Direct Contact Heat Exchange by X-ray Attenuation Technique", Ph.D. Thesis, University of Wisconsin - Madison, Department of Engineering Physics, Madison, Wisconsin.

National Instrument Corporation, 2003, 11500 N. Mopac Expwy, Austin, TX, 7859-3504, www.ni.com.

Paladino, D., 2000, "Investigation of Mechanisms for Melt Coolability with Bottom Coolant Injection", Licentiate Thesis, Department of Energy Technolgy, Division of Nuclear Power Safety, Royal Institute of Technology, Stockholm, Sweden. 
Paladino, D., Theerthan, S.A., Sehgal, B.R., 2002, "DECOBI: Investigation of Melt Coolability with Bottom Coolant Injection”, Progress in Nuclear Energy, Vol. 40, 2, p. 161-206.

Roche, M.F., Leibowitz, L., Fink, J.K., Baker, L., 1993, "Solidus and Liquidus Temperatures of Core-Concrete Mixtures", NUREG/CR-6032, ANL/93/9, Argonne National Laboratory, Argonne, IL, USA.

Scholtyssek, W., Alsmeyer, H., Erbacher, F.J., 1992, “Decay Heat Removal after a PWR Core Meltdown Accident", International Conference on Design and Safety of Advanced Nuclear Power Plants, Tokyo, Japan.

Tromm, W., 1998, "Experimentelle Untersuchungen zum Nachweis der langfristigen Kühlbarkeit von Kernschmelzen“, FZKA 6187, Dissertation, Forschungszentrum Karlsruhe, Karlsruhe, Germany.

Tromm, W., Alsmeyer, H., Cron, T., Schmidt-Stiefel, S., Wenz, T., Adleheim, C., Grehl, C., Merkel, G., 2002, "Experiment on cooling of nuclear reactors under meltdown conditions, using bottom-up water flooding", Annual Meeting on Nuclear Technology, Stuttgart, Germany.

Wallis, G., 1969, “One-dimensional Two-phase Flow”, McGraw-Hill, New York, USA.

Widmann, W., Bürger, M., Lohnert, G., 2002, “COMET Concept: Effects of Non-Porous Regions and Resulting Design Options”, Annual Meeting on Nuclear Technology, Stuttgart, Germany.

Yamano, N., Maruyama, Y., Moriyama, K., Sugimoto, J., 1996, “Technical Note on ExVessel Core Melt Debris Coolability and Steam Explosions", NEA/CSNI/R(96)24, OECD/NEA. 


\section{REFERENCES for TASKS III and IV}

Alsmeyer, H. and Tromm, W., 1999, "The COMET Concept for Cooling Core Melts: Evaluation of the Experimental Studies and Use in the EPR," FZKA 6186, EXV-CSC (99)-D036.

Atkhen, K. and Berthoud, G., 2003, "Experimental and Numerical Investigations on Debris Bed Coolability in a Multidimensional and Homogeneous Configuration with Volumetric Heat Source," Nuclear Technology, 142, pp. 270-282.

Bang, K. H., 1994, "Numerical Prediction of Forced Convection Film Boiling Heat Transfer from a Sphere," Int. J. Heat Mass Transfer, 37, pp. 2415-2424.

Bang, K. H. et al., 2002, "Development of Constitutive Models of Multiphase Flow in Severe Accidents and Safety Analysis," KAERI/CM-524/2001, Korea Atomic Energy Research Institute.

Barleon, L. et al., 1984, “Cooling of Debris Beds,” Nuclear Technology, 65, pp. 67-86.

Buchlin, J.M. et al., 1989, "Thermohydraulics of Heated Porous Media Associated with Nuclear Reactor Safety,” Transport Process in Porous Media, U.S.A., pp. 315-370

Cha, J.H. et al., 1986, "Degraded Core Cooling," J. Korean Nuclear Society, 18(1), pp.48-70.

Cha, J. H. et al., 1986, "Forced Flow Dryout Heat Flux in Heat Generating Debris Bed," J. Korean Nuclear Society, 18(4), pp. 273-280.

Dhir, V. K. and Catton, I., 1977, "Dryout Heat Fluxes for Inductively Heated Particles Beds, Trans. ASME, J. Heat Transfer, 69, pp. 250-256.

Dhir, V. K. and Purohit, G. P., 1978, "Subcooled Film Boiling Heat Transfer from Spheres,” Nucl. Eng. Design, 47, pp. 49-66.

Doh, D. H,. Kobayashi, T., Saga, T. and Segawa, S., 1993, "A New Consideration for Measuring Temperature and Velocimetry Using Micro-Capsulated Liquid Crystals", Proc. of FLOMEKO'93, Vol. 2, Seoul, Korea, pp.461-468.

Farmer, M. T. et al., 1992, "Results of MACE Test M0 and M1," Proceedings of the $2^{\text {nd }}$ OECD (NEA) CSNI Specialist's Meeting on Molten Core Debris-Concrete Interactions, Karlsruhe, Germany.

Hartline, B. K. and Lister C. R. B., 1977, “Thermal Convection in a Hele-Shaw Cell”, J. of Fluid Mech, Vol. 79, pp.29-48. 
Hohmann. H. et al., 1997, "FCI Experiments in Corium/Water System," Nucl. Eng. Des., 177, p. 339-349.

Hu, K. and Theofanous, T. G., 1991, "On the Measurement and Mechanism of Dryout in Volumetrically Heated Coarse Particle Beds,” Int. J. Multiphase Flow, 17(4), pp. 519-532.

Kazachkov I. V. and Konovalikhin M. J., 2002, "Steam flow through the volumetrically heated particle bed," Int. J. Thermal Sciences, 41, pp. 1077-1087.

Kim, S. H., 1996, "A Modeling of the Liquid-Vapor Flow in a Self-Heated Porous Medium: With Application to the Dryout Limits," J. Nuclear Science and Technology, 33(9), pp. 686-695.

Klockow, H. B. et al., 2003, "Simulant Melt Pool Quench Behavior via Coolant Injection from Below," Proc. 10 $0^{\text {th }}$ Int. Topical Meeting on Nuclear Reactor Thermal Hydraulics (NURETH-10), Seoul.

Lipinski, R. J., 1984, “A Coolability Model for Postaccident Nuclear Reactor Debris," Nuclear Technology, 65, p. 53.

Liu, C. and Theofanous, T. G., 1995, "Film Boiling on Spheres in Single and Two-phase Flows. Part I: Experimental Studies," ANS Proceedings, National Heat Transfer Conf., Portland, August, pp. 34-47.

Mills, A. F., 1992, Heat Transfer, Irwin.

Naik, A.S. and Dhir, V.K., 1982, "Forced Flow Evaporative Cooling of a Volumetrically Heated Porous Layer," Int. J. Heat Mass Transfer, vol.25, pp.541-552.

Ostensen, R. W. and Lipinski, R. J., 1981, "A Particle Bed Dryout Model Based on Flooding,” Nucl. Sci. Eng., 79, pp. 110-113.

Tsai, F. P. and Catton, I., 1983, "On Dryout Heat Flux and Pressure Drop of a Submerged Inductively Heated Bed Flow From Below," Proc. Nat. Heat Transfer Conf., AIChe Symposium Series, 79(225), pp. 296-302.

Turland, B. D. and Moore, K., 1983, "Debris Bed Heat Transfer with Top and Bottom Cooling," Proc. Nat. Heat Transfer Conf., AIChe Symposium Series, 79(225), pp. 250255. 


\section{Project Organizational Structure}

\section{UW-Madison Lead Organization}

M.Anderson, R.Bonazza, M.Corradini

TASK I:

ANL Lead
TASK II:

UW-Mad. Lead
TASK III:

KMU Lead
TASK IV:

KMU Lead

Budget and Expenditures for Year 3: U.S. Organizations

\begin{tabular}{|l|l|l|}
\hline Organization & Year 3 (Budget) & $\begin{array}{l}\text { Year 3 } \\
\text { (Actual: Jan 31 }^{\text {st }} \text {, 2005) }\end{array}$ \\
\hline $\begin{array}{l}\text { University of } \\
\text { Wisconsin }\end{array}$ & $\$ 213,000$ (est.) & $\$ 213,000^{*}$ \\
\hline $\begin{array}{l}\text { Argonne Nat'l } \\
\text { Laboratory }\end{array}$ & $\$ 213,000$ (est.) & $\$ 213,000^{*}$ \\
\hline Total & $\$ 426,000$ (est) & $\$ 426,000^{*}$ \\
\hline
\end{tabular}

* Because of administrative problems in finalizing the contracts, each participant did not financially begin until May 2002, although technical work had begun on Tasks I \& II. 


\begin{tabular}{|c|c|}
\hline TASK and DELIVERABLES & MILESTONE \\
\hline \multicolumn{2}{|l|}{ Task I: Transient Thermal Mapping of the Thermal Mixing Zone } \\
\hline Ia: Modify existing test apparatus and upgrade instrumentation & Year 1: COMPLETED \\
\hline Ib: Develop detailed experimental plan and begin liquid metal tests & $\begin{array}{l}\text { Year 1: COMPLETED } \\
\text { First year report }\end{array}$ \\
\hline Ic: Continue experiments with liquid metal and molten salts & $\begin{array}{l}\text { Year 2: COMPLETED } \\
\text { Second year report }\end{array}$ \\
\hline Id: Analyze experimental results and finish experiments & Year 3: IN PROGRESS \\
\hline Ie: Incorporate analysis into other collaborators tasks (Task 2-5) & $\begin{array}{l}\text { Year 3: } 6 \text { months } \\
\text { Third year report }\end{array}$ \\
\hline \multicolumn{2}{|l|}{ Task II: Real-Time X-ray Imaging of Multiphase Structure } \\
\hline IIa: Modify existing test apparatus and upgrade instrumentation & Year 1: COMPLETED \\
\hline $\begin{array}{l}\text { IIb: Collaborate with Argonne and develop detailed experimental test plan } \\
\text { and begin liquid metal experiments }\end{array}$ & $\begin{array}{l}\text { Year 1: COMPLETED } \\
\text { First year report }\end{array}$ \\
\hline IIc: Continue experiments with liquid metals & $\begin{array}{l}\text { Year 2: COMPLETED } \\
\text { Second year report }\end{array}$ \\
\hline IId: Analyze experimental results and finish experiments with X-ray imaging & Year 3: IN PROGRESS \\
\hline IIe: Collaborate with Korean and ANL collaborators on Task 1, 3-5 & $\begin{array}{l}\text { Year 3: } 6 \text { months } \\
\text { Third year report }\end{array}$ \\
\hline \multicolumn{2}{|l|}{$\begin{array}{l}\text { Task III: Analytical Modeling of Interfacial Transport Phenomena, } \\
\text { Separate Effect Tests }\end{array}$} \\
\hline IIIa: Design and construct experimental apparatus, experimental planning & Year 1: COMPLETED \\
\hline $\begin{array}{l}\text { IIIb: Development of advanced measurement technique: liquid crystal, PIV, } \\
\text { image analysis method }\end{array}$ & $\begin{array}{l}\text { Year 1: COMPLETED } \\
\text { First year report }\end{array}$ \\
\hline IIIc: Conduct flow film boiling experiment and data reduction & Year 2: COMPLETED \\
\hline IIId: Conduct drag coefficient experiment and data reduction & $\begin{array}{l}\text { Year 2: COMPLETED } \\
\text { Second year report }\end{array}$ \\
\hline IIIe: Model development and incorporating experimental results & Year 3: IN PROGRESS \\
\hline $\begin{array}{l}\text { IIIf: Evaluate applicability of models to melt-water multiphase flows and } \\
\text { report on models and applicability }\end{array}$ & $\begin{array}{l}\text { Year 3: six months } \\
\text { Final Report }\end{array}$ \\
\hline \multicolumn{2}{|l|}{$\begin{array}{l}\text { Task IV: Integration of analytical models in the framework of TRACER } \\
\text { code }\end{array}$} \\
\hline IVa: Code restructuring of TRACER-II and numerical enhancement & Year 1: COMPLETED \\
\hline IVb: Enhancement of robustness of numerical method and solvers & $\begin{array}{l}\text { Year 1: COMPLETED } \\
\text { First year report }\end{array}$ \\
\hline IVc: Development of three-dimensional code (TRACER-III) & Year 2: COMPLETED \\
\hline IVd: Implementation of multiphase interfacial transport models & $\begin{array}{l}\text { Year 2: COMPLETED } \\
\text { Second year report }\end{array}$ \\
\hline IVe: Code validation and verification analysis and report on the models & $\begin{array}{l}\text { Year 3: twelve months } \\
\text { Final report }\end{array}$ \\
\hline \multicolumn{2}{|l|}{ Task V: Development of an Innovative Core Coolability Concept } \\
\hline Va: Development of a Scaling Methodology & Years 2-3 COMPLETED \\
\hline Vb: Evaluation of Data in Regard to Coolability and Scaling Methodology & Years 2 to 3 and Report \\
\hline
\end{tabular}




\begin{tabular}{|c|c|c|c|c|c|c|c|c|c|c|c|c|}
\hline \multicolumn{13}{|c|}{ INERI RESEARCH PROJECT: ANL- UW- KMU: DE-FG06-02RL14347 } \\
\hline $\begin{array}{l}\text { Task } \\
\text { No. }\end{array}$ & $\begin{array}{l}1-3 \\
2002\end{array}$ & $\begin{array}{l}4-6 \\
2002\end{array}$ & $\begin{array}{l}7-9 \\
2002\end{array}$ & $\begin{array}{c}10-12 \\
2002\end{array}$ & $\begin{array}{l}1-3 \\
2003\end{array}$ & $\begin{array}{l}4-6 \\
2003\end{array}$ & $\begin{array}{l}\text { port } \\
7-9 \\
2003\end{array}$ & $\begin{array}{l}\text { ad Wo } \\
10-12 \\
2003\end{array}$ & $\begin{array}{r}\text { Con } \\
1-3 \\
2004\end{array}$ & $\begin{array}{l}\text { oleted } \\
4-6 \\
2004\end{array}$ & $\begin{array}{l}7-9 \\
2004\end{array}$ & $\begin{array}{l}10-12 \\
2004\end{array}$ \\
\hline \multirow{2}{*}{\multicolumn{13}{|c|}{$\mathbf{I}-\mathbf{a}$}} \\
\hline & & & & & & & & & & & & \\
\hline & & & & & & & & & & & & \\
\hline \multirow{2}{*}{\multicolumn{13}{|c|}{$\mathbf{I}-\mathbf{b}$}} \\
\hline & & & & & & & & & & & & \\
\hline \multicolumn{13}{|l|}{$\mathbf{I}-\mathbf{c}$} \\
\hline \multirow{2}{*}{\multicolumn{13}{|c|}{$I-d$}} \\
\hline & & & & & & & & & & & & \\
\hline & & & & & & & & & & & & \\
\hline \multirow{2}{*}{\multicolumn{13}{|c|}{ I-e }} \\
\hline & & & & & & & & & & & & \\
\hline \multicolumn{13}{|l|}{ II $-\mathbf{a}$} \\
\hline & & & & & & & & & & & & \\
\hline \multicolumn{13}{|l|}{ II $-\mathbf{b}$} \\
\hline \multirow{2}{*}{\multicolumn{13}{|c|}{ II $-\mathbf{c}$}} \\
\hline & & & & & & & & & & & & \\
\hline & & & & & & & & & & & & \\
\hline \multicolumn{13}{|l|}{ II $-\mathbf{d}$} \\
\hline & & & & & & & & & & & & \\
\hline \multicolumn{13}{|l|}{ II $-\mathbf{e}$} \\
\hline \multirow{2}{*}{\multicolumn{13}{|c|}{ III-a }} \\
\hline & & & & & & & & & & & & \\
\hline & & & & & & & & & & & & \\
\hline \multicolumn{13}{|l|}{ III-b } \\
\hline & & & & & & & & & & & & \\
\hline III-c & & & & & & & & & & & & \\
\hline & & & & & & & & & & & & \\
\hline III-d & & & & & & & & & & & & \\
\hline & & & & & & & & & & & & \\
\hline III-e & & & & & & & & & & & & \\
\hline & & & & & & & & & & & & \\
\hline III-f & & & & & & & & & & & & \\
\hline & & & & & & & & & & & & \\
\hline IV $-\mathbf{a}$ & & & & & & & & & & & & \\
\hline & & & & & & & & & & & & \\
\hline IV-b & & & & & & & & & & & & \\
\hline IV-c & & & & & & & & & & & & \\
\hline & & & & & & & & & & & & \\
\hline IV-d & & & & & & & & & & & & \\
\hline & & & & & & & & & & & & \\
\hline IV-e & & & & & & & & & & & & \\
\hline $\mathrm{V}$-a/b & & & & & & & & & & & & \\
\hline
\end{tabular}


